\title{
Stent thrombosis and antithrombotic strategies in percutaneous coronary intervention
}

Citation for published version (APA):

Zwart, B. (2021). Stent thrombosis and antithrombotic strategies in percutaneous coronary intervention. [Doctoral Thesis, Maastricht University]. Maastricht University. https://doi.org/10.26481/dis.20210528bz

Document status and date:

Published: 01/01/2021

DOI:

$10.26481 /$ dis.20210528bz

Document Version:

Publisher's PDF, also known as Version of record

\section{Please check the document version of this publication:}

- A submitted manuscript is the version of the article upon submission and before peer-review. There can be important differences between the submitted version and the official published version of record.

People interested in the research are advised to contact the author for the final version of the publication, or visit the DOI to the publisher's website.

- The final author version and the galley proof are versions of the publication after peer review.

- The final published version features the final layout of the paper including the volume, issue and page numbers.

Link to publication

\footnotetext{
General rights rights.

- You may freely distribute the URL identifying the publication in the public portal. please follow below link for the End User Agreement:

www.umlib.nl/taverne-license

Take down policy

If you believe that this document breaches copyright please contact us at:

repository@maastrichtuniversity.nl

providing details and we will investigate your claim.
}

Copyright and moral rights for the publications made accessible in the public portal are retained by the authors and/or other copyright owners and it is a condition of accessing publications that users recognise and abide by the legal requirements associated with these

- Users may download and print one copy of any publication from the public portal for the purpose of private study or research.

- You may not further distribute the material or use it for any profit-making activity or commercial gain

If the publication is distributed under the terms of Article $25 \mathrm{fa}$ of the Dutch Copyright Act, indicated by the "Taverne" license above, 
Stent thrombosis and antithrombotic strategies in percutaneous coronary intervention

\author{
Bastiaan Zwart
}


Stent thrombosis and antithrombotic strategies in percutaneous coronary intervention

ISBN: 978-94-6423-237-0

Cover artwork: Vera van Beek / ProefschriftMaken.nl

Layout design: Dennis Hendriks / ProefschriftMaken.nl

Printed: ProefschriftMaken.nl

No part of this publication may be reproduced or transmitted in any form or by means, electronic or mechanical, including photocopy, recording or any other information storage or retrieval system without the prior written permission of the author.

All rights reserved.

Copyright (c) 2021 B. Zwart

Publication of this thesis was financially supported by ACIST Europe, Bayer bv, Biotronik, Boehringer-Ingelheim, Chipsoft, Daiichi Sankyo Nederland bv, Fix You Consultancy, Pfizer bv, Salveo Medical bv, Sanofi Aventis, Servier, St. Antonius ziekenhuis maatschap cardiologie, St. Antonius ziekenhuis RvB, Terumo, TD Medical bv, Teva Nederland and Vifor Pharma Nederland bv 


\title{
Stent thrombosis and antithrombotic strategies in percutaneous coronary intervention
}

\author{
PROEFSCHRIFT \\ ter verkrijging van de graad van doctor aan de Universiteit Maastricht, \\ op gezag van de Rector Magnificus, Prof. dr. Rianne M. Letschert \\ volgens het besluit van het College van Decanen, \\ in het openbaar te verdedigen \\ op vrijdag 28 mei 2021 om 16.00 uur
}

door

Bastiaan Zwart 


\section{Promotores}

Prof. dr. J.M. ten Berg

Prof. dr. A.W.J. van 't Hof

\section{Beoordelingscommissie}

Prof. dr. T.M. Hackeng (voorzitter)

Prof. dr. H. ten Cate

Prof. dr. R.J.M van Geuns (Radboud Universiteit Nijmegen)

Prof. dr. J.W. Jukema (Universiteit Leiden)

Prof. dr. K. Vernooy

Financial support by the Dutch Heart Foundation for the publication of this thesis is gratefully acknowledged. 



\section{Table of Contents}

\section{INTRODUCTION}

\section{Chapter 1}

Stent Thrombosis in the current era: challenges and opportunities for

treatment

\section{Chapter 2}

A paradigm shift: from reducing stent thrombosis towards balancing

ischaemic and bleeding risk

\section{Chapter 3}

Antithrombotic therapy in $\mathrm{AF}$ patients undergoing $\mathrm{PCl}$

\section{Chapter 4}

Outline of this thesis

\section{PART I}

\section{Chapter 5}

Triggering mechanisms of stent thrombosis

\section{Chapter 6}

High risk of stent thrombosis in the first 6 months after coronary stenting:

Do not discontinue clopidogrel early after ACS

\section{Chapter 7}

Use of glycoprotein Ilb/IIla antagonists to prevent stent thrombosis in morphine-treated patients with ST-elevation myocardial infarction

\section{Chapter 8}

Individual cases in stent thrombosis

Chapter 8.1 Vigorous exercise as a triggering mechanism for late stent thrombosis: A description of three cases

Chapter 8.2 Time does not heal every wound: coronary stent thrombosis of a bare-metal stent more than one decade after its implantation

Chapter 8.3 3-dimensional optical coherence tomography imaging in early coronary stent thrombosis 


\section{PART II}

\section{Chapter 9}

Value and possibilities of platelet function testing in clinical practice

\section{Chapter 10}

Measuring high on-treatment platelet reactivity in clinical practice;

should we use a panel of platelet function tests?

\section{PART III}

\section{Chapter 11}

Identifying $\mathrm{AF}$ patients undergoing $\mathrm{PCl}$ at high thrombotic risk.

Is there a benefit of triple therapy?

\section{Chapter 12}

Estimating bleeding risk in $\mathrm{AF}$ patients undergoing $\mathrm{PCl}$ :

Dual or Triple Therapy in AF patients undergoing PCI: the DATA-PCI risk score

\section{Chapter 13}

Summary and General Discussion

\section{APPENDICES}

$\begin{array}{lr}\text { Nederlandse samenvatting } & 230\end{array}$

Impact paragraph 234

Dankwoord 236

List of publications $\quad 239$

Curriculum Vitae 242 
CHAPTER

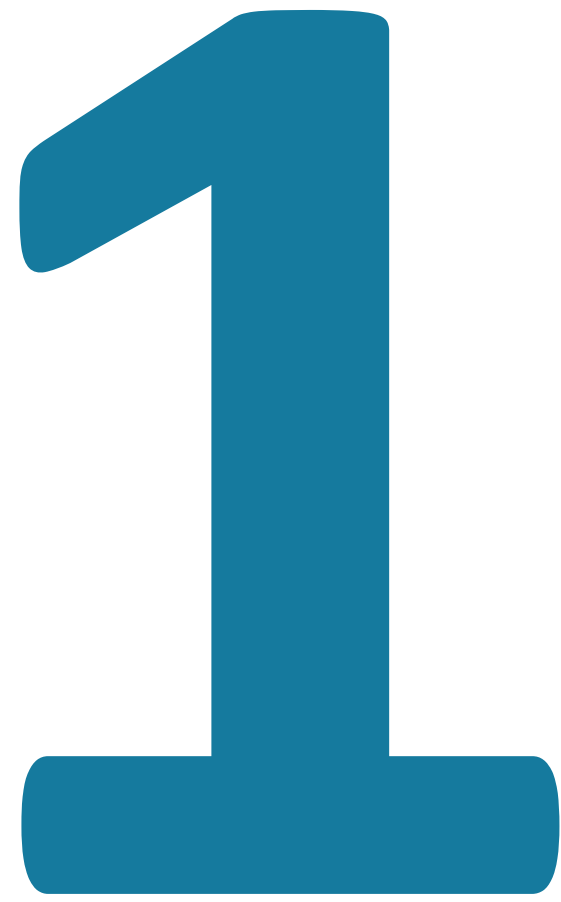




\section{Coronary Stent Thrombosis in the current era:}

Challenges and Opportunities for Treatment 


\begin{abstract}
The introduction of the drug-eluting stent has raised concerns regarding the occurrence of stent thrombosis (ST), particularly late (and very late) thrombosis. This renewed attention shows that ST remains a major concern after implantation of both bare metal and drug-eluting stents. Cardiologists should be aware of this dreadful complication, because it is associated with substantial morbidity and mortality. Numerous clinical, procedural, and angiographic risk factors have been identified. Moreover, the influence of novel determinants, such as high on-treatment reactivity, genetic predisposition, and the stent's direct effects on the (healing of the) vessel wall, now are recognized. Consequently, the pathophysiology of ST has evolved into a complex multifactorial model. This broader understanding of the pathophysiology of ST enables cardiologists to perform extensive risk stratification to identify patients at higher risk and provides clues to important treatment options. The core of primary prevention after stent implantation, as well as secondary prevention after ST, should consist of a) the prevention of modifiable risk factors and b) optimal individualized treatment for each patient. Future developments, such as genetic bedside testing, point-ofcare platelet testing, and sophisticated imaging modalities, might aid in this approach.
\end{abstract}




\subsection{Introduction}

The treatment of patients with coronary artery disease has changed dramatically since Andreas Grüntzig ${ }^{1}$ introduced percutaneous coronary intervention (PCI) in 1977. By means of a simple expanding balloon at the site of coronary narrowing, it was possible to reduce the narrowing and relieve angina pectoris. However, initial treatment with plain-old balloon angioplasty was limited by early elastic recoil, negative remodeling, and intimal hyperplasia, leading to restenosis (35\%-45\%). The high percentage of acute closures $(5 \%-8 \%)$ was another major limitation, although it was drastically reduced by the introduction of coronary stents.

\section{Coronary stenting}

Coronary stenting initially was a bail-out indication for treating acute complications of balloon angioplasty. The most important bail-out indications for coronary stent implantation were to provide a mechanical scaffold for the vessel wall, to seal dissections, and to prevent elastic recoil. Studies in the mid-1990s demonstrated that coronary stenting also reduced angiographic restenosis, from the $30 \%$ to $40 \%$ rate seen with balloon angioplasty to $10 \%$ to $20 \%$. However, the broad use of coronary stents introduced a new complication of coronary stent implantation: coronary stent thrombosis (ST).

\section{Coronary stent thrombosis}

$\mathrm{PCl}$ with stent implantation induces mechanical laceration and fissuring of the atherosclerotic plaque as well as denudation of the arterial endothelium. Hence, it is not surprising that the studies done in the mid-1990s reported ST rates as high as $20 \%$ to $25 \%$, because little concomitant anticoagulation was administered ${ }^{2}$. Acute thrombotic closure of the coronary stent results in a life-endangering condition with catastrophic consequences. It usually presents as an acute myocardial infarction or sudden death. Initially, this problem was tackled with complex anticoagulation regimes such as aspirin, heparin, and warfarin therapy; however, these treatments led to unacceptably high rates of major bleeding, vascular complications, and prolonged hospital stays. The development and introduction of new antiplatelet agents, such as the thienopyridines (eg, ticlopidine and clopidogrel) and the glycoprotein IIb/IIla inhibitors (abciximab, tirofiban, eptifibatide), as well as advances in techniques (eg, application of high-pressure stent dilatation) led to a breakthrough in the general use of coronary stents.

\section{Stent technologies}

Improvements in strut configuration and thickness, as well as new materials, enhanced deliverability and reduced vessel damage. These advancements led to the introduction in 2003 of drug-eluting stents (DES), which release drugs that reduce neointimal formation through the arrest of cell proliferation. DES reduced rates of in-stent restenosis significantly. 
By that time, it was generally believed that ST occurring after the first month was rare. Nevertheless, soon after the introduction of DES, the interventional community was alarmed by a suspected high incidence rate of late ST (beyond 1 month). Although late ST was not investigated extensively in bare metal stents (BMS), the introduction of DES brought this subject to the attention of cardiologists ${ }^{3,4}$. Consequently, in recent years, renewed attention has been paid to late ST, with experts concluding that ST continues to occur at a stable rate after the first month [5, 6]. Given the fact that ST often has devastating clinical consequences, there has been considerable interest in identifying patients at high risk for this catastrophic event. Multiple studies and registries have investigated the relationships between patient, lesion, and procedural factors and ST, but all have been hampered by methodologic challenges, primarily the low incidence of ST in contemporary patient series $^{7-10}$. Despite these important limitations, several predictors have been found, providing much insight into this complex pathophysiology. The primary aim of this review is to provide a better understanding of the underlying mechanisms responsible for ST and, ultimately, to establish an optimal strategy to reduce this dreadful complication.

\subsection{Definition of stent thrombosis}

Despite being a quantitatively minor problem, ST has a major clinical impact because of the high risk of myocardial infarction and death. However, the true impact and incidence of ST have been neglected for more than 10 years, partly because its definition has varied greatly among randomized clinical trials and observational registries. To allow a fair comparison (ie, provide consistency across studies) between the true rates of ST across different trials and registries, a new uniform definition of ST was proposed recently by the Academic Research Consortium (ARC), a collaboration of research organizations from Europe and the United States ${ }^{11}$. \& ST is classified according to 1 ) its timing and 2) the level of evidence for its presence. Timing is defined in four categories, implying different pathophysiologic mechanisms (Table 1). The level of evidence is stratified into three categories, indicating varying degrees of certainty: possible, probable, and definite ST (Table 2).

Table 1. Temporal categories of stent thrombosis.

\begin{tabular}{ll} 
Timing & Time after stent implantation \\
\hline Acute* $^{*}$ & $<24$ hours \\
Subacute* & $>24$ hours but $<30$ days \\
Late & $>30$ days but $<1$ year \\
Very late & $>1$ year \\
\hline
\end{tabular}

\footnotetext{
* together referred to as 'early'
} 
Table 2. Definite, probable and possible stent thrombosis.

\begin{tabular}{|c|c|}
\hline Category & Description \\
\hline Definite & $\begin{array}{l}\text { - Angiographic confirmation of stent thrombosis: intracoronary throm- } \\
\text { bus in or }<5 \mathrm{~mm} \text { proximal/distal to the stent } \\
\text { AND } \\
\text { clinical or biochemical changes compatible with cardiac ischemia, or } \\
\text { angiographic thrombus } \\
\text { Pathological confirmation of thrombus (at autopsy or after thrombec- } \\
\text { tomy) }\end{array}$ \\
\hline Probable & $\begin{array}{l}\text { - } \quad \text { Any unexplained death }<30 \text { days after coronary stenting } \\
\text { - } \quad \text { Any } \mathrm{MI} \text { in the territory of the implanted stent }\end{array}$ \\
\hline Possible & - $\quad$ Any unexplained death $>30$ days after coronary stenting \\
\hline
\end{tabular}

\subsection{Epidemiology}

\section{BMS versus DES}

The pivotal trials investigating the safety of DES initially reported on a follow-up of 1 to 2 years. After their use was embraced by interventional cardiologists because of reductions of in-stent restenosis rates, DES came under fire from the US Food and Drug Administration in 2003 because of a supposed surplus of late, and particularly very late, ST accompanying the use of DES ${ }^{3,4}$. \& Recently, several reviews and meta-analyses thoroughly addressed this issue ${ }^{12,13}$. Although several confounding factors (eg, off-label use of DES, indications for index $\mathrm{PCl}$, subtypes of stents, and the complexity of lesions treated) varied broadly across the studies, complicating a head-to-head comparison, the following general conclusions can be drawn: 1) mortality rates with BMS and DES are similar, 2) the incidence of early ST is the same for BMS and DES, and 3) the use of BMS might impose a slight excess risk of ST within the first 6 months, whereas DES are associated with a moderate increase in ST after 1 year. However, the latter does not translate into higher mortality rates, which can be explained by the reduced need for revascularization associated with the use of DES. Some authors report even lower mortality rates with DES compared with $\mathrm{BMS}^{14}$. \& In an important meta-analysis published in 2009, Brar et al. ${ }^{15}$ compared DES with BMS in 33,873 patients with myocardial infarction treated with primary $\mathrm{PCl}$. The authors concluded that the use of DES in myocardial infarction appears safe and efficacious and is not associated with an increase in ST. These data were confirmed by a large study from Shishehbor et al. ${ }^{16}$.

\section{Incidence of coronary stent thrombosis}

In the BMS era, the incidence of ST declined quickly, from initial rates of approximately $24 \%$ to only $1 \%$ to $5 \%$ in the first month. \& The incidence of ST beyond 1 month after implantation was not recognized until the publication of case reports of late ST associated with brachytherapy $[17,18]$. Since then, late BMS thrombosis received researchers' attention, although relatively few studies on the subject were published. These studies reported a yearly incidence of less than $1 \%$ for late ST in $\mathrm{BMS}^{5,19}$. The aforementioned meta-analyses 
estimated the incidence of late ST in both BMS and DES, despite different definitions of ST among the studies. The overall incidence of late and very late ST from registries and trials was estimated at $0.5 \%$ to $1.5 \%$ during the first year and $0.5 \%$ per year thereafter.

\section{Outcome after stent thrombosis}

Although several studies addressed the important question regarding clinical outcome after ST, they provided little consistency regarding mortality rates ${ }^{20-22}$. However, recently published studies assessed the outcome in larger cohorts of patients with ST. De la Torre-Hernandez et al. ${ }^{23}$ analyzed 23,500 patients after stent implantation, 301 of whom developed definite ST. Mortality at 1 year follow-up was $16 \%$, and recurrent ST occurred in $4.6 \%$ of patients. In addition, several risk factors for mortality were identified, including older age, left ventricular ejection fraction less than 45\%, nonrestoration of Thrombolysis in Myocardial Infarction (TIMI) flow grade 3, and additional stenting. Van Werkum et al. ${ }^{24}$ performed a long-term follow-up in a consecutive cohort of 431 patients with definite ST. After a median followup of 27.1 months, the primary end point (a composite of cardiac death and definitive ST) occurred in 111 patients (25.8\%), with a cardiac mortality rate of $12.3 \%$.The cumulative incidence rates of definite recurrent ST, definite or probable recurrent ST, any myocardial infarction, and any target vessel revascularization were $18.8 \%, 20.1 \%, 21.3 \%$, and $32.0 \%$, respectively. This unexpectedly high recurrence rate was confirmed by another study by Lemesle et al. ${ }^{25}$, who reported a recurrence rate of $36 \%$ in patients successfully treated for a first ST during a median follow-up of 40 months.

\subsection{Pathophysiology and predictors of stent thrombosis}

The pathophysiology of ST has evolved from the identification of single causative factors to a complex multifactorial model (Fig. 1). Numerous risk factors have been identified during the past years Historically, these predictors can be classified as clinical, procedural, or lesion related. More recently, researchers recognized the involvement of novel determinants, including a heightened platelet reactivity status despite antiplatelet therapy, impaired responsiveness to antiplatelet therapy, genetic predisposition, and direct effects of the stent on the vessel wall. The many factors contributing to ST are depicted in Fig. 1. Although early and late ST share several common risk factors, the impact of these factors varies. Early and late ST represent unique pathophysiologic characteristics, which are discussed separately.

\section{Early stent thrombosis}

Numerous studies have reported the predominance of mechanical and anatomic etiologies underlying early ST, including bifurcation and restenotic lesions, number of stents implanted, small vessels, lesion diameter and complexity (types B and C), undersizing and/or underexpansion of the coronary stent, (residual) dissections, postprocedural TIMI flow grade less than 3, absence of glycoprotein Ilb/IIla inhibitor treatment, and lack of 
intravascular ultrasound (IVUS) guidance ${ }^{7-10}$. Disturbances in coronary flow (increased shear stress) at bifurcations and restenotic lesions may activate platelets and contribute to delays in arterial healing. Moreover, a large number of stents and long total stent length delay the process of endothelialization, which in turn increases the risk of ST. Another very important nonmechanical cause of early ST is premature cessation of clopidogrel therapy, which is associated with hazard ratios up to $90^{20}$.

\section{Late and very late stent thrombosis}

Late ST seems less strongly linked to mechanical factors related to the index $\mathrm{PCl}$ procedure. In addition, the influence of clopidogrel cessation on late and very late ST is less well established, and when an association has been found, the risk has been consistently lower than that for early $\mathrm{ST}^{10,21,26-30}$. Nevertheless, several clinical predictors are strongly related to late and very ST, including acute coronary syndrome as the indication for the index $\mathrm{PCl}$, active malignancy, diabetes, low ejection fraction, and renal failure ${ }^{10 \bullet, 20}$. In addition, the stent itself is involved in the development of ST. Several autopsy studies described the histopathologic changes of the vessel wall following stent implantation, presumably as a result of the direct effects of the coronary artery ${ }^{31}$. Chronic inflammation surrounding the stent is found in a substantial number of patients. This phenomenon has been exclusively related to the use of polymers and other components in DES. Within months, this inflammatory process can induce late malapposition and vascular remodeling. Besides the negative influence of this process, DES induce delayed healing and incomplete endothelialization, resulting in impaired coverage of stent struts, even beyond 1 year after stent implantation ${ }^{32}$. These bare stent struts are thought to induce thrombus formation to the vessel wall. Although (the extent of) these findings might be biased by the fact that they are from autopsy studies representing a small and selected patient population, they were reproduced recently in studies using intravascular imaging technologies (eg, IVUS and optical coherence tomography) and histopathologic findings from thrombi obtained with thrombectomy catheters ${ }^{31-33}$. Cook et al. ${ }^{33}$ found both histopathologic (thrombus) signs of inflammation and IVUS evidence of vessel modeling. Importantly, histopathologic analysis of harvested thrombus showed infiltration of eosinophils and macrophages following implantation of sirolimus-eluting and paclitaxeleluting stents, respectively, suggesting a hypersensitivity reaction.

\section{The importance of concomitant antithrombotic therapy}

Various antithrombotic regimens have been studied for their ability to minimize the incidence of acute and subacute ST while reducing the risks of hemorrhagic complications. Current guidelines recommend dual-antiplatelet therapy (aspirin and clopidogrel) for all patients undergoing coronary stent implantation. Dual-antiplatelet therapy is absolutely necessary to prevent ST, although the optimal duration of this therapy after coronary stent implantation remains unclear. It is hoped that ongoing trials such as Double Randomization of a Monitoring Adjusted Antiplatelet Treatment Versus a Common Antiplatelet Treatment 
for DES Implantation, and Interruption Versus Continuation of Double Antiplatelet Therapy (ARCTIC, NCT00827411) and Safety and Efficacy of Six Months Dual Antiplatelet Therapy After Drug-Eluting Stenting (ISAR-SAFE, NCT00661206) will reveal the optimal duration of dual-antiplatelet therapy after DES implantation.

\section{High on-treatment platelet reactivity}

Despite the standard "one-size-fits-all" dual-antiplatelet therapy regimen with aspirin and clopidogrel, it has become clear that many patients still suffer from recurrent atherothrombotic coronary events. As a result, the number of studies and papers focusing on this socalled treatment failure has grown exponentially since 2003. Throughout the past few years, multiple studies have demonstrated that the response to a fixed dose of antiplatelet therapy (clopidogrel and aspirin) is highly variable and the responsiveness to clopidogrel, as measured with adenosine diphosphate (ADP)-induced aggregation, follows a bell-shaped gaussian distribution. Consequently, many patients receiving combination therapy with aspirin and clopidogrel fail to obtain the optimal benefit from it. This phenomenon has been termed resistance to antiplatelet therapy in the medical literature. However, the somewhat confusing term resistance implies that these drugs do not reach their pharmacologic target at all, which is not the case in most instances. Hence, the alternative term high ontreatment platelet reactivity was introduced recently. To date, six studies have demonstrated a clear association between the magnitude of ontreatment platelet reactivity and the occurrence of ST. Thus, high ontreatment platelet reactivity has emerged as another important risk factor for ST. Moreover, consistent findings across multiple studies indicate that high on-treatment platelet reactivity is associated particularly with early ST ${ }^{34,35}$. Whether high on-treatment platelet reactivity also is associated with late ST needs to be explored in sufficiently powered studies.

\section{Pharmacogenetics}

The pathophysiology of arterial thrombosis is very complex, and multiple factors have been identified as being involved. Nonetheless, these known factors alone do not fully explain an individual's risk profile, and it is likely that multiple genetic polymorphisms are involved. Likewise, there is much interindividual heterogeneity in the response to antithrombotic therapy ${ }^{36,37,38}$, and it has been demonstrated clearly that interindividual variations in metabolism, transporters, and drug targets are important determinants of drug efficacy. Because this straightforward principle of pharmacogenetics can affect any step in modulating the pharmacokinetics and pharmacodynamics, this concept might be more relevant than complex genetics leading to the development of cardiovascular diseases 39. During the past four years, the impact of a genetic mutation related to clopidogrel metabolism has been elucidated. In 2006, Hulot et al. ${ }^{40}$ identified the CYP2C19*2 mutation responsible for the biotransformation of the prodrug into its active metabolite. This cytochrome P-450 enzyme is involved in the biotransformation of clopidogrel into its 
active metabolite. Carriers of the $* 2$ alleles exhibit higher platelet reactivity ${ }^{40,41}$. Of equal importance, the CYP2C19*2 mutation is not uncommon, with carrier frequencies varying between $20 \%$ and $50 \%$, depending on the population and ethnicity. In addition, a dose response is evident: homozygotes for $\mathrm{CYP} 2 \mathrm{C} 19 * 2 / * 2$ respond even less well to clopidogrel therapy than heterozygotes for CYP2C19*2, who in turn respond less well than wildtype homozygotes. Importantly, several large trials published in 2009 demonstrated that genetic variation has an effect on the pharmacologic and clinical response to clopidogrel. Several studies correlated these genetic variations to clinical outcomes, including cardiovascular death, myocardial infarction, and ST. In their subanalysis of the Trial to Assess Improvement in Therapeutic Outcomes by Optimizing Platelet Inhibition With Prasugrel (TRITON)-TIMI 38, Mega et al. ${ }^{41}$ found that CYP2C19*2 carriers had a threefold risk of ST. Sibbing et al. ${ }^{42}$ found CYP2C19*2 carriers to have a fourfold risk of ST. Other CYP mutations have been associated with high on-treatment platelet reactivity. Harmsze et al. ${ }^{43}$ investigated a large cohort of clopidogrel-treated patients undergoing elective $\mathrm{PCl}$ and discovered that CYP2C9*3 carriers exhibited higher platelet reactivity and more often were poor responders. These findings represent a major step forward in this field of research and might have important treatment implications. Future trials will have to prove the clinical relevance of genetic testing.

\section{Triggering mechanisms of stent thrombosis}

Several superimposing factors have been investigated in myocardial infarction, including time of day, physical exercise, infection, and emotional stress. However, only case reports have been published so far on a possible relationship between triggering mechanisms and $\mathrm{ST}^{44,45}$. In our own institutional experience, however, triggering mechanisms seem to play an important role (unpublished data). All consecutive patients with definite ST in our large cohort were interviewed about the possible performance of vigorous physical exercise, the presence of an infection, or the presence of acute emotional stress preceding the onset of symptoms accompanying the ST. In $23 \%$ of these patients, a trigger was identified. Importantly, a clear circadian variation with a steep morning peak also was identified ${ }^{46}$.

\subsection{Treatment}

\section{Curative treatment}

It should be kept in mind that curative management strategies for patients presenting with ST are mainly empirically based, as only a few studies have evaluated (observationally) the available treatment modalities ${ }^{5}$. Nonetheless, data from numerous registries and casecontrol studies do offer certain guidance for managing patients with ST. For instance, evidence from histopathologic studies indicates that patients in whom ST is highly suspected should be treated with emergent $\mathrm{PCl}$, not thrombolytic therapy ${ }^{47-49}$. 


\section{Emergent $\mathrm{PCl}$}

Because in most cases ST presents as myocardial infarction, or even cardiogenic shock, the credo "time is muscle" is of utmost importance, and patients should be transported immediately to an interventional center upon diagnosis. The diagnosis of ST is confirmed by coronary angiography, although it must be noted that, in general, the identification of a thrombus on a conventional angiogram may be a difficult challenge.

Given the relatively large thrombus load associated with ST, thrombus aspiration might be beneficial in obtaining effective reperfusion ${ }^{50}$, although more clinical data are urgently needed. Subsequent balloon dilatation should be performed; if stent malapposition (eg, due to undersizing or late malapposition) is identified, additional balloon dilatation with wellsized balloons and higher balloon pressure is advisable. However, if the stent appears well expanded and no residual dissection is present, another stent should not be implanted, as several studies have demonstrated that implanting an additional coronary stent at the time of the first ST is associated with an increased risk of recurrent ST and even death ${ }^{23,24}$. \& The use of glycoprotein IIb/IIla therapy during emergent PCI for ST is strongly recommended, as two large observational studies indicated protective effects against ST recurrence ${ }^{5,24}$. 


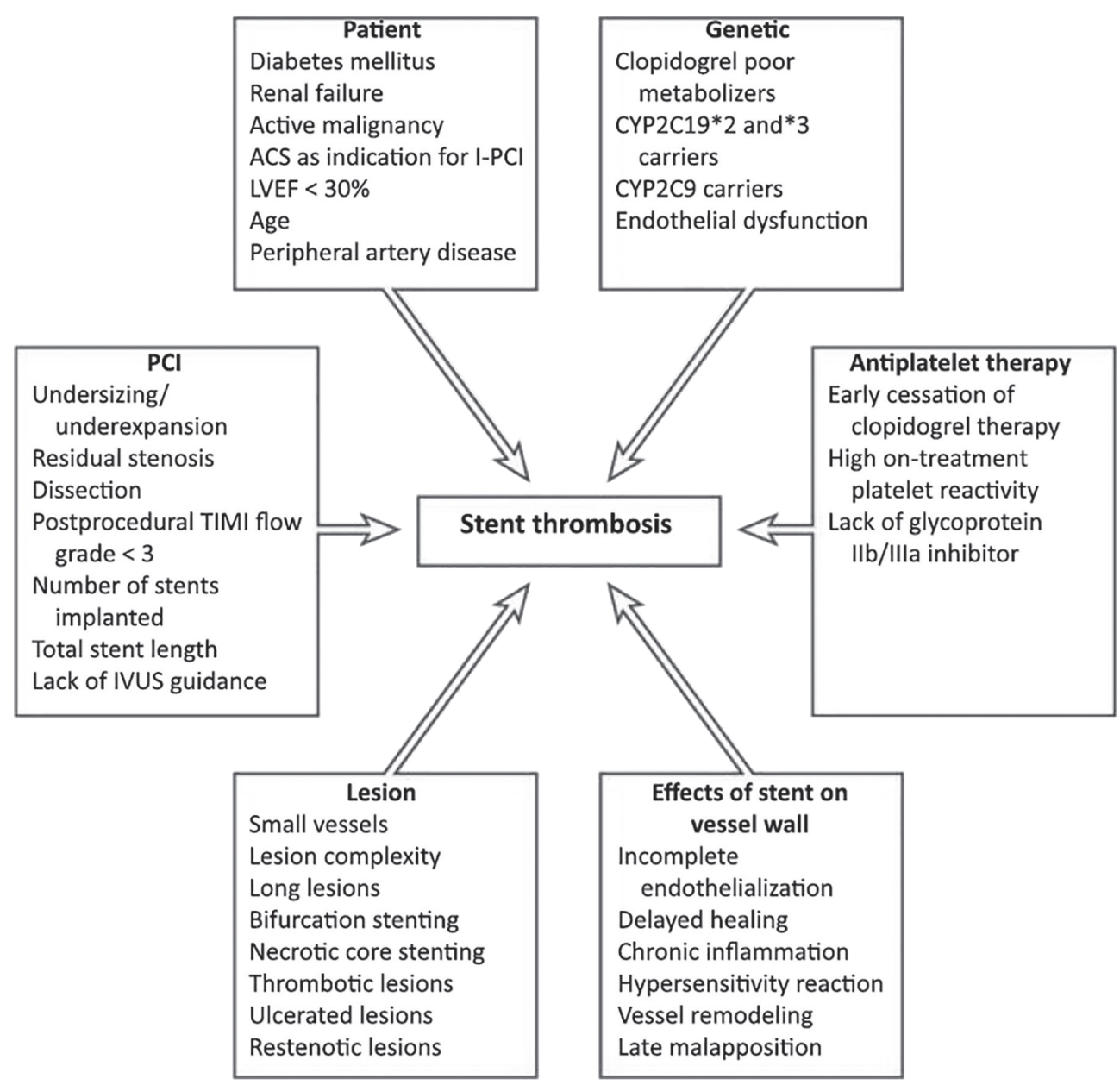

Figure 1. Predictors of stent thrombosis. ACS - acute coronary syndrome; I-PCI - index percutaneous coronary intervention; IVUS - intravascular ultrasound; LVEF - left ventricular ejection fraction; PCI percutaneous coronary intervention; TIMI - Trombolysis in Myocardial Infarction. 


\section{Reference List}

$1 \quad$ Gruntzig A: Transluminal dilatation of coronary-artery stenosis. Lancet 1978;1:263.

2 Serruys PW, Strauss BH, Beatt KJ, Bertrand ME, Puel J, Rickards AF, Meier B, Goy JJ, Vogt P, Kappenberger $\mathrm{L}, .:$ Angiographic follow-up after placement of a self-expanding coronary-artery stent. N Engl J Med 1991;324:13-17.

3 Camenzind E, Steg PG, Wijns W: Stent thrombosis late after implantation of first-generation drugeluting stents: a cause for concern. Circulation 2007;115:1440-1455.

4 McFadden EP, Stabile E, Regar E, Cheneau E, Ong AT, Kinnaird T, Suddath WO, Weissman NJ, Torguson R, Kent KM, Pichard AD, Satler LF, Waksman R, Serruys PW: Late thrombosis in drug-eluting coronary stents after discontinuation of antiplatelet therapy. Lancet 2004;364:1519-1521.

5 Wenaweser P, Rey C, Eberli FR, Togni M, Tuller D, Locher S, Remondino A, Seiler C, Hess OM, Meier $B$, Windecker S: Stent thrombosis following bare-metal stent implantation: success of emergency percutaneous coronary intervention and predictors of adverse outcome. Eur Heart J 2005;26:11801187.

6 Daemen J, Wenaweser P, Tsuchida K, Abrecht L, Vaina S, Morger C, Kukreja N, Juni P, Sianos G, Hellige G, van Domburg RT, Hess OM, Boersma E, Meier B, Windecker S, Serruys PW: Early and late coronary stent thrombosis of sirolimus-eluting and paclitaxel-eluting stents in routine clinical practice: data from a large two-institutional cohort study. Lancet 2007;369:667-678.

7 Roy P, Torguson R, Okabe T, Pinto Slottow TL, Steinberg DH, Smith K, Xue Z, Satler LF, Pichard AD, Waksman R: Angiographic and procedural correlates of stent thrombosis after intracoronary implantation of drug-eluting stents. J Interv Cardiol 2007;20:307-313.

8 Uren NG, Schwarzacher SP, Metz JA, Lee DP, Honda Y, Yeung AC, Fitzgerald PJ, Yock PG: Predictors and outcomes of stent thrombosis: an intravascular ultrasound registry. Eur Heart J 2002;23:124-132.

9 Cheneau E, Leborgne L, Mintz GS, Kotani J, Pichard AD, Satler LF, Canos D, Castagna M, Weissman NJ, Waksman R: Predictors of subacute stent thrombosis: results of a systematic intravascular ultrasound study. Circulation 2003;108:43-47.

10 van Werkum JW, Heestermans AA, Zomer AC, Kelder JC, Suttorp MJ, Rensing BJ, Koolen JJ, Brueren BR, Dambrink JH, Hautvast RW, Verheugt FW, ten Berg JM: Predictors of coronary stent thrombosis: the Dutch Stent Thrombosis Registry. J Am Coll Cardiol 2009;53:1399-1409.

11 Cutlip DE, Windecker S, Mehran R, Boam A, Cohen DJ, van Es GA, Steg PG, Morel MA, Mauri L, Vranckx P, McFadden E, Lansky A, Hamon M, Krucoff MW, Serruys PW: Clinical end points in coronary stent trials: a case for standardized definitions. Circulation 2007;115:2344-2351.

12 Maluenda G, Lemesle G, Waksman R: A critical appraisal of the safety and efficacy of drug-eluting stents. Clin Pharmacol Ther 2009;85:474-480.

13 Stettler C, Wandel S, Allemann S, Kastrati A, Morice MC, Schomig A, Pfisterer ME, Stone GW, Leon MB, de Lezo JS, Goy JJ, Park SJ, Sabate M, Suttorp MJ, Kelbaek H, Spaulding C, Menichelli M, Vermeersch P, Dirksen MT, Cervinka P, Petronio AS, Nordmann AJ, Diem P, Meier B, Zwahlen M, Reichenbach S, Trelle $S$, Windecker S, Juni P: Outcomes associated with drug-eluting and bare-metal stents: a collaborative network meta-analysis. Lancet 2007;370:937-948. 
14 Shishehbor MH, Goel SS, Kapadia SR, Bhatt DL, Kelly P, Raymond RE, Galla JM, Brener SJ, Whitlow PL, Ellis SG: Long-term impact of drug-eluting stents versus bare-metal stents on all-cause mortality. J Am Coll Cardiol 2008;52:1041-1048.

15 Brar SS, Leon MB, Stone GW, Mehran R, Moses JW, Brar SK, Dangas G: Use of drug-eluting stents in acute myocardial infarction: a systematic review and meta-analysis. J Am Coll Cardiol 2009;53:16771689.

16 Shishehbor MH, Amini R, Oliveria LP, Singh IM, Kelly P, Bhatt DL, Kapadia SR, Ellis SG, Whitlow PL, Brener SJ: Comparison of drug-eluting stents versus bare-metal stents for treating ST-segment elevation myocardial infarction. JACC Cardiovasc Interv 2008;1:227-232.

17 Maehara A, Mintz GS, Weissman NJ, Bui AB, Castagna MT, Ajani AE, Pichard AD, Satler LF, Suddath WO, Kent KM, Yang N, Chan R, White L, Waksman R: Late thrombosis after gamma-brachytherapy. Catheter Cardiovasc Interv 2003;58:455-458.

18 Waksman R: Late thrombosis after radiation. Sitting on a time bomb. Circulation 1999;100:780-782

19 Doyle B, Rihal CS, O'Sullivan CJ, Lennon RJ, Wiste HJ, Bell M, Bresnahan J, Holmes DR, Jr.: Outcomes of stent thrombosis and restenosis during extended follow-up of patients treated with bare-metal coronary stents. Circulation 2007;116:2391-2398.

20 lakovou I, Schmidt T, Bonizzoni E, Ge L, Sangiorgi GM, Stankovic G, Airoldi F, Chieffo A, Montorfano M, Carlino M, Michev I, Corvaja N, Briguori C, Gerckens U, Grube E, Colombo A: Incidence, predictors, and outcome of thrombosis after successful implantation of drug-eluting stents. JAMA 2005;293:21262130.

21 Kuchulakanti PK, Chu WW, Torguson R, Ohlmann P, Rha SW, Clavijo LC, Kim SW, Bui A, Gevorkian N, Xue Z, Smith K, Fournadjieva J, Suddath WO, Satler LF, Pichard AD, Kent KM, Waksman R: Correlates and long-term outcomes of angiographically proven stent thrombosis with sirolimus- and paclitaxeleluting stents. Circulation 2006;113:1108-1113.

22 Park DW, Park SW, Park KH, Lee BK, Kim YH, Lee CW, Hong MK, Kim JJ, Park SJ: Frequency of and risk factors for stent thrombosis after drug-eluting stent implantation during long-term follow-up. Am J Cardiol 2006;98:352-356.

23 de la Torre-Hernandez JM, Alfonso F, Hernandez F, Elizaga J, Sanmartin M, Pinar E, Lozano I, Vazquez JM, Botas J, de Prado AP, Hernandez JM, Sanchis J, Nodar JM, Gomez-Jaume A, Larman M, Diarte JA, Rodriguez-Collado J, Rumoroso JR, Lopez-Minguez JR, Mauri J: Drug-eluting stent thrombosis: results from the multicenter Spanish registry ESTROFA (Estudio ESpanol sobre TROmbosis de stents FArmacoactivos). J Am Coll Cardiol 2008;51:986-990.

24 van Werkum JW, Heestermans AA, de Korte FI, Kelder JC, Suttorp MJ, Rensing BJ, Zwart B, Brueren BR, Koolen JJ, Dambrink JH, van't Hof AW, Verheugt FW, ten Berg JM: Long-term clinical outcome after a first angiographically confirmed coronary stent thrombosis: an analysis of 431 cases. Circulation 2009;119:828-834.

25 Lemesle G, Sudre A, Modine T, Delhaye C, Rosey G, Gourlay T, Bauters C, Lablanche JM: High incidence of recurrent in stent thrombosis after successful treatment of a first in stent thrombosis. Catheter Cardiovasc Interv 2008;72:470-478. 
26 Pfisterer M, Brunner-La Rocca HP, Buser PT, Rickenbacher P, Hunziker P, Mueller C, Jeger R, Bader F, Osswald S, Kaiser C: Late clinical events after clopidogrel discontinuation may limit the benefit of drug-eluting stents: an observational study of drug-eluting versus bare-metal stents. J Am Coll Cardiol 2006;48:2584-2591.

27 Eisenstein EL, Anstrom KJ, Kong DF, Shaw LK, Tuttle RH, Mark DB, Kramer JM, Harrington RA, Matchar DB, Kandzari DE, Peterson ED, Schulman KA, Califf RM: Clopidogrel use and long-term clinical outcomes after drug-eluting stent implantation. JAMA 2007;297:159-168.

28 Roy P, Bonello L, Torguson R, Okabe T, Pinto Slottow TL, Steinberg DH, Kaneshige K, Xue Z, Satler LF, Kent KM, Suddath WO, Pichard AD, Lindsay J, Waksman R: Temporal relation between Clopidogrel cessation and stent thrombosis after drug-eluting stent implantation. Am J Cardiol 2009;103:801-805.

29 Tanzilli G, Greco C, Pelliccia F, Pasceri V, Barilla F, Paravati V, Pannitteri G, Gaudio C, Mangieri E: Effectiveness of two-year clopidogrel + aspirin in abolishing the risk of very late thrombosis after drug-eluting stent implantation (from the TYCOON [two-year ClOpidOgrel need] study). Am J Cardiol 2009;104:1357-1361.

30 Park DW, Yun SC, Lee SW, Kim YH, Lee CW, Hong MK, Cheong SS, Kim JJ, Park SW, Park SJ: Stent thrombosis, clinical events, and influence of prolonged clopidogrel use after placement of drugeluting stent data from an observational cohort study of drug-eluting versus bare-metal stents. JACC Cardiovasc Interv 2008;1:494-503.

31 Finn AV, Nakazawa G, Joner M, Kolodgie FD, Mont EK, Gold HK, Virmani R: Vascular responses to drug eluting stents: importance of delayed healing. Arterioscler Thromb Vasc Biol 2007;27:1500-1510. Joner M, Finn AV, Farb A, Mont EK, Kolodgie FD, Ladich E, Kutys R, Skorija K, Gold HK, Virmani R: Pathology of drug-eluting stents in humans: delayed healing and late thrombotic risk. J Am Coll Cardiol 2006;48:193-202.

33 Cook S, Ladich E, Nakazawa G, Eshtehardi P, Neidhart M, Vogel R, Togni M, Wenaweser P, Billinger M, Seiler C, Gay S, Meier B, Pichler WJ, Juni P, Virmani R, Windecker S: Correlation of intravascular ultrasound findings with histopathological analysis of thrombus aspirates in patients with very late drug-eluting stent thrombosis. Circulation 2009;120:391-399.

34 Geisler T, Zurn C, Simonenko R, Rapin M, Kraibooj H, Kilias A, Bigalke B, Stellos K, Schwab M, May AE, Herdeg C, Gawaz M: Early but not late stent thrombosis is influenced by residual platelet aggregation in patients undergoing coronary interventions. Eur Heart J 2009.

35 Pinto Slottow TL, Bonello L, Gavini R, Beauzile P, Sushinsky SJ, Scheinowitz M, Kaneshige K, Xue Z, Torguson R, Tantry U, Pichard AD, Satler LF, Suddath WO, Kent K, Gurbel P, Waksman R: Prevalence of aspirin and clopidogrel resistance among patients with and without drug-eluting stent thrombosis. Am J Cardiol 2009;104:525-530.

36 Shuldiner AR, O'Connell JR, Bliden KP, Gandhi A, Ryan K, Horenstein RB, Damcott CM, Pakyz R, Tantry US, Gibson Q, Pollin TI, Post W, Parsa A, Mitchell BD, Faraday N, Herzog W, Gurbel PA: Association of cytochrome $\mathrm{P} 4502 \mathrm{C} 19$ genotype with the antiplatelet effect and clinical efficacy of clopidogrel therapy. JAMA 2009;302:849-857.

37 Serebruany VL, Steinhubl SR, Berger PB, Malinin Al, Bhatt DL, Topol EJ: Variability in platelet responsiveness to clopidogrel among 544 individuals. J Am Coll Cardiol 2005;45:246-251. 
38 Gurbel PA, Bliden KP, Hiatt BL, O'Connor CM: Clopidogrel for coronary stenting: response variability, drug resistance, and the effect of pretreatment platelet reactivity. Circulation 2003;107:2908-2913.

39 Marin F, Gonzalez-Conejero R, Capranzano P, Bass TA, Roldan V, Angiolillo DJ: Pharmacogenetics in cardiovascular antithrombotic therapy. J Am Coll Cardiol 2009;54:1041-1057.

40 Hulot JS, Bura A, Villard E, Azizi M, Remones V, Goyenvalle C, Aiach M, Lechat P, Gaussem P: Cytochrome P450 2C19 loss-of-function polymorphism is a major determinant of clopidogrel responsiveness in healthy subjects. Blood 2006;108:2244-2247.

41 Mega JL, Close SL, Wiviott SD, Shen L, Hockett RD, Brandt JT, Walker JR, Antman EM, Macias W, Braunwald E, Sabatine MS: Cytochrome $\mathrm{p}-450$ polymorphisms and response to clopidogrel. N Engl J Med 2009;360:354-362.

42 Sibbing D, Stegherr J, Latz W, Koch W, Mehilli J, Dorrler K, Morath T, Schomig A, Kastrati A, von BN: Cytochrome P450 2C19 loss-of-function polymorphism and stent thrombosis following percutaneous coronary intervention. Eur Heart J 2009;30:916-922.

43 Harmsze A, van Werkum JW, Bouman HJ, Ruven HJ, Breet NJ, ten Berg JM, Hackeng CM, Tjoeng MM, Klungel OH, de BA, Deneer VH: Besides CYP2C19*2, the variant allele CYP2C9*3 is associated with higher on-clopidogrel platelet reactivity in patients on dual antiplatelet therapy undergoing elective coronary stent implantation. Pharmacogenet Genomics 2009.

44 Zwart B, Van Kerkvoorde TC, van Werkum JW, Breet NJ, ten Berg JM, van 't Hof AW: Vigorous exercise as a triggering mechanism for late stent thrombosis: A description of three cases. Platelets 2009.

45 Parodi G, Antoniucci D: Late coronary stent thrombosis associated with exercise testing. Catheter Cardiovasc Interv 2004;61:515-517.

46 Zwart B, van Werkum JW, Heestermans AA, ten Berg JM: Triggering mechanisms of stent thrombosis: data from the Dutch Stent Thrombosis Registry [abstract]. Presented at the American Heart Scientific Session.New Orleans, USA. November 11; 2008.

47 Jeong MH, Owen WG, Staab ME, Srivatsa SS, Sangiorgi G, Stewart M, Holmes DR, Jr., Schwartz RS: Porcine model of stent thrombosis: platelets are the primary component of acute stent closure.

Cathet Cardiovasc Diagn 1996;38:38-43.

48 Casserly IP, Hasdai D, Berger PB, Holmes DR, Jr., Schwartz RS, Bell MR: Usefulness of abciximab for treatment of early coronary artery stent thrombosis. Am J Cardiol 1998;82:981-985.

49 Hasdai D, Garratt KN, Holmes DR, Jr., Berger PB, Schwartz RS, Bell MR: Coronary angioplasty and intracoronary thrombolysis are of limited efficacy in resolving early intracoronary stent thrombosis. J Am Coll Cardiol 1996;28:361-367.

50 Lemesle G, de LA, Bonello L, Pinto Slottow TL, Torguson R, Kaneshige K, Steinberg DH, Roy P, Xue Z, Suddath WO, Satler LF, Kent KM, Lindsay J, Pichard AD, Waksman R: Impact of thrombus aspiration use for the treatment of stent thrombosis on early patient outcomes. J Invasive Cardiol 2009;21:210214. 


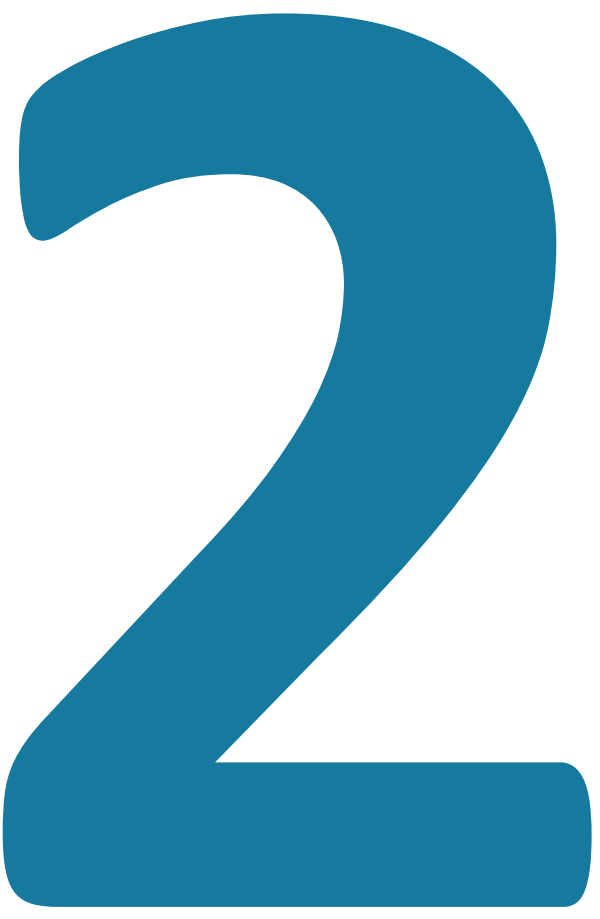




\section{A paradigm shift: from reducing stent thrombosis towards balancing ischaemic versus bleeding risk}

Based on:

Optimal duration of dual antiplatelet therapy after percutaneous coronary intervention or after acute coronary syndrome. 


\begin{abstract}
The introduction of the drug-eluting stent has raised concerns regarding the occurrence of stent thrombosis (ST), particularly late (and very late) thrombosis. This renewed attention shows that ST remains a major concern after implantation of both bare metal and drug-eluting stents. Cardiologists should be aware of this dreadful complication, because it is associated with substantial morbidity and mortality. Numerous clinical, procedural, and angiographic risk factors have been identified. Moreover, the influence of novel determinants, such as high on-treatment reactivity, genetic predisposition, and the stent's direct effects on the (healing of the) vessel wall, now are recognized. Consequently, the pathophysiology of ST has evolved into a complex multifactorial model. This broader understanding of the pathophysiology of ST enables cardiologists to perform extensive risk stratification to identify patients at higher risk and provides clues to important treatment options. The core of primary prevention after stent implantation, as well as secondary prevention after ST, should consist of a) the prevention of modifiable risk factors and b) optimal individualized treatment for each patient. Future developments, such as genetic bedside testing, point-ofcare platelet testing, and sophisticated imaging modalities, might aid in this approach.
\end{abstract}




\subsection{Optimal duration of dual antiplatelet therapy after percutaneous coronary intervention or after acute coronary syndrome.}

\subsubsection{Introduction}

Dual antiplatelet therapy (DAPT) with acetylsalicylic acid in combination with a $\mathrm{P}_{2} \mathrm{Y}_{12}$ inhibitor is now the standard of care after an acute coronary syndrome (ACS) and after percutaneous coronary intervention (PCI). DAPT is recommended with a class I level of evidence in the current European and American guidelines ${ }^{1-3}$.

Since the introduction of second-generation DES, rates of stent thrombosis have decreased by approximately $50 \%{ }^{4}$. Current rates of ST are estimated to be approximately $0,5-0.8 \%$ in the first year ${ }^{5,6}$. Very late ST beyond one year has become a rarity with incidence rates of ST in newer generation DES be estimated at 0.1-0.2 per 100 persons-years ${ }^{7}$. The total ST risk amounts to $<1 \%$, even at a follow-up duration of more than five years ${ }^{5,8}$.

With the fall in the incidence of stent thrombosis associated with newer generation DES together with the use of stronger $\mathrm{P}_{2} \mathrm{Y}_{12}$ inhibitors, attention has shifted to the downsides of DAPT. Due to the very action of platelet inhibitors, patients are at increased risk of bleeding. Although premature discontinuation of $\mathrm{P}_{2} \mathrm{Y}_{12}$-inhihitors has been shown to be the most important risk factor for $\mathrm{ST}^{9-12}$, the lower complication rates of coronary stents together with an increased awareness of bleeding on DAPT, has led cardiologists to question the optimal duration of DAPT after coronary stenting.

From a mechanical point of view, DAPT is mandatory in the first months after stent implantation until endothelialisation has been completed. Interestingly, two recent studies using a new-generation DES demonstrated that an ultra-short course (1 month) of DAPT was DES was superior to $\mathrm{BMS}^{13,14}$.

As the risk of (very) late ST is less of a concern with the development of $2^{\text {nd }}$ generation DES, prolonged DAPT is now more aimed at preventing (recurrent) myocardial infarction and other ischemic events not related to the implanted stent. The PROSPECT (Providing Regional Observations to Study Predictors of Events in the Coronary Tree) study demonstrated that approximately one-half of events during follow-up after ACS were attributable to nonculprit lesions ${ }^{15}$. Similarly, in the Dual Antiplatelet Study (DAPT Study) 55\% of myocardial infarctions beyond one year of stenting were not related to stent thrombosis thus occurred spontaneously ${ }^{16}$. Nevertheless, it is important to realise that ST is associated with very high mortality rates ${ }^{17}$ and therefore it is crucial to identify those at increased risk for ST. 
Rather than focussing on the stent or the angiogram only, the key to success is to treat the patient's overall thrombotic risk. An example of such an approach is the PEGASUS-TIMI 54 trial ${ }^{18}$, which investigated whether patients who had a previous myocardial infarction with additional risk factors could benefit from prolonged DAPT.

In the last five years, multiple studies have been published comparing duration of DAPT after $\mathrm{PCl}$ and in ACS patients. While some of these studies investigated whether a shorter DAPT duration might be as safe as the standard regimen, the other studies tried to establish a benefit from prolonged dual antiplatelet therapy.

Although these studies have focused attention on individualised treatment and current ESC guidelines provide backup to individualize treatment, few patients in daily practice are currently being treated with a shorter or prolonged DAPT duration in our experience. This article summarizes the results of relevant studies and meta-analysis and interprets the main findings and differences. Furthermore, we propose a practical approach for the clinician to identify patients who are likely to benefit from an alternative DAPT duration.

\subsubsection{Studies on optimal duration of DAPT}

At least 18 randomized controlled trials (RCTs) of optimal DAPT duration after PCI have been performed. However, results are not easy to interpret, as length of treatment varied (short course of DAPT varied from 3 to 6 months, standard duration from 6 to 12 months and prolonged from $>12$ to 48 months). Furthermore, comparison strategies varied (short versus standard DAPT, prolonged vs. standard DAPT and short vs. prolonged) and different definitions were used, as reflected for example by the use of multiple bleeding definitions (TIMI, BARC, STEEPLE, GUSTO). Subsequently, an almost equal number of high quality metaanalyses have been published, often using trial-level data.

\section{Shorter duration}

In summary, the results of the RCTs and several meta-analyses after shorter DAPT duration indicate that a shorter DAPT regimen is non-inferior (and thus equally effective) as standard DAPT duration and might even provide a benefit in terms of bleeding. Importantly from a mechanical view point, the OPTIMA-C trial demonstrated favourable stent strut coverage at six months follow-up. ${ }^{19}$ However, it must be noted that most studies included low-risk patients and only patients with stable and unstable angina, or a very low proportion of ACS patients $(<15 \%)^{20-24}$.

Details regarding ACS patients must be derived from a few randomised trials and from subanalyses and meta-analyses. The REDUCE trial, a physician-initiated multicentre randomised trial which included 1,500 ACS patients treated with the COMBO-stent, showed 
that three months was non-inferior to twelve months of DAPT ${ }^{25}$. However, numerically higher rates of mortality and ST were observed in the three-month DAPT group. The SMART-DATE, a large randomised non-inferiority trial randomised a total of 2712 ACS patients to either 6 or 12 months of DAPT ${ }^{26}$. The authors failed to demonstrate non-inferiority: myocardial infarction occurred more frequently in the 6-month DAPT group than in the 12-month or longer DAPT group ( $1.8 \%$ vs. $0.8 \%, p=0.02)$. On the other hand, a pooled analysis of three randomised controlled trials demonstrate that short-duration DAPT ( 6 months or less) showed a similar incidence of net adverse cardiovascular and clinical events as compared to ${ }^{3} 12$ months DAPT. Moreover, a 2017 review used individual patient data and compared efficacy of reduced DAPT duration in patients with and without ACS ${ }^{27}$ concluded that in ACS patients, 6 month DAPT or less was associated with numerically higher rates of MI and ST as compared to 12 month DAPT. By network meta-analysis, 3 month DAPT, but not 6 month DAPT was associated with higher rates of MI and ST. Three month DAPT was safe in patients with stable CAD undergoing $\mathrm{PCI}$. Short DAPT was associated with lower rates of major bleeding irrespective of clinical presentation. No differences in all-cause mortality were observed.

Another network meta-analysis suggested no increase in ischaemic events with short term DAPT in ACS patients ${ }^{28}$.

Two other studies deserve special notion. The LEADERS FREE trial compared a regimen of one month of DAPT in BMS treated patients vs. patients treated with a polymer-free drug-coated umirolimus (a sirolimus analogue) stent among patients with high bleeding risk (defined by meeting at least one out of 13 criteria such as high age, long term oral anticoagulation or hospital admission for bleeding) ${ }^{13}$. The study found that this DES was superior to BMS. The ZEUS trial randomized patients either at high bleeding risk or high ischemic risk to either a second-generation zotarolimus-eluting stent (ZES) or bare-metal stents (BMS). DAPT duration was based on patient based characterics and was similar between the two groups. Two-thirds of patients qualified for a very short (30 day) course of DAPT. Overall, Major Adverse Cardiac event rate was lower in the DES treated group (17.5 vs. $22.1 \mathrm{p}=0.011$ ) and definite or probable ST rate was lower as well $2.0 \%$ vs. $4.1 \% ; p=0.019)^{14}$.

\section{Prolonged dual antiplatelet therapy}

The majority of RCTs after prolonged DAPT failed to demonstrate a benefit of prolonged treatment or met the non-inferiority hypothesis. Two studies (comparing 6 vs 24 months of DAPT and 12 vs. 18-30 months of DAPT, respectively) even suggested potential harm from prolonged DAPT in terms of increased rates of major bleeding ${ }^{29,30}$. Of note, none of the RCTs has demonstrated an increase in fatal bleeding rates with prolonged DAPT, although interpretability again is hampered by low event rates. 
Although no consistent benefit of prolonged DAPT was observed in the individual RCTs for the ischemic end points, most subsequent meta-analyses using pooled data did find a significant benefit of prolonged DAPT, but also more bleeding complications.

Consequently, it is now believed that DAPT after 12 months reduces ischemic events but at the cost of increased bleeding rates. In the American College of Cardiology and American Heart (ACC/AHA) focused update on DAPT it was estimated that prolonged DAPT leads to an absolute decrease in ST and ischemic complications of $\approx 1 \%$ to $2 \%$ at the cost of an absolute increase in bleeding complications of $\approx 1 \%^{2}$.

\section{Mortality in prolonged DAPT}

Several previous studies have raised concerns that serious bleeding events resulting from prolonged DAPT might lead to increased rates of all-cause death, thereby offsetting the reduction in cardiac death and nonfatal ischemic events with prolonged antithrombotic therapy. This suspicion arose in the DAPT study and in some ${ }^{31-34}$ but not all meta-analyses ${ }^{35,36}$ One meta-analysis suggested higher all-cause mortality in prolonged DAPT as compared to short DAPT in patients treated with $2^{\text {nd }}$ generation DES. ${ }^{28}$

The DAPT study ${ }^{16}$ was by far the largest trial demonstrated a benefit of prolonged DAPT (30 vs. 12 months) in reducing ST (0.4 vs $1.4 \%, p=0.001)$ and major adverse cardiac and cerebrovascular events ( 4.3 vs. $5.9 \%, p=<0.001$ ), but at the cost of significantly more GUSTO moderate or severe bleeding ( 2.6 vs. $1.6 \%, p=0.001$ ). An unexpected but important finding was a borderline significant $(p=0.05)$ excess mortality (all-cause death $2.0 \%$ in prolonged DAPT vs. $1.5 \%$ in placebo treated patients) due to more non-cardiovascular deaths ${ }^{16,37}$.

The meta-analysis in the ACC/AHA focused update addressed this topic as well and found "weak evidence" of increased mortality with prolonged thienopyridine-based DAPT in RCTs that successfully achieved their predefined enrolment target ${ }^{4}$ Another analysis in this review suggested increased mortality with prolonged DAPT in patients without a prior history of ACS but not in patients with a history of prior ACS.

The mechanisms of this possible association are to date not clear, neither did the studies suggesting increased mortality rates investigate whether this is related to prolonged DAPT in general or specifically with the thienopyridine-based $\mathrm{P}_{2} \mathrm{Y}_{12}$-receptor antagonists (i.e. clopidogrel, prasugrel) as opposed to ticagrelor which is not a thienopyridine.

\section{Prolonged DAPT after MI}

The subgroup of patients who have had an $\mathrm{MI}$ are particularly at risk for recurrent ischemic events. Unfortunately, only few studies focused on this specific patient group. 
The PEGASUS is a double-blind RCT including 21,162 patients with a previous myocardial infarction and at least one of the following additional -risk factors: age of 65 years or older, diabetes mellitus requiring medication, a second prior spontaneous myocardial infarction, multivessel coronary artery disease, or chronic renal dysfunction, Patients were randomized to prolonged DAPT with ticagrelor at one of two maintenance doses $(90 \mathrm{mg}$ or $60 \mathrm{mg}$ twice daily for a minimum of 12 months) or placebo ${ }^{18}$. This study demonstrated an absolute risk reduction of cardiovascular death, myocardial infarction and stroke of $1.3 \%$ at the cost of an equally increased risk of major bleeding. All-cause death did not differ significantly between the groups. Again, the effect of prolonged DAPT in this trial seems to be attributable to the progressive natural course of coronary artery disease rather than to the stent implantation.

Udell et al. analysed in a recent meta-analysis in patients with previous $\mathrm{MI}$ either treated medically or managed with PCI whether prolonged DAPT after one year (mean difference in achieved duration of DAPT 30 months) is beneficial and found a reduction in major adverse cardiovascular events including stent thrombosis ( 6.4 vs. $7.5 \%$; risk ratio, RR $0.78, p=0.001$ ) and cardiovascular death ( 2.3 vs. $2.6 \%$; RR $0.85, p=0.03$ ), but no significant effect on overall mortality (RR of $0.92(95 \% \mathrm{Cl} 0.83-1.03 ; \mathrm{p}=0.13)(35)$. An increased rate of major bleeding was observed (1.85 vs. $1.09 \%$; RR 1.73, $p=0.004$ ), but not fatal bleeding. Overall, it is seems that the benefit of prolonged DAPT in reducing future ischemic events is much stronger after $\mathrm{MI}$ as compared to stable CAD patients ${ }^{38}$.

\subsubsection{Interpretation}

Conceptually, some of the foregoing conclusions are difficult to interpret. How can shorterduration DAPT be as effective as the "standard regimen" while on the other hand extended duration DAPT does reduce recurrent ischemic events including stent thrombosis?

Moreover, the paradigm that platelet inhibitors reduce thrombotic risk but increase bleeding still holds true for the various strategies. As this principle was observed in studies after prolonged DAPT duration but not in studies after shorter duration, this observed asymmetrical treatment effect might thus be due to the low number of events, selection of patients or chance.

Indeed, it proves useful to look in detail at these studies. With regard to stent thrombosis, which is an important end point, studies investigating a shorter DAPT duration are hampered by very low event rates. In ISAR-SAFE ( 6 vs. 12 months), at 9 months only 5 vs. 3 patients with ST were observed; in EXCELLENT ( 6 vs. 12 months): 6 vs. 1 ST at 12 months; in SECURITY ( 6 vs. 12 months): 2 vs 3 ST at 12 months, OPTIMIZE ( 3 vs. 12 months): 4 vs 1 ST at 12 months, in RESET ( 3 vs. 12 months): 2 vs. 3 ST at 12 months, in REDUCE 6 vs 12 ST 20-25. 
Thus none of these studies were powered to detect differences in stent thrombosis rates and in addition, some of these studies enrolled less patients than expected. Therefore, the clinical outcomes of these RCT's investigating shorter DAPT duration should be interpreted with caution with regard to the end point stent thrombosis and for the group of patients with ACS.

With regard to prolonged DAPT, another consideration should be borne in mind. In most RCTs, patients were randomized after the first year and only if they did not have any major bleeding or in some studies did not have any (bleeding neither ischemic) events at all. In these patients, a reduction of ischemic events was observed although at the cost of increased bleeding rates, but it should be noted that this is a highly selected patient group. On the other hand, one can argue that this is a reflection of clinical practice, in which the decision to extend DAPT after a year can be revised at any stage should haemorrhagic or ischemic events occur.

Although in most studies ischemic outcomes are reported next to bleedings or even as a combined end point, it is hard to appreciate how bleeding risks should be weighed against ischemic risks. Clearly, cardiovascular death is more relevant than a non-fatal extracranial bleeding whereas a disabling intracranial haemorrhage is more devastating than an uncomplicated myocardial infarction. The impact of bleeding should however not be underestimated, as it is a strong predictor of mortality - in some studies even greater than mortality associated with myocardial infarction. ${ }^{36,39}$

The ADAPT-DES study ${ }^{17}$ has provided important detailed information on this subject. The authors demonstrated that ST (especially early ST) is associated with the highest mortality rates. Although ST was infrequent (incidence of $0.9 \%$ ), it was associated with very high mortality rates ranging from 15 to 38\% (the latter for early ST). Spontaneous (non ST-related) MI was less frequently fatal, although late MI (after 1 year) was more dangerous than early MI ( 7.5 vs. 5.1 and $0.8 \%$ for $>365$ days, 30-365 and $<30$ days, respectively). Mortality rates after clinically relevant bleeding were comparable with spontaneous $\mathrm{MI}$ with again higher mortality rates when the events occurred later after $\mathrm{PCl}$. An interesting finding of this study was that DAPT discontinuation within 12 months was only slightly more frequent after clinically relevant bleeding. No excess ST or MI was observed in patients with clinically relevant bleeding.

In conclusion, as there is evidence of potential harm associated with prolonged DAPT, it should only be considered in carefully selected patients at substantially high ischaemic risk and low haemorrhagic risk. 


\section{Current guidelines}

The 2018 European Society of Cardiology (ESC) guidelines on myocardial revascularisation advise to treat patients with stable coronary artery disease undergoing $\mathrm{PCl}$ with DAPT for six months, irrespective of stent type (class I level A) ${ }^{1}$. Shorter DAPT duration may be considered after DES implantation in patients with high bleeding risk (Ila, A), whereas the guideline advises that DAPT may be used for more than 6 months in patients at high ischemic risk and low bleeding risk who have tolerated the first course of DAPT without bleeding complications ( $\mathrm{Ilb}, \mathrm{A}$ ). The latter is remarkable, because the benefit of prolonged DAPT in reducing future ischemic events is much stronger after $\mathrm{MI}$ as compared to stable CAD - and might even cause harm in some patients.

The STEMI guidelines, which stem from 2017, advise 12 months of DAPT as default therapy ${ }^{40}$. In patients who are at high risk of severe bleeding complications (not defined), discontinuation of $\mathrm{P}_{2} \mathrm{Y}_{12}$-inhibitor after 6 months should be considered (Ila, B). The guidelines advise that in high ischaemic-risk patients (criteria according to PEGASUS trial) who have tolerated DAPT without a bleeding complication, extended treatment beyond 12 months may be considered (Class IIB, B)

In patients with NSTE-ACS treated with PCl, standard DAPT duration is recommended for 12 months according to recently updated guidelines ${ }^{3}$. In patients with an excessive bleeding risk, discontinuation after 3 months should be considered (IIa, B) - even though evidence stems predominantly from studies including mostly low-risk patients with stable CAD. The use of bleeding scores (e.g. PRECISE-DAPT score) is encouraged when deciding to reduce DAPT duration. On the other hand, in patients with ACS and high risk for recurrent ischaemic events (defined as complex CAD and at least 1 high risk criterion) and without increased risk of major bleeding (for extensive list of definitions refer to ESC guidelines), continuation of DAPT for more than 12 months may be considered (class lla).

\subsection{The right strategy for the right patient: use of risk scores}

\subsubsection{Introduction}

In conclusion, the aforementioned studies and reviews suggest that a minimum duration of three to six months is effective in low-risk patients with stable coronary artery disease after $2^{\text {nd }}$ generation DES implantation, whereas in ACS patients DAPT duration $<12$ months should only be considered in patients with excessive bleeding risk. Extension of DAPT beyond 12 months appears to be only beneficial in selected subgroups, most notably patients with prior myocardial infarction who are at higher risk of ST and other recurrent spontaneous atherothrombotic events as well as cardiovascular death. 
The large RCTs and high quality meta-analyses do however not support one new standard DAPT duration in all patients. They rather support a personalised treatment in which the duration of DAPT is determined on an individual patient basis, reflecting an accurate tradeoff between the individual ischemic and haemorrhagic risks.

\subsubsection{Available risk scores}

Risk scores may aid in this decision making. Previously, several clinical patient characteristics (e.g. ACS, diabetes, impaired left ventricular function) as well as procedural (e.g. dissection, bifurcation stenting) and angiographic factors (e.g. undersizing of the stent, small stent diameter) have been identified as risk factors for stent thrombosis. ${ }^{9,41,42}$. As was demonstrated in previous studies, however, approximately $50 \%$ of recurrent atherothrombotic evens are not related to stent thrombosis ${ }^{15,16}$. Therefore, the patients overall ischemic risk should be considered when it comes to longer duration of DAPT.

Traditionally used scores to assess ischemic risk include the TIMI and GRACE risk score ${ }^{43,44}$. Whereas these risk scores are very useful in the initial assessment of ischemic risk and hence in guiding treatment and timing of coronary angiography, the clinical applicability in the out-patient setting is limited, as the variables focus mainly on patient characteristics at presentation (STT-deviation, cardiac biomarkers). Several other ischemic risk scores have been developed to assess the risk of recurrent atherothrombotic events including stent thrombosis. ${ }^{45-47}$

The DAPT risk score ${ }^{41}$ is currently the only risk score which can be used to identify patients benefitting from prolonged DAPT. In the DAPT study, patients free from major bleeding or ischaemic events during the initial course of DAPT, were randomised at 12 months after PCI to receive either prolonged DAPT or placebo. A net clinical model was developed, considering both ischaemic and bleeding risk. The risk score consists of nine variables, including age, smoking, diabetes, $\mathrm{Ml}$ at presentation, prior $\mathrm{PCl}$ or $\mathrm{MI}$, paclitaxel-eluting stent, stent diameter $<3 \mathrm{~mm}$, congestive heart failure or left ventricular ejection fraction below $30 \%$ and vein graft stenting. A simplified model was constructed. Point were adjudicated to each variable, with the total score ranging from -2 to 10 . Patients with a score of ${ }^{3} 2$ are considered to have a high thrombotic risk and were found to benefit from prolonged DAPT, whereas patients with a DAPT risk score <2 did not derive any benefit or even harm with prolonged DAPT. In conclusion, the DAPT score was able to discriminate patients who were likely to benefit vs. those who were likely to be harmed by prolonged DAPT. Although no prospective validation has to date been performed, several studies have retrospectively evaluated the use of the DAPT score in different external cohorts, which showed fair discriminatory properties. ${ }^{48,49-51}$ The DAPT risk score is believed to a useful tool to guide DAPT duration in event free patients one year after $\mathrm{PCl}$. 
Bleeding risk in hospitalised patients is typically assessed by the CRUSADE risk score ${ }^{52}$. However, this risk score is not applicable to ambulant patients undergoing elective $\mathrm{PCl}$ for stable angina. In the PRECISE-DAPT trial ${ }^{53}$, Costa and co-workers developed a prediction tool for out-of-hospital bleeding in a mixed cohort of 15,000 patients with both stable coronary artery disease and $\mathrm{ACS}$ who underwent $\mathrm{PCl}$ (and were predominantly treated with clopidogrel). Their model used five items (age, creatinine clearance, haemoglobin, whiteblood-cell count, and previous spontaneous bleeding) to predict Thrombosis in Myocardial Infarction (TIMI) major or minor bleeding with fair discrimination (C-index 0.71-0.73)

The performance of the model was subsequently verified in two validation cohorts (including the BernPCl registry, which is representative of the population seen in daily clinical practice) that demonstrated only moderate predictability (C-index $0.65-0.70$ ). The researchers observed significantly more bleeding events in patients with the highest bleeding risk (highest quartile, score $>25$ ) who were treated with prolonged DAPT (12-24 months) compared with those treated with a short (3-6 month) duration (absolute risk difference $2.59 \%, 95 \% \mathrm{Cl} 0.82-4.34)$, but not in patients with very low to moderate bleeding score (0.14\%, $95 \% \mathrm{Cl}-0.22$ to 0.49$)$. Interestingly, the researchers found that prolonged DAPT in patients at high bleeding risk did not reduce the rate of ischaemic events, although no competing-risk analyses had been performed. Similar results were observed in the subset of patients with ACS at the time of $\mathrm{PCl}$. Prospective validation of the risk score is currently being investigated. ${ }^{54}$

Finally, the PARIS ${ }^{46}$ score is another risk score, which was developed to predict both bleeding and ischaemic risk. The separate risk scores for bleeding and ischaemic events both contain 6 items. The score have a similar discrimination properties as compared to the PRECISEDAPT and DAPT risk score, but was not tested in an alternative DAPT regimen and therefore it cannot be used as a clinical decision instrument to guide DAPT duration.

\subsubsection{Using risk scores in clinical practice}

The 2018 and 2020 ESC guidelines on myocardial revascularization and NSTE-ACS state that the PRECISE-DAPT risk score can be used to select patients eligible for reduced DAPT duration. The DAPT score is not specifically mentioned. The 2017 ESC focused update on DAPT does mention the DAPT score as a risk stratification tool for clinical practice ${ }^{7}$.

A difficulty in clinical daily practice is that several risk factors for bleeding and ischemic risk overlap (e.g. renal function, age, malignancies), which complicates the use of a score for one or other risk alone. Interestingly, the DAPT study found that higher age increased bleeding risk more than ischemic risk. ${ }^{41}$ On the other hand, the PEGASUS trial, which considered older age and chronic renal dysfunction among others a risk factor for ischemic risk did 
convincingly demonstrate a benefit from prolonged DAPT with ticagrelor although at the cost of major but not fatal or intracranial bleeding.

Our own study group recently proposed ${ }^{55}$ an algorithm implementing both risk scores. We proposed the consecutive use of PRECISE-DAPT for the in-hospital phase, thereby selecting high bleeding-risk patients (i.e. PRECISE-DAPT score $\geq 25$ ) in whom a short course of DAPT should be considered. Subsequently, in patients who are treated with standard DAPT duration (i.e. PRECISE-DAPT score <25) and who do not encounter haemorrhagic complications during the first months of DAPT, the DAPT score is calculated. In patients with DAPT score >2, DAPT can be prolonged after the first year (Figure 1).

\section{Implementation in clinical practice}

Algorithms like the PRECISE-DAPT and DAPT-scores and, ideally, a consecutive approach using both risk scores, should be tested either in existing patient cohorts and in future prospective studies to prove their validity and applicability. In testing such strategies, it is important to acknowledge a distinction according to clinical presentation: stable coronary artery disease and ACS patients.

We believe in an important advisory role for the interventional cardiologist. As angiographic complexity (including multivessel disease) and procedural results are best known by the doctor who performed the $\mathrm{PCl}$, the interventional cardiologist should be in the lead to determine the minimum DAPT duration which has to be incorporated in the PCl report. For patients who are conservatively managed, the treating physician is in the lead.

In all scenario's, it is essential to include the recommended DAPT duration (and preferred P2 $\mathrm{Y}_{12}$ inhibitor) in the discharge letter. This advice should be communicated to the referring district hospitals if applicable, and to his or her general practitioner. Secondly, patient awareness and patient empowerment is very important. Therefore, we advise to discuss the length of the DAPT duration and considerations with the patient whilst he is in hospital. Finally, DAPT duration is not a static advise and can be revised at any time in the course of the patient's follow-up (e.g. recurrent myocardial infarct, stroke or bleeding complications). This implies an important role for the cardiologist who follows his patient in clinic. At least, the DAPT duration should be rediscussed at the time of the first follow-up visit after discharge and at every yearly follow-up. 


\section{References}

1. Neumann F-J, Sousa-Uva M, Ahlsson A, Alfonso F, Banning AP, Benedetto U, et al. 2018 ESC/EACTS Guidelines on myocardial revascularization. European Heart Journal. 2019 Jan 7;40(2):87-165.

2. Levine GN, Bates ER, Bittl JA, Brindis RG, Fihn SD, Fleisher LA, et al. 2016 ACC/AHA Guideline Focused Update on Duration of Dual Antiplatelet Therapy in Patients With Coronary Artery Disease: A Report of the American College of Cardiology/American Heart Association Task Force on Clinical Practice Guidelines: An Update of the 2011 ACCF/AHA/SCAI Guideline for Percutaneous Coronary Intervention, 2011 ACCF/AHA Guideline for Coronary Artery Bypass Graft Surgery, 2012 ACC/AHA/ACP/AATS/PCNA/SCAI/STS Guideline for the Diagnosis and Management of Patients With Stable Ischemic Heart Disease, 2013 ACCF/AHA Guideline for the Management of ST-Elevation Myocardial Infarction, 2014 AHA/ACC Guideline for the Management of Patients With Non-ST-Elevation Acute Coronary Syndromes, and 2014 ACC/ AHA Guideline on Perioperative Cardiovascular Evaluation and Management of Patients Undergoing Noncardiac Surgery. Circulation. 2016 Sep 6;134(10):123.

3. Collet J-P, Thiele H, Barbato E, Barthélémy O, Bauersachs J, Bhatt DL, et al. 2020 ESC Guidelines for the management of acute coronary syndromes in patients presenting without persistent ST-segment elevation. Eur Heart J. 2020 Aug 29;

4. Bittl JA, Baber U, Bradley SM, Wijeysundera DN. Duration of Dual Antiplatelet Therapy: A Systematic Review for the 2016 ACC/AHA Guideline Focused Update on Duration of Dual Antiplatelet Therapy in Patients With Coronary Artery Disease: A Report of the American College of Cardiology/American Heart Association Task Force on Clinical Practice Guidelines. Journal of the American College of Cardiology. 2016 Mar 22;

5. Tada T, Byrne RA, Simunovic I, King LA, Cassese S, Joner M, et al. Risk of stent thrombosis among bare-metal stents, first-generation drug-eluting stents, and second-generation drugeluting stents: results from a registry of 18,334 patients. JACC Cardiovascular interventions. 2013 Dec;6(12):1267-74.

6. Räber L, Magro M, Stefanini GG, Kalesan B, van Domburg RT, Onuma Y, et al. Very late coronary stent thrombosis of a newer-generation everolimus-eluting stent compared with early-generation drug-eluting stents: a prospective cohort study. Circulation. 2012 Mar 6;125(9):1110-21.

7. Valgimigli M, Bueno H, Byrne RA, Collet J-P, Costa F, Jeppsson A, et al. 2017 ESC focused update on dual antiplatelet therapy in coronary artery disease developed in collaboration with EACTS: The Task Force for dual antiplatelet therapy in coronary artery disease of the European Society of Cardiology (ESC) and of the European Association for Cardio-Thoracic Surgery (EACTS). European Heart Journal. 2017 26;

8. Torrado J, Buckley L, Durán A, Trujillo P, Toldo S, Valle Raleigh J, et al. Restenosis, Stent Thrombosis, and Bleeding Complications: Navigating Between Scylla and Charybdis. J Am Coll Cardiol. 2018 17;71(15):1676-95. 
9. Werkum JW van, Heestermans AA, Zomer AC, Kelder JC, Suttorp MJ, Rensing BJ, et al. Predictors of coronary stent thrombosis: the Dutch Stent Thrombosis Registry. Journal of the American College of Cardiology. 2009 Apr 21;53(16):1399-409.

10. lakovou I, Schmidt T, Bonizzoni E, Ge L, Sangiorgi GM, Stankovic G, et al. Incidence, predictors, and outcome of thrombosis after successful implantation of drug-eluting stents. Jama. 2005 May 4;293(17):2126-30.

11. Spertus JA, Kettelkamp R, Vance C, Decker C, Jones PG, Rumsfeld JS, et al. Prevalence, predictors, and outcomes of premature discontinuation of thienopyridine therapy after drug-eluting stent placement: results from the PREMIER registry. Circulation. 2006 Jun 20;113(24):2803-9.

12. Schulz S, Schuster T, Mehilli J, Byrne RA, Ellert J, Massberg S, et al. Stent thrombosis after drugeluting stent implantation: incidence, timing, and relation to discontinuation of clopidogrel therapy over a 4-year period. European heart journal. 2009 Nov;30(22):2714-21.

13. Urban P, Meredith IT, Abizaid A, Pocock SJ, Carrie D, Naber C, et al. Polymer-free Drug-Coated Coronary Stents in Patients at High Bleeding Risk. The New England journal of medicine. 2015 Nov 19;373(21):2038-47.

14. Valgimigli M, Patialiakas A, Thury A, McFadden E, Colangelo S, Campo G, et al. Zotarolimuseluting versus bare-metal stents in uncertain drug-eluting stent candidates. Journal of the American College of Cardiology. 2015 Mar 3;65(8):805-15.

15. Stone GW, Maehara A, Lansky AJ, de Bruyne B, Cristea E, Mintz GS, et al. A prospective naturalhistory study of coronary atherosclerosis. N Engl J Med. 2011 Jan 20;364(3):226-35.

16. Mauri L, Kereiakes DJ, Yeh RW, Driscoll-Shempp P, Cutlip DE, Steg PG, et al. Twelve or 30 months of dual antiplatelet therapy after drug-eluting stents. The New England journal of medicine. 2014 Dec 4;371(23):2155-66.

17. Brener SJ, Kirtane AJ, Stuckey TD, Witzenbichler B, Rinaldi MJ, Neumann F-J, et al. The Impact of Timing of Ischemic and Hemorrhagic Events on Mortality After Percutaneous Coronary Intervention: The ADAPT-DES Study. JACC Cardiovascular interventions. $2016 \mathrm{Jul}$ 25;9(14):1450-7.

18. Bonaca MP, Bhatt DL, Cohen M, Steg PG, Storey RF, Jensen EC, et al. Long-term use of ticagrelor in patients with prior myocardial infarction. The New England journal of medicine. 2015 May 7;372(19):1791-800.

19. Lee B-K, Kim J-S, Lee O-H, Min P-K, Yoon Y-W, Hong B-K, et al. Safety of six-month dual antiplatelet therapy after second-generation drug-eluting stent implantation: OPTIMA-C Randomised Clinical Trial and OCT Substudy. Eurolntervention. 2018 20;13(16):1923-30.

20. Colombo A, Chieffo A, Frasheri A, Garbo R, Masotti-Centol M, Salvatella N, et al. Secondgeneration drug-eluting stent implantation followed by 6 - versus 12 -month dual antiplatelet therapy: the SECURITY randomized clinical trial. Journal of the American College of Cardiology. 2014;64(20):2086-97.

21. Gwon HC, Hahn JY, Park KW, Song YB, Chae IH, Lim DS, et al. Six-month versus 12-month dual antiplatelet therapy after implantation of drug-eluting stents: the Efficacy of Xience/Promus 
Versus Cypher to Reduce Late Loss After Stenting (EXCELLENT) randomized, multicenter study. Circulation. 2012 Jan 24;125(3):505-13.

22. Kim BK, Hong MK, Shin DH, Nam CM, Kim JS, Ko YG, et al. A new strategy for discontinuation of dual antiplatelet therapy: the RESET Trial (REal Safety and Efficacy of 3-month dual antiplatelet Therapy following Endeavor zotarolimus-eluting stent implantation). Journal of the American College of Cardiology. 2012 Oct 9;60(15):1340-8.

23. Feres F, Costa RA, Abizaid A, Leon MB, Marin-Neto J, Botelho RV, et al. Three vs twelve months of dual antiplatelet therapy after zotarolimus-eluting stents: the OPTIMIZE randomized trial. Jama. 2013 Dec 18;310(23):2510-22.

24. Schulz-Schupke S, Byrne RA, Berg JMT, Neumann FJ, Han Y, Adriaenssens T, et al. ISAR-SAFE: a randomized, double-blind, placebo-controlled trial of 6 vs. 12 months of clopidogrel therapy after drug-eluting stenting. European heart journal. 2015 May 21;36(20):1252-63.

25. De Luca G, Damen SA, Camaro C, Benit E, Verdoia M, Rasoul S, et al. Final results of the randomised evaluation of short-term dual antiplatelet therapy in patients with acute coronary syndrome treated with a new-generation stent (REDUCE trial). Eurolntervention. 2019 06;15(11):e990-8.

26. Hahn J-Y, Song YB, Oh J-H, Cho D-K, Lee JB, Doh J-H, et al. 6-month versus 12-month or longer dual antiplatelet therapy after percutaneous coronary intervention in patients with acute coronary syndrome (SMART-DATE): a randomised, open-label, non-inferiority trial. Lancet. 2018 31;391(10127):1274-84.

27. Palmerini T, Della Riva D, Benedetto U, Bacchi Reggiani L, Feres F, Abizaid A, et al. Three, six, or twelve months of dual antiplatelet therapy after DES implantation in patients with or without acute coronary syndromes: an individual patient data pairwise and network meta-analysis of six randomized trials and 11473 patients. Eur Heart J. 2017 07;38(14):1034-43.

28. Yin S-H-L, Xu P, Wang B, Lu Y, Wu Q-Y, Zhou M-L, et al. Duration of dual antiplatelet therapy after percutaneous coronary intervention with drug-eluting stent: systematic review and network meta-analysis. BMJ. 2019 28;365:12222.

29. Valgimigli M, Campo G, Monti M, Vranckx P, Percoco G, Tumscitz C, et al. Short- versus longterm duration of dual-antiplatelet therapy after coronary stenting: a randomized multicenter trial. Circulation. 2012 Apr 24;125(16):2015-26.

30. Collet JP, Silvain J, Barthelemy O, Range G, Cayla G, Belle EV, et al. Dual-antiplatelet treatment beyond 1 year after drug-eluting stent implantation (ARCTIC-Interruption): a randomised trial. Lancet (London, England). 2014 Nov 1;384(9954):1577-85.

31. Palmerini T, Benedetto U, Bacchi-Reggiani L, Riva DD, Biondi-Zoccai G, Feres F, et al. Mortality in patients treated with extended duration dual antiplatelet therapy after drug-eluting stent implantation: a pairwise and Bayesian network meta-analysis of randomised trials. Lancet (London, England). 2015 Jun 13;385(9985):2371-82.

32. Navarese EP, Andreotti F, Schulze V, Kołodziejczak M, Buffon A, Brouwer M, et al. Optimal duration of dual antiplatelet therapy after percutaneous coronary intervention with drug eluting stents: meta-analysis of randomised controlled trials. BMJ (Clinical research ed). 2015;350:h1618. 
33. Spencer FA, Prasad M, Vandvik PO, Chetan D, Zhou Q, Guyatt G. Longer- Versus ShorterDuration Dual-Antiplatelet Therapy After Drug-Eluting Stent Placement: A Systematic Review and Meta-analysis. Annals of Internal Medicine. 2015 Jul 21;163(2):118-26.

34. Palmerini T, Reggiani LB, Riva DD, Romanello M, Feres F, Abizaid A, et al. Bleeding-Related Deaths in Relation to the Duration of Dual-Antiplatelet Therapy After Coronary Stenting. Journal of the American College of Cardiology. 2017 Apr 25;69(16):2011-22.

35. Udell JA, Bonaca MP, Collet J-P, Lincoff AM, Kereiakes DJ, Costa F, et al. Long-term dual antiplatelet therapy for secondary prevention of cardiovascular events in the subgroup of patients with previous myocardial infarction: a collaborative meta-analysis of randomized trials. European Heart Journal. 2016 Jan 21;37(4):390-9.

36. Elmariah S, Mauri L, Doros G, Galper BZ, O’Neill KE, Steg PG, et al. Extended duration dual antiplatelet therapy and mortality: a systematic review and meta-analysis. Lancet (London, England). 2015 Feb 28;385(9970):792-8.

37. Mauri L, Elmariah S, Yeh RW, Cutlip DE, Steg PG, Windecker S, et al. Causes of late mortality with dual antiplatelet therapy after coronary stents. European Heart Journal. 2016 Jan 21;37(4):378-85.

38. Palmerini T, Stone GW. Optimal duration of dual antiplatelet therapy after drug-eluting stent implantation: conceptual evolution based on emerging evidence. European Heart Journal. 2016 Jan 21;37(4):353-64.

39. Généreux P, Giustino G, Witzenbichler B, Weisz G, Stuckey TD, Rinaldi MJ, et al. Incidence, Predictors, and Impact of Post-Discharge Bleeding After Percutaneous Coronary Intervention. Journal of the American College of Cardiology. 2015 Sep 1;66(9):1036-45.

40. Ibanez B, James S, Agewall S, Antunes MJ, Bucciarelli-Ducci C, Bueno H, et al. 2017 ESC Guidelines for the management of acute myocardial infarction in patients presenting with ST-segment elevation: The Task Force for the management of acute myocardial infarction in patients presenting with ST-segment elevation of the European Society of Cardiology (ESC). European Heart Journal. 2017 26;

41. Yeh RW, Secemsky EA, Kereiakes DJ, Normand SL, Gershlick AH, Cohen DJ, et al. Development and Validation of a Prediction Rule for Benefit and Harm of Dual Antiplatelet Therapy Beyond 1 Year After Percutaneous Coronary Intervention. Jama. 2016 Apr 26;315(16):1735-49.

42. Ong DS, Jang IK. Causes, assessment, and treatment of stent thrombosis-intravascular imaging insights. Nature reviewsCardiology. 2015 Jun;12(6):325-36.

43. Antman EM, Cohen M, Bernink PJ, McCabe CH, Horacek T, Papuchis $\mathrm{G}$, et al. The TIMI risk score for unstable angina/non-ST elevation MI: A method for prognostication and therapeutic decision making. JAMA. 2000 Aug 16;284(7):835-42.

44. Eagle KA, Lim MJ, Dabbous OH, Pieper KS, Goldberg RJ, Werf FV de, et al. A validated prediction model for all forms of acute coronary syndrome: estimating the risk of 6-month postdischarge death in an international registry. JAMA. 2004 Jun 9;291(22):2727-33. 
45. Dangas GD, Claessen BE, Mehran R, Xu K, Fahy M, Parise H, et al. Development and validation of a stent thrombosis risk score in patients with acute coronary syndromes. JACC Cardiovasc Interv. 2012 Nov;5(11):1097-105.

46. Baber U, Mehran R, Giustino G, Cohen DJ, Henry TD, Sartori S, et al. Coronary Thrombosis and Major Bleeding After PCI With Drug-Eluting Stents: Risk Scores From PARIS. Journal of the American College of Cardiology. 2016 May 17;67(19):2224-34.

47. Fox KAA, Fitzgerald G, Puymirat E, Huang W, Carruthers K, Simon T, et al. Should patients with acute coronary disease be stratified for management according to their risk? Derivation, external validation and outcomes using the updated GRACE risk score. BMJ Open. 2014 Feb 21;4(2):e004425.

48. Yoshikawa $\mathrm{Y}$, Shiomi $\mathrm{H}$, Watanabe $\mathrm{H}$, Natsuaki $\mathrm{M}$, Kondo $\mathrm{H}$, Tamura $\mathrm{T}$, et al. Validating Utility of Dual Antiplatelet Therapy Score in a Large Pooled Cohort From 3 Japanese Percutaneous Coronary Intervention Studies. Circulation. 2018 06;137(6):551-62.

49. Kereiakes DJ, Yeh RW, Massaro JM, Cutlip DE, Steg PG, Wiviott SD, et al. DAPT Score Utility for Risk Prediction in Patients With or Without Previous Myocardial Infarction. J Am Coll Cardiol. 2016 May 31;67(21):2492-502.

50. Ueda P, Jernberg T, James S, Alfredsson J, Erlinge D, Omerovic E, et al. External Validation of the DAPT Score in a Nationwide Population. J Am Coll Cardiol. 2018 04;72(10):1069-78.

51. Witberg G, Zusman O, Yahav D, Perl L, Vaknin-Assa H, Kornowski R. Meta-Analysis of Studies Examining the External Validity of the DAPT Score. Eur Heart J Cardiovasc Pharmacother. 2019 Dec 3;

52. Subherwal S, Bach RG, Chen AY, Gage BF, Rao SV, Newby LK, et al. Baseline risk of major bleeding in non-ST-segment-elevation myocardial infarction: the CRUSADE (Can Rapid risk stratification of Unstable angina patients Suppress ADverse outcomes with Early implementation of the ACC/AHA Guidelines) Bleeding Score. Circulation. 2009 Apr 14;119(14):1873-82.

53. Costa F, Klaveren D van, James S, Heg D, Räber L, Feres F, et al. Derivation and validation of the predicting bleeding complications in patients undergoing stent implantation and subsequent dual antiplatelet therapy (PRECISE-DAPT) score: a pooled analysis of individual-patient datasets from clinical trials. Lancet (London, England). 2017 Mar 11;389(10073):1025-34.

54. Frigoli E, Smits P, Vranckx P, Ozaki Y, Tijssen J, Jüni P, et al. Design and rationale of the Management of High Bleeding Risk Patients Post Bioresorbable Polymer Coated Stent Implantation With an Abbreviated Versus Standard DAPT Regimen (MASTER DAPT) Study. Am Heart J. 2019;209:97-105.

55. Chan Pin Yin DRPP, Vos G-JA, van der Sangen NMR, Walhout R, Tjon Joe Gin RM, Nicastia DM, et al. Rationale and Design of the Future Optimal Research and Care Evaluation in Patients with Acute Coronary Syndrome (FORCE-ACS) Registry: Towards "Personalized Medicine" in Daily Clinical Practice. J Clin Med. 2020 Sep 30;9(10). 


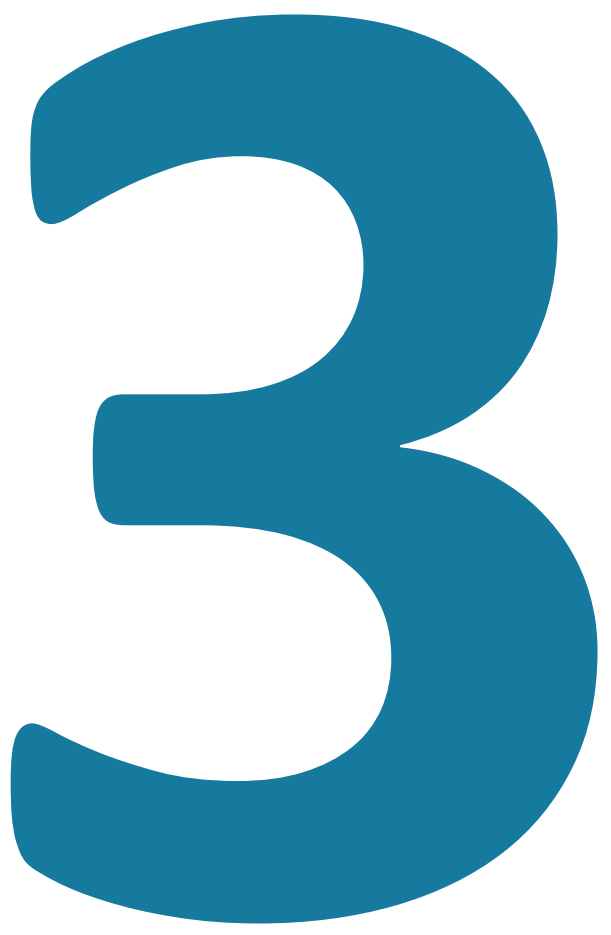




\section{Antithrombotic therapy in patients with atrial fibrillation undergoing percutaneous coronary intervention}





\subsection{Introduction}

Whereas duration of dual antiplatelet therapy (DAPT) has become more complex than before, antithrombotic regimens in patients with atrial fibrillation (AF) undergoing percutaneous coronary intervention ( $\mathrm{PCl}$ ) could arguably be even more complex. Illustrating the relevant overlap in clinical practice, approximately 1 in 5 patients with $\mathrm{AF}$ undergo $\mathrm{PCl}$ at some point in life. From the $\mathrm{PCl}$ perspective, 1 in 12 patients undergoing coronary stenting has concomitant $\mathrm{AF}$ and an indication for $\mathrm{OAC}^{1,2}$.

In AF patients with a CHADSVASC score ${ }^{3} 1$ in males and $\geq 2$ in females, oral anticoagulation (OAC) is warranted to reduce the risk of systemic thromboembolic events including stroke, whereas patients undergoing $\mathrm{PCl}$ have an indication for dual antiplatelet therapy consisting of aspirin and a $\mathrm{P}_{2} \mathrm{Y}_{12}$ inhibitor in order reduce the risk of stent thrombosis or other recurrent atherothrombotic events ${ }^{2-4}$. The combination of dual antiplatelet therapy and OAC is referred to as 'triple therapy' (TAT) and is recommended by current international guidelines and consensus documents for one week and up to one month in patients at high thrombotic risk ${ }^{4,6,7}$.

Triple antithrombotic therapy (TAT) confers at least a two times higher risk of bleeding as compared to 'double therapy' (DAT, a combination of OAC and a P2Y $\mathrm{Y}_{12}$ inhibitor, i.e. with the omittance of aspirin) ${ }^{8,9}$. Therefore, it is advised to keep the duration of TAT as short as possible or to consider an alternative regimen of double therapy ${ }^{3,4}$.

\subsection{Trials investigating triple therapy versus double therapy}

Five large randomised controlled trials compared TAT with the combination of (N)OAC and an antiplatelet agent. The WOEST study was the first to investigate a regime of omitting aspirin from the TAT regime in patients treated with vitamin $\mathrm{K}$ antagonists (VKA) undergoing $\mathrm{PCl}^{10}$. All patients were treated with clopidogrel. The WOEST study showed that DAT was associated with a reduction of bleeding without an increase in thrombotic events, as compared to patients treated with TAT.

Meanwhile, the world of antiplatelet and antithrombotic agents changed with the introduction of more potent $\mathrm{P} 2 \mathrm{Y}_{12}$-inhibitors including prasugrel and ticagrelor and with the introduction of the of nonvitamin $\mathrm{K}$ oral anticoagulant therapy (NOAC). The use of NOACs (rivaroxaban and dabigatran, respectively) plus a $\mathrm{P}_{2} \mathrm{Y}_{12}$-inhibitor were compared with a triple therapy strategy including VKA in the PIONEER AF-PCI and RE-DUAL PCI trials ${ }^{11,12}$. Both studies demonstrated a lower risk of bleeding associated with the former regimen, but due to the design of these studies, it was not clear whether this was an effect of omitting aspirin, a benefit of NOAC over VKA or an effect of the lower NOAC dose used in the studies. Surprisingly, the ENTRUST-AF PCI study, which was the most recent trial comparing a DAT 
regimen with edoxaban versus VKA-based TAT, failed to show a reduction in bleeding rates and no differences in ischemic outcomes either ${ }^{13}$. Finally, the in 2019 published AUGUSTUS study assessed the efficacy and safety of TAT in a $2 \times 2$ design, which allowed the independent comparisons of VKA versus NOAC and aspirin versus placebo. ${ }^{14}$ This largest study thus far included 4614 patients with ACS or who underwent PCl. The study demonstrated that a combination of full dose apixaban with a $\mathrm{P}_{2} \mathrm{Y}_{12}$-inhibitor but without aspirin resulted in less bleeding as compared with regimens that included a vitamin $\mathrm{K}$ antagonist and/or aspirin. In patients treated with DAT, no significant differences in ischaemic events was observed. First, this study established the benefits of NOAC over VKA which now also holds true in patients with concomitant (dual) antiplatelet therapy. Based on their superior safety profile, NOAC should be preferred over VKA, also in combination with antiplatelet agents. Second, the evidence was strongly in favour of double therapy. However, it must be noted that this study again was not powered for ischemic events and a numerical higher incidence of stent thrombosis was observed in patients not receiving aspirin. Furthermore, it is important to acknowledge that the AUGUSTUS patients were low-risk patients, as the majority of patients (>60\% in all treatment arms) underwent either elective PCl or had medically managed ACS.

Several meta-analyses have been published using pooled data from the randomised trials. These meta-analyses demonstrated a relative reduction in bleeding with approximately 40-50\% and did not find a significant difference in ischemic outcomes ${ }^{8,15-19}$. Only two meta-analysis of randomised controlled trials signalled a small increase in terms of stent thrombosis (but not spontaneous myocardial infarction) associated with DAT ${ }^{20,21}$. In these two studies, stent thrombosis was significantly reduced with TAT, although incidence rates were low ( $0.6 \%$ vs. $1.0 \%, p=0.04$ and $0.7 \%$ vs. $1.1 \%, p=0.041)$. Importantly, this effect was counterbalanced by a significantly higher bleeding rate (International Society on Thrombosis and Haemostasis major or clinically relevant nonmajor bleeding $13.5-14.6 \%$ vs. 20.3-22.6\%,). No significant differences in all-cause death or cardiovascular death were observed.

In conclusion, several trials showed that DAT is associated with a lower rate of bleeding complications (safety) with no increase in thrombotic complications (efficacy) as compared to TAT in AF patients undergoing PCI. However, all trials were underpowered for ischaemic endpoints and, a numerical increase in ischemic events (small absolute numbers) was observed in some trials ${ }^{11,14,22}$. With regard to stent thrombosis, a small was observed in some meta-analyses. It should be kept in mind that in some trials, aspirin was used for several days up to one week during and after $\mathrm{PCl}^{12,14}$. 


\subsection{Bleeding and association with adverse outcomes}

It was already known that risk of major bleeding is about 1.8-fold higher with DAPT than with aspirin alone and at least 2.5-fold higher when aspirin is combined with VKA ${ }^{23}$. In the aforementioned trials, bleeding risk was associated with a $\sim 1.5$ to 2 -fold increase in major of clinically relevant bleeding.

So why does bleeding matter? Bleeding is one of the most dreaded iatrogenic complications of antithrombotic treatment, as it is strongly associated with adverse outcomes including a strong link with mortality. When major bleeding occurs, it is associated with an $\leq 4$ fold increase in ischaemic events and up to a 5-fold increase in death ${ }^{23,24}$ or even up to a 10-fold mortality risk with GUSTO severe bleeding ${ }^{25}$. In-hospital major bleeding confers a $\sim 5$-fold risk of mortality ${ }^{26}$. Spontaneous bleeds might confer a higher risk of mortality as compared to access-site related bleeds. ${ }^{27,28}$

Besides the direct link between bleeding events and increased morbidity and mortality and reflecting in part the effect of interrupting antithrombotic therapy, there appears to be an indirect link between haemorrhagic complications are adverse outcomes. ${ }^{29}$

Other trials showed that bleeding complications confer a similar or even higher risk of mortality as compared to recurrent ischaemic events ${ }^{30,31}$.

\subsection{Optimal treatment of $\mathrm{AF}$ patients undergoing $\mathrm{PCl}$}

To summarise, bleeding is very prevalent among patients treated with a combination of anticoagulation and antiplatelet drugs. In AF patients undergoing $\mathrm{PCl}$, TAT is associated with a $1.5-2$ fold increase in bleeding rates, which are already very high in these patient group. Bleeding is not a benign side effects as it confers a high-risk of adverse events including death.

With regard to ischaemic outcomes, most reviews and meta-analyses could not show a difference in ischaemic outcomes, although two meta-analyses signalled a small increase in stent thrombosis with DAT. However, in absolute terms, ischaemic events are roughly $10-$ fold less prevalent in contemporary practice as compared to the bleeding complications ${ }^{20}$. Arguably, net clinical risk of these patients seems to be determined by bleeding risk and not by ischaemic risk.

Therefore, DAT seems a very reasonable strategy in AF patients undergoing $\mathrm{PCl}$ and could be the new default strategy. However, to be able to further improve and tailor treatment in these specific group of $A F$ patients undergoing $\mathrm{PCl}$, several questions remain to be answered. 
First, is DAT also effective and safe in patients at high ischaemic risk? Some studies described specific sub groups of patients included in the original trials. An analysis of prespecified subgroups in the RE-DUAL trial could not detect differences in outcomes across the subgroups of diabetes, age $\geq 80$ years, or when stratified for indication for $\mathrm{PCl} .{ }^{11}$ Other subgroup analyses from RE-DUAL, AUGUSTUS and PIONEER AF-PCI trials focusing on patients with ACS or diabetes or with high risk procedural or characteristics suggested no difference in these patients either, although it must be stressed that these studies focused on one parameter only ${ }^{22,32-34}$. Therefore, it remains unknown whether patients with a combination of ischaemic risk factors who are therefore at high risk for recurrent thrombotic events can safely be treated with DAT.

Focusing on bleeding again, another unresolved clinical issue is how we can quantify bleeding risk and identify high-risk patients. Currently, no bleeding model exists for this specific patient population of AF patients undergoing $\mathrm{PCI}$. For ACS patients the CRUSADE risk score is being used, whereas the HAS-BLED score is currently being used to estimate bleeding risk in patients with atrial fibrillation. ${ }^{35,36}$ However, neither of these scores is applicable to the specific subset of patients with AF who undergo $\mathrm{PCl}$ currently exists. The development of a bleeding score would be a very useful addition to improve the care for these patients in daily practice. 


\section{Reference list}

1. Mehta SR. Refining Antithrombotic Therapy for Atrial Fibrillation and Acute Coronary Syndromes or PCI. The New England Journal of Medicine 2019;380(16):1580-1. Doi: 10.1056/ NEJMe1902214.

2. Valgimigli M., Bueno H., Byrne RA., et al. 2017 ESC focused update on dual antiplatelet therapy in coronary artery disease developed in collaboration with EACTS: The Task Force for dual antiplatelet therapy in coronary artery disease of the European Society of Cardiology (ESC) and of the European Association for Cardio-Thoracic Surgery (EACTS). European Heart Journal 2017. Doi: 10.1093/eurheartj/ehx419.

3. Hindricks G., Potpara T., Dagres N., et al. 2020 ESC Guidelines for the diagnosis and management of atrial fibrillation developed in collaboration with the European Association of Cardio-Thoracic Surgery (EACTS). Eur Heart J 2020. Doi: 10.1093/eurheartj/ehaa612.

4. Neumann F-J., Sousa-Uva M., Ahlsson A., et al. 2018 ESC/EACTS Guidelines on myocardial revascularization. European Heart Journal 2019;40(2):87-165. Doi: 10.1093/eurheartj/ehy394.

5. Kirchhof P., Benussi S., Kotecha D., et al. 2016 ESC Guidelines for the management of atrial fibrillation developed in collaboration with EACTS. European Heart Journal 2016;37(38):2893962. Doi: 10.1093/eurheartj/ehw210.

6. Collet J-P., Thiele H., Barbato E., et al. 2020 ESC Guidelines for the management of acute coronary syndromes in patients presenting without persistent ST-segment elevation. Eur Heart J 2020. Doi: 10.1093/eurheartj/ehaa575.

7. Angiolillo DJ., Goodman SG., Bhatt DL., et al. Antithrombotic Therapy in Patients With Atrial Fibrillation Treated With Oral Anticoagulation Undergoing Percutaneous Coronary Intervention. Circulation 2018;138(5):527-36. Doi: 10.1161/CIRCULATIONAHA.118.034722.

8. Golwala HB., Cannon CP., Steg PG., et al. Safety and efficacy of dual vs. triple antithrombotic therapy in patients with atrial fibrillation following percutaneous coronary intervention: a systematic review and meta-analysis of randomized clinical trials. Eur Heart J 2018;39(19):1726-1735a. Doi: 10.1093/eurheartj/ehy162.

9. Lamberts M., Gislason GH., Olesen JB., et al. Oral anticoagulation and antiplatelets in atrial fibrillation patients after myocardial infarction and coronary intervention. J Am Coll Cardiol 2013;62(11):981-9. Doi: 10.1016/j.jacc.2013.05.029.

10. Dewilde WJM., Oirbans T., Verheugt FWA., et al. Use of clopidogrel with or without aspirin in patients taking oral anticoagulant therapy and undergoing percutaneous coronary intervention: an open-label, randomised, controlled trial. Lancet (London, England) 2013;381(9872):1107-15. Doi: 10.1016/S0140-6736(12)62177-1.

11. Cannon CP., Bhatt DL., Oldgren J., et al. Dual Antithrombotic Therapy with Dabigatran after PCl in Atrial Fibrillation. N Engl J Med 2017;377(16):1513-24. Doi: 10.1056/NEJMoa1708454.

12. Gibson CM., Mehran R., Bode C., et al. Prevention of Bleeding in Patients with Atrial Fibrillation Undergoing PCl. N Engl J Med 2016;375(25):2423-34. Doi: 10.1056/NEJMoa1611594. 
13. Vranckx P., Valgimigli M., Eckardt L., et al. Edoxaban-based versus vitamin $\mathrm{K}$ antagonist-based antithrombotic regimen after successful coronary stenting in patients with atrial fibrillation (ENTRUST-AF PCI): a randomised, open-label, phase 3b trial. Lancet 2019;394(10206):1335-43. Doi: 10.1016/S0140-6736(19)31872-0.

14. Lopes RD., Heizer G., Aronson R., et al. Antithrombotic Therapy after Acute Coronary Syndrome or PCl in Atrial Fibrillation. N Engl J Med 2019;380(16):1509-24. Doi: 10.1056/ NEJMoa1817083.

15. Lopes RD., Hong H., Harskamp RE., et al. Safety and Efficacy of Antithrombotic Strategies in Patients With Atrial Fibrillation Undergoing Percutaneous Coronary Intervention: A Network Meta-analysis of Randomized Controlled Trials. JAMA Cardiol 2019. Doi: 10.1001/ jamacardio.2019.1880.

16. Cavallari I., Patti G. Meta-Analysis Comparing the Safety and Efficacy of Dual Versus Triple Antithrombotic Therapy in Patients With Atrial Fibrillation Undergoing Percutaneous Coronary Intervention. Am J Cardiol 2018;121(6):718-24. Doi: 10.1016/j.amjcard.2017.12.014.

17. Fortuni F., Ferlini M., Leonardi S., et al. Dual versus triple therapy in patients on oral anticoagulants and undergoing coronary stent implantation: A systematic review and metaanalysis. Int J Cardiol 2018;273:80-7. Doi: 10.1016/j.ijcard.2018.08.019.

18. Haller PM., Sulzgruber P., Kaufmann C., et al. Bleeding and ischaemic outcomes in patients treated with dual or triple antithrombotic therapy: systematic review and meta-analysis. Eur Heart J Cardiovasc Pharmacother 2019;5(4):226-36. Doi: 10.1093/ehjcvp/pvz021.

19. Dahal K., Mustafa U., Sharma SP., et al. Ischemic and bleeding outcomes of triple therapy in patients on chronic anticoagulation undergoing percutaneous coronary intervention: $A$ meta-analysis of randomized trials. JRSM Cardiovasc Dis 2019;8:2048004019885572. Doi: $10.1177 / 2048004019885572$.

20. Gargiulo G., Goette A., Tijssen J., et al. Safety and efficacy outcomes of double vs. triple antithrombotic therapy in patients with atrial fibrillation following percutaneous coronary intervention: a systematic review and meta-analysis of non-vitamin $\mathrm{K}$ antagonist oral anticoagulant-based randomized clinical trials. Eur Heart J 2019;40(46):3757-67. Doi: 10.1093/ eurheartj/ehz732.

21. Potpara TS., Mujovic N., Proietti M., et al. Revisiting the effects of omitting aspirin in combined antithrombotic therapies for atrial fibrillation and acute coronary syndromes or percutaneous coronary interventions: meta-analysis of pooled data from the PIONEER AF-PCI, RE-DUAL PCI, and AUGUSTUS trials. Europace 2020;22(1):33-46. Doi: 10.1093/europace/euz259.

22. Oldgren J., Steg PG., Hohnloser SH., et al. Dabigatran dual therapy with ticagrelor or clopidogrel after percutaneous coronary intervention in atrial fibrillation patients with or without acute coronary syndrome: a subgroup analysis from the RE-DUAL PCI trial. Eur Heart J 2019;40(19):1553-62. Doi: 10.1093/eurheartj/ehz059.

23. Chan NC., Weitz JI. Antithrombotic Agents. Circ Res 2019;124(3):426-36. Doi: 10.1161/ CIRCRESAHA.118.313155. 
24. Eikelboom JW., Mehta SR., Anand SS., Xie C., Fox KAA., Yusuf S. Adverse impact of bleeding on prognosis in patients with acute coronary syndromes. Circulation 2006;114(8):774-82. Doi: 10.1161/CIRCULATIONAHA.106.612812.

25. Rao SV., O'Grady K., Pieper KS., et al. Impact of bleeding severity on clinical outcomes among patients with acute coronary syndromes. Am J Cardiol 2005;96(9):1200-6. Doi: 10.1016/j. amjcard.2005.06.056.

26. Suh J-W., Mehran R., Claessen BE., et al. Impact of in-hospital major bleeding on late clinical outcomes after primary percutaneous coronary intervention in acute myocardial infarction the HORIZONS-AMI (Harmonizing Outcomes With Revascularization and Stents in Acute Myocardial Infarction) trial. J Am Coll Cardiol 2011;58(17):1750-6. Doi: 10.1016/j. jacc.2011.07.021.

27. Ducrocq G., Schulte PJ., Becker RC., et al. Association of spontaneous and procedure-related bleeds with short- and long-term mortality after acute coronary syndromes: an analysis from the PLATO trial. Eurolntervention 2015;11(7):737-45. Doi: 10.4244/EIJY14M09_11.

28. Verheugt FWA., Steinhubl SR., Hamon M., et al. Incidence, prognostic impact, and influence of antithrombotic therapy on access and nonaccess site bleeding in percutaneous coronary intervention. JACC Cardiovasc Interv 2011;4(2):191-7. Doi: 10.1016/j.jcin.2010.10.011.

29. Ndrepepa G., Schuster T., Hadamitzky M., et al. Validation of the Bleeding Academic Research Consortium definition of bleeding in patients with coronary artery disease undergoing percutaneous coronary intervention. Circulation 2012;125(11):1424-31. Doi: 10.1161/ CIRCULATIONAHA.111.060871.

30. Pocock SJ., Mehran R., Clayton TC., et al. Prognostic modeling of individual patient risk and mortality impact of ischemic and hemorrhagic complications: assessment from the Acute Catheterization and Urgent Intervention Triage Strategy trial. Circulation 2010;121(1):43-51. Doi: 10.1161/CIRCULATIONAHA.109.878017.

31. Généreux P., Giustino G., Witzenbichler B., et al. Incidence, Predictors, and Impact of PostDischarge Bleeding After Percutaneous Coronary Intervention. Journal of the American College of Cardiology 2015;66(9):1036-45. Doi: 10.1016/j.jacc.2015.06.1323.

32. Windecker S., Lopes RD., Massaro T., et al. Antithrombotic Therapy in Patients with Atrial Fibrillation and Acute Coronary Syndrome Treated Medically or with Percutaneous Coronary Intervention or Undergoing Elective Percutaneous Coronary Intervention: Insights from the AUGUSTUS Trial. Circulation 2019. Doi: 10.1161/CIRCULATIONAHA.119.043308.

33. Maeng M., Steg PG., Bhatt DL., et al. Dabigatran Dual Therapy Versus Warfarin Triple Therapy Post-PCl in Patients With Atrial Fibrillation and Diabetes. JACC Cardiovasc Interv 2019;12(23):2346-55. Doi: 10.1016/j.jcin.2019.07.059.

34. Kerneis M., Gibson CM., Chi G., et al. Effect of Procedure and Coronary Lesion Characteristics on Clinical Outcomes Among Atrial Fibrillation Patients Undergoing Percutaneous Coronary Intervention: Insights From the PIONEER AF-PCI Trial. JACC Cardiovasc Interv 2018;11(7):62634. Doi: 10.1016/j.jcin.2017.11.009. 
52 | Chapter 3

35. Subherwal S., Bach RG., Chen AY., et al. Baseline risk of major bleeding in non-STsegment-elevation myocardial infarction: the CRUSADE (Can Rapid risk stratification of Unstable angina patients Suppress ADverse outcomes with Early implementation of the ACC/AHA Guidelines) Bleeding Score. Circulation 2009;119(14):1873-82. Doi: 10.1161/ CIRCULATIONAHA.108.828541 [doi].

36. Pisters R., Lane DA., Nieuwlaat R., Vos CB de., Crijns HJGM., Lip GYH. A novel user-friendly score (HAS-BLED) to assess 1-year risk of major bleeding in patients with atrial fibrillation: the Euro Heart Survey. Chest 2010;138(5):1093-100. Doi: 10.1378/chest.10-0134. 


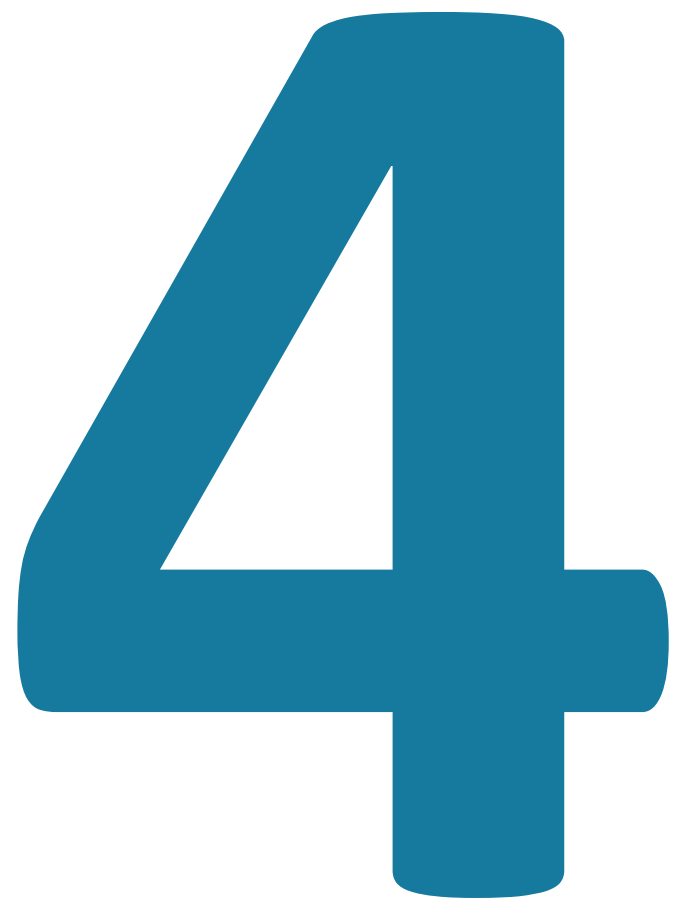


Aims and outline of this thesis 

Part I of this thesis focuses on stent thrombosis. Although many knowledge has been gathered about stent thrombosis, including predictors and treatment modalities, some other area's remain unchartered territory. Triggering mechanisms such as vigorous exercise and emotional stress are known to play a role in luxating spontaneous myocardial infarction (i.e. not stent thrombosis related), but it is unknown whether triggering mechanisms play a role in stent thrombosis as well. In Chapter 5 the role of triggering mechanisms in provoking stent thrombosis is investigated. Chapter 6 describes the absolute risk of stent thrombosis when clopidogrel is discontinued early. Finally, chapter 7 focuses on an antithrombotic strategy to overcome the delayed absorption of $\mathrm{P}_{2} \mathrm{Y}_{12}$-inhibitors associated with morphine when this is given in STEMI patients before undergoing primary $\mathrm{PCI}$. In Chapter $\mathbf{8}$, three individual patient reports are included to illustrate particularly interesting cases of stent thrombosis.

Part II starts with an overview (chapter 9) of the current literature on platelet function testing and discusses the value and possibilities of its use in clinical practice. In chapter 10 , correlation and agreement of four different platelet function test are discussed and the performance and feasibility of the use of a panel of three combined tests is described.

Part III addresses the subgroup of AF patients who undergo PCI. Currently, these patients are more and more treated with oral anticoagulation and a $\mathrm{P}_{2} \mathrm{Y}_{12}$-inhibitor but with the omittance of aspirin. Chapter 11 investigates whether a strategy of so-called "double therapy" is also effective in patients at high thrombotic risk and how to select those patients who might benefit from triple therapy. Finally, in chapter 12, the development and validation of a prediction tool to estimate individual patients bleeding risk is described. 


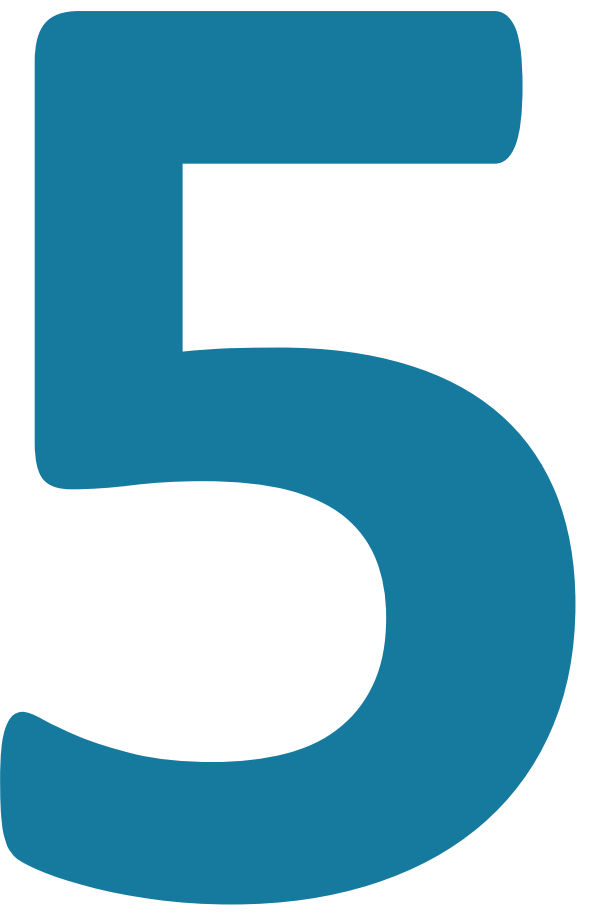




\section{Triggering mechanisms of stent thrombosis}

B. Zwart, J.W. van Werkum, A.A.C.M. Heestermans, J.C. Kelder, A.C. Zomer, A.W.J. van 't Hof, F.W.A. Verheugt, J.M. ten Berg 


\section{Abstract}

Aims:

The aim of this study was to determine the role of potential triggers of stent thrombosis.

\section{Methods and results:}

Patients ( $n=437$ ) with "definite" ST were recruited consecutively in the setting of a large multicentre observational cohort study. Patients were interviewed with validated questionnaires to identify one of the following triggers: I) timing of onset of ST, II) performance of vigorous (S $6 \mathrm{MET}$ ) physical activity in the two hours preceding ST, III) presence of emotional stress (experiencing a serious life event in the 14 days preceding the ST or feelings of anger in the 12 hours of ST) and IV) presence of a documented active infection at the time of ST. A total of 363 patients (83.1\%) were able to supply adequate information. A significant trigger was identified in 83 patients $(22.9 \%)$. Analysis of the different categories according to timing of ST revealed a higher prevalence of triggers with an increasing time-interval between index $\mathrm{PCl}$ and $\mathrm{ST}$. Analysis of circadian variation showed a steep peak incidence from $7 \mathrm{am}-12 \mathrm{pm}$.

\section{Conclusions:}

Triggering mechanisms such as time of the day, physical exertion, emotional stress and infection may play an important role in a considerable number of patients presenting with ST, in particular in patients with (very) late ST. 


\section{Introduction}

Stent thrombosis (ST) is a feared complication of percutaneous coronary intervention ( $\mathrm{PCl}$ ) because it is associated with considerable morbidity and mortality. ${ }^{1-4}$ Given the devastating clinical consequences of ST, comprehensive risk stratification to identify those patients at high risk for this catastrophic event is mandatory. Previous studies have identified several important clinical, procedural and angiographic predictors that are associated with ST. These include acute coronary syndromes as the indication for $\mathrm{PCl}$, premature discontinuation of clopidogrel therapy, high ontreatment (clopidogrel) platelet reactivity, bifurcation stenting, diabetes mellitus, renal failure, LAD stenting, impaired left ventricle ejection fraction, small stent diameter and long total stent length..$^{2-9}$ Nonetheless, it is surprising why only a small subgroup of patients with risk factors for ST will eventually develop ST. Or the other way around, there remains a group of patients experiencing ST that is not characterised by the above mentioned conventional determinants. Consequently, further identification of superimposing mechanisms beyond the currently known risk factors will probably advance our understanding of the pathogenesis of ST.

Although several triggering mechanisms of myocardial infarction have been well established, only anecdotal evidence exists on the association between triggers and stent thrombosis. ${ }^{10-12}$ Given a certain degree of similarity in most pathophysiological pathways between ST and myocardial infarction8, we sought to extrapolate the triggering factors that are commonly known for myocardial infarction (such as timing of onset ${ }^{13-15}$, vigorous physical exercise ${ }^{15-19}$, infection $^{20-23}$ and emotional stress ${ }^{24-28}$ ) to the arena of stent thrombosis.

\section{Methods}

The present study is a sub study of the Dutch Stent Thrombosis Registry (DSTR) ${ }^{1,7}$. In brief, the DSTR is a large-scale, multi-centre study conducted in three high-volume centres (>2,500 interventions per centre per year) in The Netherlands. All consecutive patients with an angiographically confirmed stent thrombosis ("definite" according to the ARC-criteria ${ }^{29}$ ) between January 2004 and February 2007 were enrolled. Stent thrombosis was categorised according to the timing of the event: acute (occurrence within the first $24 \mathrm{~h}$ after the indexprocedure), subacute (from $24 \mathrm{~h}$ to 30 days), late (from 30 days to one year) and very late (>1 year after the index procedure).

\section{Patient interview}

All patients enrolled in the DSTR were intensively interviewed using standardised questionnaires about the conditions and activities in the time frame preceding the stent thrombosis. To minimise bias in ascertainment, conditions and circumstances elicited from 
patients in response to the open question: "Please describe in detail what you were doing in the hours before the onset of chest pain" were recorded. The open question was followed by a set of predefined, well-validated questions about the hypothesised triggers. The interviewers used a structured data abstraction and questionnaire form for data acquisition.

\section{Timing of onset}

The onset of discomfort was used as the onset time for ST. This reported time was checked with PCl-reports. All acute ST's were excluded from this analysis, to eliminate the influence of $\mathrm{PCl}$-time on the circadian variation.

\section{Physical exercise}

Patients were asked whether they had performed any physical activity in the two hours preceding the stent thrombosis. The degree of physical activity intensity was quantified by the Compendium of Physical Activities ${ }^{30}$, a coding scheme that classifies physical activity by rate of energy expenditure. This list, developed to enhance comparability of results across studies using self-reports of physical activity, characterises specific physical activities (both daily activities and sports) based on the standard of a metabolic equivalent (MET) ${ }^{16,30}$. The MET is used to estimate the amount of oxygen used during physical activity. One MET correlates with the energy (oxygen) required sitting down quietly. Any activity that burns three to five METs is considered moderate-intensity physical activity. Activity that burns $\geq 6$ METs is considered vigorous-intensity physical activity. Patients were considered to have been engaged in vigorous exertion if they reported a peak MET of six or more in the two hours preceding the ST.

\section{Infection}

Patients were asked about any signs and conditions indicating the presence of an infection at the time of ST. All medical records were checked and laboratory charts were screened for inflammatory and infectious parameters indicative for an infection, including positive cultures, antibiotics use, (hs)-C-Reactive Protein (CRP), blood sedimentation rate (BSE), leukocyte count and leukocyte differentiation. Referring hospitals, general practitioners and pharmacies were also contacted to obtain additional information. Only documented infections (confirmed in clinical records) or by means of at least one positive cultures in combination with a Creactive protein level >100 (mg/L).

\section{Emotional stress}

To study the impact of emotional stress as a potential trigger, two components of emotional stress were considered relevant: 1 ) life events and 2) anger. 


\section{Life events}

To objectify the impact of life events, the Social Readjustment Rating Scale (SRRS) by Holmes and Rahe was used ${ }^{31,32}$. This scale has been designed to assess the cumulative stress of several positive or negative life events, as measured over the last year. The SRRS consists of a list of 43 life events. These items are ranked in order from the most impact (death of spouse, 100 points) to the least impact (minor violations of the law, 11 points). The number of "Life Change Units" that apply to events in the past year of an individual's life are added and the final score will give a rough estimate of how stress affects health.

Because the aim of this study was to determine whether a life event can provoke stent thrombosis, the SRRS was slightly modified. Instead of using the cumulative incidence of life events in the last year, the occurrence of life events in the two weeks prior to the stent thrombosis was recorded. Furthermore, as in our opinion the clinical relevance of the life events is rapidly decreasing towards the bottom of the list, only life events mentioned on the upper half of the SRRS were regarded as potential triggers (i.e., the first 22 of 43 items, corresponding to $\geq 29$ points).

\section{Acute emotional stress}

Beside life events, other acute emotions (e.g., anger and extreme anxiety) can also induce stress. Given the subjective character of this category of mental stress, only episodes of anger were recorded as an potential mental stressor, as this emotional trigger has been most intensively investigated ${ }^{24,33}$. The requirement for this acute emotional stressor was the occurrence of anger within 12 hours preceding the stent thrombosis.

\section{Statistical analysis}

Continuous variables were reported as medians with $25^{\text {th }}$ and $75^{\text {th }}$ percentiles, and categorical variables were reported as frequencies with percentages. The chi squared test was used to compare categorical variables and for trend in proportions. A p-value $<0.05$ was considered significant. Descriptive statistics was performed with SAS, version 9.1.3 (SAS Institute Inc., Cary, NC, USA). The number of triggers determined was presented as "number of triggers identified" for the several separate of triggers and as "number of patients in whom a trigger was identified" for the cumulative number of triggers. 


\section{Results}

A total of 437 patients were enrolled in the DSTR. Of these, $56(12.8 \%)$ patients died before the interview had taken place. Cardiovascular causes (including stent thrombosis) accounted for $88.8 \%$ of all deaths. Fourteen (3.2\%) patients were lost-to-follow-up and four (0.9\%) patients were not able to supply adequate information. These patients were also excluded from the analysis (Figure 1).

The remaining 363 patients $(83.1 \%)$ were able to supply adequate information. In the majority of cases, data were collected by direct patient interview. In eight cases $(2.2 \%)$ the partner instead of the patient was interviewed because of communication problems (e.g., language problem, previous history of cerebrovascular accident). The median time between the ST and patient interview was 11 months ( $25^{\text {th }}-75^{\text {th }}$ percentiles: $6-18$ months).

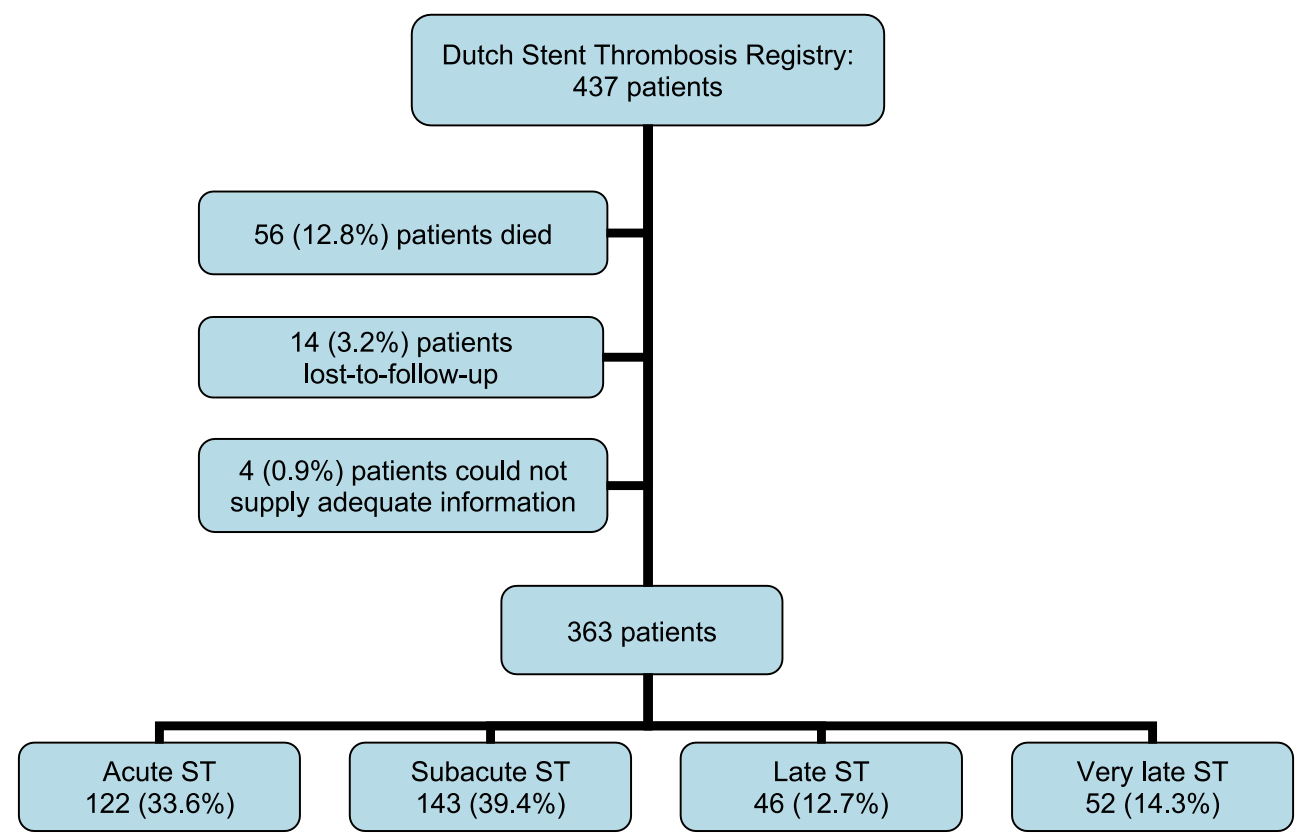

Figure 1: Study design and subject disposition.

\section{Timing of onset}

The hourly distribution of the timing of the onset of chest pain is depicted in Figure 2. A marked circadian variation - although less pronounced in patients with late or very late ST - in frequency of symptom-onset was observed with a minimum of events during night hours and a steep increase in events in the morning hours from 07:00 to 12:00 (noon). This six hour time-interval accounted for $\sim 50 \%$ of all ST. 


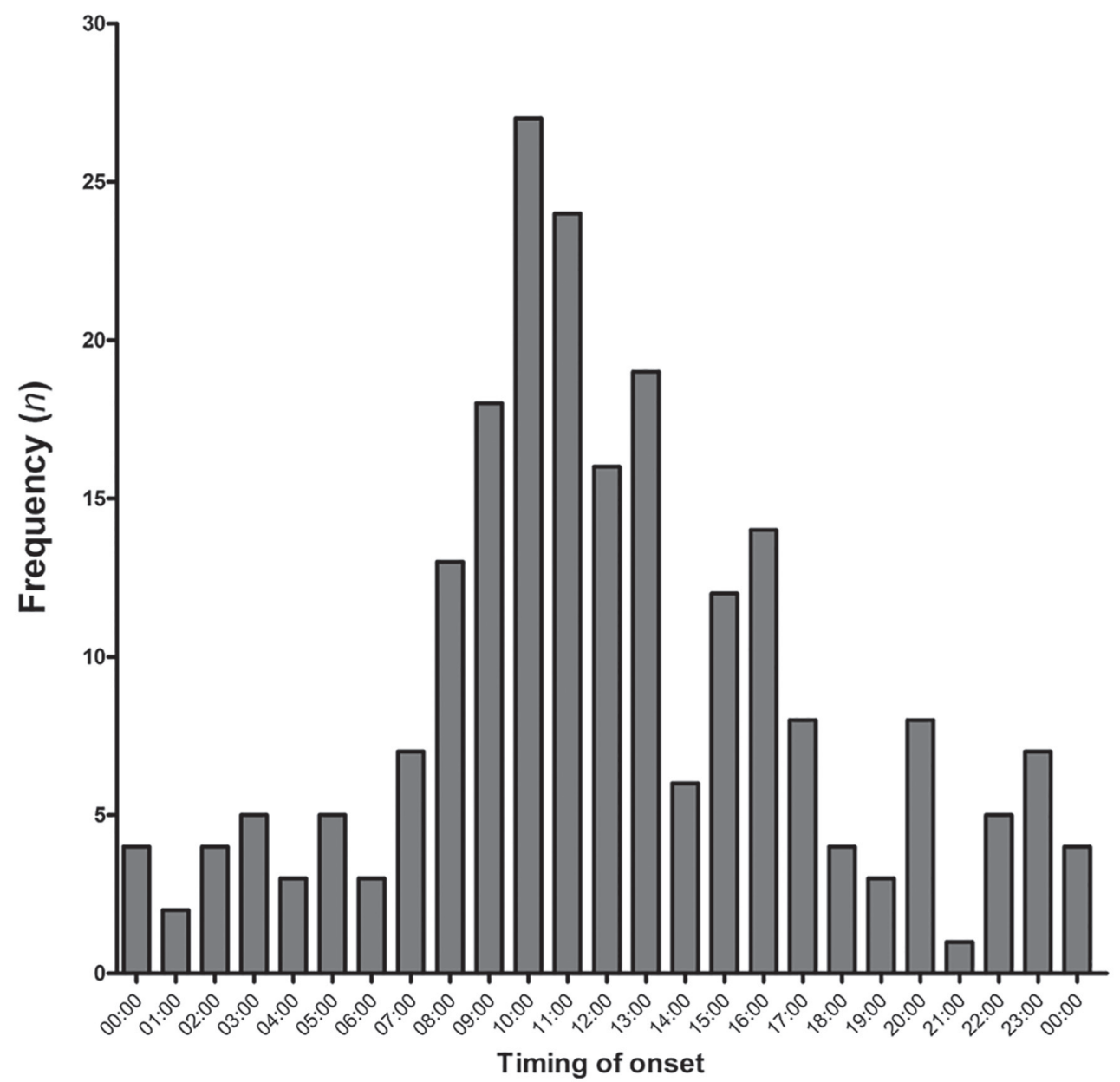

Figure 2: The hourly distribution of the timing of the onset of the chest pain.

\section{Triggering factors}

Eighty-three patients (22.9\%) reported the presence of at least one triggering event or condition. Four patients reported two different triggers. In two patients both an infection trigger and an emotional trigger were recorded, whereas in two other patients both an infection trigger and a physical exercise trigger was recorded. Figure 3 shows the prevalence of the different triggers preceding the stent thrombosis subdivided in categories according to the timing of ST. The cumulative prevalence of the different triggers in the acute group is fairly low, whereas the prevalence of triggers in the subacute, late and very late group is higher. Analysis of the different categories of ST revealed a higher prevalence of triggers with an increasing time-interval between index PCI and ST ( $p$ for trend $<0.0001$ ). 


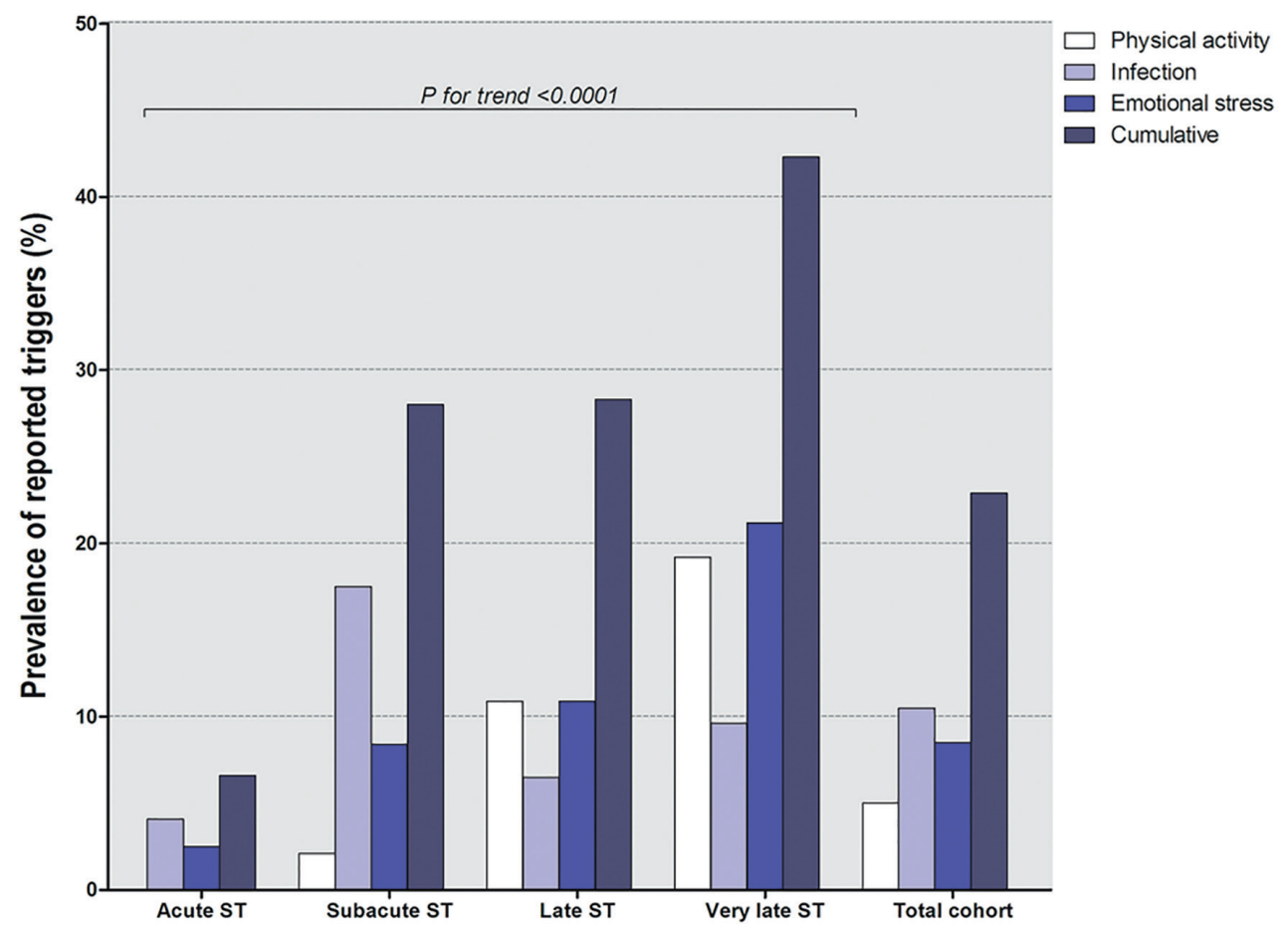

Figure 3: The prevalence of the different triggers preceding the stent thrombosis subdivided in categories according to the timing of ST. Separate triggers displayed as percentage identified triggers; cumulative charts displayed as percentage patients with an identified trigger.

\section{Physical exercise}

A total of 28 patients reported that they had performed physical exercise preceding the onset of ST. Of these, in 10 patients the MET was $<6$ and these patients did not fulfil the requirements for a significant exercise trigger. In the remaining 18 patients (5.0\%), vigorous physical exertion (MET S6) was identified as a trigger preceding ST.

\section{Infection}

Thirty-eight patients (10.5\%) reported the presence of an infection on the day of the stent thrombosis. Review of medical charts, laboratory parameters and cultures confirmed the presence of an active infection in all cases. The different types of infections are summarised in Table 1. 
Table 1: Specification of infection focus.

\begin{tabular}{ll}
\hline Type of infection & Number of patients \\
\hline Pneumonia & 12 \\
Urinary Tract Infection & 10 \\
Gastro-enteritis & 3 \\
Focus unknown & 3 \\
Bacteraemia & 2 \\
Orthopaedic infection & 2 \\
Other & 6 \\
\hline
\end{tabular}

\section{Emotional stress}

A total of 31 patients (8.5\%) reported the occurrence of a life event or feelings of anger preceding the stent thrombosis. Twenty-two patients (6.1\%) experienced a life event within two weeks prior to the stent thrombosis. According to the SRRS, the mean \pm SD score was $52 \pm 17$ points, ranging from a minimum score of 29 (corresponding with "change of responsibilities at work") to a maximum score of 100 (corresponding with "death of spouse"). Nine patients (2.5\%) reported an episode of anger within 12 hours preceding the ST.

\section{Risk factors}

The prevalence of risk factors is generally comparable in patients with and without a trigger preceding the stent thrombosis, although patients in whom a trigger was identified are on average three years younger (Table 2). In addition, left ventricular ejection fraction $<30 \%$ and cessation of clopidogrel at the time of stent thrombosis were more frequently observed in patients with a trigger.

Table 2: Baseline table.

\begin{tabular}{llll}
\hline Risk factor & $\begin{array}{l}\text { Trigger identified: yes } \\
\mathbf{n}(\%)\end{array}$ & $\begin{array}{l}\text { Trigger identified: no } \\
\mathbf{n}(\%)\end{array}$ & $\begin{array}{l}\text { Significance } \\
(\mathbf{p} \text {-value) }\end{array}$ \\
\hline Age & 58.1 (mean) & 61.0 (mean) & 0.052 \\
LAD stenting & $53 / 83(63.9)$ & $166 / 280(59.3)$ & 0.54 \\
Cessation of clopidogrel & $38 / 82(46.3)$ & $74 / 280(26.4)$ & $<0.001$ \\
DES implantation & $32 / 83(38.6)$ & $102 / 280(36.4)$ & 0.82 \\
Diabetes & $22 / 83(26.5)$ & $54 / 280(19.3)$ & 0.21 \\
Bifurcation stenting & $43 / 83(51.8)$ & $139 / 280(49.6)$ & 0.82 \\
Renal failure (MDRD <30ml/min) & $0 / 76(0.0)$ & $5 / 262(1.9)$ & 0.50 \\
LVEF <30\% & $12 / 83(14.5)$ & $19 / 280(6.8)$ & 0.049 \\
Stent length >30mm & $26 / 83(31.3)$ & $78 / 279(28.0)$ & 0.65 \\
STEMI as indication for index-PCl & $51 / 83(61.4)$ & $161 / 278(57.9)$ & 0.66 \\
\hline
\end{tabular}




\section{Discussion}

The present study is the first exploratory study investigating the relationship between triggering mechanisms and the occurrence of stent thrombosis in a large consecutive cohort of patients with ST, although no causal conclusions could be drawn from these descriptive data.

Substantial experimental and clinical evidence from the 80s and 90s strongly supports a causal relationship between several triggering mechanisms (such as timing of onset, strenuous exercise, presence of an infection and emotional stress) and the occurrence of myocardial infarction. Given the fact that ST and myocardial infarction share some, but not all, pathophysiological mechanisms, it is likely that these triggers may play a role in the pathophysiology of ST as well. However, only anecdotal evidence exists on the role of triggering mechanisms in ST. ${ }^{10-12}$

Despite the absence of a plaque rupture in the initial cascade of events leading to ST, numerous studies have revealed that other relevant physiologic processes are stimulated by several triggering mechanisms and contribute to the formation of an occlusive thrombus in the implanted coronary stent. These processes include increased sympathetic activity and vagal withdrawal, elevation in plasma catecholamines and renin levels, increased thrombin generation, increased heart rate and blood pressure, exercise induced coronary-artery spasm, increased systemic inflammation, increased vascular resistance, increased vesselwall stress, a heightened platelet reactivity status and a hypercoagulability state ${ }^{34-38}$. These effects are mediated by complex mechanisms, involving ?2-adrenergic receptor expression, von Willebrand factor platelet interaction, GPIIb/IIla interaction, P-selectin expression of platelets and the release of nitric oxide.

With regard to physical exercise, several studies revealed paradoxical effects of moderate exercise and vigorous exercise on platelet function. ${ }^{39,40}$, suggesting that moderate exercise suppresses platelet reactivity and increases fibrinolysis. Conversely, vigorous exercise especially in untrained individuals - enhances both platelet reactivity and coagulation, whereas it promotes fibrinolysis as well. From this perspective, moderate-intensity activity could be considered safe, whereas vigorous exercise might lead to a prothrombotic state ultimately leading to the formation of a thrombus.

In the present study, a surprisingly high percentage (almost 25\%) of patients with ST reported a trigger. Analysis of the categories of ST revealed a higher prevalence of triggers with an increasing time interval between index PCl and ST. Interestingly, the prevalence of the studied triggering mechanisms was the highest (42\%) in the group of patients presenting with a very late stent thrombosis. 
The lowest prevalence of the studied triggering mechanisms was found in patients presenting with acute ST. This observation is in line with previous findings identifying mechanical and procedural factors as the predominant cause of acute stent thrombosis ${ }^{41,42}$. Consequently, the pathophysiology of acute stent thrombosis should be considered distinct from the other categories of stent thromboses.

The identification of potential triggering mechanisms of ST might have important clinical implications related to both prognosis and prevention ${ }^{26}$. From a prognostic perspective, the presence of in particular emotional stress may imply that certain individuals are more vulnerable to stress-induced biological responses than others ${ }^{35}$. Consequently, the presence of emotional stress should be considered as a marker of increased risk. In addition, previous studies found personality to be an important predictor of adverse clinical outcome: type-D personality (patients high in negative affectivity and social inhibition) was independently associated with myocardial infarction and death in patients undergoing $\mathrm{PCl}$ with stent implantation. ${ }^{43}$ Of even more importance, Denollet et al demonstrated that the interaction effect of negative emotions with social inhibition - more than negative emotions alone - is associated with major adverse cardiac events. These findings might provide additional clues to identification of specific patients at increased risk of stent thrombosis. ${ }^{44}$

In relation to prevention, the ideal approach should involve a range of various strategies for the different types of triggering mechanisms. First, patients undergoing coronary stent implantation should be encouraged to perform moderate physical activity on a regular basis, because the beneficial effects of exercise training in the secondary prevention of coronary artery disease have been well established. ${ }^{45}$ In addition, several epidemiological studies demonstrated that the performance of moderate exercise on a regular basis lowers both the baseline risk as well as the relative risk that an episode of heavy physical exertion will trigger myocardial infarction16,19,46. However, caution remains warranted when patients plan to perform vigorous exercise, especially when untrained. According to the guidelines of the ACC/AHA47, patients should undergo an exercise test under supervised conditions, before starting to perform vigorous exercise.

Second, it has been known for several decades that infections (in particularly pneumonia and influenza) $)^{22,23,48}$ are associated with myocardial infarction. The high prevalence of infection (almost 20\%) especially in patients with subacute ST suggests that infection plays an important role in the pathogenesis of subacute ST. Better surveillance and management strategies in order to timely identify the first symptoms of infection in hospitalised patients with a recently implanted coronary stent and strict compliance with current standards for the prevention followed by prompt antibiotic treatment of infections may aid in prevention. 


\section{Limitations}

The results of our study should be interpreted in the light of the following limitations. First, the substantial period of time between the ST and the patient interview makes this population susceptible to information and recall bias. This may have resulted in both an underestimation as well as an overestimation of the prevalence of some triggering mechanisms (in particular vigorous exercise and emotional stress). However, this cannot explain the high prevalence of triggers found in this study. Moreover, exceptional activities or emotions in the hours preceding the catastrophic event of a ST are easy to remember. In addition, well-documented markers of infection and positive cultures as well as the reported time of performance of the emergent PCI for ST are not subjected to these forms of bias.

Second, the retrospective character of our study did not allow a case-crossover study design (cases serve as their own controls and therefore the design eliminates confounding by stable individual characteristics) because a detailed memory of the daily activities on just an ordinary day in the past (control-day) or a broader period of time is often not very clear. Due to the absence of this control group, a comparison with the prevalence of triggers in an average $\mathrm{PCl}$-cohort cannot be made. Nonetheless, our data reveal a relatively high prevalence of triggering mechanisms in patients with ST as compared to the prevalence of similar triggering mechanisms in myocardial infarction (vigorous physical exercise: $3.8 \%$ to $10 \%{ }^{16,28,33,46,49}$, any emotional stress: $4.4 \%-6.8 \%^{26,28,49}$ ) To overcome the aforementioned important limitations, very strict criteria were used to assign the presence of an exercise or emotional trigger. In addition, the interview was always started with an open question. Moreover, well-standardised reference charts and questionnaires from the field of sports medicine and psychology were used.

In conclusion, triggering mechanisms such as time of the day, physical exertion, emotional stress and infection may play an important role in a considerable number of patients presenting with ST. The prevalence of these triggering mechanisms is particularly high in patients with late and very late ST. 


\section{References}

1. van Werkum JW, Heestermans AA, de Korte FI, Kelder JC, Suttorp MJ, Rensing BJ, Zwart B, Brueren BR, Koolen JJ, Dambrink JH, van't Hof AW, Verheugt FW, ten Berg JM: Long-term clinical outcome after a first angiographically confirmed coronary stent thrombosis: an analysis of $\mathbf{4 3 1}$ cases. Circulation 2009; 119(6):828-834.

2. lakovou I, Schmidt T, Bonizzoni E, Ge L, Sangiorgi GM, Stankovic G, Airoldi F, Chieffo A, Montorfano M, Carlino M, Michev I, Corvaja N, Briguori C, Gerckens U, Grube E, Colombo A: Incidence, predictors, and outcome of thrombosis after successful implantation of drug-eluting stents. JAMA 2005; 293(17):2126-2130.

3. Kuchulakanti PK, Chu WW, Torguson R, OhImann P, Rha SW, Clavijo LC, Kim SW, Bui A, Gevorkian N, Xue Z, Smith K, Fournadjieva J, Suddath WO, Satler LF, Pichard AD, Kent KM, Waksman R: Correlates and long-term outcomes of angiographically proven stent thrombosis with sirolimusand paclitaxel-eluting stents. Circulation 2006; 113(8):1108-1113.

4. de la Torre-Hernandez JM, Alfonso F, Hernandez F, Elizaga J, Sanmartin M, Pinar E, Lozano I, Vazquez JM, Botas J, de Prado AP, Hernandez JM, Sanchis J, Nodar JM, Gomez-Jaume A, Larman M, Diarte JA, Rodriguez-Collado J, Rumoroso JR, Lopez-Minguez JR, Mauri J: Drug-eluting stent thrombosis: results from the multicenter Spanish registry ESTROFA (Estudio ESpanol sobre TROmbosis de stents FArmacoactivos). J Am Coll Cardiol 2008; 51(10):986-990.

5. Daemen J, Wenaweser P, Tsuchida K, Abrecht L, Vaina S, Morger C, Kukreja N, Juni P, Sianos G, Hellige G, van Domburg RT, Hess OM, Boersma E, Meier B, Windecker S, Serruys PW: Early and late coronary stent thrombosis of sirolimus-eluting and paclitaxel-eluting stents in routine clinical practice: data from a large two-institutional cohort study. Lancet 2007; 369(9562):667678.

6. Rinaldi MJ, Kirtane AJ, Piana RN, Caputo RP, Gordon PC, Lopez JJ, Dauerman HL, Ryan TJ, Jr., Kiernan FJ, Cutlip DE, Ho KK, Gibson CM, Murphy SA, Cohen DJ: Clinical, procedural, and pharmacologic correlates of acute and subacute stent thrombosis: results of a multicenter casecontrol study with 145 thrombosis events. Am Heart J 2008; 155(4):654-660.

7. van Werkum JW, Heestermans AA, Zomer AC, Kelder JC, Suttorp MJ, Rensing BJ, Koolen JJ, Brueren BR, Dambrink JH, Hautvast RW, Verheugt FW, ten Berg JM: Predictors of coronary stent thrombosis: the Dutch Stent Thrombosis Registry. J Am Coll Cardiol 2009; 53(16):1399-1409.

8. Lev El, Alviar CL, Arikan ME, Dave BP, Granada JF, DeLao T, Tellez A, Maresh K, Kleiman NS: Platelet reactivity in patients with subacute stent thrombosis compared with non-stent-related acute myocardial infarction. Am Heart J 2007; 153(1):41-46.

9. Sibbing D, Braun S, Morath T, Mehilli J, Vogt W, Schomig A, Kastrati A, von BN: Platelet reactivity after clopidogrel treatment assessed with point-of-care analysis and early drug-eluting stent thrombosis. J Am Coll Cardiol 2009; 53(10):849-856.

10. Tamura A, Watanabe T, Nagase K, Nakaishi T, Aso N, Kawano Y, Abe Y, Zaizen H, Yano S, Kadota J: Circadian variation in symptomatic subacute stent thrombosis after bare metal coronary stent implantation. Am J Cardiol 2006; 97(2):195-197. 
11. Ormezzano O, Polack B, Vanzetto G, Sahnoun M, Machecourt J: Platelet hyperactivity during exercise leading to iterative coronary stent thrombosis: clinical implications. J Thromb Thrombolysis 2009.

12. Parodi G, Antoniucci D: Late coronary stent thrombosis associated with exercise testing. Catheter Cardiovasc Interv 2004; 61(4):515-517.

13. Muller JE, Stone PH, Turi ZG, Rutherford JD, Czeisler CA, Parker C, Poole WK, Passamani E, Roberts $\mathrm{R}$, Robertson $\mathrm{T}$, .: Circadian variation in the frequency of onset of acute myocardial infarction. N Engl J Med 1985; 313(21):1315-1322.

14. Muller JE, Tofler GH, Stone PH: Circadian variation and triggers of onset of acute cardiovascular disease. Circulation 1989; 79(4):733-743.

15. Tofler GH, Muller JE, Stone PH, Forman S, Solomon RE, Knatterud GL, Braunwald E: Modifiers of timing and possible triggers of acute myocardial infarction in the Thrombolysis in Myocardial Infarction Phase II (TIMI II) Study Group. J Am Coll Cardiol 1992; 20(5):1049-1055.

16. Mittleman MA, Maclure M, Tofler GH, Sherwood JB, Goldberg RJ, Muller JE: Triggering of acute myocardial infarction by heavy physical exertion. Protection against triggering by regular exertion. Determinants of Myocardial Infarction Onset Study Investigators. N Engl J Med 1993; 329(23):1677-1683.

17. Albert CM, Mittleman MA, Chae CU, Lee IM, Hennekens CH, Manson JE: Triggering of sudden death from cardiac causes by vigorous exertion. N Engl J Med 2000; 343(19):1355-1361.

18. Thompson PD, Funk EJ, Carleton RA, Sturner WQ: Incidence of death during jogging in Rhode Island from 1975 through 1980. JAMA 1982; 247(18):2535-2538.

19. Willich SN, Lewis M, Lowel H, Arntz HR, Schubert F, Schroder R: Physical exertion as a trigger of acute myocardial infarction. Triggers and Mechanisms of Myocardial Infarction Study Group. N Engl J Med 1993; 329(23):1684-1690.

20. Smeeth L, Thomas SL, Hall AJ, Hubbard R, Farrington P, Vallance P: Risk of myocardial infarction and stroke after acute infection or vaccination. N Engl J Med 2004; 351(25):2611-2618.

21. Meier CR, Jick SS, Derby LE, Vasilakis C, Jick H: Acute respiratory-tract infections and risk of firsttime acute myocardial infarction. Lancet 1998; 351(9114):1467-1471.

22. Moschos $\mathrm{N}$, Christoforaki $\mathrm{M}$, Antonatos $\mathrm{P}$ : Seasonal distribution of acute myocardial infarction and its relation to acute infections in a mild climate. Int J Cardiol 2004; 93(1):39-44.

23. Warren-Gash C, Smeeth L, Hayward AC: Influenza as a trigger for acute myocardial infarction or death from cardiovascular disease: a systematic review. Lancet Infect Dis 2009; 9(10):601-610.

24. Mittleman MA, Maclure M, Sherwood JB, Mulry RP, Tofler GH, Jacobs SC, Friedman R, Benson H, Muller JE: Triggering of acute myocardial infarction onset by episodes of anger. Determinants of Myocardial Infarction Onset Study Investigators. Circulation 1995; 92(7):1720-1725.

25. Gullette EC, Blumenthal JA, Babyak M, Jiang W, Waugh RA, Frid DJ, O'Connor CM, Morris JJ, Krantz DS: Effects of mental stress on myocardial ischemia during daily life. JAMA 1997; 277(19):1521-1526. 
26. Bhattacharyya MR, Steptoe A: Emotional triggers of acute coronary syndromes: strength of evidence, biological processes, and clinical implications. Prog Cardiovasc Dis 2007; 49(5):353365.

27. Tofler GH, Muller JE: Triggering of acute cardiovascular disease and potential preventive strategies. Circulation 2006; 114(17):1863-1872.

28. Strike PC, Steptoe A: Behavioral and emotional triggers of acute coronary syndromes: a systematic review and critique. Psychosom Med 2005; 67(2):179-186.

29. Cutlip DE, Windecker S, Mehran R, Boam A, Cohen DJ, van Es GA, Steg PG, Morel MA, Mauri L, Vranckx P, McFadden E, Lansky A, Hamon M, Krucoff MW, Serruys PW: Clinical end points in coronary stent trials: a case for standardized definitions. Circulation 2007; 115(17):2344-2351.

30. Ainsworth BE, Haskell WL, Whitt MC, Irwin ML, Swartz AM, Strath SJ, O'Brien WL, Bassett DR, Jr., Schmitz KH, Emplaincourt PO, Jacobs DR, Jr., Leon AS: Compendium of physical activities: an update of activity codes and MET intensities. Med Sci Sports Exerc 2000; 32(9 Suppl):S498-S504.

31. Holmes TH, Rahe RH: The Social Readjustment Rating Scale. J Psychosom Res 1967; 11(2):213218.

32. Thomas SA, Friedmann E, Wimbush F, Schron E: Psychological factors and survival in the cardiac arrhythmia suppression trial (CAST): a reexamination. Am J Crit Care 1997; 6(2):116-126.

33. Strike PC, Perkins-Porras L, Whitehead DL, McEwan J, Steptoe A: Triggering of acute coronary syndromes by physical exertion and anger: clinical and sociodemographic characteristics. Heart 2006; 92(8):1035-1040.

34. Lee KW, Lip GY: Effects of lifestyle on hemostasis, fibrinolysis, and platelet reactivity: a systematic review. Arch Intern Med 2003; 163(19):2368-2392.

35. Strike PC, Magid K, Whitehead DL, Brydon L, Bhattacharyya MR, Steptoe A: Pathophysiological processes underlying emotional triggering of acute cardiac events. Proc Natl Acad Sci U S A 2006; 103(11):4322-4327.

36. Black A, Black MM, Gensini G: Exertion and acute coronary artery injury. Angiology 1975; 26(11):759-783.

37. Hilberg T, Prasa D, Sturzebecher J, Glaser D, Gabriel HH: Thrombin potential and thrombin generation after exhaustive exercise. Int J Sports Med 2002; 23(7):500-504.

38. Gordon JB, Ganz P, Nabel EG, Fish RD, Zebede J, Mudge GH, Alexander RW, Selwyn AP: Atherosclerosis influences the vasomotor response of epicardial coronary arteries to exercise. J Clin Invest 1989; 83(6):1946-1952.

39. Kestin AS, Ellis PA, Barnard MR, Errichetti A, Rosner BA, Michelson AD: Effect of strenuous exercise on platelet activation state and reactivity. Circulation 1993; 88(4 Pt 1):1502-1511.

40. Wang JS: Exercise prescription and thrombogenesis. J Biomed Sci 2006; 13(6):753-761.

41. Roy P, Torguson R, Okabe T, Pinto Slottow TL, Steinberg DH, Smith K, Xue Z, Satler LF, Pichard AD, Waksman R: Angiographic and procedural correlates of stent thrombosis after intracoronary implantation of drug-eluting stents. J Interv Cardiol 2007; 20(5):307-313. 
42. Moussa I, Di MC, Reimers B, Akiyama T, Tobis J, Colombo A: Subacute stent thrombosis in the era of intravascular ultrasound-guided coronary stenting without anticoagulation: frequency, predictors and clinical outcome. J Am Coll Cardiol 1997; 29(1):6-12.

43. Pedersen SS, Denollet J, Ong AT, Sonnenschein K, Erdman RA, Serruys PW, van Domburg RT: Adverse clinical events in patients treated with sirolimus-eluting stents: the impact of Type D personality. Eur J Cardiovasc Prev Rehabil 2007; 14(1):135-140.

44. Denollet J, Pedersen SS, Ong AT, Erdman RA, Serruys PW, van Domburg RT: Social inhibition modulates the effect of negative emotions on cardiac prognosis following percutaneous coronary intervention in the drug-eluting stent era. Eur Heart J 2006; 27(2):171-177.

45. Warburton DE, Nicol CW, Bredin SS: Health benefits of physical activity: the evidence. CMAJ 2006; 174(6):801-809.

46. Giri S, Thompson PD, Kiernan FJ, Clive J, Fram DB, Mitchel JF, Hirst JA, McKay RG, Waters DD: Clinical and angiographic characteristics of exertion-related acute myocardial infarction. JAMA 1999; 282(18):1731-1736.

47. Gibbons RJ, Balady GJ, Bricker JT, Chaitman BR, Fletcher GF, Froelicher VF, Mark DB, McCallister BD, Mooss AN, O'Reilly MG, Winters WL, Jr., Gibbons RJ, Antman EM, Alpert JS, Faxon DP, Fuster V, Gregoratos G, Hiratzka LF, Jacobs AK, Russell RO, Smith SC, Jr.: ACC/AHA 2002 guideline update for exercise testing: summary article: a report of the American College of Cardiology/ American Heart Association Task Force on Practice Guidelines (Committee to Update the 1997 Exercise Testing Guidelines). Circulation 2002; 106(14):1883-1892.

48. Bainton D, Jones GR, Hole D: Influenza and ischaemic heart disease--a possible trigger for acute myocardial infarction? Int J Epidemiol 1978; 7(3):231-239.

49. Culic V, Eterovic $D$, Miric D: Meta-analysis of possible external triggers of acute myocardial infarction. Int J Cardiol 2005; 99(1):1-8 
Triggering mechanisms of stent thrombosis | 75 


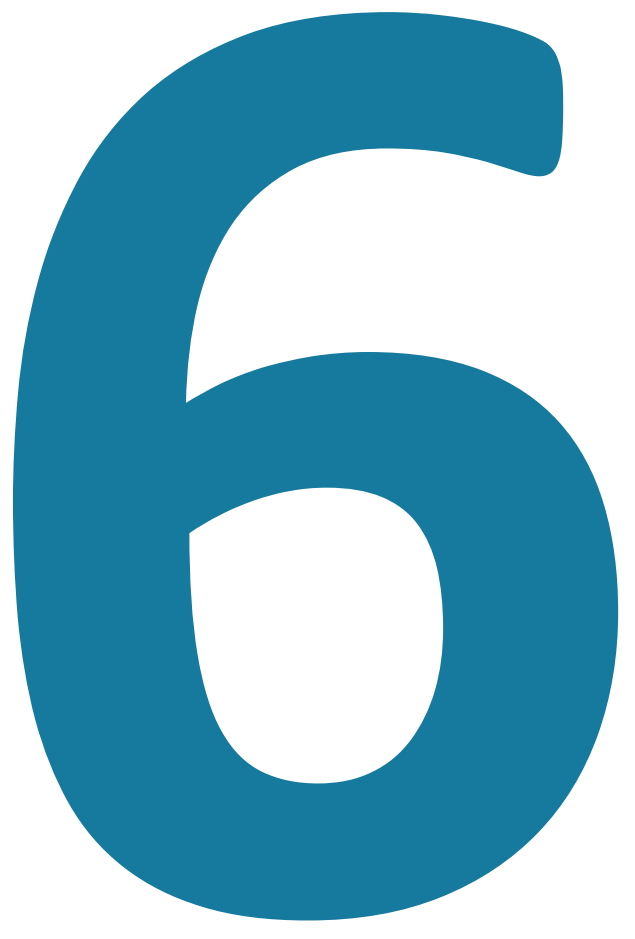




\section{High risk of stent thrombosis in the first 6 months after coronary stenting}

B. Zwart, T.C. Godschalk, J.C. Kelder, J.M. ten Berg 


\section{Abstract}

\section{Objectives:}

To estimate the incidence of stent thrombosis (ST) after early discontinuation of clopidogrel.

\section{Background:}

Premature discontinuation of clopidogrel is the strongest risk factor for ST. In contrast, recent studies suggest that shorter dual antiplatelet therapy (DAPT) can be discontinued as soon as 3 months after stenting. However, these studies included very few ACS patients and were not powered for ST. Hence, little is known about the occurrence of ST in high-risk populations when DAPT is discontinued early.

\section{Methods:}

This is a subanalysis of The Dutch ST Registry 437 ST cases (mainly first generation DES and $\mathrm{BMS}$ ). Acute coronary syndrome was the indication for index- $\mathrm{PCl}$ in $74 \%$ of the patients. Clopidogrel discontinuation rates in ST patients and matched controls were used to calculate the absolute incidence of ST after early clopidogrel discontinuation.

\section{Results:}

The overall rate of ST after cessation of clopidogrel was $4.6 \%(95 \% \mathrm{Cl}: 3.9-5.4 \%)$, as compared to $1.7 \%(95 \% \mathrm{Cl}: 1.5-1.9 \%)$ in patients who did not discontinue clopidogrel. The incidence of ST was $35.4 \%$ when clopidogrel was discontinued in the first 30 days after index-PCl declining to $11.7 \%$ when clopidogrel was discontinued in the first 180 days.

\section{Conclusions:}

This dedicated ST registry shows that ST rates were very high when clopidogrel was discontinued before 6 months after index- $\mathrm{PCl}$ and therefore suggests that clopidogrel discontinuation in the first 6 months after ACS should be avoided. 


\section{Introduction}

Stent thrombosis (ST) is a feared complication of percutaneous coronary intervention (PCI) with stent implantation. Although the incidence in recent studies has declined, it is estimated to occur in $0.5-1 \%$ of patients in the first year after stent implantation, falling to $0.5 \%$ or less in the following years ${ }^{1-6}$.

Dual antiplatelet therapy (DAPT) with acetylsalicylic acid in combination with a P2Y12inhibitor in order to prevent atherothrombotic events, such as ST, is the standard of care after PCI. DAPT is recommended with a class I level of evidence in current American and European guidelines, ${ }^{7-9}$ with a recommended treatment duration of 6-12 months depending on the indication for $\mathrm{PCl}$. Clopidogrel is the most commonly used $\mathrm{P}_{2} \mathrm{Y}_{12}$-inhibitor and it is still first choice in $\mathrm{PCl}$ patients with stable coronary artery disease. Although the stronger $\mathrm{P} 2 \mathrm{Y} 12$ inhibitors ticagrelor and prasugrel are recommended in the acute coronary syndrome (ACS) setting, ${ }^{9}$ two recent studies showed that clopidogrel is still frequently used in ACS in both the United States and Europe. ${ }^{10,11}$

Premature discontinuation of clopidogrel (discontinuation before the recommended treatment duration) has been shown to be the strongest risk factor for the occurrence of ST. ${ }^{4,6,12-14}$ Nevertheless, several recent randomized controlled trials suggest that shorter DAPT duration (3-6 months) might be as safe as the standard regime. However, these studies were underpowered ${ }^{15}$ for the endpoint ST with ST numbers of 10 or less per study. In addition, these studies included mainly low-risk patients and no or only small numbers of ACS patients.

Looking from a mechanical view point, the concept of delayed arterial healing in drug-eluting stents (DES) emphasizes the risks of discontinuing clopidogrel in the first months after stenting. Previous studies identified several factors associated with DES, including delayed healing (delayed endothelial regeneration), neoatherosclerosis, and chronic inflammatory response, which typically develop months or even years after stent implantation, leaving DES at persisting risk for atherothrombotic events. ${ }^{16-21}$ Although second generation DES have undergone several changes such as thinner stent struts and more biocompatible polymer coatings in order to minimize these problems, it is not clear when arterial healing has been completed and thus when DAPT can be discontinued safely.

As it is currently unknown what the impact of early clopidogrel cessation on the occurrence of ST is, particularly after ACS, we sought to investigate the absolute risk of ST after clopidogrel discontinuation in our Dutch Stent Thrombosis Registry, one of the largest consecutive ST cohorts. ${ }^{4}$ 


\section{Materials and Methods}

The Dutch Stent Thrombosis Registry (DSTR) is a multi-center study conducted in three high-volume centers in the Netherlands ( $>2500$ interventions/center/year). All consecutive patients with an angiographically confirmed (definite) ST were enrolled. Both DES (73\% first generation [ie, Taxus or Cypher] and bare-metal stents [BMS]) were used. The recommended duration of clopidogrel therapy was 12 months for ACS patients. For patients undergoing $\mathrm{PCl}$ for stable coronary artery disease, the recommended standard DAPT duration was 12 months for DES (3-6 months in selected patients, eg., because of bleeding events) and 1 month for patients undergoing BMS angioplasty. The duration of clopidogrel use as well as aspirin compliance after patient discharge was assessed with telephonic patient interview as well as data from pharmacy records (the date of clopidogrel dispensed and the number of days supplied for each dispense). In case of disagreement, the pharmacy data were used for the analysis.

ST was defined according to the Academic Research Consortium criteria for "definite" ST22. Consecutive patients suffering ST were matched in a 1:2 ratio to patients who underwent $\mathrm{PCl}$ with stent implantation but without ST during follow-up. Matching criteria included indication for index- $\mathrm{PCl}$ ( $\mathrm{PCl}$ of stent implantation), $\mathrm{PCl}$ center, and date of index- $\mathrm{PCl}$, in order to correct for patient or procedure related factors.

To study the impact of discontinuation of clopidogrel, a "virtual ST time" was assigned for the matched controls, which was based on the same duration between index-PCI and ST as in patients with ST (cases). This virtual ST time allowed to calculate the time between clopidogrel discontinuation and the virtual ST date for the matched controls (Figure 1). The study design and methods were published in more detail previously. ${ }^{4}$

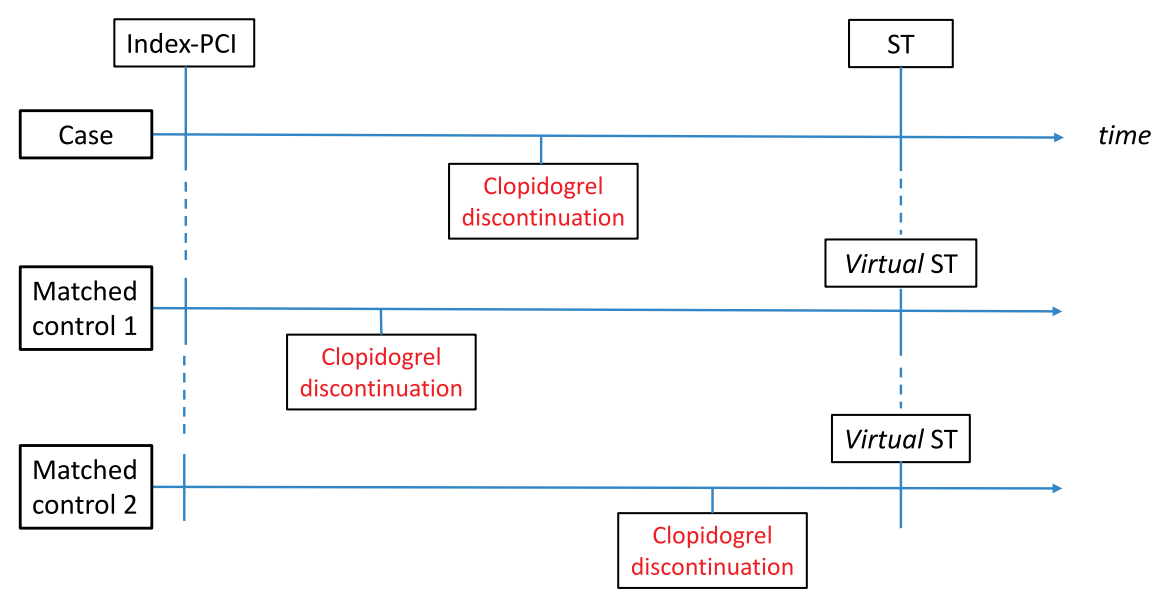

Figure 1: Clopidogrel discontinuation in matched controls. 
The aim of the present study was to determine the incidence of ST after cessation of clopidogrel and to calculate this absolute risk for specific time frames (ST $\leq 30, \leq 90, \leq 180$ days) after index-PCl.

The incidence of ST after clopidogrel discontinuation was calculated by comparing the number of patients suffering ST after discontinuation of clopidogrel to the estimated total number of patients in the $\mathrm{PCl}$ registry who discontinued clopidogrel but did not suffer a ST. This total number of patients discontinuing clopidogrel was estimated by extrapolating the discontinuation rate in the matched controls to the total cohort of the $\mathrm{PCl}$ registry (Figure 2 ).

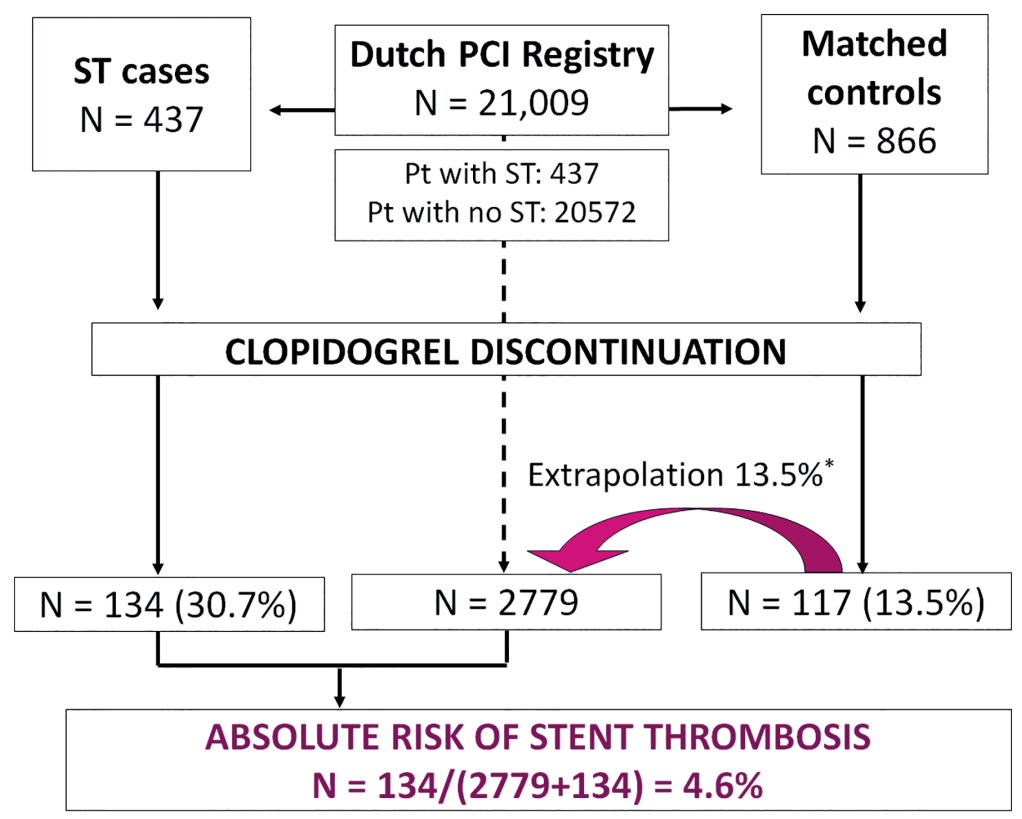

Figure 2: Method of calculation of absolute risk of stent thrombosis.

The absolute risk of ST after clopidogrel discontinuation in specific time frames (ST $\leq 30, \leq 90$, and $\leq 180$ days after index-PCI) was calculated in a similar manner (Figure 3 ). ST cases in the predefined time frames were matched to their controls. The percentage of discontinuation in the matched control patients for this time frame was extrapolated to the total cohort of the registry to estimate the number of patients discontinuing clopidogrel in that same time frame. Subsequently, the absolute risks of ST after clopidogrel discontinuation in different time frames could be calculated (ST cases after discontinuation of clopidogrel in a specific time frame divided by all patients who had discontinued clopidogrel in the same time frame). 


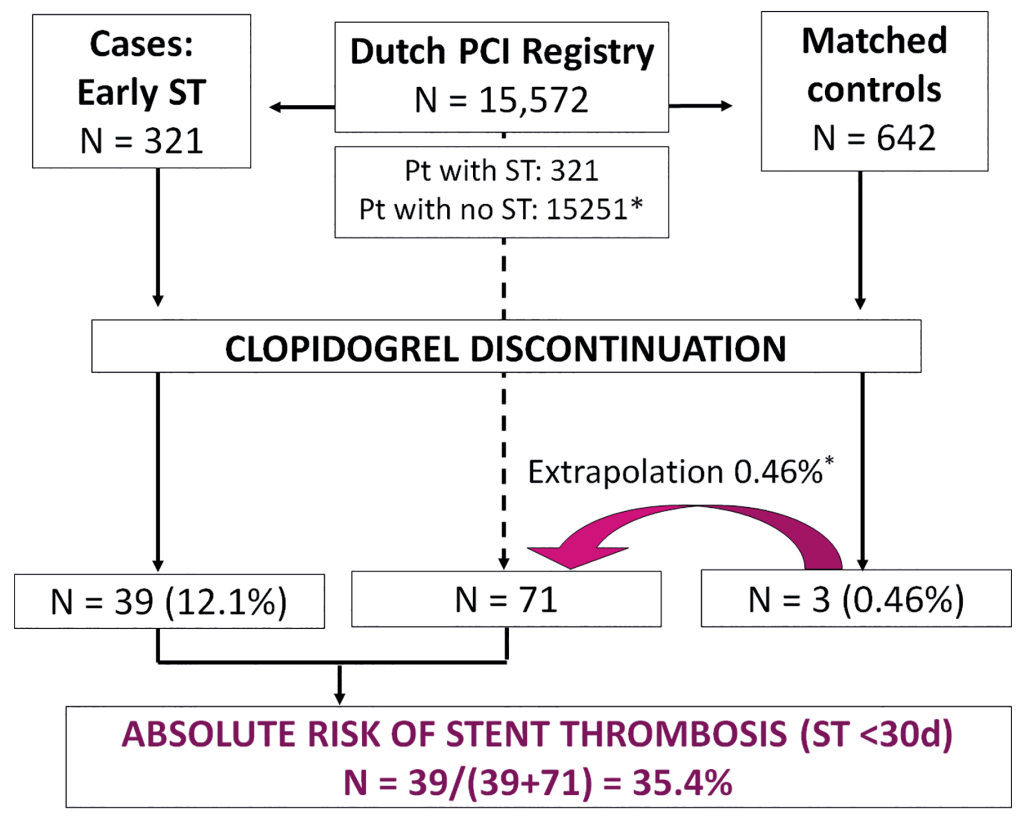

Figure 3: Method of calculation of absolute risk of stent thrombosis in cases with ST $\leq 30$ days after index-PCI.

To assess whether the found association between clopidogrel cessation and the occurrence of ST was likely to be a causal relation, the timing of ST after discontinuation of clopidogrel was assessed. As platelet inhibition is believed to persist for 5-7 days after clopidogrel cessation, we calculated the proportion of patients suffering a ST $<7$ days after discontinuing clopidogrel. In addition, we calculated the proportion of patients suffering a ST $<14$ days after clopidogrel cessation, following the findings of the PARIS study that suggested that interruption for 14 days might be safe. ${ }^{23}$

Statistical analysis was performed with SAS v 9.3 (SAS Institute, Inc., Cary, NC). Continuous variables were summarized by means, standard deviations, medians, interquartile ranges, and minimum and maximum values. Categorical variables were summarized by frequencies and percentages.

\section{Results}

A total of 437 patients out of 21009 patients (2.1\%) presented with a definite ST during a median follow-up of 30.9 months. Relevant baseline characteristics are shown in Table 1. The majority of patients (74.1\%) underwent the index-PCI for the indication unstable angina/ NSTEMI (16.5\%) or STEMI (57.7\%). 
Table 1: Baseline characteristics.

\begin{tabular}{|c|c|c|c|}
\hline & Cases $(n=437)$ & $\begin{array}{l}\text { Matched Control } \\
\text { Subjects }(n=866)\end{array}$ & p Value \\
\hline \multicolumn{4}{|l|}{ Clinical characteristics/total (\%) } \\
\hline Age, yrs & $61.0 \pm 11.8$ & $62.3 \pm 11.7$ & 0.0616 \\
\hline Female/total (\%) & $108 / 437(24.7)$ & $235 / 862(27.3)$ & 0.3512 \\
\hline \multicolumn{4}{|l|}{ Indication/total (\%) } \\
\hline Stable angina & $113 / 437(25.9)$ & $242 / 866$ (27.9) & Matched item \\
\hline UAP/NSTEMI & $72 / 437(16.5)$ & $124 / 866(14.3)$ & Matched item \\
\hline STEMI & $252 / 437(57.7)$ & $500 / 866(57.7)$ & Matched item \\
\hline \multicolumn{4}{|l|}{ Lesion characteristics/total (\%) } \\
\hline $\mathrm{ACC} / \mathrm{AHA} \mathrm{B} 2$ or $\mathrm{C}$ & $334 / 437(76.4)$ & $516 / 866(59.6)$ & 0.0001 \\
\hline Bifurcation lesion & $228 / 437$ (51.7) & $210 / 866(24.3)$ & 0.0001 \\
\hline \multicolumn{4}{|l|}{ Coronary vessel } \\
\hline LAD & $273 / 437(62.5)$ & $375 / 866(43.3)$ & 0.0001 \\
\hline RCA & $128 / 437(29.3)$ & $348 / 866(40.2)$ & 0.0001 \\
\hline RCX & $65 / 437(14.9)$ & $148 / 866(17.1)$ & 0.3411 \\
\hline Vein graft & $5 / 437(1.1)$ & $21 / 866(2.4)$ & 0.1435 \\
\hline \multicolumn{4}{|c|}{ Procedural characteristics/total (\%) } \\
\hline \multicolumn{4}{|c|}{ Stent type } \\
\hline BMS & $270(61.8)$ & $614(70.9)$ & 0.0015 \\
\hline DES & $152(34.8)$ & $238(27.5)$ & \\
\hline Mixed stent(s) & $15(3.4 \%)$ & $14(1.6)$ & \\
\hline Total stent length, mm & $27.8 \pm 15.2$ & $23.7 \pm 14.2$ & 0.0001 \\
\hline Total number of stents & $1.5 \pm 0.8$ & $1.3 \pm 0.7$ & 0.0001 \\
\hline Minimal stent diameter*, mm & $3.0 \pm 0.4$ & $3.1 \pm 0.4$ & 0.0001 \\
\hline
\end{tabular}

A total of 134 out of 437 (30.7\%) of patients discontinued clopidogrel prior to suffering ST, as compared to $117 / 866$ (13.5\%) patients in the matched controls group (Figure 2 ). The majority of these patients (88.1\%) were on aspirin therapy at the time of ST, whereas the small proportion of patients not started on aspirin were mainly treated with oral anticoagulation ( $84 \%$ of patients).

The absolute risk of ST after discontinuation of clopidogrel therapy was $4.6 \%$ (95\% Cl: 3.9$5.4 \%)$ as compared to a rate of $1.7 \%(95 \% \mathrm{Cl}: 1.5-1.9 \%)$ in patients who did not discontinue clopidogrel (Figure 2). When stratified for timing after index- $\mathrm{PCl}$, the absolute ST risk when clopidogrel was discontinued was $35.4 \%$ for ST in the first 30 days after index-PCI (Figure 3 ). The ST risk decreased inversely over time but remained high until 6 months after index-PCl, with an absolute ST risk of $19.0 \%$ and $11.7 \%$ for the first 90 days and first 180 days after index- $\mathrm{PCl}$, respectively (Figure 4).

In patients suffering early ST (ie, $\leq 30$ days after index-PCI), ST occurred within 7 and 14 days after clopidogrel cessation in respectively $84.6 \%$ and $92.3 \%$ of patients. In patients developing ST within 90 and within 180 days after index-PCl, this proportion was respectively $76.0 \%$ and $68.3 \%$ within 7 days and respectively $86.0 \%$ and $83.3 \%$ within 14 days (Table 2 ). 


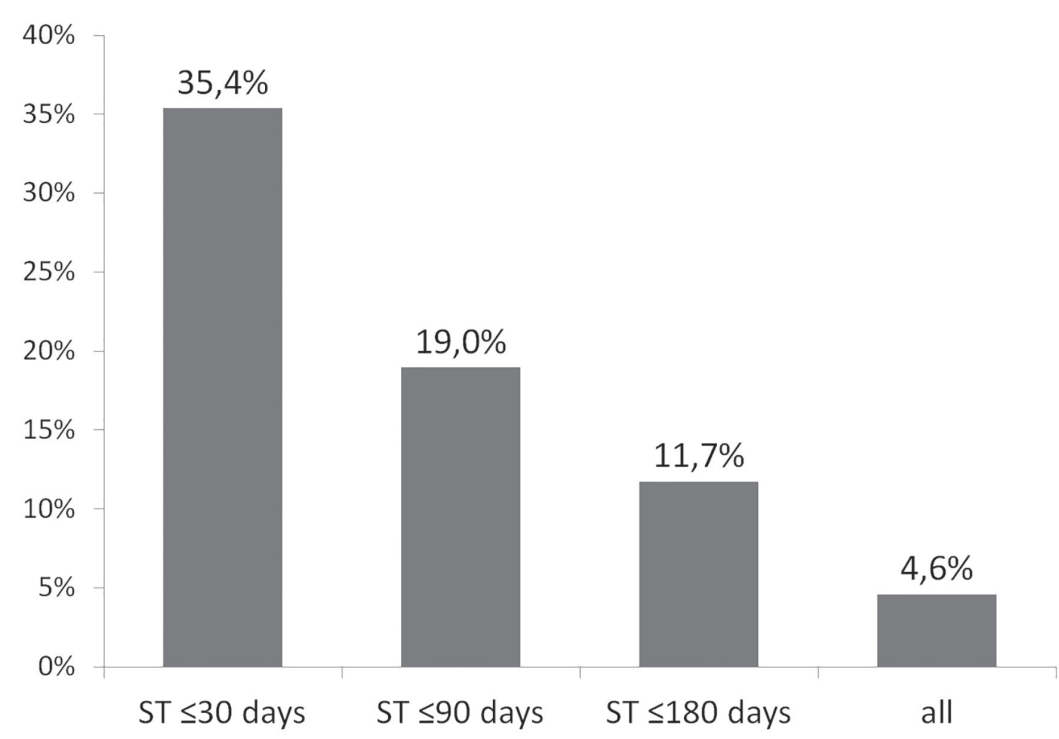

Figure 4: Absolute risk of stent thrombosis after clopidogrel discontinuation.

Table 2: Timing of ST after discontinuation of clopidogrel .

\begin{tabular}{lll} 
& \multicolumn{2}{c}{ Duration of clopidogrel discontinuation } \\
\cline { 2 - 3 } & $\leq 7$ days & $\leq 14$ days \\
\hline ST $\leq 30$ days after index-PCI & $84.6 \%(33 / 39)$ & $92.3 \%(36 / 39)$ \\
ST $\leq \mathbf{9 0}$ days after index-PCI & $76.0 \%(38 / 50)$ & $86.0 \%(43 / 50)$ \\
ST $\leq 180$ days after index-PCI & $68.3 \%(41 / 60)$ & $83.3 \%(50 / 60)$ \\
\hline
\end{tabular}

\section{Discussion}

Our study demonstrates that early cessation of clopidogrel was strongly associated with the occurrence of ST. We showed a remarkably high absolute risk of ST when clopidogrel was discontinued in the first 30 days after index- $\mathrm{PCl}$ (35.4\%) and within 90 and 180 days (19.0\% and $11.7 \%$, respectively), which was not reported before. These results apply mainly to ACS patients, as this was the indication for the index- $\mathrm{PCl}$ in the majority (74\%) of ST patients.

The occurrence of ST should be considered as a serious complication, given the fact that ST presents in nearly all cases as myocardial infarction and given the poor clinical outcome after ST with high rates of recurrent ST and cardiac death (18.2\% and $9.5 \%$,respectively) at 1 year in the Dutch Stent Thrombosis Registry. ${ }^{24}$

Until now, information on the absolute incidence of ST after clopidogrel cessation is scarce and relies on smaller studies. Schultz et al. calculated in a prospective cohort study including 
73 ST cases that the cumulative incidence of ST in patients who discontinued clopidogrel before 6 months was approximately $12.5 \%$, which is comparable with our study. ${ }^{25}$

\section{Should we shorten the duration of DAPT after ACS?}

Recently, several studies have been published, suggesting that a shorter DAPT duration (3-6 months) might be as safe as the standard DAPT of 6-12 months. However, all of these studies are hampered by very low ST rates (ISAR-SAFE: five vs. three patients with ST at 9 months; EXCELLENT: six vs. one ST at 12 months; SECURITY: two vs. three ST at 12 months; OPTIMIZE: four vs. one ST at 12 months; RESET: two vs. three ST at 12 months). ${ }^{26-30}$ Most of these studies were not powered to detect differences in ST rates or enrolled less patients than expected. Therefore, the clinical outcomes of these randomized controlled trials regarding ST should be interpreted with caution. Moreover, most of these studies included low-risk patients and a small proportion of ACS patients. However, a recent meta-analysis addressed this question specifically and concluded that 3 months of DAPT after ACS-but not after PCI for stable CAD) - was associated with higher ST and MI rates. ${ }^{31}$

Hence, registries such as the present one are needed to study the risks of low-frequent events such as ST in high-risk patients. The current registry with 437 ST cases enabled us to detect and highlight the risks of early DAPT discontinuation. It might be advisable to be reluctant in reducing DAPT duration in STEMI patients who underwent $\mathrm{PCl}$, although further prospective and randomized studies are needed.

\section{Perioperative interruption of DAPT}

In patients undergoing surgery shortly after $\mathrm{PCl}$, the issue whether it is safe to temporarily discontinue clopidogrel is of special importance. Need for surgery is not uncommon as demonstrated by a recent study estimating that $14.3 \%$ of patients undergo surgery in the first year after coronary stenting ${ }^{32}$. Current guidelines recommend to discontinue clopidogrel 5 days in advance ${ }^{33}$. However, the risk of ST is distinctively increased in the first week after cessation of clopidogrel therapy ${ }^{4}$.

The recently published PARIS registry investigated DAPT interruption, defined as planned cessation of antiplatelet treatment due to surgical necessity with reinstitution of DAPT within 14 days $^{23}$. The authors found an increased overall Major Adverse Cardiac Events risk after brief interruption, but no significant increase in thrombotic events, thereby suggesting that with interruption $<14$ days of DAPT for surgical procedures might be safe. However, the timing of interruption was not provided and the mean duration of sustained DAPT of 357 days suggested a small number of patients discontinuing DAPT in the first 6 months. Moreover, the overall rate of interruption and adverse events in this study was low, thereby limiting the power of the study. Although this PARIS study provided important insights, no conclusions can be drawn unfortunately with regard to when it is safe to temporarily discontinue DAPT. 
The current study, although not specifically addressing patients undergoing surgery, highlights the possible risks of early clopidogrel discontinuation after $\mathrm{PCl}$. The majority of ST occurred within 14 days in this registry and this observation might question the findings in the PARIS study that a brief interruption is safe. However, again prospective studies are needed to address this issue and strategies to minimize the risks in patients undergoing surgery shortly after $\mathrm{PCl}$.

\section{Limitations}

The incidence of ST in the Dutch Stent Thrombosis Registry is higher than in more recent studies. This may in part be explained by the high proportion of first-generation DES. As the overall ST incidence has declined, the absolute risk calculations of ST after discontinuation of clopidogrel might be lower in current clinical practice. Of note, the absolute ST rates might be underestimated for the reported time frames, as only information on clopidogrel therapy at the time of ST was used. Consequently, patients discontinuing clopidogrel early but suffering ST in a later time frame were not counted in the former time frame. Secondly, results are shown as aggregate data (rather than separate analyses for STEMI, NSTEMI, and stable patients), as the small patient numbers and the used extrapolation method did not allow for such a sub analysis. However, as the cohort consisted of a mix of unstable/ACS patients (74\%) and stable patients (26\%), the risks associated with early DAPT discontinuation after ACS might still be underestimated.

Furthermore, current guidelines now recommend the use of stronger $\mathrm{P}_{2} \mathrm{Y}_{12}$-inhibitors such as ticagrelor and prasugrel over clopidogrel. However, clopidogrel is still widely used in patients with acute coronary syndrome $(A C S)^{10,11}$, despite this recommendation. Therefore, we believe the message of our study is still contemporary in endorsing the importance of clopidogrel continuation in the first 6 months after stent implantation.

Finally, ST risk might interfere with the reason of clopidogrel cessation, for example, bleeding or surgery, which might lead to a prothrombotic state and thus adding to ST risk. As the current study is a registry, it is not possible to correct for such factors. However, this is a "real world registry" reflecting the real risks associated with early clopidogrel discontinuation.

\section{Conclusion}

The absolute rates of ST in this large registry with a high proportion of ACS patients were very high when clopidogrel was discontinued in the first 6 months after index-PCl. Clinicians should be reluctant in reducing DAPT duration in ACS patients, unless the patient is considered to have an excessive bleeding risk. 


\section{Reference list}

1. Tada T, Byrne RA, Simunovic I et al. Risk of stent thrombosis among bare-metal stents, firstgeneration drug-eluting stents, and second-generation drug-eluting stents: results from a registry of 18,334 patients. JACC Cardiovasc Interv 2013 Dec;6(12):1267-1274.

2. Kereiakes DJ, Yeh RW, Massaro JM et al. Stent Thrombosis in Drug-Eluting or Bare-Metal Stents in Patients Receiving Dual Antiplatelet Therapy. JACC Cardiovasc Interv 2015 Oct;8(12):15521562.

3. Vignali L, Saia F, Belotti LMB et al. New-generation drug-eluting stents reduce stent thrombosis and myocardial infarction: a propensity-score-adjusted analysis from the multicenter REAL registry (REgistro Regionale AngiopLastiche Dell'Emilia-Romagna). Catheter Cardiovasc Interv 2015 Apr;85(5):797-806.

4. van Werkum JW, Heestermans AA, Zomer AC et al. Predictors of coronary stent thrombosis: the Dutch Stent Thrombosis Registry. J Am Coll Cardiol 2009;53:1399-1409.

5. Iqbal J, Sumaya W, Tatman V et al. Incidence and predictors of stent thrombosis: a single-center study of 5,833 consecutive patients undergoing coronary artery stenting. Eurolntervention 2013;9:62-69.

6. Palmerini T, Benedetto $U$, Biondi-Zoccai G et al.. Long-Term Safety of Drug-Eluting and BareMetal Stents: Evidence From a Comprehensive Network Meta-Analysis. J Am Coll Cardiol 2015;65:2496-2507.

7. Levine GN, Bates ER, Blankenship JC et al. American College of, Cardiology Foundation, American Heart Association Task Force on, Practice Guidelines, Society for Cardiovascular Angiography, and Interventions. 2011 ACCF/AHA/SCAI Guideline for Percutaneous Coronary Intervention. A report of the American College of Cardiology Foundation/American Heart Association Task Force on Practice Guidelines and the Society for Cardiovascular Angiography and Interventions. J Am Coll Cardiol 2011;58:44.

8. Authors/Task Fm, Windecker S, Kolh P, Alfonso F, Collet et al. 2014 ESC/EACTS Guidelines on myocardial revascularization: The Task Force on Myocardial Revascularization of the European Society of Cardiology (ESC) and the European Association for Cardio-Thoracic Surgery (EACTS) Developed with the special contribution of the European Association of Percutaneous Cardiovascular Interventions (EAPCI). Eur Heart J 2014;35:2541-2619.

9. Roffi M, Patrono C, Collet JP et al.. 2015 ESC Guidelines for the management of acute coronary syndromes in patients presenting without persistent ST-segment elevation: Task Force for the Management of Acute Coronary Syndromes in Patients Presenting without Persistent STSegment Elevation of the European Society of Cardiology (ESC). Eur Heart J 2016;37:267-315.

10. Fan W, Plent S, Prats J, Deliargyris EN. Trends in ${\mathrm{P} 2 \mathrm{Y}_{12}}_{12}$ Inhibitor Use in Patients Referred for Invasive Evaluation of Coronary Artery Disease in Contemporary US Practice. Am J Cardiol 2016;117:1439-1443.

11. Bueno $H$, Sinnaeve $P$, Annemans L et al.. Opportunities for improvement in anti-thrombotic therapy and other strategies for the management of acute coronary syndromes: Insights from 
EPICOR, an international study of current practice patterns. Eur Heart J Acute Cardiovasc Care 2016;5:3-12.

12. lakovou I, Schmidt T, Bonizzoni E et al. Incidence, predictors, and outcome of thrombosis after successful implantation of drug-eluting stents. JAMA 2005;293:2126-2130.

13. Airoldi $\mathrm{F}$, Colombo $\mathrm{A}$, Morici $\mathrm{N}$ et al. Incidence and predictors of drug-eluting stent thrombosis during and after discontinuation of thienopyridine treatment. Circulation 2007;116:745-754.

14. Spertus JA, Kettelkamp R, Vance $\mathrm{C}$ et al.. Prevalence, predictors, and outcomes of premature discontinuation of thienopyridine therapy after drug-eluting stent placement: results from the PREMIER registry. Circulation 2006;113:2803-2809.

15. Levine GN, Bates ER, Bittl JA et al. 2016 ACC/AHA Guideline Focused Update on Duration of Dual Antiplatelet Therapy in Patients With Coronary Artery Disease: A Report of the American College of Cardiology/American Heart Association Task Force on Clinical Practice Guidelines: An Update of the 2011 ACCF/AHA/SCAI Guideline for Percutaneous Coronary Intervention, 2011 ACCF/AHA Guideline for Coronary Artery Bypass Graft Surgery, 2012 ACC/AHA/ACP/AATS/PCNA/ SCAI/STS Guideline for the Diagnosis and Management of Patients With Stable Ischemic Heart Disease, 2013 ACCF/AHA Guideline for the Management of ST-Elevation Myocardial Infarction, 2014 AHA/ACC Guideline for the Management of Patients With Non-ST-Elevation Acute Coronary Syndromes, and 2014 ACC/AHA Guideline on Perioperative Cardiovascular Evaluation and Management of Patients Undergoing Noncardiac Surgery. Circulation 2016;134:123.

16. Byrne RA, Joner M, Kastrati A. Stent thrombosis and restenosis: what have we learned and where are we going? The Andreas Gruntzig Lecture ESC 2014. Eur Heart J 2015;36:3320-3331.

17. Barthelemy O, Montalescot G. Moving Toward Eradication of Stent Thrombosis. J Am Coll Cardiol 2016;67:763-765.

18. Claessen BE, Henriques JP, Jaffer FA, Mehran R, Piek JJ, Dangas GD. Stent thrombosis: a clinical perspective. JACC Cardiovasc Interv 2014;7:1081-1092.

19. Nakazawa G, Otsuka F, Nakano M et al. The pathology of neoatherosclerosis in human coronary implants bare-metal and drug-eluting stents. J Am Coll Cardiol 2011;57:1314-1322.

20. Otsuka F, Byrne RA, Yahagi $\mathrm{K}$ et al. Neoatherosclerosis: overview of histopathologic findings and implications for intravascular imaging assessment. Eur Heart J 2015;36:2147-2159.

21. Yamaji K, Kubo S, Inoue $\mathrm{K}$ et al. Association of localized hypersensitivity and in-stent neoatherosclerosis with the very late drug-eluting stent thrombosis. PLoS ONE 2014;9:e113870.

22. Cutlip DE, Windecker S, Mehran R et al. Academic RC. Clinical end points in coronary stent trials: a case for standardized definitions. Circulation 2007;115:2344-2351.

23. Mehran R, Baber U, Steg PG et al. Cessation of dual antiplatelet treatment and cardiac events after percutaneous coronary intervention (PARIS): 2 year results from a prospective observational study. Lancet 2013;382:1714-1722.

24. van Werkum JW, Heestermans AA, de Korte Fl et al.. Long-term clinical outcome after a first angiographically confirmed coronary stent thrombosis: an analysis of 431 cases. Circulation 2009;119:828-834. 
25. Schulz S, Schuster T, Mehilli J et al. Stent thrombosis after drug-eluting stent implantation: incidence, timing and relation to discontinuation of clopidogrel therapy over a 4-year period. Eur Heart J. 2009;30:2714-2721.

26. Gwon HC, Hahn JY, Park KW et al. Six-month versus 12-month dual antiplatelet therapy after implantation of drug-eluting stents: the Efficacy of Xience/Promus Versus Cypher to Reduce Late Loss After Stenting (EXCELLENT) randomized, multicenter study. Circulation 2012;125:505-513.

27. Schulz-Schupke S, Byrne RA, Ten Berg JM et al. Intracoronary Stenting and Antithrombotic Regimen: Safety And EFficacy of 6 Months Dual Antiplatelet Therapy After Drug-Eluting Stenting (ISAR-SAFE), Trial Investigators. ISAR-SAFE: a randomized, double-blind, placebo-controlled trial of 6 vs. 12 months of clopidogrel therapy after drug-eluting stenting. Eur Heart J 2015;36:12521263.

28. Colombo A, Chieffo A, Frasheri A et al. Second-generation drug-eluting stent implantation followed by 6 - versus 12-month dual antiplatelet therapy: the SECURITY randomized clinical trial. J Am Coll Cardiol 2014;64:2086-2097.

29. Feres F, Costa RA, Abizaid A et al. OPTIMIZE TI. Three vs twelve months of dual antiplatelet therapy after zotarolimus-eluting stents: the OPTIMIZE randomized trial. JAMA 2013;310:25102522.

30. Kim BK, Hong MK, Shin DH, et al. Investigators R. A new strategy for discontinuation of dual antiplatelet therapy: the RESET Trial (REal Safety and Efficacy of 3-month dual antiplatelet Therapy following Endeavor zotarolimus-eluting stent implantation). J Am Coll Cardiol 2012;60:1340-1348.

31. Palmerini T, Della Riva D, Benedetto $U$ et al. Three, six, or twelve months of dual antiplatelet therapy after DES implantation in patients with or without acute coronary syndromes: an individual patient data pairwise and network meta-analysis of six randomized trials and 11473 patients. Eur Heart J. 2017; Epub ahead of print

32. Saia F, Belotti LM, Guastaroba P et al. Risk of Adverse Cardiac and Bleeding Events Following Cardiac and Noncardiac Surgery in Patients With Coronary Stent: How Important Is the Interplay Between Stent Type and Time From Stenting to Surgery?. Circ Cardiovasc Qual Outcomes 2016;9:39-47.

33. Kristensen SD, Knuuti J, Saraste A et al. Authors/Task FM. 2014 ESC/ESA Guidelines on noncardiac surgery: cardiovascular assessment and management: The Joint Task Force on noncardiac surgery: cardiovascular assessment and management of the European Society of Cardiology (ESC) and the European Society of Anaesthesiology (ESA). Eur Heart J 2014;35:23832431. 
CHAPTER

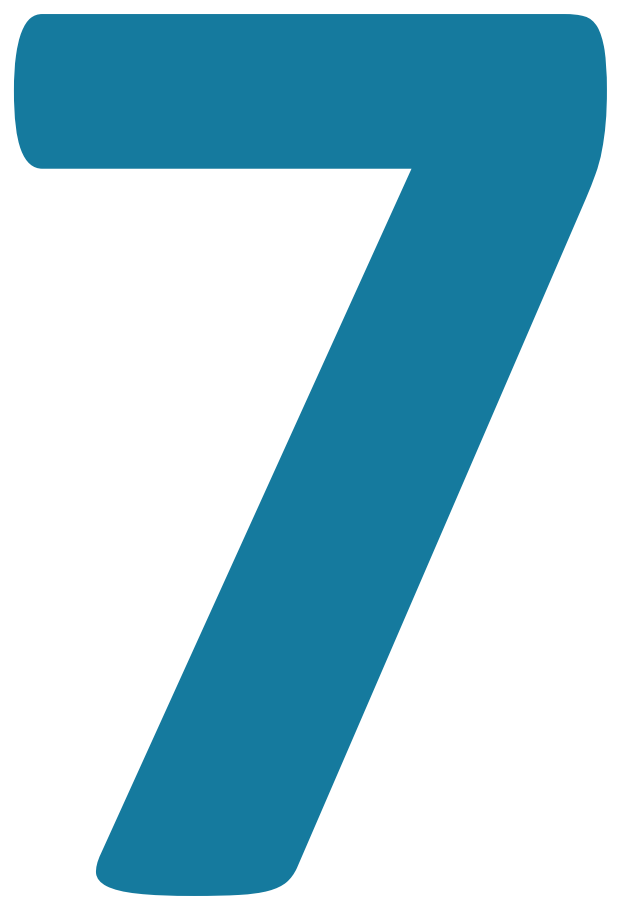




\section{Use of glycoprotein IIb/IIla antagonists to prevent stent thrombosis in morphine-treated patients with ST-elevation myocardial infarction}

B. Zwart, M. Yazdani, K.W. Ow, J.D. Richardson, J. Iqbal, J.P. Gunn, R.F. Storey 


\begin{abstract}
Morphine can delay absorption of $\mathrm{P}_{2} \mathrm{Y}_{12}$-inhibitors in ST-elevation myocardial infarction (STEMI) patients, which has the potential to expose these patients to increased stent thrombosis risk after primary percutaneous coronary intervention (PPCI). Limited evidence exists for pharmacotherapeutic strategies aiming to mitigate this risk. We evaluated the impact of guideline-driven 'routine' glycoprotein Ilb/IIla antagonist (GPI) use in morphinetreated patients undergoing $\mathrm{PPCl}$. 3224 consecutive STEMI patients undergoing $\mathrm{PPCl}$ at a large tertiary cardiac centre between 2012 and 2017 were evaluated. GPI use and outcomes before and after introduction of a local guideline were compared, and rates of definite stent thrombosis were identified at 24 hours and 30 days. GPI use increased from $42.4 \%$ to $69.9 \%$ after the introduction of the new guideline. Stent thrombosis occurred in $1.3 \%$ $(26 / 1947)$ pre-guideline and $0.6 \%(7 / 1244)$ post-guideline $(P=0.037)$. Of the 33 stent thrombosis cases, $90 \%$ (27/30) had received morphine, of whom $85.2 \%$ (23/27) had not received adjunctive GPI. Routine GPI use in morphine-treated STEMI patients undergoing $\mathrm{PPCl}$ appears to protect against stent thrombosis. Although hampered by low patient numbers, GUSTO mild to moderate bleeding was more frequently observed in GPI treated patients, whereas differences in GUSTO moderate or severe bleeding were not significantly different. Large-scale studies are needed to establish the overall risk-benefit of GPI therapy in morphine-treated $\mathrm{PPCl}$ patients and to assess alternative strategies for preventing acute stent thrombosis in these patients.
\end{abstract}




\section{Introduction}

Dual antiplatelet therapy (DAPT) with aspirin and a $\mathrm{P}_{2} \mathrm{Y}_{12}$ inhibitor is the standard of care for the management of acute coronary syndromes (ACS) and for percutaneous coronary intervention $(\mathrm{PCl})$, being recommended in the current international guidelines. ${ }^{1,2,3,4}$ In the setting of ST-elevation myocardial infarction (STEMI) and other ACS manifestations, the P2Y inhibitors ticagrelor and prasugrel are now preferred to clopidogrel as first-line therapy in those without contraindications, except in those requiring oral anticoagulant therapy. ${ }^{1,24}$ Morphine is often used in patients with STEMI for analgesia, sedation, anxiolysis and reduction of adrenergic drive, heart rate and myocardial oxygen consumption. ${ }^{1,2,5}$ However, morphine has been shown to delay absorption of $\mathrm{P}_{2} \mathrm{Y}_{12}$-inhibitors in STEMI patients, which has the potential to expose these patients to increased thrombotic risk. ${ }^{6,7,8,9}$ Some evidence of a harmful effect comes from the ATLANTIC (Administration of Ticagrelor in the Cath Lab or in the Ambulance for New ST Elevation Myocardial Infarction to Open the Coronary Artery) study, which showed a significant interaction between morphine use and the effects of pre-hospital administration of ticagrelor; pre-hospital compared to in-hospital ticagrelor administration appeared to improve resolution of ST-elevation in those who did not receive morphine whereas no apparent benefit was seen in morphine-treated patients. ${ }^{10}$ Another study found that morphine-treated STEMI patients exhibited larger infarct size and lower myocardial salvage index ${ }^{11}$, although a further observational study found no differences in in-hospital complications or 1-year mortality. ${ }^{12}$ Evidence for clinical efficacy of GPI use in morphine-treated patients with STEMI is limited. In a small observational study (32 STEMI patients treated with prasugrel), a bridging strategy with abciximab in morphine-treated patients appeared to ensure adequate platelet inhibition as measured with Multiplate electrode aggregometry. ${ }^{13}$ However, no evidence is available regarding clinical outcomes with such a strategy and no data exist about the effect in ticagrelor-treated patients in this setting. The recommendations for GPI use in addition to $\mathrm{P}_{2} \mathrm{Y}_{12}$ inhibitors in the current guidelines are restricted to specific situations (bail-out strategy, no-reflow or angiographic evidence of a large thrombus). ${ }^{24}$ No specific recommendations are given for morphinetreated patients. Although the aforementioned studies suggest that platelet function and clinical outcomes are worse in morphine treated STEMI patients, no accepted strategies exist to overcome this issue. Therefore, an institutional guideline was introduced in our hospital in 2012 with the purpose of improving the outcomes of morphine treated STEMI patients.

The aim of the current observational cohort study was to compare the effect of GPI before and after the introduction of this guideline for morphine-treated STEMI patients in terms of stent thrombosis and mortality, as well as to obtain pilot data on bleeding events. 


\section{Methods}

Consecutive patients undergoing primary PCI for STEMI at South Yorkshire Cardiothoracic Centre, Sheffield, United Kingdom, between 1 April 2012 and 28 February 2017 were included. This hospital provides a primary $\mathrm{PCl}$ service for the surrounding population of approximately 1.8 million people. Standard antithrombotic therapy throughout the observation period consisted of aspirin and ticagrelor (or prasugrel if ticagrelor was not tolerated or cautioned for reasons other than bleeding risk). Heparin was given intravenously or intra-arterially at a dose of approximately 70 units/kilogram. Use of GPI in morphinetreated patients was encouraged after introduction of the local protocol in March 2015, which specifically recommended that "in the absence of contraindication, tirofiban should be considered routinely in patients who have received morphine prior to or shortly after loading dose of $\mathrm{P}_{2} \mathrm{Y}_{12}$ inhibitor" at an intravenous bolus dose of tirofiban $25 \mathrm{mcg} / \mathrm{kg}$ followed by maintenance dose of $0.15 \mathrm{mcg} / \mathrm{kg} / \mathrm{min}$ for a duration of 6 hours, unless a reduced dose was indicated for renal failure or longer duration was indicated for management of residual thrombus.

GPI use as documented in the procedure information system was collected and compared between the pre-guideline group (April 2012 to February 2015) and the post-guideline group (from March 2015 to February 2017).

A search was performed for patients undergoing a re-PCl within 30 days and $\mathrm{PCl}$ reports were reviewed to identify any possible cases of stent thrombosis. Cases that met the Academic Research Consortium criteria for definite stent thrombosis ${ }^{14}$ were recorded and additional details regarding morphine were collected for these patients. 30-day vital status was available for all patients from the national register of deaths.

\section{Bleeding rates in local cohort}

Bleeding rates and details of in-ambulance morphine use were not available for many patients, partly due to transfer to local hospitals after 12 hours meaning that complete hospital records were not available or due to incomplete records. Consequently, a detailed analysis was performed in a sub-cohort of 374 local STEMI patients in order to provide pilot data on bleeding rates, according to Global Utilization of Streptokinase and tPA for Occluded arteries (GUSTO) criteria for mild, moderate and severe bleeding, in the first 30 days. Bleeding rates were compared between the pre-guideline cohort and the post-guideline cohort, between GPI-treated patients and patients not treated with GPI, and, finally, in patients who received the institutional "guideline-based therapy" (i.e. morphine-treated patients who received GPI or patients who did not receive morphine and did not receive GPI) versus patients not receiving the institutional guideline-based therapy. Patients were excluded if they were transferred after $\mathrm{PCl}$ to their local district general hospital. For the 
bleeding outcomes, only procedures performed by operators using predominantly radial access at the beginning of the census date (1 April 2012) were included in order to reduce bias from increased adoption of, and skill in using, radial artery access during the second period leading to reduced bleeding risk. ${ }^{1-2,15}$

\section{Statistical analysis}

Categorical variables were summarized by frequencies and percentages and Chi-square tests were used in intergroup comparisons of categorical variables. Fisher's Exact Test was used for low frequency events. Continuous variables were summarized as mean and standard deviation, and values were compared using a standard t-test for normally distributed data. Stent thrombosis rates were compared with Kaplan Meier plots using log ranks test. The primary outcome was definite stent thrombosis at 30 days and secondary outcomes were definite stent thrombosis at 24 hours and all-cause mortality at 30 days.

\section{Results}

\section{Study population}

3224 consecutive STEMI patients undergoing primary $\mathrm{PCl}$ were included. Details of repeat $\mathrm{PCl}$ procedures and all-cause deaths within 24 hours and at 30 days were available for all these patients. In the post-guideline cohort, radial access was more common, and patients presented more frequently with cardiogenic shock, whereas peripheral arterial disease was less common (Table 1). Details regarding GPI use were available in 2297/3224 (71.2\%) of patients. GPI use increased from $42.4 \%$ to $69.9 \%$ after the introduction of the new guideline (Table 2).

Table 1: Baseline characteristics.

\begin{tabular}{|c|c|c|c|c|c|c|}
\hline n (\%) unless indicated & $\begin{array}{l}\text { Main cohort } \\
\text { Pre guideline }\end{array}$ & $\begin{array}{l}\text { Main cohort } \\
\text { Post guideline }\end{array}$ & $\begin{array}{c}P \\
\text { value }\end{array}$ & $\begin{array}{l}\text { Local cohort } \\
\text { Pre-guideline }\end{array}$ & $\begin{array}{l}\text { Local cohort } \\
\text { Post guideline }\end{array}$ & $\begin{array}{c}P \\
\text { value }\end{array}$ \\
\hline Age, mean \pm SD & $62.9 \pm 12.7$ & $63.6 \pm 12.5$ & 0.10 & $62.1 \pm 12.9$ & $62.6 \pm 12.9$ & 0.71 \\
\hline Female sex & $547 / 1973$ (27.7) & $335 / 1251$ (26.8) & 0.59 & $55 / 233(23.6)$ & $32 / 141(22.7)$ & 0.79 \\
\hline Diabetes & $265 / 1823(14.5)$ & $178 / 1071(16.6)$ & 0.13 & $29 / 212(13.7)$ & $17 / 113(15.0)$ & 0.73 \\
\hline Hypercholesterolaemia & $542 / 1586(34.2)$ & $253 / 831(30.4)$ & 0.06 & $62 / 192$ (32.3) & $30 / 93(32.3)$ & 0.99 \\
\hline Hypertension & $673 / 1586(42.4)$ & $315 / 831$ (37.9) & 0.03 & $74 / 192$ (38.5) & $34 / 93(36.6)$ & 0.75 \\
\hline Current or ex smoker & $1064 / 1468(72.5)$ & $507 / 747$ (67.9) & 0.02 & $127 / 174(73.0)$ & $56 / 84(66.7)$ & 0.30 \\
\hline Radial access & $994 / 1745(57.0)$ & $810 / 1119(72.5)$ & 0.001 & $142 / 226(62.8)$ & $101 / 125(80.8)$ & 0.001 \\
\hline \multicolumn{7}{|l|}{ Culprit vessel } \\
\hline LAD & $845 / 1959$ (43.1) & $511 / 1235(41.4)$ & 0.33 & $86 / 220(39.1)$ & $39 / 125$ (31.2) & 0.14 \\
\hline$C X$ & $305 / 1959$ (15.6) & $190 / 1235(15.4)$ & 0.89 & $38 / 220(17.3)$ & $24 / 125$ (19.2) & 0.29 \\
\hline RCA & $895 / 1959$ (45.7) & $546 / 1235$ (43.3) & 0.21 & $112 / 220(50.9)$ & $69 / 125(55.2)$ & 0.44 \\
\hline Peripheral Artery Disease & $69 / 1586(4.4)$ & $13 / 831(1.6)$ & 0.001 & $8 / 192(4.2)$ & $0 / 93(0)$ & 0.05 \\
\hline Previous CVA & $38 / 1586(2.4)$ & $13 / 831(1.6)$ & 0.18 & $3 / 192(1.6)$ & $2 / 93(2.2)$ & 0.72 \\
\hline \multicolumn{7}{|l|}{$\begin{array}{l}\text { History of renal disease } \\
\quad \text { (creatinine }>220 \text { umol/I }\end{array}$} \\
\hline or dialysis) & $21 / 1726(1.2)$ & 11/1033 (1.1) & 0.72 & 2/199 (1.0) & $0 / 110(0)$ & 0.29 \\
\hline Previous myocardial infarction & $202 / 1675$ (12.1) & $136 / 958$ (14.2) & 0.12 & $27 / 190(14.2)$ & $12 / 100(12.0)$ & 0.60 \\
\hline Previous $\mathrm{PCl}$ & $161 / 1861(8.7)$ & $105 / 1032(10.2)$ & 0.17 & $18 / 212(8.5)$ & $7 / 104(6.7)$ & 0.59 \\
\hline Previous CABG & $32 / 1867(1.7)$ & $21 / 1048(2.0)$ & 0.57 & $3 / 211(1.4)$ & $1 / 103(1.0)$ & 0.74 \\
\hline Cardiogenic shock & $93 / 1886$ (4.9) & $72 / 1089(6.6)$ & 0.054 & $6 / 216(2.8)$ & $4 / 111(3.6)$ & 0.74 \\
\hline
\end{tabular}


Table 2: Frequencies of GPI use in primary $\mathrm{PCI}$ patients.

\begin{tabular}{llll}
\hline Cohort & $\begin{array}{l}\text { GPI use } \\
\text { pre-guideline } \mathbf{n}(\%)\end{array}$ & $\begin{array}{l}\text { GPI use } \\
\text { post-guidelinen (\%) }\end{array}$ & P value \\
\hline Main cohort & $587 / 1385(42.4)$ & $628 / 898(69.9)$ & $<0.001$ \\
Local sub-cohort & $100 / 232(43.1)$ & $93 / 141(66.0)$ & $<0.001$ \\
$\quad$ No Morphine & $29 / 66(43.9)$ & $16 / 27(59.3)$ & 0.18 \\
Morphine & $68 / 160(42.5)$ & $75 / 110(68.2)$ & $<0.001$ \\
\hline
\end{tabular}

GPI: glycoprotein IIb/IIla receptor antagonist (abciximab or tirofiban).

\section{Outcomes}

85 of 3224 patients underwent re-PCl within 30 days, in whom 33 cases of definite stent thrombosis were identified (1.0\%). 26 stent thrombosis events occurred in the cohort before the introduction of the guideline $(26 / 1973 ; 1.3 \%)$ compared with 7 stent thrombosis events $(7 / 1251 ; 0.6 \%)$ occurring after the introduction of the new guideline $(p=0.037$, log-rank test)(Figure $1 A)$. The majority of stent thrombosis events (29/33) were acute (i.e. occurring within 24 hours) with fewer events post-guideline compared with pre-guideline $(P=0.037$, log-rank test)(Figure 1B). For 30 out of 33 stent thrombosis patients, details on morphine use were available: $27 / 30$ (90\%) patients had received morphine, of whom $23 / 27$ (85.2\%) had not received adjunctive GPI. No significant difference in 30-day mortality was observed between the pre- and post-guideline group ( $5.9 \%$ vs. $7.3 \%, p=0.13$ ).

When stratified for GPI use rather than time period, 5/1217 (0.4\%) of patients receiving GPI suffered a stent thrombosis vs. $28 / 1080(2.6 \%, p<0.0001)$ of patients who did not receive GPI (Table 3).

Table 3: 30-day outcomes according to era or use of GPI.

\begin{tabular}{lccc} 
& $\begin{array}{c}\text { Pre-guideline group } \\
\mathbf{n ~ ( \% )}\end{array}$ & $\begin{array}{c}\text { Post-guideline group } \\
\mathbf{n}(\%)\end{array}$ & P value \\
\hline Stent thrombosis & $26 / 1973(1.3)$ & $7 / 1251(0.6)$ & 0.037 \\
All-cause mortality & $117 / 1973(5.9)$ & $91 / 1251(7.3)$ & 0.13 \\
\hline & $\mathbf{N o ~ G P I}$ & $\mathbf{G P I}$ (\%) value \\
\hline Stent thrombosis & $\mathbf{n}(\%)$ & $<0.0001$ \\
All-cause mortality & $28 / 1080(2.6)$ & $5 / 1217(0.4)$ & 0.18 \\
\hline
\end{tabular}

$P$ values are derived using log-rank test. 
A

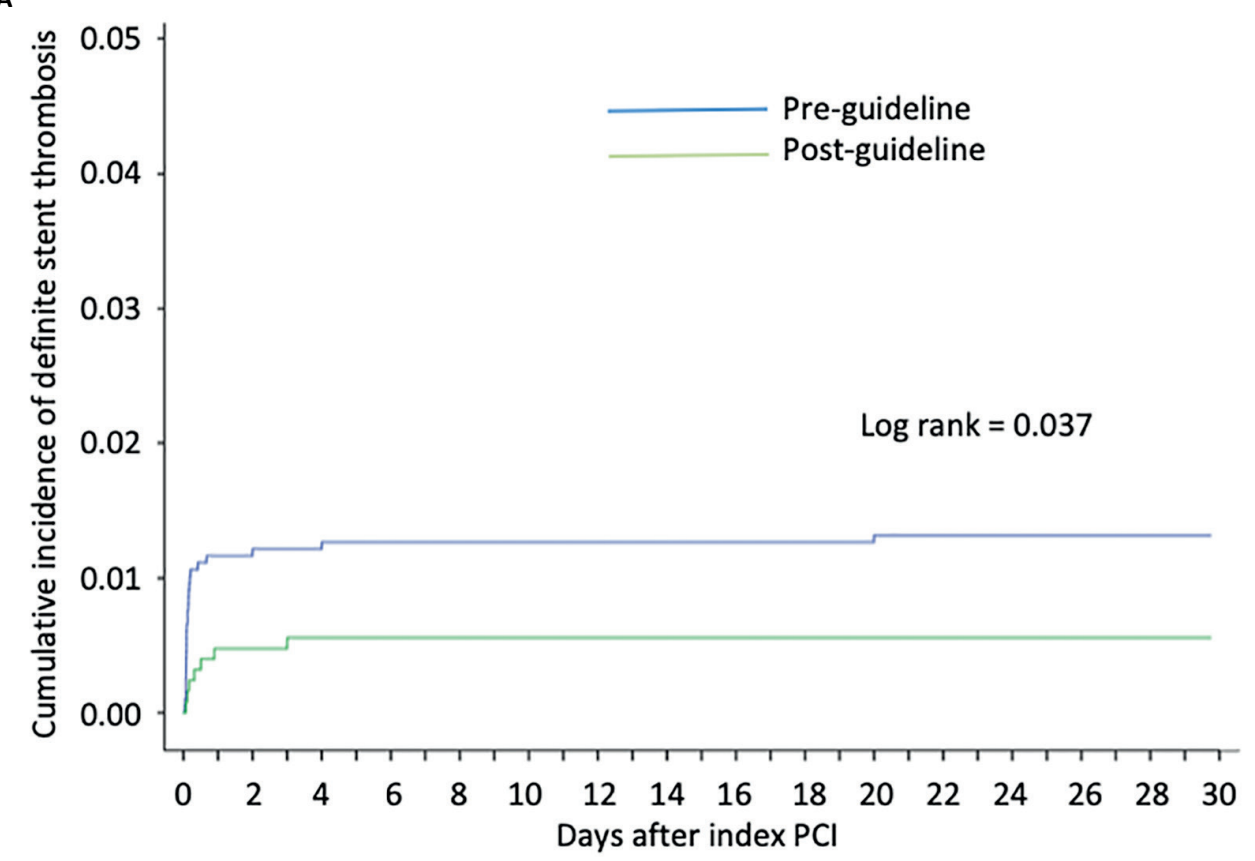

B

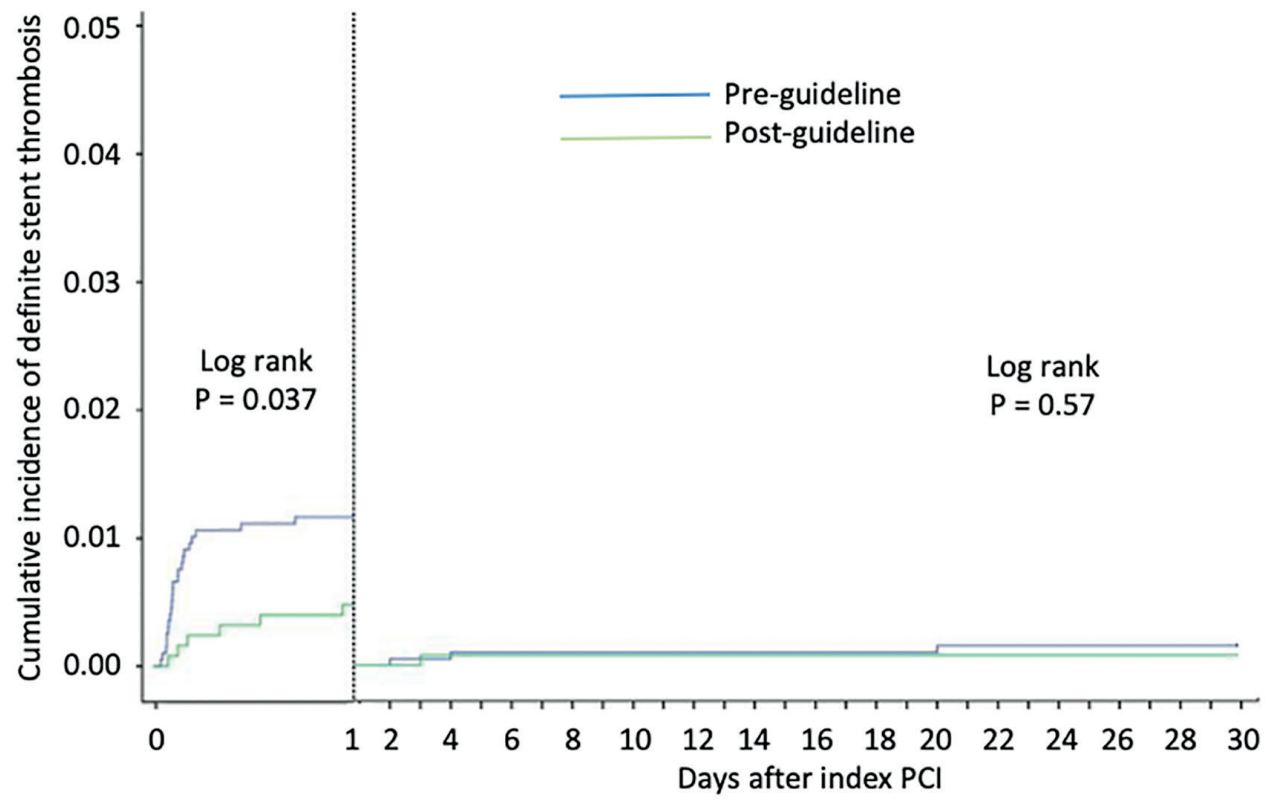

Figure 1: Rates of definite stent thrombosis pre- and post-introduction of local guideline. 


\section{Bleeding rates in local subgroup}

2387 patients were transferred back to their local hospital following their primary $\mathrm{PCl}$ procedure. Of the remaining 937 patients, a total of 374 patients were included in the bleeding analysis (Figure 2). Details regarding GPI use were available in all patients and details regarding morphine use were available in 363 of 374 patients (97.1\%). Baseline characteristics were similar to the overall cohort (Table 1). Following introduction of the institutional guideline, GPI use increased from $42.9 \%$ to $66.4 \%$. Any GUSTO bleeding occurred in $17.6 \%$ of patients pre-guideline and $13.5 \%$ of patients post-guideline $(p=0.29)$ and GUSTO moderate or severe bleeding occurred in $1.7 \%$ and $2.8 \%$, respectively $(p=0.47)$.

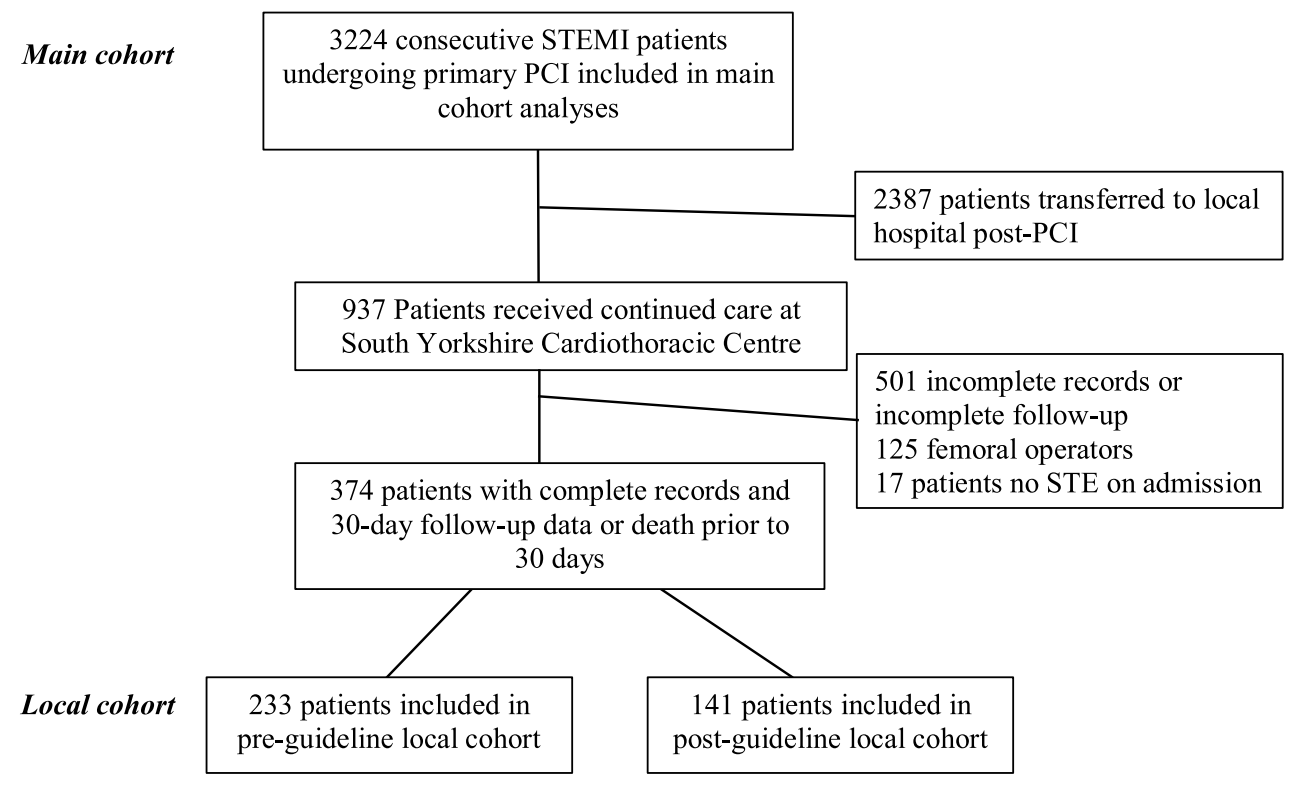

Figure 2: Flow Chart of Patient Selection.

$\mathrm{PCI}$, percutaneous coronary intervention; STEMI, ST-elevation myocardial infarction; STE, ST elevation.

In GPI-treated patients during either time period, any GUSTO bleeding was more frequently observed compared with patients not treated with GPI $(21.8 \%$ vs. $10.0 \%$, respectively; $\mathrm{p}=0.002$ ) but differences in GUSTO moderate or severe bleeding were numerically but not statistically significant ( $3.1 \%$ vs. $1.1 \% ; p=0.29)$. Despite the aim of limiting differences in radial access use between the two time periods, there was an increase in use of radial access in the post-guideline period (Table 1). 
Table 4: Bleeding rates in local sub cohort according to era, GPI use and protocol-guided therapy.

\begin{tabular}{llll}
\hline & $\begin{array}{l}\text { Pre-guideline group } \\
\mathbf{n}(\%)\end{array}$ & $\begin{array}{l}\text { Post-guideline group } \\
\mathbf{n}(\%)\end{array}$ & P value \\
\hline $\begin{array}{l}\text { Any GUSTO bleeding } \\
\text { GUSTO moderate or severe bleeding }\end{array}$ & $\begin{array}{l}41 / 233(17.6) \\
4 / 233(1.7)\end{array}$ & $\begin{array}{l}19 / 141(13.5) \\
4 / 141(2.8)\end{array}$ & $\begin{array}{l}0.29 \\
0.47\end{array}$ \\
\hline & No GPI & P value \\
\hline Any GUSTO bleeding & (18/180 (10.0) & GPI group & (\%) \\
GUSTO moderate or severe bleeding & $2 / 180(1.1)$ & $6 / 193(21.8)$ & 0.002 \\
\hline & Guideline-based & Not guideline-based & P value \\
\hline Any GUSTO bleeding & GPI use $\mathbf{n}(\%)$ & GPI use $\mathbf{n}(\%)$ & 0.29 \\
\hline GUSTO moderate or severe bleeding & $24 / 172(14.0)$ & $33 / 192(17.2)$ & 0.40 \\
\hline
\end{tabular}

\section{Discussion}

The introduction of a new guideline in our centre has led to a $65 \%$ relative increase of GPI use in patients with STEMI undergoing primary $\mathrm{PCI}$. There was a significant decrease in the number of definite stent thrombosis cases after the introduction of the new guideline. Overall, a significantly lower incidence of stent thrombosis was observed in GPI-treated patients. The majority of patients suffering a stent thrombosis had received morphine but not adjunctive GPI. More bleeding events were observed with GPI use but there was not a statistically significant increase in moderate-to-severe GUSTO bleeding. The increased risk of major bleeding with GPI is well documented and consequently this strategy may not be the optimal means of preventing acute stent thrombosis in morphine-treated primary $\mathrm{PCl}$ patients. Indeed, we have recently conducted a pharmacodynamic study to assess the impact of a bolus and 6-hour infusion of enoxaparin in primary $\mathrm{PCl}$ patients as an alternative strategy to routine use of GPI in morphine-treated patients and are currently comparing this against a strategy of routine use of tirofiban with unfractionated heparin (NCT03568838) ${ }^{16}$. Cangrelor is a rational option for providing parenteral $\mathrm{P}_{2} \mathrm{Y}_{12}$ inhibition pending the absorption of an oral $\mathrm{P}_{2} \mathrm{Y}_{12}$ inhibitor although a standard 2-hour cangrelor infusion may not be sufficient to cover the period of delayed absorption of the oral inhibitor in all patients and care must be taken if clopidogrel or prasugrel is used as the oral inhibitor since cangrelor can block the binding of clopidogrel and prasugrel active metabolites to the $P 2 Y_{12}$ receptor. ${ }^{17,18}$

This observational study is the first to describe the feasibility and outcomes of 'routine' GPI use in morphine-treated patients undergoing primary $\mathrm{PCl}$. Overall, the adherence to the protocol was fair. Whereas the use of GPI has substantially increased after the introduction of the new guideline, still not all morphine-treated patients received adjunctive GPI. This could in part be explained by other factors playing a role in clinical practice, such as patient bleeding risk and possible contra-indications. Equally, other patients received GPI without 
being treated with morphine, thus a reflection of other perceived indications for GPI use, such as residual thrombus load after $\mathrm{PCl}$.

\section{Limitations}

The observational and retrospective nature of this registry, evaluating the effects of the introduction a new local guideline, implies that treatment strategy was not randomised. Patients were not followed up prospectively and so we cannot be certain that events were not missed. However, since our hospital is the only one providing a $\mathrm{PCl}$ service to the surrounding population, we considered that re-PCl rates for non-fatal stent thrombosis at our centre are a reasonable reflection of the impact of a change in protocol on event rates.

A further limitation is that details on bleeding outcomes were only available in a local subcohort that was relatively small since a substantial number of patients had been excluded, mostly due to repatriation within 12-24 hours of patients to district general hospitals following primary $\mathrm{PCl}$, and so our analyses are not sufficient to evaluate the safety of increased use of GPI. Selection on the basis of geography is unlikely to alter the finding of this registry other than to reduce the sample size. However, the unavailability of a large number of complete records may have biased the findings and further prospective studies are required for more reliable assessment of bleeding rates. The increased use of radial artery access may have attenuated the effect of increased GPI use on bleeding events. As such, the bleeding data are intended only to provide crude pilot data for planning such studies and also do not provide any guide to the safety of increased GPI use when femoral artery access is used.

Finally, over time between the two observation periods, procedural techniques might have changed. Although adjustment for possible confounding variables was not possible, we assume that changes in procedural techniques were limited, as the total time period ( $<5$ years) of this registry was relatively small. Moreover, as illustrated in Table 1 , no major differences with regard to baseline clinical and procedural characteristics were observed between the two cohorts.

\section{Conclusions}

This observational study is the first to describe the feasibility and outcomes of 'routine' GPI use in morphine-treated patients undergoing primary $\mathrm{PCl}$. Our results suggest that GPI use is highly protective for the occurrence of acute stent thrombosis. Further large-scale registries and clinical trials are needed to further establish the overall risk-benefit of GPI therapy in morphine-treated STEMI patients and to assess alternative strategies for preventing acute stent thrombosis in morphine-treated patients. 


\section{References}

1. Valgimigli M, Bueno H, Byrne RA, Collet JP, Costa F, Jeppsson A, Jüni P, Kastrati A, Kolh P, Mauri L, et al. 2017 ESC focused update on dual antiplatelet therapy in coronary artery disease developed in collaboration with EACTS: The Task Force for dual antiplatelet therapy in coronary artery disease of the European Society of Cardiology (ESC) and of the European Association for Cardio-Thoracic Surgery (EACTS). Eur Heart J. 2018;39:213-260

2. Ibanez B, James S, Agewall S, Antunes MJ, Bucciarelli-Ducci C, Bueno H, Caforio ALP, Crea F, Goudevenos JA, Halvorsen S, et al. 2017 ESC Guidelines for the management of acute myocardial infarction in patients presenting with ST-segment elevation: The Task Force for the management of acute myocardial infarction in patients presenting with ST-segment elevation of the European Society of Cardiology (ESC). Eur Heart J. 2018; 39:119-177.

3. Levine GN, Bates ER, Blankenship JC, Bailey SR, BittI JA, Cercek B, Chambers CE, Ellis SG, Guyton RA, Hollenberg SM, et al. 2011 ACCF/AHA/SCAI Guideline for Percutaneous Coronary Intervention. A report of the American College of Cardiology Foundation/American Heart Association Task Force on Practice Guidelines and the Society for Cardiovascular Angiography and Interventions. Am Coll Cardiol. 2011;58:e44-122

4. Roffi M, Patrono C, Collet JP, Mueller C, Valgimigli M, Andreotti F, Bax JJ, Borger MA, Brotons C, Chew DP, et al. 2015 ESC Guidelines for the management of acute coronary syndromes in patients presenting without persistent ST-segment elevation: Task Force for the Management of Acute Coronary Syndromes in Patients Presenting without Persistent ST-Segment Elevation of the European Society of Cardiology (ESC). Eur Heart J 2016;37:267-315

5. McCarthy CP, Mullins KV, Sidhu SS, Schulman SP, McEvoy JW. The on- and off-target effects of morphine in acute coronary syndrome: A narrative review. Am Heart J 2016;176:114-21

6. Silvain J, Storey RF, Cayla G, Esteve JB, Dillinger JG, Rousseau H, Tsatsaris A, Baradat C, Salhi N, Hamm CW. P2Y12 receptor inhibition and effect of morphine in patients undergoing primary $\mathrm{PCI}$ for ST-segment elevation myocardial infarction. The PRIVATE-ATLANTIC study. Thromb Haemost 2016;116:369-78

7. Kubica J, Adamski P, Ostrowska M, Sikora J, Kubica JM, Sroka WD, Stankowska K, Buszko K, Navarese EP, Jilma B, et al. Morphine delays and attenuates ticagrelor exposure and action in patients with myocardial infarction: the randomized, double-blind, placebo-controlled IMPRESSION trial. Eur Heart J 2016;37:245-52

8. Thomas MR, Morton AC, Hossain R, Chen B, Luo L, Shahari NN, Hua P, Beniston RG, Judge HM, Storey RF. Morphine delays the onset of action of prasugrel in patients with prior history of STelevation myocardial infarction. Thromb Haemost 2016;116:96-102

9. Parodi G, Bellandi B, Xanthopoulou I, Capranzano P, Capodanno D, Valenti R, Stavrou K, Migliorini A, Antoniucci D, Tamburino C, et al. Morphine is associated with a delayed activity of oral antiplatelet agents in patients with ST-elevation acute myocardial infarction undergoing primary percutaneous coronary intervention. Circ Cardiovasc Interv 2015;8; pii: e001593 
10. Montalescot G, van 't Hof AW, Lapostolle F, Silvain J, Lassen JF, Bolognese L, Cantor WJ, Cequier A, Chettibi M, Goodman SG. Prehospital ticagrelor in ST-segment elevation myocardial infarction. N Engl J Med 2014;371:1016-27

11. de Waha S, Eitel I, Desch S, Fuernau G, Lurz P, Urban D, Schuler G, Thiele H. Intravenous morphine administration and reperfusion success in ST-elevation myocardial infarction: insights from cardiac magnetic resonance imaging. Clin Res Cardiol 2015;104:727-34

12. Puymirat E, Lamhaut L, Bonnet N, Aissaoui N, Henry P, Cayla G, Cattan S, Steg G, Mock L, Ducrocq $\mathrm{G}$, et al. Correlates of pre-hospital morphine use in ST-elevation myocardial infarction patients and its association with in-hospital outcomes and long-term mortality: the FAST-MI (French Registry of Acute ST-elevation and non-ST-elevation Myocardial Infarction) programme. Eur Heart J 2016;37:1063-71

13. Siller-Matula JM, Specht S, Kubica J, Alexopoulos D, De Caterina R, Hobl EL, Jilma B, Christ G, Lang IM. Abciximab as a bridging strategy to overcome morphine-prasugrel interaction in STEMI patients. Br J Clin Pharmacol 2016;82:1343-50

14. Cutlip DE, Windecker S, Mehran R, Boam A, Cohen DJ, van Es GA, Steg PG, Morel MA, Mauri L, Vranckx $P$, et al. Clinical end points in coronary stent trials: a case for standardized definitions. Circulation 2007;115:2344-51

15. Ferrante G, Rao SV, Jüni P, Da Costa BR, Reimers B, Condorelli G, Anzuini A, Jolly SS, Bertrand OF, Krucoff MW, et al. Radial Versus Femoral Access for Coronary Interventions Across the Entire Spectrum of Patients With Coronary Artery Disease: A Meta-Analysis of Randomized Trials. JACC Cardiovasc Interv 2016;9:1419-34

16. Sumaya W, Parker WAE, Fretwell R, Hall IR, Barmby DS, Richardson JD, Iqbal J, Adam Z, Morgan KP, Gunn JP, et al. Pharmacodynamic Effects of a 6-Hour Regimen of Enoxaparin in Patients Undergoing Primary Percutaneous Coronary Intervention (PENNY PCI Study). Thromb Haemost 2018;118:1250-6

17. Storey RF, Sinha A. Cangrelor for the management and prevention of arterial thrombosis. Expert Rev Cardiovasc Ther 2016;14:991-9

18. Angiolillo DJ, Rollini F, Storey RF, Bhatt DL, James S, Schneider DJ, Sibbing D, So DYF, Trenk D, Alexopoulos D, Gurbel PA, et al. International Expert Consensus on Switching Platelet P2Y12 Receptor-Inhibiting Therapies. Circulation 2017;136:1955-75 
Use of GPI to prevent stent thrombosis in morphine treated STEMI patients | 103 


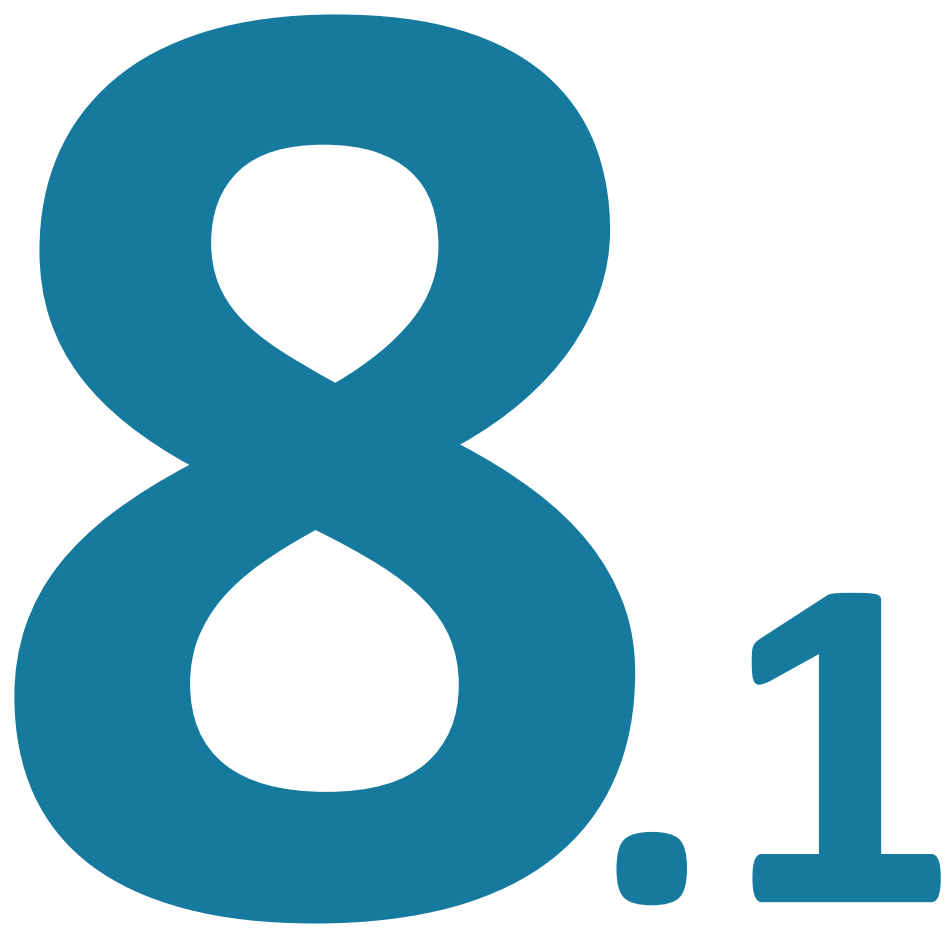




\title{
Vigorous exercise as a triggering mechanism for late stent thrombosis:
}

\author{
a description of three cases
}

B. Zwart, T.C. van Kerkvoorde, J.W. van Werkum, N.J. Breet, J.M. ten Berg, A.W.J. van 't Hof 


\begin{abstract}
Although (very) late coronary stent thrombosis is a rare complication after percutaneous coronary interventions ( $\mathrm{PCl})$, its consequences are devastating with a high morbidity and mortality. Previous studies have identified several clinical, procedural and angiographic characteristics that are associated with stent thrombosis but little is known about the underlying mechanisms that induce, provoke or trigger the of stent thrombosis. In the present paper, we describe three patients who suffered from a stent thrombosis immediately after vigorous exercise. Patient 1 suffered a stent thrombosis (ST) after performing an in-hospital bicycle ergometer test, 6 weeks after an acute coronary syndrome. Patient 2 suffered from ST immediately following his first excessive endurance cycling tour, more than 2 years after myocardial infarction. Patient 3 suffered ST while performing vigorous exercise on a bicycle ergometer in a fitness centre. These findings implicate that ST might be triggered by vigorous exercise, especially in untrained patients. Further research after triggering mechanisms of ST is urgently warranted.
\end{abstract}




\section{Introduction}

Stent thrombosis, and in particular late stent thrombosis, is a feared complication of percutaneous coronary intervention $(\mathrm{PCl})$ because it is associated with considerable morbidity and mortality ${ }^{1-3}$. The observed unusual incidence of late and very late stent thrombosis with the first-generation drugeluting stents has alerted the interventional cardiology society. Several research groups have already identified clinical factors, procedural and angiographic characteristics that are associated with the occurrence of stent thrombosis $1,2,4,5$. However, little is known about the superimposing mechanisms that induce, provoke or trigger the stent thrombosis. We describe three patients who suffered from a late stent thrombosis immediately after vigorous exercise.

\section{Case 1}

A 47-year old male with a history of hypertension, hypercholesterolemia, smoking and peripheral arterial disease underwent successful $\mathrm{PCl}$ of the right coronary artery (RCA) with two bare-metal stents (Vision!, Guidant, Santa Clara, CA, USA): one in the mid-RCA $(3.5 * 18 \mathrm{~mm})$ and one in the distal-RCA $(3.0 * 15 \mathrm{~mm})$ because of an acute coronary syndrome (ACS) with minimal elevated troponines. The post-procedural Thrombolysis in Myocardial Infarction (TIMI) flow was grade 3. Two days later, the patient was discharged while on aspirin (100 mg/day) everyday, and a statin and clopidogrel (75 mg/day) for 6 months.

During $\mathrm{PCl}$, two lesions in the Left Anterior Descending (LAD) and in the Marginal Obtuse (MO)-branch of the Ramus Circumflex (RCX) were observed. To objective the significance of these lesions, the patient underwent an exercise stress test (estimated Metabolic Equivalent (MET)[6]: 7) with 99mTc-sestamibi single photon emission computed tomography (SPECT) 6 weeks after $\mathrm{PCl}$, while he was still on dual antiplatelet therapy. The patient had not performed strenuous exercise since his $\mathrm{PCl}$. Thirty minutes after this exercise-test, he developed an acute infero-posterior myocardial infarct and underwent a coronary angiography demonstrating a thrombotic occlusion in the proximal stent in the RCA. The occlusion was successfully reopened with balloon angioplasty and adjunctive abciximab therapy. After the procedure there was a TIMI-III flow. The maximal Creatine Kinase (CK)/ Creatine Kinase isoenzyme MB (CKMB) was 617/ $54 \mathrm{U} / \mathrm{L}$. His systolic ejection fraction after the stent thrombosis remained $450 \%$ and 2 days later the patient left the hospital in good clinical condition.

\section{Case 2}

A 45-year old man with a history of non-insulin dependent diabetes and a family history of coronary artery disease (CAD) underwent successful PCl of the mid LAD as well as a $80 \%$ stenosis in the first diagonal branch with Taxus stents (Boston Scientific, Natick, MA, 
USA) $(2.75 * 32$ in the mid-LAD, $2.25 * 12$ in the first diagonal branch) because of an acute ST-segment elevated myocardial infarction (STEMI). The TIMI flow was grade 3 and his hospitalization was uneventful. He was discharged on aspirin (for a lifetime), a beta-blocker, oral anti-diabetics and clopidogrel $75 \mathrm{mg}$ for the duration of at least 6 months.

More then 2 years later, while he was on single antiplatelet therapy with aspirin, he made his first excessive endurance cycling tour, although he had been training on his bicycle several times before. He travelled $130 \mathrm{~km}$ within 4,5 hours, corresponding with an average speed of 25-30 km/hour (estimated MET: 7). Fifteen minutes after completion, he experienced chest pain and was presented to an interventional centre. Coronary angiography showed a thrombotic occlusion of the stent in the LAD. The stent thrombosis was successfully treated with balloon angioplasty and adjunctive abciximab therapy and after the procedure there was a TIMI-III flow. The maximal CK/CKMB was 1242/123 U/L. His systolic ejection fraction after the stent thrombosis remained $>50 \%$. He was discharged at day 3 on aspirin, betablocker, ACE-inhibitor, oral antidiabetics and clopidogrel $75 \mathrm{mg}$ daily for a year.

\section{Case 3}

A 40-year-old man with a history of insulin dependent diabetes, hypercholesterolemia and a family history of coronary artery disease (CAD) underwent successful $\mathrm{PCl}$ of the bifurcation of the mid LAD and the first diagonal branch with a Taxus! stent $(3.5-16 \mathrm{~mm})$ because of a non-STEMI myocardial infarction. The post procedural TIMI-flow was grade 3 and 2 days later he was discharged with aspirin for a lifetime, a statin, ezetimibe, oral anti-diabetics and clopidogrel $75 \mathrm{mg}$ for the duration of at least 6 months.

Approximately 6 months later, his cardiologist agreed to discontinue the clopidogrel according to ACC/AHA guidelines by that time. In addition, he was encouraged to increase the frequency of his weekly exercise. Six days after his clopidogrel cessation, the patient visited a fitness-centre and performed strenuous spinning (indoor cycling on a ergometer, estimated MET: 7) for the first time. He reported having a moderate physical condition at that time. During the final phase of the spinning program (after \pm 45 minutes) he suddenly experienced chest pain and lost conscience. He was adequately resuscitated by fitnessinstructors. Upon arrival of the ambulance, he was diagnosed with ventricular fibrillation and he was successfully defibrillated. He was transferred to our catheterization laboratory by ambulance. Coronary angiography showed a thrombotic occlusion in the first diagonal branch that was successfully treated with balloon angioplasty and adjunctive tirofiban therapy with a post-procedural TIMI-flow was 3 and the maximal CK/CKMB was 870/63 U/L. The systolic ejection fraction after the stent thrombosis remained $>50 \%$ and 1 day later the patient was discharged on aspirin, a statin, ezetimibe, oral anti-diabetics and clopidogrel $75 \mathrm{mg}$ therapy for the duration of one year. 


\section{Discussion}

Abrupt vessel occlusion caused by a stent thrombosis is a feared complication after $\mathrm{PCl}$ and is associated with a considerable high morbidity and mortality. Stent thrombosis is not a rare complication, with an estimated occurrence rate between $2-5 \%$. Given the enormous absolute number of total PCls performed world wide, stent thrombosis imposes an enormous risk for a large group of patients, Traditionally, stent thrombosis can be categorized in four different groups according to the time elapsed since implantation. The categories include acute ( $<24$ hours), subacute ( $>24$ hours and $<30$ days), late- ( $>30$ days and $<1$ year) and very late stent thrombosis (beyond 1 year) 7 . Recently, there has been much debate about the difference in incidence of in particular late and very late stent thrombosis between different stent types, with the first generation of Drug-Eluting Stent (DES) being the most dreadful ones ${ }^{8}$.

Daemen et al. demonstrated that the incidence of DES thrombosis was 1,9\% after a mean follow-up period of 3 years ${ }^{2}$. From these patients $60 \%$ suffered an early stent thrombosis (<30 days), $24 \%$ experienced a late stent thrombosis ( 51 year) and $16 \%$ suffered a very late stent-thrombosis (41 year) after a follow-up of 1180 days. Importantly, late stent thrombosis continued to occur over time with a linear incidence-slope of $0.6 \%$ per year.

Similarly, Wenaweser and colleagues demonstrated that the incidence of bare-metal stent thrombosis was $1,6 \%$ after a mean follow-up period of approximately 2 years ${ }^{9}$. From all the patients with a Bare Metal Stent (BMS) thrombosis, early stent thrombosis occurred at a rate of $75 \%$, late stent thrombosis at a rate of $23 \%$ and very late stent thrombosis at a rate of $2 \%$. Importantly, a linear slope in the cumulative incidence of very late stent thrombosis was not seen.

Multiple studies have already identified several factors that are associated with both BMS and DES thrombosis. These include: acute coronary syndromes as indication for $\mathrm{PCl}$, bifurcation stenting, diabetes mellitus, renal failure, stenting in the proximal LAD, impaired left ventricle ejection fraction, small stent diameter and total stent length ${ }^{1,2,4,5,10}$. Furthermore, several important mechanisms that are associated with late DES thrombosis have recently been revealed, including (1) lack of or delayed endothelialisation, (2) (late) incomplete stent malaposition, (3) polymer/drug hypersensitivity reactions, and (4) premature discontinuation of (dual) antiplatelet therapy ${ }^{11-15}$.

Nonetheless, thus far, little is known about the superimposing triggering mechanisms that provoke a stent thrombosis on a certain time point. Several studies in myocardial infarction indicate that a considerable number of these major adverse cardiac events are not random events but rather can be triggered by the daily activities of the patient which ultimately can 
cause the rupture of an atherosclerotic plaque. In addition, other factors might play a role, as is reflected by a morning increase in cardiac events. However, very little is known about superimposing factors potent to provoke stent thrombosis. In the present report, which is hypothesis generating in nature, we describe three patients with a late stent thrombosis during or direct after strenuous exercise. Although all three patients were characterized by several major risk factors which definitely puts these patients at an increased a priori risk for the development of stent thrombosis (Case 1: ACS and long total stent length. Case 2: diabetes, ACS, bifurcation-lesion, LAD-lesion, clopidogrel cessation and long total stentlength. Case 3: diabetes, ACS, bifurcation-lesion, clopidogrel cessation and LADlesion), the triggering mechanism causing this acute event seems to be vigorous exercise.

Multiple studies have demonstrated that habitual physical activity reduces the progression of atherosclerosis, decreases platelet reactivity and thus the incidence of atherothrombotic events in patients with coronary artery disease $(C A D)^{16}$. Vigorous exercise, however, might also increases the risk of acute myocardial infarction (AMI) and suddencardiac death (SCD), with or without $C A D^{17,18}$.

The pathophysiological background of vigorous exercise provoked stent thrombosis is not yet fully elucidated, but factors include exercise induced coronary-artery spasm, increased heart rate and blood pressure, increased sympathetic activity (including levels of catecholamines) and vagal withdrawal, increased thrombin generation, increased vesselwall stress and heightened platelet reactivity ${ }^{19-22}$.

Several studies investigated the paradoxical effects of moderate exercise and vigorous exercise with regard to platelet function. The opposite effects of these levels of physical intensity have now been well established ${ }^{23-25}$. This evidence suggests that moderate exercise suppresses platelet reactivity and increases fibrinolysis. Conversely, vigorous exercise - especially in untrained individuals - enhances both platelet reactivity and coagulation, whereas it promotes fibrinolysis as well. Aforementioned affects are mediated by several complex mechanisms, including epinephrine, !2-adrenergic receptor expression, von Willebrand factor platelet interaction, GPIIb/IIla interaction, P-selectin expression of platelets and the release of nitric oxide. From this perspective, moderate-intensity activity can be considered safe, whereas vigorous exercise might lead to a prothrombotic state ultimately leading to the formation of a thrombus.

Remarkably, all patients are relatively young. Although the present report is a series of case reports and thus no general conclusions can be drawn, this observation might be related to more frequent engagement of younger patients in rehabilitation programs and more frequent performance of vigorous physical exercise in general by younger people. Consequently, the question arises whether exercise induced events like stent thrombosis are 
unique to young people. However, this is not likely, as several large studies after triggering mechanisms of myocardial infarction do not report this phenomenon. In addition, the young age of these patients is not reflected by their risk profiles and consequent 'biological age'.

\section{Should we discourage exercise for patients with an implanted coronary stent?}

The answer to this question is rather difficult and needs to be further nuanced. Regular physical activity is widely advocated in the general population ${ }^{26}$, because ample evidence suggests that physical exercise delays the development of atherosclerosis, reduces platelet reactivity and decreases the incidence of coronary heart disease (CHD) events. However, it seems that vigorous exercise - not moderate exercise - can also acutely increase the risk of $\mathrm{AMI}$ and SCD. Of special importance in this context is the observation that regular exercise lowers the base-line risk of trigger-induced myocardial infarction ${ }^{18,27,28}$.

In our opinion, patients should be encouraged to perform physical activity after myocardial infarction or stent implantation, because the beneficial effects of exercise training in the secondary prevention of coronary artery disease are well established ${ }^{29}$. However, caution is warranted when patients plan to perform vigorous exercise, especially when untrained. According to the guidelines of the American College of Cardiology (ACC)/American Heart Association $(\mathrm{AHA})^{30}$, these patients should undergo an exercise test under supervised conditions, before starting to perform vigorous exercise.

Furthermore, physicians play an important role in advising the patients to perform physical exercise after stent implantation, adapted to the individual physical condition of the patient. Physicians and patients might make use of standardized indicators of physical activity (e.g. metabolic equivalent, $\mathrm{MET}^{6}$ ) and mobile devices like heart rate monitors to quantify and compare the intensity activity in order to guide in this complex manner.

In conclusion, vigorous exercise might trigger ST. Further research should be directed towards the relationship between stent thrombosis and possible triggering mechanisms. Until then, patients should undergo a thorough medical evaluation prior to increasing vigorous physical activity. Risk-stratification should be based upon risk factors that are associated with the development of a stent thrombosis as well as the intensity of the activity and the level and frequency of regular exercise. 


\section{References}

1. lakovou I, Schmidt T, Bonizzoni E, Ge L, Sangiorgi GM, Stankovic G, Airoldi F, Chieffo A, Montorfano $\mathrm{M}$, Carlino $\mathrm{M}$ et al. Incidence, predictors, and outcome of thrombosis after successful implantation of drug-eluting stents. JAMA 2005;293:2126-2130.

2. Daemen J, Wenaweser P, Tsuchida K, Abrecht L, Vaina S, Morger C, Kukreja N, Juni P, Sianos $G$, Hellige $G$ et al..Early and late coronary stent thrombosis of sirolimus-eluting and paclitaxeleluting stents in routine clinical practice: data from a large two-institutional cohort study. Lancet 2007;369:667-678.

3. van Werkum JW, Heestermans AA, de Korte FI, Kelder JC, Suttorp MJ, Rensing BJ, Zwart $\mathrm{B}$, Brueren BR, Koolen JJ, Dambrink JH et al. Long-term clinical outcome after a first angiographically confirmed coronary stent thrombosis: an analysis of 431 cases. Circulation 2009;119:828-834.

4. de la Torre-Hernandez JM, Alfonso F, Hernandez F, Elizaga J, Sanmartin M, Pinar E, Lozano I, Vazquez JM, Botas J, de Prado AP et al. Drug-eluting stent thrombosis: results from the multicenter Spanish registry ESTROFA (Estudio ESpanol sobre TROmbosis de stents FArmacoactivos). J Am Coll Cardiol 2008;51:986-990.

5. van Werkum JW, Heestermans AA, Zomer AC, Kelder JC, Suttorp MJ, Rensing BJ, Koolen JJ, Brueren BR, Dambrink JH, Hautvast RW et al. Predictors of coronary stent thrombosis: the Dutch Stent Thrombosis Registry. J Am Coll Cardiol 2009;53:1399-1409.

6. Ainsworth BE, Haskell WL, Whitt MC, Irwin ML, Swartz AM, Strath SJ, O'Brien WL, Bassett DR, Jr., Schmitz KH, Emplaincourt PO et al. Compendium of physical activities: an update of activity codes and MET intensities. Med Sci Sports Exerc 2000;32:S498-S504.

7. Cutlip DE, Windecker S, Mehran R, Boam A, Cohen DJ, van Es GA, Steg PG, Morel MA, Mauri L, Vranckx $P$ et al. Clinical end points in coronary stent trials: a case for standardized definitions. Circulation 2007;115:2344-2351.

8. Cutlip DE, Baim DS, Ho KK, Popma JJ, Lansky AJ, Cohen DJ, Carrozza JP, Jr., Chauhan MS, Rodriguez $\mathrm{O}$, Kuntz RE. Stent thrombosis in the modern era: a pooled analysis of multicenter coronary stent clinical trials. Circulation 2001;103:1967-1971.

9. Wenaweser P, Rey C, Eberli FR, Togni M, Tuller D, Locher S, Remondino A, Seiler C, Hess $\mathrm{OM}$, Meier $\mathrm{B}$ et al. Stent thrombosis following bare-metal stent implantation: success of emergency percutaneous coronary intervention and predictors of adverse outcome. Eur Heart J 2005;26:1180-1187.

10. Smit JJ, van 't Hof AW, de Boer MJ, Hoorntje JC, Dambrink JH, Gosselink AT, Ottervanger JP, Kolkman JJ, Suryapranata $\mathrm{H}$. Incidence and predictors of subacute thrombosis in patients undergoing primary angioplasty for an acute myocardial infarction. Thromb Haemost 2006;96:190-195.

11. Virmani R, Guagliumi G, Farb A, Musumeci G, Grieco N, Motta T, Mihalcsik L, Tespili M, Valsecchi $\mathrm{O}$, Kolodgie FD. Localized hypersensitivity and late coronary thrombosis secondary to a sirolimus-eluting stent: should we be cautious? Circulation 2004;109:701-705. 
12. Joner M, Finn AV, Farb A, Mont EK, Kolodgie FD, Ladich E, Kutys R, Skorija K, Gold HK, Virmani R. Pathology of drug-eluting stents in humans: delayed healing and late thrombotic risk. J Am Coll Cardiol 2006;48:193-202.

13. Eisenstein EL, Anstrom KJ, Kong DF, Shaw LK, Tuttle RH, Mark DB, Kramer JM, Harrington RA, Matchar DB, Kandzari DE et al. Clopidogrel use and long-term clinical outcomes after drugeluting stent implantation. JAMA 2007;297:159-168.

14. Cook S, Wenaweser P, Togni M, Billinger M, Morger C, Seiler C, Vogel R, Hess O, Meier B, Windecker $\mathrm{S}$. Incomplete stent apposition and very late stent thrombosis after drug-eluting stent implantation. Circulation 2007;115:2426-2434.

15. Cook S, Ladich E, Nakazawa G, Eshtehardi P, Neidhart M, Vogel R, Togni M, Wenaweser $\mathrm{P}$, Billinger $\mathrm{M}$, Seiler $\mathrm{C}$ et al. Correlation of intravascular ultrasound findings with histopathological analysis of thrombus aspirates in patients with very late drug-eluting stent thrombosis. Circulation 2009;120:391-399.

16. Thompson PD, Franklin BA, Balady GJ, Blair SN, Corrado D, Estes NA, III, Fulton JE, Gordon $N F$, Haskell WL, Link MS et al. Exercise and acute cardiovascular events placing the risks into perspective: a scientific statement from the American Heart Association Council on Nutrition, Physical Activity, and Metabolism and the Council on Clinical Cardiology. Circulation 2007;115:2358-2368.

17. Albert CM, Mittleman MA, Chae CU, Lee IM, Hennekens CH, Manson JE. Triggering of sudden death from cardiac causes by vigorous exertion. N Engl J Med 2000;343:1355-1361.

18. Giri S, Thompson PD, Kiernan FJ, Clive J, Fram DB, Mitchel JF, Hirst JA, McKay RG, Waters DD. Clinical and angiographic characteristics of exertion-related acute myocardial infarction. JAMA 1999;282:1731-1736.

19. Black A, Black MM, Gensini G. Exertion and acute coronary artery injury. Angiology 1975;26:759-783.

20. Hilberg T, Schmidt V, Glaser D, Schammne D, Losche W, Gabriel HH. Platelet activity, sensitivity to agonist, and platelet--leukocyte conjugate formation after long-term exercise. Platelets 2002;13:273-277.

21. Gordon JB, Ganz P, Nabel EG, Fish RD, Zebede J, Mudge GH, Alexander RW, Selwyn AP. Atherosclerosis influences the vasomotor response of epicardial coronary arteries to exercise. $J$ Clin Invest 1989;83:1946-1952.

22. Hilberg T, Prasa D, Sturzebecher J, Glaser D, Gabriel HH. Thrombin potential and thrombin generation after exhaustive exercise. Int J Sports Med 2002;23:500-504.

23. Wang JS, Li YS, Chen JC, Chen YW. Effects of exercise training and deconditioning on platelet aggregation induced by alternating shear stress in men. Arterioscler Thromb Vasc Biol 2005;25:454-460.

24. Wang JS. Exercise prescription and thrombogenesis. J Biomed Sci 2006;13:753-761.

25. Kestin AS, Ellis PA, Barnard MR, Errichetti A, Rosner BA, Michelson AD. Effect of strenuous exercise on platelet activation state and reactivity. Circulation 1993;88:1502-1511. 
26. Haskell WL, Lee IM, Pate RR, Powell KE, Blair SN, Franklin BA, Macera CA, Heath GW, Thompson PD, Bauman A. Physical activity and public health: updated recommendation for adults from the American College of Sports Medicine and the American Heart Association. Circulation 2007;116:1081-1093.

27. Mittleman MA, Maclure M, Tofler GH, Sherwood JB, Goldberg RJ, Muller JE. Triggering of acute myocardial infarction by heavy physical exertion. Protection against triggering by regular exertion. Determinants of Myocardial Infarction Onset Study Investigators. N Engl J Med 1993;329:1677-1683.

28. Willich SN, Lewis M, Lowel H, Arntz HR, Schubert F, Schroder R. Physical exertion as a trigger of acute myocardial infarction. Triggers and Mechanisms of Myocardial Infarction Study Group. N Engl J Med 1993;329:1684-1690.

29. Warburton DE, Nicol CW, Bredin SS. Health benefits of physical activity: the evidence. CMAJ 2006;174:801-809.

30. Gibbons RJ, Balady GJ, Bricker JT, Chaitman BR, Fletcher GF, Froelicher VF, Mark DB, McCallister BD, Mooss AN, O'Reilly MG et al. ACC/AHA 2002 guideline update for exercise testing: summary article: a report of the American College of Cardiology/American Heart Association Task Force on Practice Guidelines (Committee to Update the 1997 Exercise Testing Guidelines). Circulation 2002;106:1883-1892. 


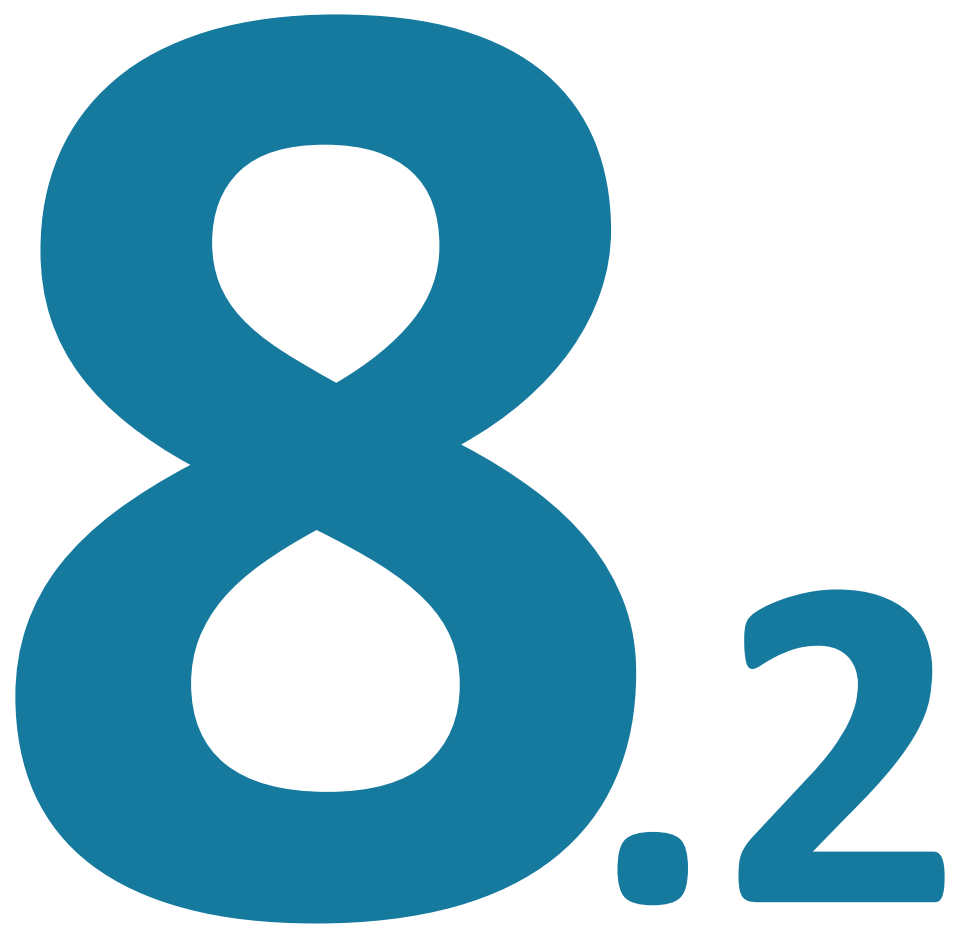




\section{Time does not heal every wound:}

Coronary stent thrombosis of a bare-metal stent more than one decade after its implantation

A.C. Zomer, B. Zwart, J.W. van Werkum, M.J. Suttorp 


\begin{abstract}
In the present report, we describe a unique case of very late stent thrombosis with a bare-metal stent that occurred more than a decade after stent implantation. Potential explanations for the late stent thrombosis are non-compliance to aspirin, late acquired malapposition of the stent, progression of atherosclerosis or in-stent restenosis. In our patient, none of these explanations seems to have played a role. Although the occurrence of (very) late stent thrombosis is not uncommon with drug-eluting stent (DES), it is rather unusual with bare-metal stent (BMS). Nevertheless, cardiologists should be aware of the potential complication of late stent thrombosis, even with bare-metal stents.
\end{abstract}




\section{Introduction}

Coronary stent thrombosis is the major downside of percutaneous coronary intervention and is associated with high morbidity and mortality ${ }^{1-4}$. Stent thrombosis is usually classified according to the time elapsed since implantation. Four different categories are routinely used: acute ( $<24$ hours), subacute ( $>24$ hours and $<30$ days), late- ( $>30$ days and $<1$ year) and very late stent thrombosis (beyond 1 year) ${ }^{5}$.

The introduction of the drug-eluting stents (DES) in 2004 has drastically reduced the incidence of restenosis but recent studies point out that stent thrombosis with DES continues to occur beyond the 1-month time-frame. ${ }^{4,6}$ Although DES have proven their safety and efficacy over a longer period (4 years), it appears that late ST occurs more frequently in DES. Despite the controversy regarding the true incremental risk that is associated with late (beyond 30 days) and very late (beyond 1 year) DES thrombosis, it must be noted that little data is available on the (very) long-term safety of BMS. However, several more recent large studies confirm that late ST occurs in BMS as well, but at a lower rate as compared with DES. ${ }^{7,8}$ The incidence of bare-metal stent (BMS) thrombosis is estimated to be between 1-2\% and it occurs in the majority of cases within the first month after stent implantation. ${ }^{1,2,7,8}$

As we describe in the following case report, even 10 years of uneventful living with a BMS cannot guarantee its patency for a lifetime.

\section{The case}

A 55-year-old man with a history of smoking and hypercholesterolemia was admitted to our hospital because of an inferior-posterior myocardial infarction on November 221995. He was successfully treated with streptokinase and aspirin, which resulted in a complete resolution of the ST-elevations on the electrocardiogram. The maximal CPK/MB was 502/23 $\mathrm{U} / \mathrm{I}$. Echocardiography showed a normal cardiac function and a calculated ejection fraction of $460 \%$. Two weeks later he was brought to the catheterization laboratory because of residual angina pectoris complaints. Coronary angiography revealed a subtotal occlusion of the mid right coronary artery (RCA). Subsequently, he underwent successful $\mathrm{PCl}$ of the mid RCA with the implantation of three AVE stents (Medtronic; all 4.0_18 mm). The final result was without residual stenosis or evidence of dissection. The next day, the patient was discharged under aspirin (100 mg/day), acenocoumarol and statin therapy.

The patient remained asymptomatic for the next 10 years while he was on aspirin and a beta-blocker (acenocoumarol was discontinued in April 1996). 
In November 2005, he was admitted to our hospital because of an acute onset of chest pain. He was transferred to the cathlab for emergency $\mathrm{PCl}$. Angiography revealed a thrombotic occlusion of the stents in the RCA (Figure 1). The thrombotic occlusion was treated with an aspiration-catheter followed by balloon-angioplasty and concomitant glycoprotein IIb/ IIla therapy. Complete ST-resolution was observed at 30 minutes post- $\mathrm{PCl}$ and the maximal CPK/MB-rise was 546/62 U/I (normal CPK 0-175). Echocardiography showed akinesia of the inferior wall and a calculated ejection fraction of $55 \%$. The patient was discharged on day 4. He was prescribed lifelong aspirin, clopidogrel for at least 1 year, a beta-blocker, an ACE inhibitor and a statin.

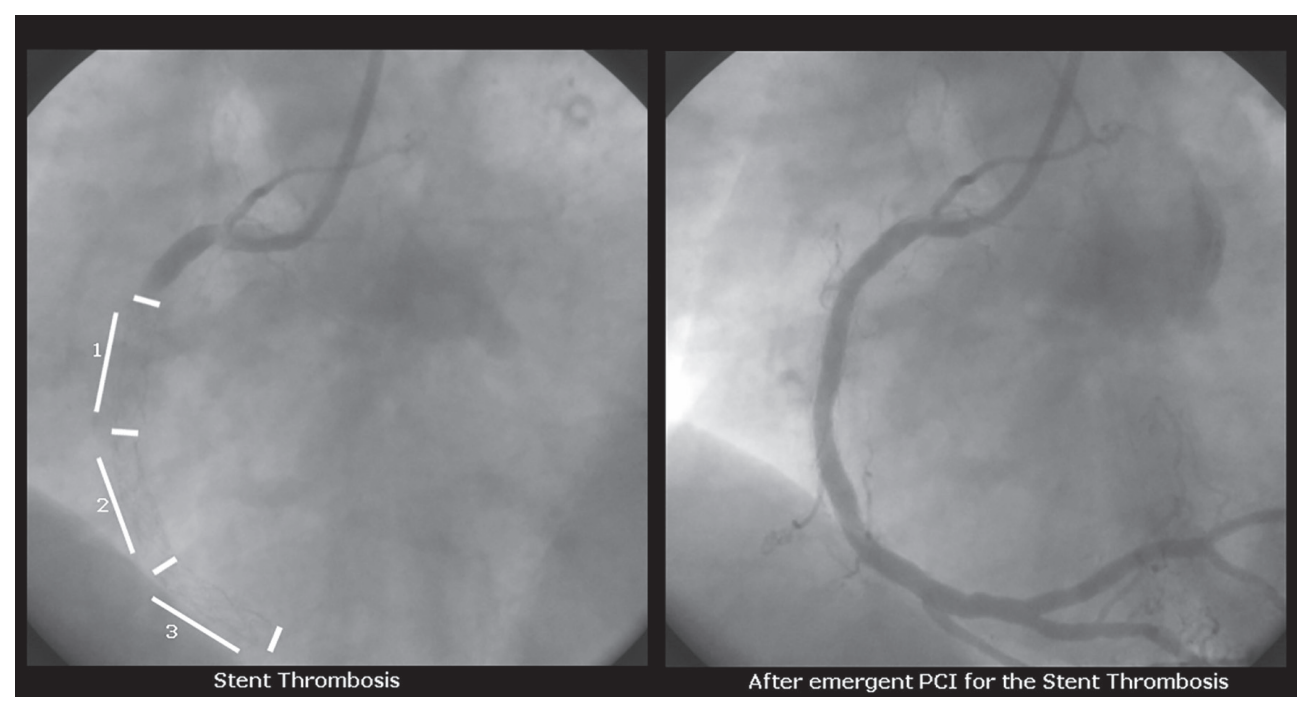

Figure 1:

Coronary angiograms of the patient. The left panel illustrates the right coronary artery (RCA) with the thrombotic occlusion in the AVE stents. The right panel shows the RCA after emergent PCI with aspiration and plain old balloon angioplasty.

Approximately one year later (after cessation of the clopidogrel therapy), the patient was asked to visit our outpatient clinic for a thorough evaluation of his platelet function and his response to aspirin and clopidogrel. Platelet function evaluation was performed by means of "classical" light transmittance aggregometry (using the APACT 4004 aggregometer, LABitec, Germany) before and 6 hours after a $600 \mathrm{mg}$ loading dose of clopidogrel. Adenosine diphosphate (ADP; final concentrations: 5 and $20 \mathrm{mmol} / \mathrm{L}$ ) and arachidonic acid (AA; final concentration: $0.5 \mathrm{mg} / \mathrm{L}$ ) were used as the agonists. Spontaneous aggregation was also recorded. Remarkably, a heightened residual platelet reactivity despite aspirin and clopidogrel therapy was still present (Figure 2$)^{9}$. 

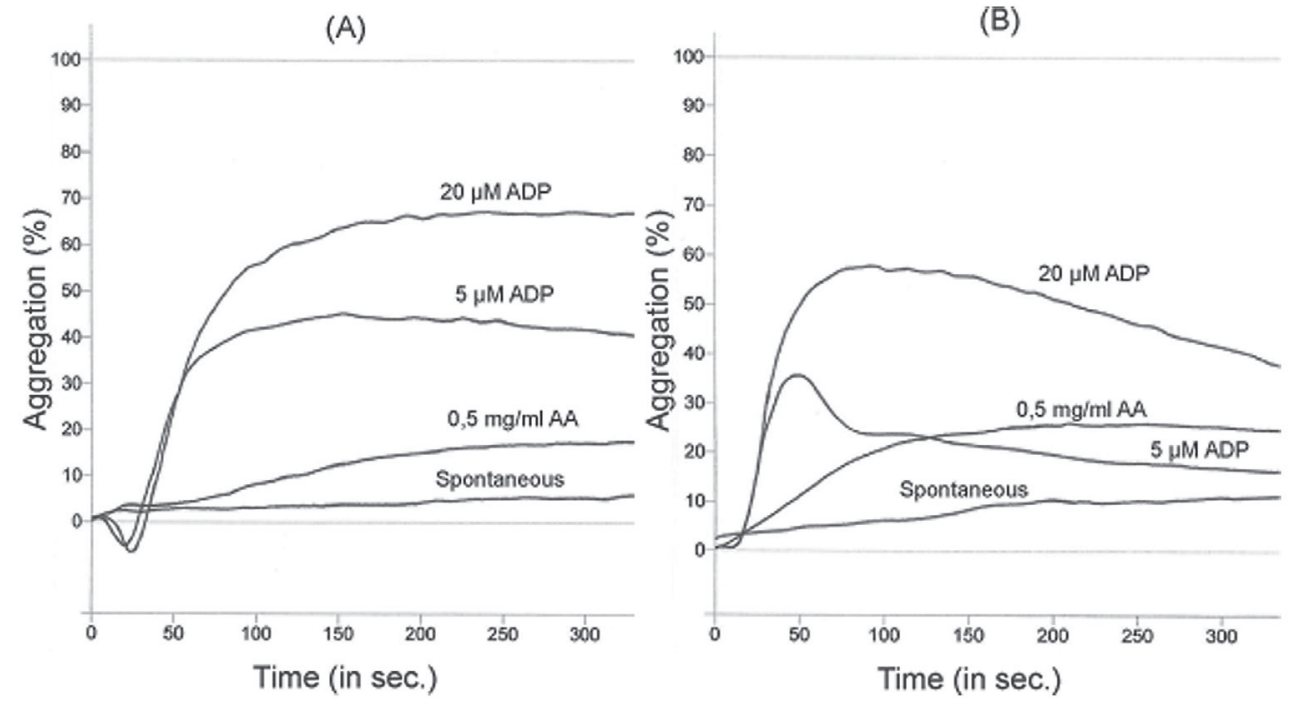

Figure 2:

Light transmission aggregation curves before (left panel) and after (right panel) a 600mg loading dose of clopidogrel. Different agonists ( $5 \mathrm{mmol} / \mathrm{L}$ and $20 \mathrm{mmol} / \mathrm{L} \mathrm{ADP}, 0.5 \mathrm{mg} / \mathrm{ml} \mathrm{AA}$ ) were used to stimulate the platelets. Spontaneous aggregation was also recorded. $A D P=$ adenosine diphosphate. $A A=$ arachidonic acid.

\section{Discussion}

Stent thrombosis is a very serious complication following $\mathrm{PCl}$. Multiple determinants may contribute to the occurrence of a stent thrombosis, including clinical factors (such as diabetes mellitus, renal failure, low ventricular ejection fraction), lesion specific factors (such as total occlusions, bifurcation lesions and calcified lesion), and procedural factors (such as long stents, multiple stent implantation, small stent diameter, residual dissection and complex $\mathrm{PCl}$-procedures) ${ }^{1-3,6,10-12}$. Furthermore, stent thrombosis can be the result of (premature) antiplatelet therapy discontinuation and non-responsiveness to platelet inhibitors. ${ }^{3}$

The possible higher occurrence of very late stent thrombosis with DES as compared to BMS has alarmed the interventional community. "Real world" estimates of its incidence derived from unselected cohort registries varies between 1 and $5 \%$ and it is obvious that these figures are slightly higher than the incidence that was reported in the initial randomized controlled trials with DES versus BMS ${ }^{4,6}$. This observation could be partly explained by the off-label use of DES and its use for more complex lesions. In addition, several specific - for DES only - pathophysiological mechanisms have been suggested to be responsible for very late DES thrombosis, including:

1. delayed endothelialization ${ }^{13}$;

2. (late) incomplete stent malapposition ${ }^{14}$;

3. polymer/drug hypersensitivity ${ }^{15}$; and

4. premature discontinuation of (dual) antiplatelet therapy ${ }^{3,6}$. 
Surprisingly, little data is currently available about the occurrence of very late stent thrombosis with the conventional BMS outside the context of brachytherapy. Moreover, there have been no studies dealing specifically with the incidence of very late bare-metal stent thrombosis.

In the present report, we describe a unique case of very late stent thrombosis with a BMS that occurred more than a decade after the stent implantation. Importantly, no other coronary intervention had taken place in the 10-year interval.

In spite of the heightened platelet reactivity phenotype despite aspirin and clopidogrel, we could not identify any potential explanations for the stent thrombosis in our patient ${ }^{16-18}$. Some data are not available which is a limitation of the present report. Possibly, late acquired malapposition of the stents could have taken place but we did not perform an intravascular ultrasound (IVUS) to exclude or confirm this possibility.

Perhaps, despite overstenting the atherosclerotic lesion, progression of atherosclerosis of the neoendothelium under the BMS could have formed new vulnerable plaques that might have ruptured?

In-stent restenosis is very unlikely to have played a role, as the patient was active and asymptomatic until the acute myocardial infarction occurred. In addition, in-stent neointima proliferation was only moderate on visual estimate (maximal stenosis $30 \%$ ). The possible reason for this extreme late BMS thrombotic occlusion therefore remains unknown. Nevertheless, this case clearly demonstrates that BMS can also occlude late. Therefore, although very late thrombosis is supposed to occur more frequently after DES placement, it may be unrelated to DES-related substances such as polymers and/or drugs. Proper randomized data from long term follow-up after DES and BMS placement have to demonstrate the true incidence of very late stent thrombosis in patients treated with DES and/or BMS. 


\section{References}

1. Cutlip DE, Baim DS, Ho KK et al. Stent thrombosis in the modern era: a pooled analysis of multicenter coronary stent clinical trials. Circulation. 2001;103:1967-1971.

2. Wenaweser $P, \operatorname{Rey} C$, Eberli FR et al. Stent thrombosis following bare-metal stent implantation: success of emergency percutaneous coronary intervention and predictors of adverse outcome. Eur Heart J. 2005;26:1180-1187.

3. lakovou I, Schmidt T, Bonizzoni E et al. Incidence, predictors, and outcome of thrombosis after successful implantation of drug-eluting stents. JAMA. 2005;293:2126-2130.

4. de la Torre-Hernandez JM, Alfonso F, Hernandez F et al. Drug-eluting stent thrombosis: results from the multicenter Spanish registry ESTROFA (Estudio ESpanol sobre TROmbosis de stents FArmacoactivos). J Am Coll Cardiol. 2008;51:986-990.

5. Cutlip DE, Windecker S, Mehran R et al. Clinical end points in coronary stent trials: a case for standardized definitions. Circulation. 2007;115:2344-2351.

6. Daemen J, Wenaweser P, Tsuchida K et al. Early and late coronary stent thrombosis of sirolimus-eluting and paclitaxel-eluting stents in routine clinical practice: data from a large twoinstitutional cohort study. Lancet. 2007;369:667-678.

7. Kastrati A, Mehilli J, Pache J et al. Analysis of 14 trials comparing sirolimus-eluting stents with bare-metal stents. N Engl J Med. 2007;356:1030-1039.

8. Pfisterer M, Brunner-La Rocca HP, Buser PT et al. Late clinical events after clopidogrel discontinuation may limit the benefit of drug-eluting stents: an observational study of drugeluting versus bare-metal stents. J Am Coll Cardiol. 2006;48:2584-2591.

9. Samara WM, Bliden KP, Tantry US, Gurbel PA. The difference between clopidogrel responsiveness and posttreatment platelet reactivity. Thromb Res. 2005;115:89-94.

10. van Werkum JW, Heestermans AA, Zomer AC et al. Predictors of coronary stent thrombosis: the Dutch Stent Thrombosis Registry. J Am Coll Cardiol. 2009;53:1399-1409.

11. Moussa I, Di MC, Reimers B, Akiyama T, Tobis J, Colombo A. Subacute stent thrombosis in the era of intravascular ultrasound-guided coronary stenting without anticoagulation: frequency, predictors and clinical outcome. J Am Coll Cardiol. 1997;29:6-12.

12. Baran KW, Lasala JM, Cox DA et al. A clinical risk score for prediction of stent thrombosis. Am J Cardiol. 2008;102:541-545.

13. Joner M, Finn AV, Farb A et al. Pathology of drug-eluting stents in humans: delayed healing and late thrombotic risk. J Am Coll Cardiol. 2006;48:193-202.

14. Cook S, Wenaweser $P$, Togni $M$ et al. Incomplete stent apposition and very late stent thrombosis after drug-eluting stent implantation. Circulation. 2007;115:2426-2434.

15. Virmani R, Guagliumi G, Farb A et al. Localized hypersensitivity and late coronary thrombosis secondary to a sirolimus-eluting stent: should we be cautious? Circulation. 2004;109:701-705.

16. Geisler $\mathrm{T}$, Langer $\mathrm{H}$, Wydymus $\mathrm{M}$ et al. Low response to clopidogrel is associated with cardiovascular outcome after coronary stent implantation. Eur Heart J. 2006;27:2420-2425. 
17. Buonamici P, Marcucci R, Migliorini A et al. Impact of platelet reactivity after clopidogrel administration on drug-eluting stent thrombosis. J Am Coll Cardiol. 2007;49:2312-2317.

18. Gum PA, Kottke-Marchant K, Welsh PA, White J, Topol EJ. A prospective, blinded determination of the natural history of aspirin resistance among stable patients with cardiovascular disease. J Am Coll Cardiol. 2003;41:961-965. 
Time does not heal every wound: Coronary stent thrombosis of a bare-metal stent more than one decade after its implantation | 125 


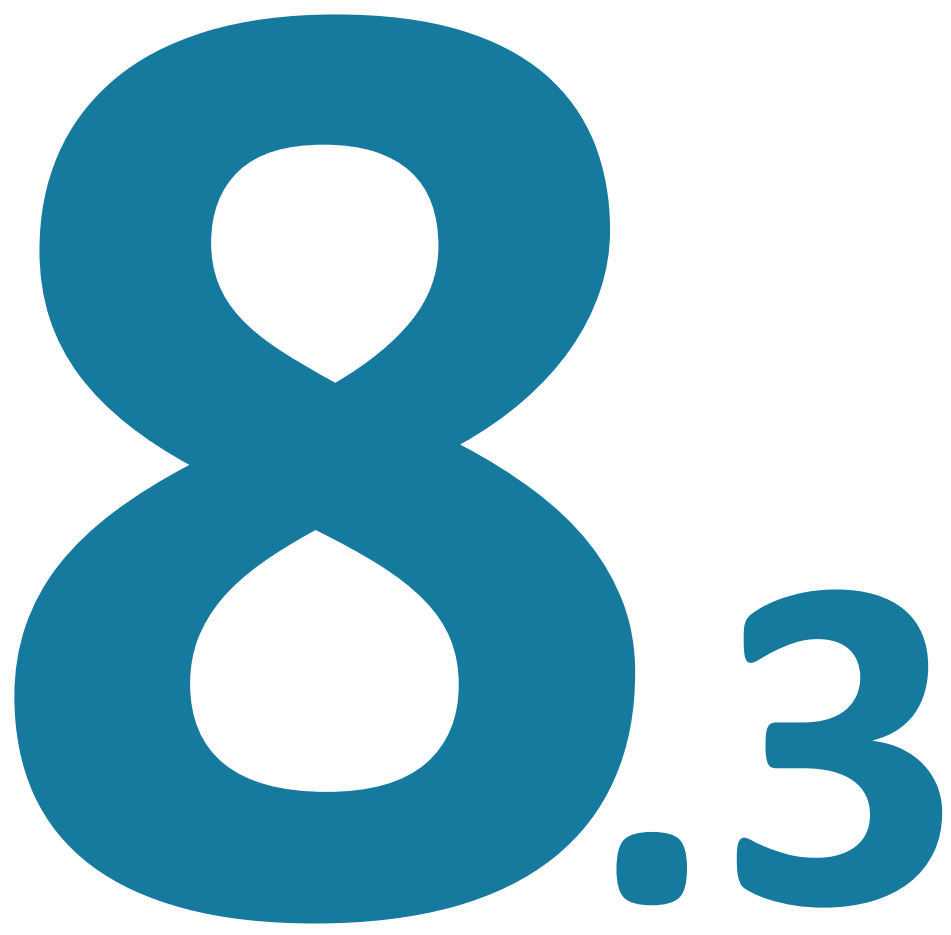




\section{3-Dimensional Optical Coherence Tomography Imaging in Early Coronary Stent Thrombosis}

K. Teeuwen, B. Zwart, J.W. van Werkum, M. Joner, J.M. ten Berg 

A 45-year-old man presented to our catheterization laboratory with an acute anterior ST-segment elevation myocardial infarction caused by a proximal occlusion of the left descending artery. Two bare-metal stents were implanted with good angiographic results. Besides aspirin and clopidogrel, the patient was treated with abciximab intravenously because of the large thrombus load.

Eight days later, the patient re-experienced severe chest pain, and emergent coronary angiography showed an acute thrombotic occlusion of the recently implanted bare-metal stents. Optical coherence tomography (OCT) was performed after coronary flow was reestablished by thrombosuction. The OCT pullback revealed the underlying pathophysiological mechanism that may have caused the subacute stent thrombosis: severe undersizing of the implanted baremetal stents with a large residual thrombus on the naked incomplete apposed stent struts (Fig. 1). After OCT pullback, repeated high-pressure balloon inflations were performed resulting in Thrombolysis In Myocardial Infarction flow grade 3.

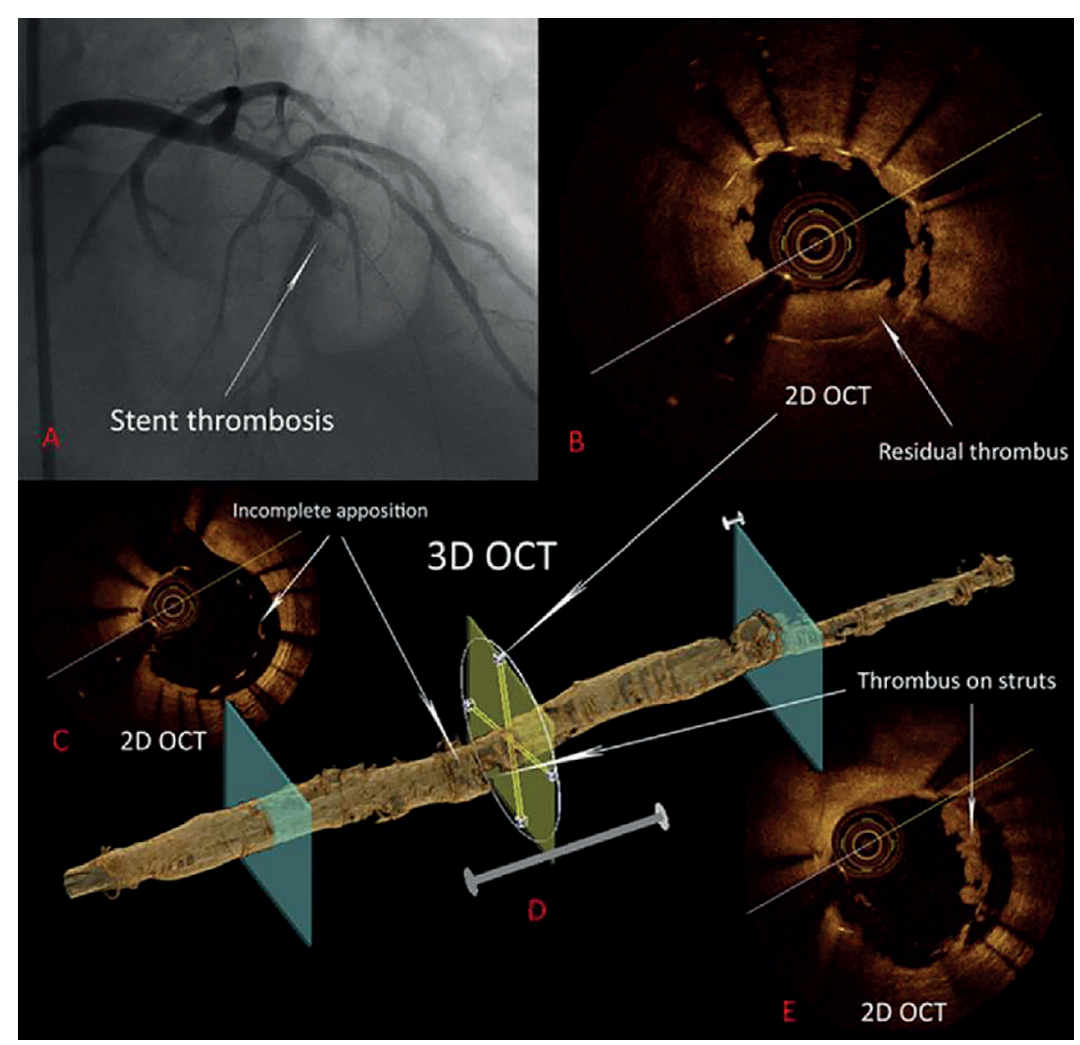

Figure 1: 3D OCT ST.

(A) Coronary angiography: stent thrombosis (ST). (B) 2-dimensional (2D) optical coherence tomography (OCT): ST with residual thrombus on stent struts. (C) 2D OCT: undersized stent with incomplete stent apposition. (D) 3-dimensional (3D) OCT: in the middle, a cavity is seen that correlates to E at 2D OCT. The cavity is caused by laser reflections on the thrombus attached to the incomplete malapposed stent struts. (E) 2D OCT: thrombus on stent struts. 
Three-dimensional (3D) OCT is a novel technique enabling 3D imaging of the intracoronary lumen. In the present case, the 3D image shows a central cavity, which correlates to thrombus on the incomplete apposed stent struts visualized on 2-dimensional OCT. In the near future, 3D OCT may be a useful tool to guide complex coronary interventions. Further research is imperative to assess the clinical relevance of 3D OCT. 


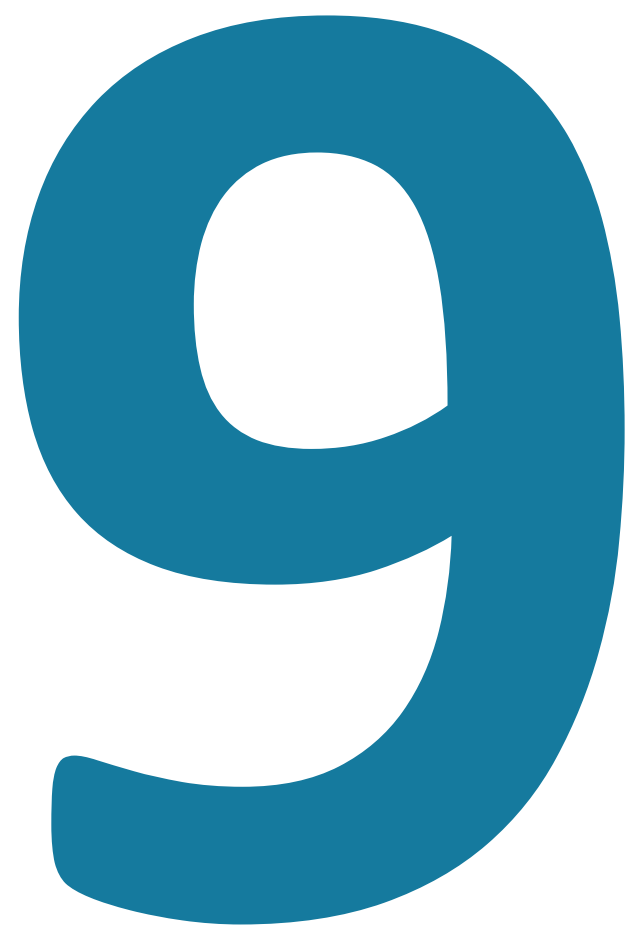




\section{Monitoring antiplatelet therapy in clinical practice:}

value and possibilities 


\section{Abstract}

This paper reviews the concepts of high and low on-treatment platelet reactivity (for aspirin and $\mathrm{P} 2 \mathrm{Y} 12$-inhibitors) and its relation with clinical outcomes. The available platelet function tests and the indications for their use are discussed. 


\section{Introduction}

Aspirin is the oldest antiplatelet drug and is considered as the cornerstone of the treatment of arterial thrombosis. Aspirin prevents platelet activation by irreversibly blocking platelet cyclo-oxygenase 1 (COX1) enzyme and hence preventing synthesis of Thromboxane. Ticlopidine, a P2Y12-inhibitor in the class of thienopyridines was introduced in 1991. It was used as adjuvant treatment modality in acute coronary syndrome (ACS). P2Y12-inhibitors prevent adenosine-diphosphate (ATP) mediated platelet activation by binding to the platelets P2Y12-receptor. Not long after the introduction of ticlopidine, it was succeeded by clopidogrel which had a similar effectivity with fewer side effects. Dual antiplatelet therapy (DAPT) with aspirin and clopidogrel proved to be superior as compared to aspirin monotherapy in preventing atherothrombotic events such as myocardial infarction (MI) and stent thrombosis (ST). Moreover, clopidogrel is now used in the treatment of cerebrovascular accidents and peripheral artery disease.

In the last decade, the P2Y12-inhibitors ticagrelor and prasugrel were introduced, which were both superior to clopidogrel in terms of ischaemic outcomes, but at the cost of a higher bleeding risk. These more potent drugs are now standard care in the treatment of ACS, whereas clopidogrel is still preferred in percutaneous coronary intervention ( $\mathrm{PCI})$ for stable coronary artery disease.

The use of more potent P2Y12-inhibitors has illustrated the delicate balance of thrombosis versus bleeding. In recent years, multiple tests have been developed to monitor (residual) platelet reactivity. This review article discusses indications and possibilities for platelet function testing (PFT) in clinical practice.

\section{Available platelet function tests}

The pharmacodynamic response to the aforementioned antiplatelet drugs have shown considerable variability in clinical practice resulting in variability in the degree of antiplatelet drug response. An impaired response to the treatment of antiplatelet drugs has been named "resistance" or, more accurately, high on-treatment platelet reactivity (HPR). On the other hand, low residual platelet reactivity (low on-treatment platelet reactivity; LPR) has been described as well and correlates with higher risk of bleeding. Multiple platelet function tests are available and the methods for assessing platelet function vary between these tests. Some tests assess the process of platelet aggregation itself, whereas other tests measure a surrogate for platelet aggregation, such as changes in the P2Y12-receptor-pathway.

An overview will be presented of the most commonly used assays. It must be noted that there is a moderate correlation between the different tests and direct comparisons between 
these tests are scarce. In this overview, we will focus on the assays measuring the response to P2Y12-inhibitors, as they are considered most reliable and have been validated well. The following tests will be discussed: light transmittance aggregometry (LTA), VerifyNow $C$, the Multiplate $($ and the Vasodilator-Stimulated Phosphoprotein (VASP) Phosphorylation Assay. Commonly used cut-off values have been described in relevant literature, although optimal cut-offs vary between studies and have changed throughout the years. Table 1 provides an overview of the different tests and their characteristics.

Table 1:

\begin{tabular}{lllll}
\hline Method & Sample type & Correlation with LTA & Practical considerations & Costs \\
\hline LTA & Plasma & - & Rather complex and labor intensive & Low \\
VerifyNow & Whole blood & Very good & Very easy to use & High \\
Multiplate & Whole blood & Good & Easy to use & Moderate \\
VASP & Whole blood & Good & Rather complex & High \\
\hline
\end{tabular}

\section{LTA}

Classical light transmittance aggregometry (LTA) has been considered the gold standard for measuring platelet reactivity. LTA uses platelet rich plasma and is based on the simple principle of optical detection. As platelet aggregation occurs (in response to an agonist), the sample becomes more translucent and light transmission increases. Platelet aggregation is expressed from $0 \%$ to $100 \%$ (the latter corresponding to maximal platelet aggregation), or as poor, moderate and good. With the use of various agonists (such as $A D P$, epinephrine and collagen), various activation pathways can be monitored. The use of different ADP concentrations has been described in previous studies. When testing the efficacy of antiplatelet drugs, it is common not to use the lower ADP concentrations (lower concentrations are used in the diagnostics of bleeding disorders). In clinical practice, either $5 \mu \mathrm{M}$ or $20 \mu \mathrm{M}$ ADP are used. In the POPular study, comparable results were obtained with using either $5 \mu \mathrm{M}$ or $20 \mu \mathrm{M}$ ADP, although slightly different cut-offs (ROC-AUC 0.63 and 0.62 , respectively). One drawback of LTA is the lack of standardization between laboratories. Furthermore, it is a rather complex and therefore a labor-intensive method.

\section{VerifyNow}

The VerifyNow system (Accumetrics, San Diego, California, US) is a point-of-care system. Similar to LTA, it is based on light transmittance but uses whole blood. The VerifyNow system is a closed system and therefore does not need additional blood handling. Three cartridges are available in order to test the effect of either aspirin, P2Y12-inhibitors or alpha2b-beta3 (Glycoprotein Ilbllla antagonists (GPI). The agonists used in each respective assay are arachidon acid, ADP and thrombin activating peptide (TRAP), respectively. Tests results are reported as "reaction units" (aspirin reaction units (ARU), platelet reaction units (PRU) and platelet aggregation units (PAU), respectively) and higher values correspond inversely 
to the degree of platelet aggregation. The VerifyNow is considered a reliable test which corresponds well to LTA. Moreover, it is a user-friendly test and therefore very suitable in clinical practice.

\section{Multiplate}

The principle of Multiplate is based on impedance platelet aggregometry, i.e. it measures increases in electrical resistance (impedance). Activated platelets attach to two independent sensors in the cuvette, leading to an increase in impedance. Multiplate uses whole blood and, depending on the used agonist, the effect of either aspirin (ASPI-test) or P2Y12inhibitors (ADP-test) can be monitored. Results are expressed as "arbitrary aggregation units" (AU). Multiplate has been shown to provide valuable prognostic information in clopidogrel treated patients. It correlates well to LTA, but only moderate with the VerifyNow assay. Multiplate requires slightly more skill and training in clinical practice, but at a lower cost than the VerifyNow system.

\section{Vasodilator-Stimulated Phosphoprotein Phosphorylation Assay (VASP)}

The vasodilator-stimulated phosphoprotein is an intracellular regulatory protein. Under resting conditions, VASP is not phosphorylated, but when the P2Y12-receptors are activated by $A D P$, the phosphoprotein becomes phosphorylated which in turn activates the Gpllbllla receptor on the platelet surface. Flow cytometry determines the degree of phosphorylation and provides an indirect estimation of the degree of $\mathrm{P} 2 \mathrm{Y} 12$-inhibition. As the test is restricted to the use of P2Y12-inhibitors, it can be used even in the presence of GPI. Although the test correlates well to LTA, it demands specific knowledge and specialized staff. Therefore, it use in clinical practice is limited. A specific advantage of the VASP assay is that the test can be executed at a later time point.

\section{Variability in the response to aspirin and clopidogrel}

The prevalence of HPR for patients treated with aspirin has been estimated in previous studies to be between 5 and $65 \%$, depending on the used methods and study population. However, many studies assessed predominantly non-COX1-specifix platelet reactivity. However, platelets possess COX2 to a much lesser extent than COX1. Moreover, aspirin primary targets COX1 and targets COX2 only in much higher doses. Monitoring platelet reactivity in aspirin treated patients therefore often yields non-specific results and overestimated the prevalence of aspirin HPR, whereas the assays specifically monitoring COX1 demonstrate a consistent platelet inhibitory effect of aspirin. Therefore, it is now believed that true 'aspirin resistance' is practically non-existent. Consequently, in clinical practice, there is no role for response to aspirin and it is not recommended by the guidelines. Measuring platelet reactivity in aspirin treated patients will therefore no further be discussed. 
The variability in the response to clopidogrel, however, has been documented extensively and consistently. The prevalence of HPR is estimated to be around $25 \%$ and therefore a substantial proportion of clopidogrel treated patients exhibit HPR. Multiple studies have demonstrated an association with (recurrent) atherothrombotic events in ACS patients and patients who underwent PCI. LPR has been shown to be clinically relevant as well and Sibbing et al. showed a threefold increase associated with LPR in a cohort of 2,533 PCl.

The variability in P2Y12-inhibition with clopidogrel can be explained by the fact that clopidogrel is a prodrug which has to be converted to an active metabolite. This metabolization process takes place in the liver by the cytochrome-P450-system in two steps involving the CYP2C19-enzym. Various genetic polymorphisms have been documented. The 'loss-offunction'-alleles CYP2C19*2 and CYP2C19*3 are most prevalent and these polymorphisms have been independently associated with ischemic outcomes. On the other hand, the 'gainof-function'-allele CYP2C19*17 is associated with an increased metabolism of clopidogrel and therefore a lower platelet reactivity.

Variability in platelet reactivity with ticagrelor and prasugrel is far less prevalent than with clopidogrel. Although prasugrel is a prodrug as well which needs to undergo CYP-mediated biotransformation, it only needs one activation step. On the other hand, ticagrelor has instantaneous biological antiplatelet activity and does not need transformation. In a recent study in patients who were switched from clopidogrel to prasugrel or ticagrelor, HPR was found in under $15 \%$ of patients. On the other hand, LPR according to conventional definitions, appears to be more prevalent than with clopidogrel. Both prasugrel and ticagrelor are more effective in preventing ischaemic events than clopidogrel, but at the cost of an increase in bleeding.

\section{Indications and evidence for the use of platelet function tests in clinical practice}

Both HPR and LPR are prevalent and multiple studies have confirmed the prognostic value of platelet function testing (PFT) with ischaemic and bleeding outcomes, although hampered by standardization of cut-offs for HPR and LPR. Based on these strong prognostic associations, it seems reasonable to determine an individual treatment strategy based on PFT, with the aim of balancing the thrombotic and bleeding risk in the individual patient. In studies, this has been referred to as the therapeutic window between HPR and LPR. Several studies in ACS patients and patients undergoing PCI have investigated whether the use of PFT as standard care improves outcomes (in ischaemic and bleeding terms). Although smaller studies initially suggested that individualizing treatment based on PFT could improve (ischaemic) outcomes, subsequent larger and randomized controlled studies could not demonstrate a benefit. Although most studies did show satisfactory results with regard to platelet aggregation, this did not translate into clinical outcomes (Table 2). 


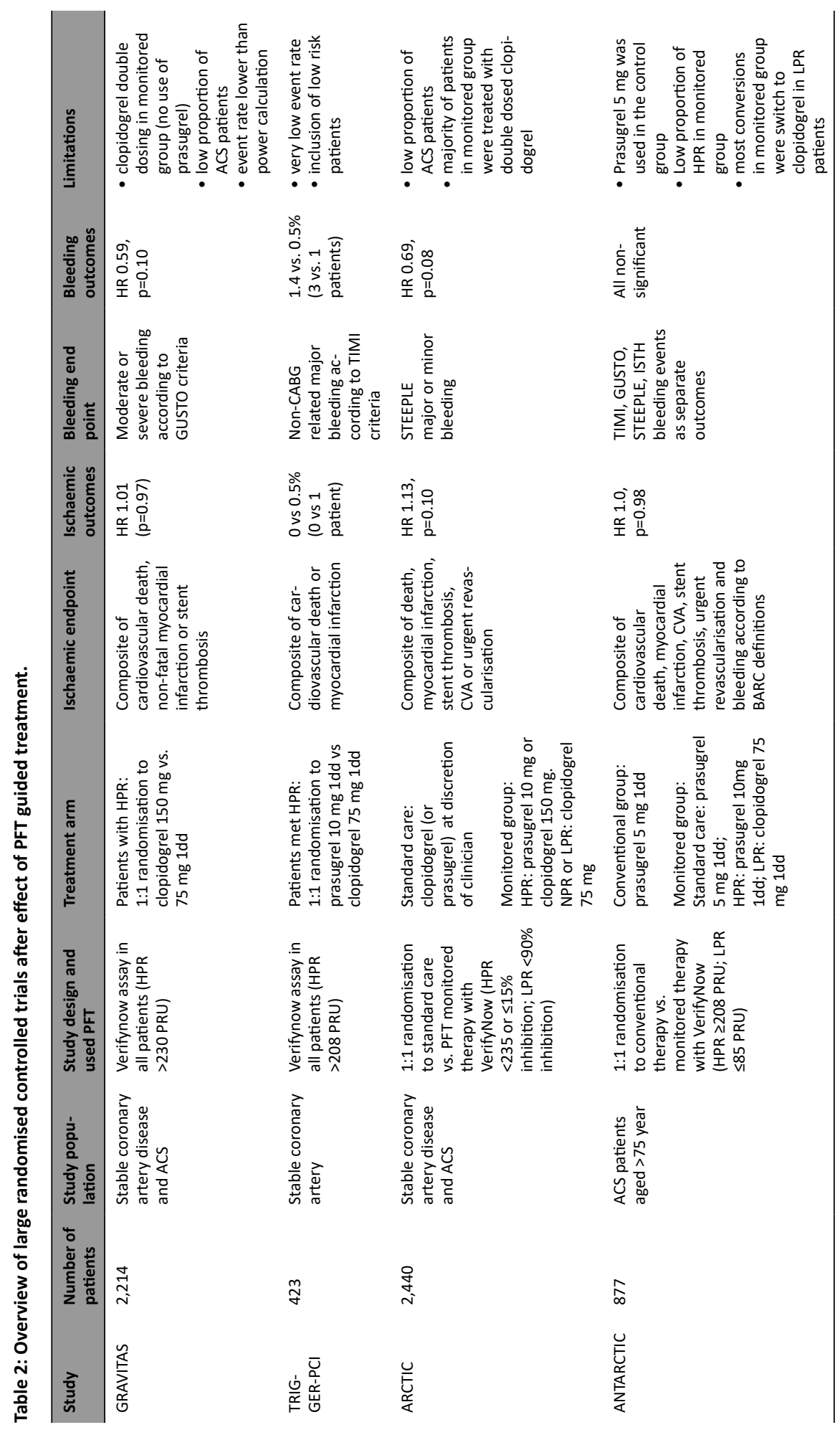


However, these studies yielded some important insights, which at the same time emphasized the limitations of these studies. First, most studies included low-risk patients ( $\mathrm{PCl}$ for stable angina or with a low proportion of ACS patients), whereas the results suggested that its high-risk patients (e.g. diabetes, three-vessel disease or patients with high bleeding risk) who might benefit most from a personalized strategy. Furthermore, most studies increased clopidogrel dosing if HPR was found, rather than switching patients to the more potent P2Y12-inhibitors prasugrel or ticagrelor, which is nowadays recommended by guidelines.

Hence, routine use of PFT in all patients is not indicated, but individual patients with high bleeding and/or ischaemic risk (or risk of stent thrombosis) might benefit by a PFT guided treatment strategy.

Another patient group in which PFT might be beneficial, is represented by DAPT treated patients undergoing (cardiac) surgery. The TARGET-CABG study showed that PFT guided timing of cardiac surgery yielded a $50 \%$ reduction in waiting time for the operation, as compared to standard discontinuation regimes. Although clinical outcomes in these studies were similar, this is an important finding, because these patients can often have instable symptoms and urgent surgery is therefore desirable.

In summary, routine PFT in all patients has not been demonstrated to be beneficial. PFT can, however, be useful in specific patient groups or for specific indications:

- Patients with stent thrombosis or other recurrent thrombotic events while on DAPT treatment

- $\quad$ Patients with significant bleeding while on DAPT treatment

- Patients treated with DAPT with both high ischaemic and high bleeding risk in whom it is desirable to balance these risks

- $\quad$ Patients treated with a P2Y12-inhibitor who need to undergo urgent (cardiac) surgery in whom timing of surgery can be determined by platelet function testing.

\section{Conclusion}

High on-treatment platelet reactivity is seen in approximately $25 \%$ of clopidogrel treated patients, but to a much lesser extent in patients treated with ticagrelor or prasugrel. On the other hand, low on-treatment residual platelet reactivity is more prevalent with ticagrelor and prasugrel. A consistent relation has been observed between HPR and LPR and adverse ischaemic and bleeding events, respectively. However, no benefit of routine PFT guided adjustment of therapy could be demonstrated. The use of PFT can be useful in selected subgroups such as high risk subgroups and in determining the optimal timing of (cardiac) surgery after interruption of antiplatelet therapy. 


\section{References}

1. Maree AO, Fitzgerald DJ. Variable platelet response to aspirin and clopidogrel in atherothrombotic disease. Circulation 2007 Apr 24,;115(16):2196-2207.

2. Leon MB, Baim DS, Popma JJ, Gordon PC, Cutlip DE, Ho KK, et al. A clinical trial comparing three antithrombotic-drug regimens after coronary-artery stenting. Stent Anticoagulation Restenosis Study Investigators. N Engl J Med 1998 Dec 03,;339(23):1665-1671.

3. Taniuchi M, Kurz HI, Lasala JM. Randomized comparison of ticlopidine and clopidogrel after intracoronary stent implantation in a broad patient population. Circulation $2001 \mathrm{Jul}$ 31,;104(5):539-543.

4. Authors/Task Fm, Windecker S, Kolh P, Alfonso F, Collet JP, Cremer J, et al. 2014 ESC/EACTS Guidelines on myocardial revascularization: The Task Force on Myocardial Revascularization of the European Society of Cardiology (ESC) and the European Association for Cardio-Thoracic Surgery (EACTS)Developed with the special contribution of the European Association of Percutaneous Cardiovascular Interventions (EAPCI). Eur Heart J 2014 Oct 1;35(37):2541-2619.

5. Roffi M, Patrono C, Collet JP, Mueller C, Valgimigli M, Andreotti F, et al. 2015 ESC Guidelines for the management of acute coronary syndromes in patients presenting without persistent STsegment elevation: Task Force for the Management of Acute Coronary Syndromes in Patients Presenting without Persistent ST-Segment Elevation of the European Society of Cardiology (ESC). Eur Heart J 2016 Jan 14;37(3):267-315.

6. Sibbing D, Steinhubl SR, Schulz S, Schömig A, Kastrati A. Platelet aggregation and its association with stent thrombosis and bleeding in clopidogrel-treated patients: initial evidence of a therapeutic window. J Am Coll Cardiol 2010 Jul 20,;56(4):317-318.

7. Aradi D, Collet J, Mair J, Plebani M, Merkely B, Jaffe AS, et al. Platelet function testing in acute cardiac care - is there a role for prediction or prevention of stent thrombosis and bleeding? Thromb Haemost 2015 Feb;113(2):221-230.

8. Tantry US, Bonello L, Aradi D, Price MJ, Jeong Y, Angiolillo DJ, et al. Consensus and update on the definition of on-treatment platelet reactivity to adenosine diphosphate associated with ischemia and bleeding. J Am Coll Cardiol 2013 Dec 17,;62(24):2261-2273.

9. Kovács EG, Katona E, Bereczky Z, Homoródi N, Balogh L, Tóth E, et al. New direct and indirect methods for the detection of cyclooxygenase 1 acetylation by aspirin; the lack of aspirin resistance among healthy individuals. Thromb Res 2013 Apr;131(4):320-324.

10. Orme R, Judge HM, Storey RF. Monitoring Antiplatelet Therapy. Semin Thromb Hemost 2017 Apr;43(3):311-319.

11. Janssen PWA, ten Berg JM. Platelet function testing and tailored antiplatelet therapy. J Cardiovasc Transl Res 2013 Jun;6(3):316-328.

12. Bouman HJ, Parlak E, van Werkum JW, Breet NJ, ten Cate H, Hackeng CM, et al. Which platelet function test is suitable to monitor clopidogrel responsiveness? A pharmacokinetic analysis on the active metabolite of clopidogrel. J Thromb Haemost 2010 Mar;8(3):482-488. 
13. Consuegra-Sánchez L, López-Palop R, Cano P, Carrillo P, Picó F, Villegas M, et al. Assessment of high on-treatment platelet reactivity in patients with ischemic heart disease: concordance between the Multiplate and VerifyNow assays. J Thromb Haemost 2013 Feb;11(2):379-381.

14. Combescure C, Fontana P, Mallouk N, Berdague P, Labruyere C, Barazer I, et al. Clinical implications of clopidogrel non-response in cardiovascular patients: a systematic review and meta-analysis. J Thromb Haemost 2010 May;8(5):923-933.

15. Breet NJ, van Werkum JW, Bouman HJ, Kelder JC, Ruven HJT, Bal ET, et al. Comparison of platelet function tests in predicting clinical outcome in patients undergoing coronary stent implantation. JAMA 2010 Feb 24,;303(8):754-762.

16. Sibbing D, Steinhubl SR, Schulz S, Schömig A, Kastrati A. Platelet aggregation and its association with stent thrombosis and bleeding in clopidogrel-treated patients: initial evidence of a therapeutic window. J Am Coll Cardiol 2010 Jul 20,;56(4):317-318.

17. Mega JL, Close SL, Wiviott SD, Shen L, Hockett RD, Brandt JT, et al. Cytochrome p-450 polymorphisms and response to clopidogrel. N Engl J Med 2009 Jan 22,;360(4):354-362.

18. Rollini F, Franchi F, Cho JR, DeGroat C, Bhatti M, Muniz-Lozano A, et al. A head-to-head pharmacodynamic comparison of prasugrel vs. ticagrelor after switching from clopidogrel in patients with coronary artery disease: results of a prospective randomized study. Eur Heart J 2016 Sep 14,;37(35):2722-2730.

19. Grosdidier C, Quilici J, Loosveld M, Camoin L, Moro PJ, Saut N, et al. Effect of CYP2C19*2 and *17 genetic variants on platelet response to clopidogrel and prasugrel maintenance dose and relation to bleeding complications. Am J Cardiol 2013 Apr 01,;111(7):985-990.

20. Hazarbasanov D, Velchev V, Finkov B, Postadjian A, Kostov E, Rifai N, et al. Tailoring clopidogrel dose according to multiple electrode aggregometry decreases the rate of ischemic complications after percutaneous coronary intervention. J Thromb Thrombolysis 2012 Jul;34(1):85-90.

21. Siller-Matula JM, Francesconi M, Dechant C, Jilma B, Maurer G, Delle-Karth G, et al. Personalized antiplatelet treatment after percutaneous coronary intervention: the MADONNA study. Int J Cardiol 2013 Sep 01,;167(5):2018-2023.

22. Siller-Matula JM, Jilma B. Why have studies of tailored anti-platelet therapy failed so far? Thromb Haemost 2013 Oct;110(4):628-631.

23. Cayla G, Cuisset T, Silvain J, Leclercq F, Manzo-Silberman S, Saint-Etienne C, et al. Platelet function monitoring to adjust antiplatelet therapy in elderly patients stented for an acute coronary syndrome (ANTARCTIC): an open-label, blinded-endpoint, randomised controlled superiority trial. Lancet 2016 Oct 22,;388(10055):2015-2022.

24. Godschalk TC, Willemsen LM, Zwart B, Bergmeijer TO, Janssen PWA, Kelder JC, et al. Effect of Tailored Antiplatelet Therapy to Reduce Recurrent Stent Thrombosis and Cardiac Death After a First Episode of Stent Thrombosis. Am J Cardiol 2017 Feb 27,.

25. Mahla E, Suarez TA, Bliden KP, Rehak P, Metzler H, Sequeira AJ, et al. Platelet function measurement-based strategy to reduce bleeding and waiting time in clopidogrel-treated patients undergoing coronary artery bypass graft surgery: the timing based on platelet 
function strategy to reduce clopidogrel-associated bleeding related to CABG (TARGET-CABG) study. Circ Cardiovasc Interv 2012 Apr;5(2):261-269. 
CHAPTER
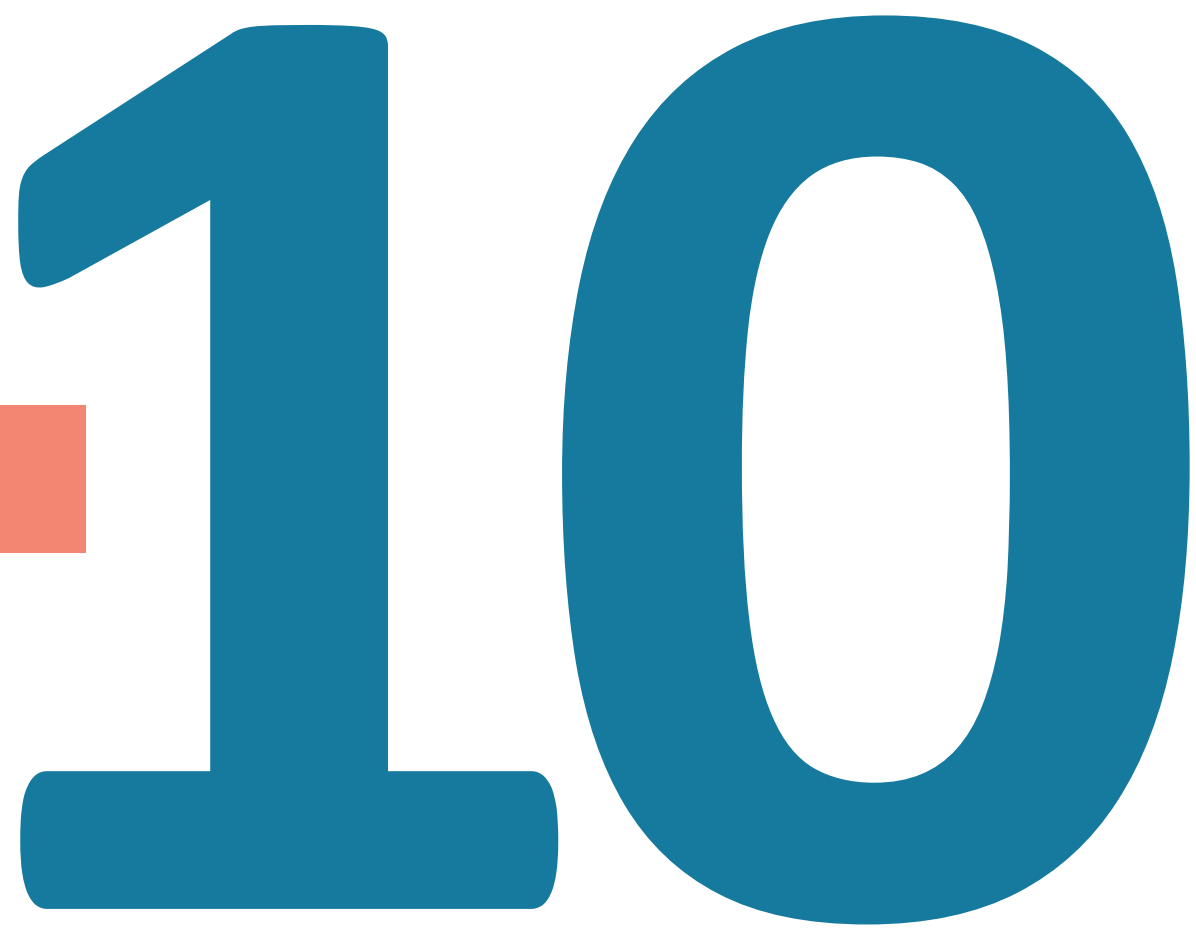


\section{Measuring High on-treatment Platelet Reactivity in clinical practice}

Should we use a panel of platelet function tests?

B. Zwart, T.C. Godschalk, K. Zheng, J. Denteneer, J.C. Kelder, J.M. ten Berg 


\section{Abstract}

\section{Background:}

High on-treatment platelet reactivity (HPR) on P2Y12-inhibitors in patients treated with dual antiplatelet therapy is strongly associated with adverse ischaemic events. Studies have shown conflicting results with regard to the correlation and agreement between the different tests. Several assays are available to establish HPR. A composite advice based on more than one test might be a better way to identify HPR patients.

\section{Objectives:}

To compare HPR rates and agreement between individual platelet function tests and a panel of three tests.

\section{Methods:}

In our large $\mathrm{PCl}$ center, all patients who suffered a stent thrombosis were invited back to a dedicated clinic. Platelet function testing was performed in all patients and matched control patients. HPR rates were compared between individual tests and with a composite comprised of three tests.

\section{Results:}

A total of 242 patients were included, of whom in 193 patients all tests were available. HPR rates ranged from $14.6 \%$ (VerifyNow cut-off $>235$ PRU) to $49.7 \%$ (VASP). HPR according to the composite advice ( $\geq 2$ out of 3 tests indicating HPR) was present in $29.8 \%$ of patients. The best correlation with the composite advice was observed with light transmittance aggregometry (kappa $=0.78$ ) and VerifyNow (lower cutoff $>208$ PRU; kappa $=0.68$ ). VerifyNow with cutoff $>235$ PRU identified the smallest proportion of patients with HPR, whereas VASP seemed to "over-identify" HPR.

\section{Conclusions:}

In this real life patient cohort, a large variability was observed between four different platelet function tests. The use of a composite advice based on three tests is a promising alternative. 


\section{Introduction}

High on-treatment platelet reactivity (HPR) on $\mathrm{P}_{2} \mathrm{Y}_{12}$-inhibitors in patients treated with dual antiplatelet therapy (DAPT) has been demonstrated to be strongly associated with adverse ischaemic events after percutaneous coronary intervention (PCI) or acute coronary syndrome (ACS). ${ }^{2-4}$ Several assays are available to establish on-treatment platelet reactivity. Classic light transmittance aggregometry (LTA) is considered as the gold standard. The VerifyNow system is considered a reliable test which is easy to use in clinical practice. ${ }^{5,6}$ Other available tests include the Vasodilator-Stimulated Phosphoprotein Assay (VASP) and Multiple Electrode Aggregometry (MEA or Multiplate ${ }^{\circledR}$ ).

The results of most randomized controlled trials after tailored P2Y12-therapy have been disappointing. These disappointing results might be a result of poor identification of patients with true "HPR". Of note, all trials used a single platelet function test (VerifyNow assay in the four largest trials).

Studies have shown conflicting results with regard to the correlation between the different platelet function tests ${ }^{1,7}$ and even less is known about the degree of agreement between the different tests. The few available studies show that agreement between tests is poor ${ }^{8,9}$. It has been suggested that a composite advice based on more than one test might be a better way to identify patients with HPR. ${ }^{8}$ However, no previous studies compared the results of a panel of tests versus individual tests. We therefore investigated the rates of HPR in our cohort of ST patients and matched controls and evaluated correlation and agreement between LTA, VerifyNow, VASP and MEA and a composite advice based on more than one test.

\section{Methods}

Since January 2010, all patients who suffered a definite stent thrombosis were invited back to a dedicated stent thrombosis clinic in our center. Patients were invited to visit the outpatient clinic between 30-60 days after ST. P2 $\mathrm{Y}_{12}$-inhibitors used included either clopidogrel, prasugrel or ticagrelor. Magnitude of on-treatment platelet reactivity was quantified using four platelet function tests in parallel: light transmittance aggregometry with adenosine diphosphate (ADP) 5 and $20 \mu \mathrm{mol} / \mathrm{L}$ as agonist, the VerifyNow P2Y12 assay, Multiplate assay and VASP assay using citrated blood. The following cut-offs for HPR based on the consensus statement were used: LTA ADP peak aggregation > 64.5\%; VASP > 50\%; MEA > 46 Units ( 1 Unit $=10 \mathrm{AU} * \mathrm{~min}$ ).[10]. For the VerifyNow, the cut-off used in the composite advice was $>235$ platelet reactivity units (PRU). For the purpose of this sub analysis, both the cut-off $>235$ PRU and >208 PRU are reported, as both cut-offs have been used in previous studies. More specifics and the procedure of platelet function testing and considerations for tailored DAPT have been previously described. ${ }^{11}$ 
A tailored DAPT advice was given based on the LTA, VerifyNow and VASP. When at least two out of three platelet function tests showed HPR, antiplatelet strategy in these patients was changed. Platelet reactivity was also tested with MEA but this was for research purposes only.

Control patients were matched based on the indication (e.g. ST-segment elevation myocardial infarction.) and date of the $\mathrm{PCl}$ with stent implantation ( \pm 14 days) of the stent thrombosis patients (cases) on a 1:1 ratio. For the current analysis, both cases and control patients were selected.

\section{Data analysis}

The distribution of HPR patients across the different tests was depicted using a Venn diagram. In order to compare the performance of the panel of tests versus the different single tests, all individual tests were plotted against the composite advice using a scatter plot. To assess agreement for continuous variables we computed Pearson correlation coefficients along with simple linear regression lines; for categorical variables we computed the Fleiss kappa coefficient.

\section{Results}

A total of 242 patients were included, of whom in 193 patients LTA, VerifyNow and VASP were all available, as needed for the composite advice. Baseline characteristics are shown in Table 1. HPR rates ranged from $14.6 \%$ (VerifyNow cut-off $>235$ PRU) to $49.7 \%$ (VASP). Separate results stratified for use of either clopidogrel or the stronger $\mathrm{P}_{2} \mathrm{Y}_{12}$-inhibitors prasugrel and ticagrelor are also shown in Table 2. HPR according to the composite advice based on the panel ( $\geq 2$ out of 3 tests) was present in $29.8 \%$ of patients.

Table 1: Baseline characteristics.

\begin{tabular}{|c|c|c|}
\hline \multirow{2}{*}{$\begin{array}{l}\text { Variable } \\
\text { Male sex, n (\%) }\end{array}$} & \multicolumn{2}{|c|}{$n=242$} \\
\hline & 192 & (79.3) \\
\hline Age, mean(SD) & 57.4 & (10.4) \\
\hline BMI & 27.1 & (3.9) \\
\hline Current smoking or quit $<12$ months & 117 & $(48.8)$ \\
\hline Diabetes mellitus & 33 & (13.8) \\
\hline Hypercholesterolaemia & 139 & (58.0) \\
\hline Renal insufficiency & 11 & $(4.6)$ \\
\hline Peripheral arterial disease & 14 & $(5.8)$ \\
\hline History of ischaemic stroke & 4 & $(1.7)$ \\
\hline LV function <45\% & 47 & (20.9) \\
\hline Previous $\mathrm{PCl}$ before index-PCI & 49 & (20.4) \\
\hline History of CABG & 5 & $(2.1)$ \\
\hline \multicolumn{3}{|l|}{ Indication for index- $\mathrm{PCl}$} \\
\hline Stable angina & 64 & $(26.7)$ \\
\hline Unstable angina & 32 & (13.3) \\
\hline STEMI & 114 & (47.5) \\
\hline NSTE-ACS & 21 & $(8.8)$ \\
\hline
\end{tabular}

ACS, acutecoronarysyndrome;CABG,coronaryarterybypassgrafting;LV,left ventricular; NSTE, non-ST-segmentelevati on; $\mathrm{PCl}$, percutaneouscoronaryinter- vention; STEMI,ST-segmentelevationmyocardialinfarction. 
Table 2: High on-treatment platelet reactivity rates according to the individual tests and according to the composite advice.

\begin{tabular}{|c|c|c|c|c|c|c|c|c|c|c|c|c|}
\hline \multirow{2}{*}{$\begin{array}{l}\text { HPR, } n(\%) \\
\text { Overall }\end{array}$} & \multicolumn{2}{|r|}{ LTA } & \multicolumn{2}{|c|}{ VN 235} & \multicolumn{2}{|c|}{ VASP } & \multicolumn{2}{|c|}{ VN 208} & \multicolumn{2}{|c|}{ MEA } & \multicolumn{2}{|c|}{$\begin{array}{c}\text { Composite } \\
\text { (LTA, VN235, VASP) }\end{array}$} \\
\hline & 63 & $(26.2)$ & 35 & (14.6) & 97 & (49.7) & 54 & (22.5) & 47 & $(25.3)$ & 56 & $(29.8)$ \\
\hline Clopidogrel & 50 & $(40.7)$ & 29 & (23.8) & 74 & (71.8) & 45 & (36.9) & 28 & $(32.2)$ & 49 & $(50.5)$ \\
\hline $\begin{array}{l}\text { Prasugrel } \\
\text { orticagrelor }\end{array}$ & 13 & $(11.1)$ & 6 & (5.1) & 23 & $(25.0)$ & 9 & (7.63) & 19 & $(19.2)$ & 7 & (7.7) \\
\hline
\end{tabular}

LoHPR, high on-treatment platelet reactivity; LTA, light transmittance aggregometry; MEA, multipl eelectrode aggregometry; VASP, Vasodilator-Stimulated Phosphoprotein Assay; VN, verify now.

Correlation between the different tests and LTA is shown in the Figures 1-3. R-values ranged from 0.33 to 0.53 corresponding to weak or moderate correlation.

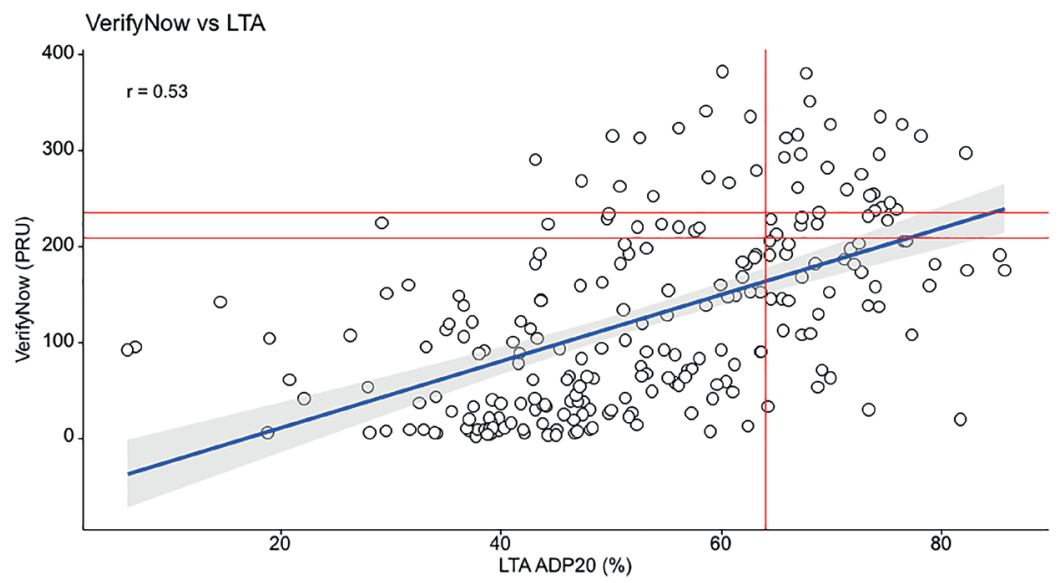

Figure 1: Correlation between Verify Now and light transmittance aggregometry.

VASP vs LTA

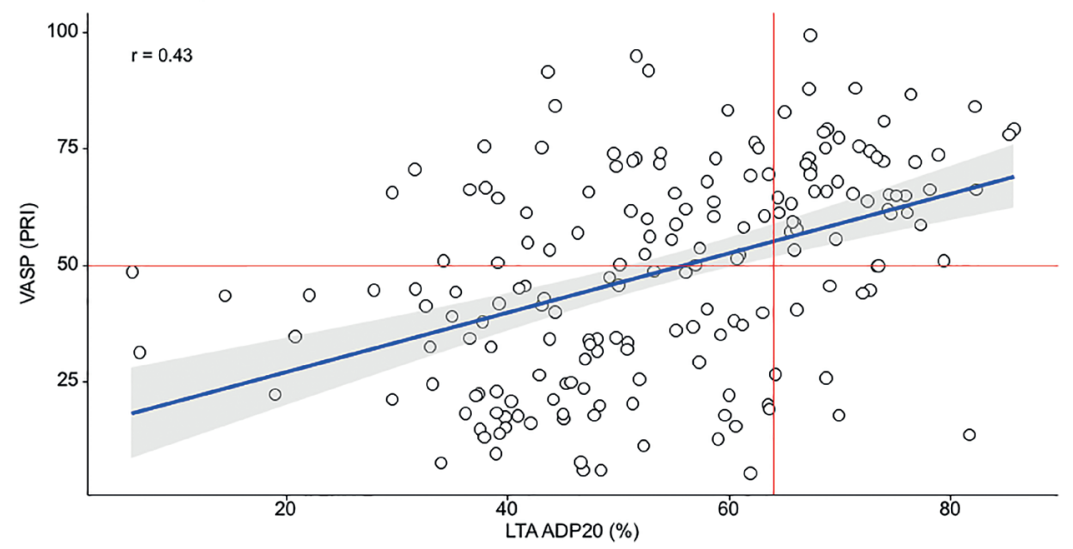

Figure 2: Correlation between Vasodilator-Stimulated Phosphoprotein Assay and light transmittance aggregometry. 


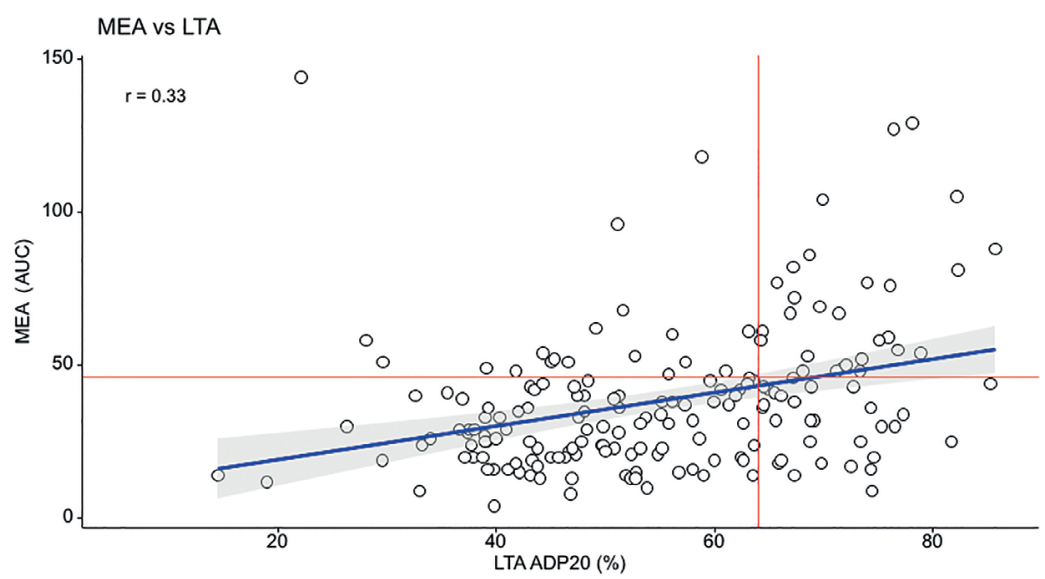

Figure 3: Correlation between multiple electrode aggregometry and light transmittance aggregometry.

The frequency of HPR according to the different tests and the overlap between the tests are shown in Figure 4. Only 10/153 (6.5\%) patients were identified with HPR according to all 4 tests, whereas 62/153 (40.5\%) patients were identified "good responders" by all four tests.
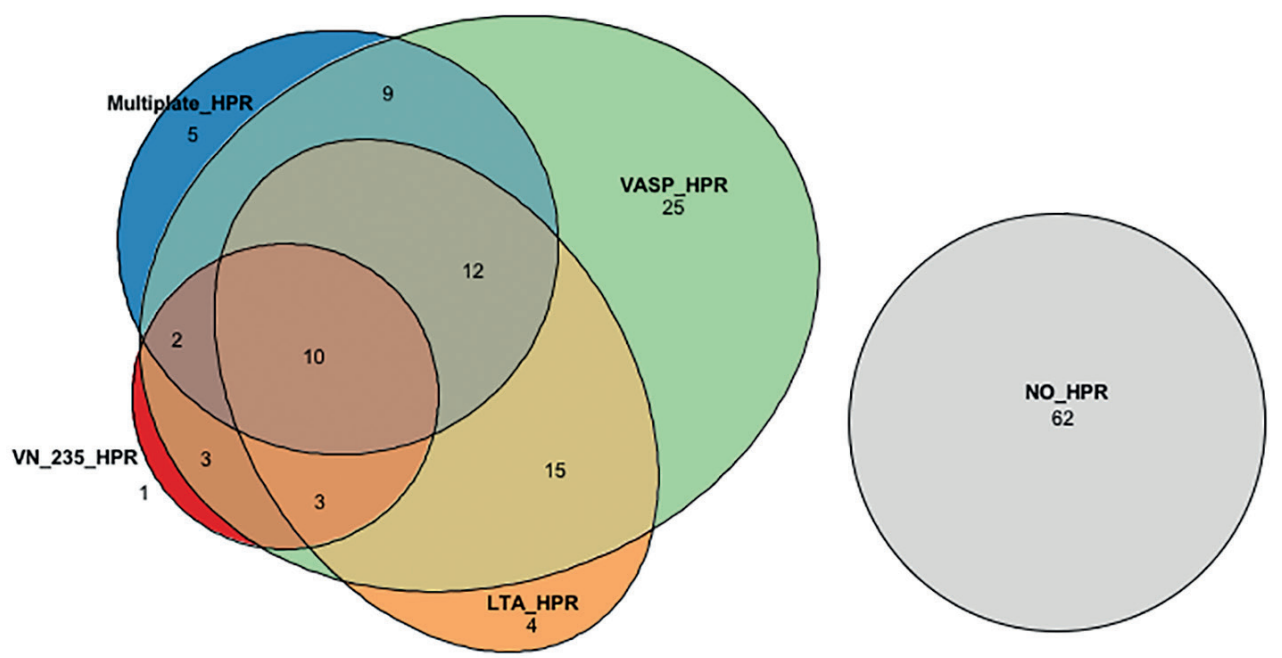

Figure 4: Venn diagram depicting overlap in high on-treatment platelet reactivity rates according to the four tests.

Figures 5 and 6 demonstrate how the composite advice relates to the results of the individual tests. The right hand plot in each figure refers to patients with HPR according to the composite of three tests, whereas the left plot refers to patients with non-HPR. The dots depict individual patients and their platelet function results plotted on the Y-axis. The horizontal line indicates the cut-off for this test. Hence, the right upper and left lower 
quadrant indicate that the individual test agrees with the composite advice (HPR and nonHPR, respectively), whereas the left upper and right lower quadrant indicate discordant results.

Figures 5A - 5C depict the tests used at the stent thrombosis clinic (LTA, VerifyNow > 235 PRU and VASP, respectively). The composite consists of the total of these three tests, hence the test plotted on the $Y$-axis is included in the composite. Figure 5D and 5E depict the alternative tests (MEA and VerifyNow with cutoff $>208$ - both tests were not used in our clinical daily practice) with again the composite including the plotted test.
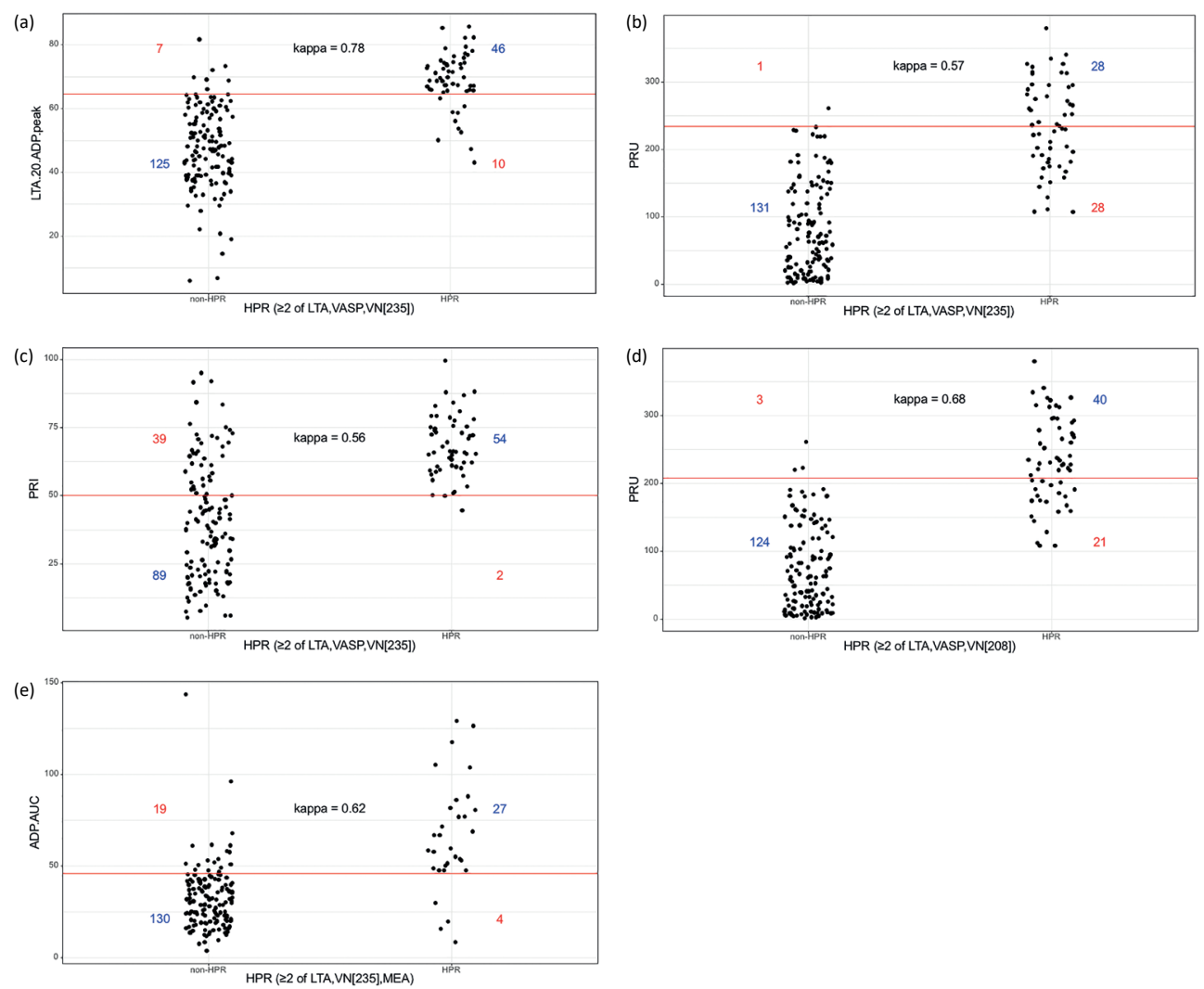

Figure 5: (a-e) Scatter plots depicting association between the individual test and the composite advice used inclinic (light transmittance aggregometry, Verifynow, Vasodilator-Stimulated Phosphoprotein Assay). 
In Figures $6 \mathrm{~A}-6 \mathrm{E}$ the test is compared to a composite of three different tests. Hence the test plotted on the $\mathrm{Y}$-axis has not been included in the composite.
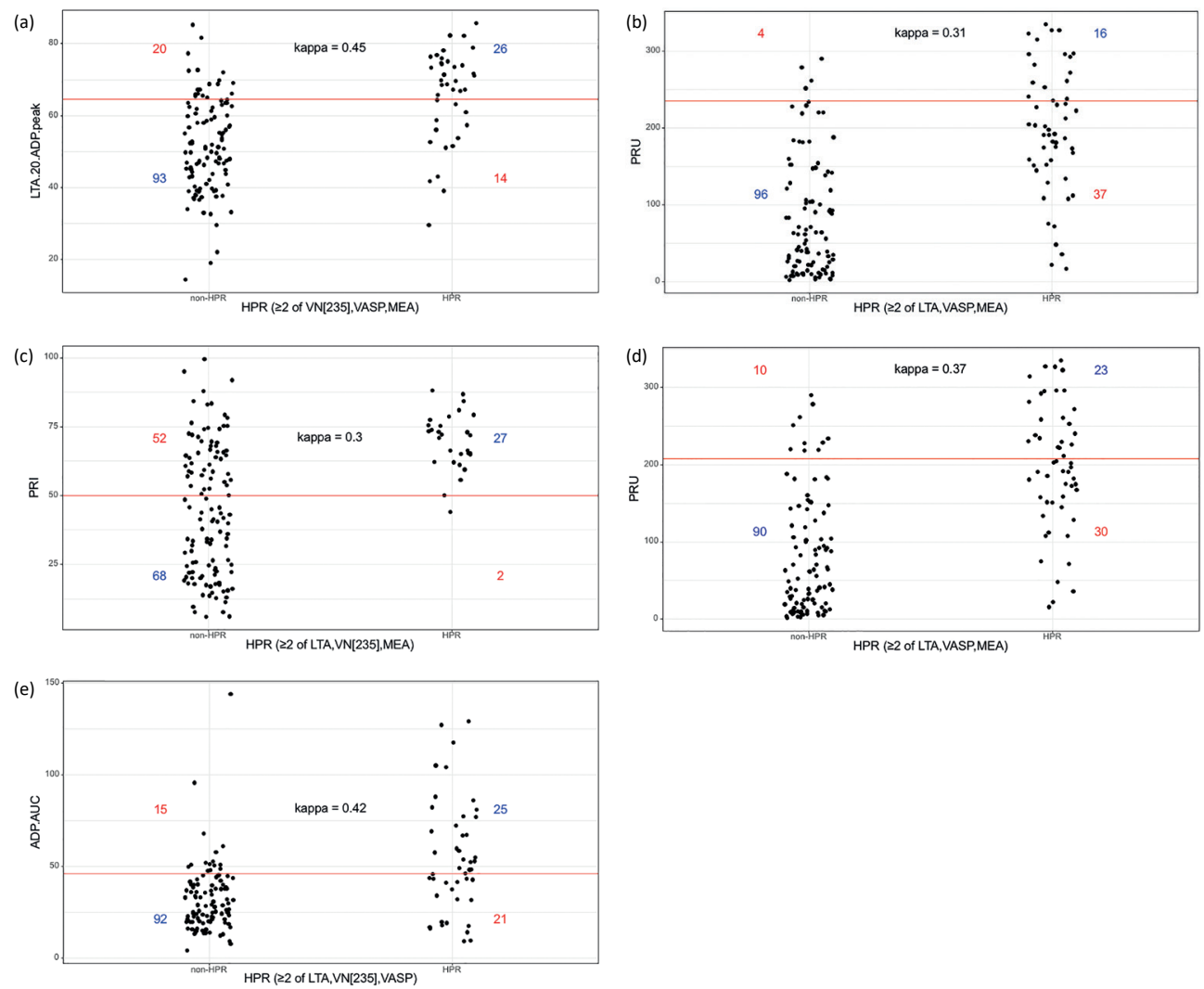

Figure 6: (a-e) Scatter plots depicting association between the individual test and a composite advice using three alternative tests.

As shown in Fig. 5A and 6A, LTA correlates best with the composite advice (kappa $=0.78$ and 0.45 , respectively) with a low proportion of discordant results (a total of 17/188 (9.0\%) or $34 / 153(22.2 \%)$, respectively). The VerifyNow with cut-off $>235$ disagreed in only $1 / 132$ $(0.8 \%)$ or $4 / 100(4.0 \%)$ with the composite advice when this indicated non-HPR. However, a substantial proportion of patients with HPR according to the panel were not identified by VerifyNow $>235$ (28/56 (50.0\%, Fig 5B or even $37 / 53$ (69.8\%, Fig 6B). The VASP, on the other hand, "over-identified" with HPR: in 39/128 (30.4\%) or 52/120 (43.3\%) patients the test indicated HPR when the panel considered these patients as 'non-HPR' (Fig 5C and 6C). Remarkably, when the lower cut-off was used for the VerifyNow, this test performed substantially better (kappa $=0.68$ and 0.37 ) as compared to VerifyNow $>235$ with fewer disconcordant results. MEA demonstrated comparable results (kappa $=0.62$ and 0.42 ) with VerifyNow $>208$ and performed better than both VerifyNow $>235$ and VASP. 


\section{Discussion}

The current study demonstrated a considerable variability in HPR rates in a large real-life cohort of high risk ACS patients. Correlation and agreement between the individual tests was found to be weak or moderate at best. The VerifyNow identified the smallest proportion of patients with HPR, whereas the VASP identified an extremely high number of patients with HPR. Heterogeneity was also illustrated by the fact that the four tests agreed in less than half (47\%) of all patients. Furthermore, we showed that the VerifyNow >235 PRU and VASP show discordant results in a large proportion of patients when compared to a panel of three tests, whereas LTA, MEA and VerifyNow > 208 performed better.

Given the large degree of variability with the individual tests, an advice based on more than one test is promising. Using a panel of three tests, $29 \%$ of patients were identified as having HPR, as compared with HPR rates ranging from $14.6 \%$ to $49.7 \%$ for the individual tests. When using a composite advice, it seems reasonable to use MEA instead of VASP, given the exceptionally high proportion of HPR patients identified by VASP. Alternatively, a different cut-off might be used for the VASP as suggested by some authors. ${ }^{12}$

This is the first study showing the results of using a composite advice based on a panel of platelet function tests and comparing it to the HPR rates of the individual tests. Lemesle et al. compared the performance of three individual platelet function tests in 2013 and already concluded that a sole test might not be sufficient. ${ }^{13}$ The authors found that only $31 \%$ was identified as normal responders according to all three tests and only $16 \%$ as poor responder by all three tests. These figures are in line with the present study.

Previously, four large randomized controlled trials failed to demonstrate a benefit of tailored antiplatelet therapy. ${ }^{14-17}$ As suggested before ${ }^{13}$, this could be a result of the difficulty of identifying true 'poor responders' with a single test. Interestingly, the VerifyNow which was used in these trials, identifies the smallest proportion of patients with HPR, leaving the possibility that a substantial proportion of poor responders is not identified. In the present cohort, more than twice as many patients were labeled as HPR by the panel of three tests as compared to the VerifyNow $>235$ as a single test ( $29.8 \%$ vs. $14.6 \%$ ). Again, speculatively, this could have influenced the results of the trials and might in part explain the non-significant findings of those studies. Therefore, future studies should use a combination of platelet function tests as opposed to one single test.

\section{Limitations}

Whereas a composite advice seems promising, no external validation could be performed as a result of lacking a true gold standard. Although intuitively more accurate, the added value of a panel of tests remains therefore speculative. No relation with clinical outcomes was 
assessed in this study. In a previous paper, we demonstrated that tailored DAPT in patients who suffered a stent thrombosis reduced the rate of cardiac death and/or recurrent stent thrombosis as compared with a historical cohorts of stent thrombosis patients. ${ }^{11}$

\section{Conclusion}

In this real life patient cohort, correlation between the four different platelet function tests was found to be weak with a poor degree of agreement. The VerifyNow assay identified the smallest proportion of HPR patients. We demonstrated that the use of a composite advice based on more than one platelet function test is a feasible alternative. When using a composite advice, MEA rather than VASP should be used given the exceptionally high proportion of patients identified with HPR according to VASP. 


\section{References}

1. Paniccia R, Antonucci E, Maggini N, Miranda M, Gori AM, Marcucci R, Giusti B et al. Comparison of methods for monitoring residual platelet reactivity after clopidogrel by pointof-care tests on whole blood in high-risk patients. Thromb Haemost. 2010 Aug [cited Feb 27, 2018];104(2):287-92.

2. Combescure C, Fontana P, Mallouk N, Berdague P, Labruyere C, Barazer I, Gris JC, et al. Clinical implications of clopidogrel non-response in cardiovascular patients: A systematic review and meta-analysis. J Thromb Haemost. 2010 May [cited Dec 17, 2017];8(5):923-33.

3. Brar SS, ten Berg J, Marcucci R, Price MJ, Valgimigli M, Kim H, Patti G, et al. Impact of platelet reactivity on clinical outcomes after percutaneous coronary intervention. A collaborative meta-analysis of individual participant data. J Am Coll Cardiol. 2011 Nov 01, [cited Dec 17, 2017];58(19):1945-54.

4. Breet NJ, van Werkum JW, Bouman HJ, Kelder JC, Ruven HJT, Bal ET, Deneer VH, et al. Comparison of platelet function tests in predicting clinical outcome in patients undergoing coronary stent implantation. JAMA. 2010 Feb 24, [cited Apr 23, 2017];303(8):754-62.

5. Orme R, Judge HM, Storey RF. Monitoring antiplatelet therapy. Semin Thromb Hemost. 2017 Apr [cited Apr 26, 2017];43(3):311-9.

6. Janssen PWA, ten Berg JM. Platelet function testing and tailored antiplatelet therapy. J Cardiovasc Transl Res. 2013 Jun [cited Apr 23, 2017];6(3):316-28.

7. Lordkipanidzé M, Pharand C, Nguyen TA, Schampaert E, Palisaitis DA, Diodati JG. Comparison of four tests to assess inhibition of platelet function by clopidogrel in stable coronary artery disease patients. Eur Heart J. 2008 Dec [cited Feb 27, 2018];29(23):2877-85.

8. Cuisset T, Frere C, Poyet R, Quilici J, Gaborit B, Bali L, Brissy O et al. Clopidogrel response: Head-to-head comparison of different platelet assays to identify clopidogrel non responder patients after coronary stenting. Arch Cardiovasc Dis. 2010 Jan [cited Feb 27, 2018];103(1):3945.

9. Gaglia MA, Torguson R, Pakala R, Xue Z, Sardi G, Suddath WO, Kent KM et al. Correlation between light transmission aggregometry, VerifyNow P2Y12, and VASP-P platelet reactivity assays following percutaneous coronary intervention. J Interv Cardiol. 2011 Dec [cited Feb 27, 2018];24(6):529-34.

10. Tantry US, Bonello L, Aradi D, Price MJ, Jeong Y, Angiolillo DJ, Stone GW et al. Consensus and update on the definition of on-treatment platelet reactivity to adenosine diphosphate associated with ischemia and bleeding. J Am Coll Cardiol. 2013 Dec 17, [cited Apr 23, 2017];62(24):2261-73.

11. Godschalk TC, Willemsen LM, Zwart B, Bergmeijer TO, Janssen PWA, Kelder JC, Hackeng CM et al. Effect of tailored antiplatelet therapy to reduce recurrent stent thrombosis and cardiac death after a first episode of stent thrombosis. Am J Cardiol. 2017 Feb 27, [cited Apr 23, 2017]. 
12. Jeong Y-, Bliden KP, Tantry US, Gurbel PA. High on-treatment platelet reactivity assessed by various platelet function tests: Is the consensus-defined cut-off of VASP-P platelet reactivity index too low? J Thromb Haemost. 2012 Mar [cited Mar 8, 2018];10(3):487-9.

13. Lemesle G, Landel J, Bauters A, Delhaye C, Bonello L, Sudre A, Susen S et al. Poor agreement between light transmission aggregometry, verify now $\mathrm{P}_{2} \mathrm{Y}_{12}$ and vasodilatator-stimulated phosphoprotein for clopidogrel low-response assessment: A potential explanation of negative results of recent randomized trials. Platelets. 2014 [cited Feb 27, 2018];25(7):499-505.

14. Collet J, Cuisset T, Rangé G, Cayla G, Elhadad S, Pouillot C, Henry P et al. Montalescot G. Bedside monitoring to adjust antiplatelet therapy for coronary stenting. N Engl J Med. 2012 Nov 29, [cited Feb 27, 2018];367(22):2100-9.

15. Trenk D, Stone GW, Gawaz M, Kastrati A, Angiolillo DJ, Müller U, Richardt G, et al. A randomized trial of prasugrel versus clopidogrel in patients with high platelet reactivity on clopidogrel after elective percutaneous coronary intervention with implantation of drugeluting stents: Results of the TRIGGER-PCI (testing platelet reactivity in patients undergoing elective stent placement on clopidogrel to guide alternative therapy with prasugrel) study. J Am Coll Cardiol. 2012 Jun 12, [cited Dec 17, 2017];59(24):2159-64.

16. Cayla G, Cuisset T, Silvain J, Leclercq F, Manzo-Silberman S, Saint-Etienne C, Delarche N et al. Platelet function monitoring to adjust antiplatelet therapy in elderly patients stented for an acute coronary syndrome (ANTARCTIC): An open-label, blinded-endpoint, randomised controlled superiority trial. Lancet. 2016 Oct 22, [cited Apr 24, 2017];388(10055):2015-22.

17. Price MJ, Berger PB, Teirstein PS, Tanguay J, Angiolillo DJ, Spriggs D, Puri S et al. Standardvs high-dose clopidogrel based on platelet function testing after percutaneous coronary intervention: The GRAVITAS randomized trial. JAMA. 2011 Mar 16, [cited Dec 17, 2017];305(11):1097-105. 
CHAPTER
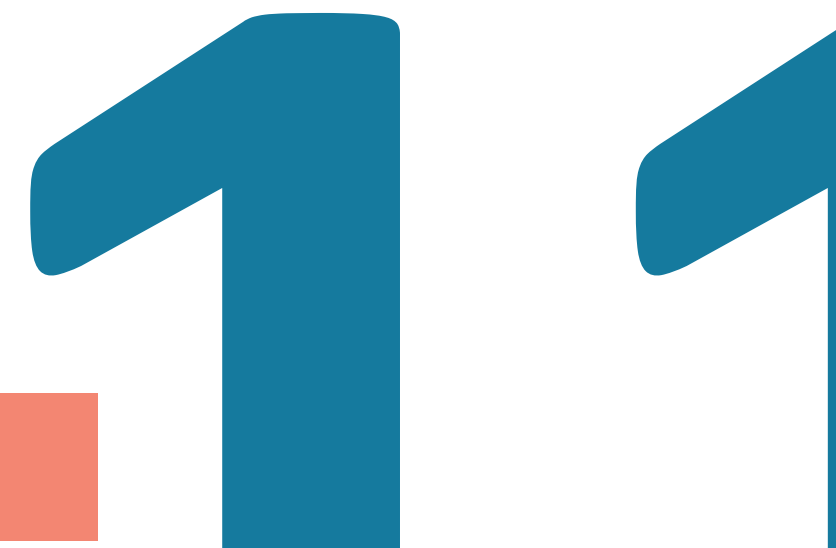


\title{
A novel risk score to identify AF patients undergoing $\mathrm{PCl}$ at high thrombotic risk
}

\section{a RE-DUAL PCI secondary analysis}

\author{
B. Zwart, W.L. Bor, A. de Veer, B.K. Mahmoodi, J.C. Kelder, \\ G.Y.H. Lip, D.L. Bhatt, C.P. Cannon, J.M. ten Berg \\ * B. Zwart and W.L. Bor contributed equally to this manuscript
}




\begin{abstract}
Objectives:

To identify patients at high thrombotic risk who might benefit from triple antithrombotic therapy (TAT) over double antithrombotic therapy (DAT).
\end{abstract}

\title{
Background:
}

Current guidelines recommend to treat atrial fibrillation (AF) patients who undergo percutaneous coronary intervention (PCI) with TAT up to one month in patients at high thrombotic risk. It is unclear how to select these high-risk patients.

\section{Methods:}

This study was a post hoc subanalysis of the RE-DUAL PCI trial. A Cox proportional hazards model was built by stepwise selection of plausible predictor variables for the combined composite endpoint defined as cardiovascular death, myocardial infarction, stent thrombosis or ischaemic stroke. Effect of TAT versus DAT was calculated in the highest proportion of predicted thrombotic risk. Based on beta-coefficients a simplified prediction rule was constructed.

\section{Results:}

In 209 patients (7.7\%) the combined ischaemic endpoint occurred during the first year. The simplified prediction rule contained 7 variables. In patients with a score $\geq 5$ ( $N$ 154, 5.7\%), a significant reduction in the composite of myocardial infarction and stent thrombosis was observed with TAT vs. DAT ( $6.3 \%$ vs. $21.0 \%, p=0.04)$, without a penalty in terms of bleeding. In patients at low thrombotic risk, a significant increase in bleeding was observed without a reduction of thrombotic events.

\section{Conclusions:}

This novel clinical prediction rule was able to identify a subgroup of high-risk patients benefiting from TAT. Our findings support the use of TAT in this small subgroup, while using DAT in the majority of $\mathrm{AF}$ patients undergoing $\mathrm{PCl}$. 


\section{Introduction}

Antithrombotic regimens in patients with atrial fibrillation (AF) undergoing percutaneous coronary intervention $(\mathrm{PCl})$ represent one of the most challenging topics for cardiologists in daily practice. In AF patients with a $\mathrm{CHA}_{2} \mathrm{DS}_{2}$ VASc score ${ }^{3} 1$ in males and $\geq 2$ in females, oral anticoagulation (OAC) is warranted to reduce the risk of systemic thromboembolic events including stroke, whereas patients undergoing $\mathrm{PCl}$ have an indication for dual antiplatelet therapy consisting of aspirin and $\mathrm{P} 2 \mathrm{Y}_{12}$ inhibitor in order reduce the risk of stent thrombosis or other recurrent atherothrombotic events ${ }^{1-3}$. Approximately one in five patients with AF undergo $\mathrm{PCl}$ at some point in life, illustrating the relevant overlap in clinical practice. ${ }^{4}$ From the $\mathrm{PCl}$ perspective, one in twelve patients undergoing coronary stenting has concomitant $\mathrm{AF}$ and an indication for $\mathrm{OAC}^{3}$ The combination of dual antiplatelet therapy and OAC is referred to as triple antithrombotic therapy (TAT). A drawback of TAT is that it confers at least a two-times higher risk of bleeding as compared to double antithrombotic therapy (DAT), i.e. with the omittance of aspirin ${ }^{5,6}$.

Current international guidelines and consensus documents recommend TAT for one week and up to one month in patients at high thrombotic risk ${ }^{2,7,8}$. To date, it is unclear how to select patients at high thrombotic risk.

Five randomised controlled trials compared TAT with the combination of (N)OAC and an antiplatelet agent. The WOEST study was the first to investigate a regime of omitting aspirin in anticoagulated patients undergoing $\mathrm{PCl}^{9}{ }^{9}$ The WOEST study showed that treatment with an VKA and the $\mathrm{P} 2 \mathrm{Y}_{12}$ inhibitor clopidogrel (DAT) was associated with a reduction of bleeding without an increase in thrombotic events, compared to patients treated with TAT. Four more recent studies, which used the same approach of TAT versus DAT with NOAC did not show any differences in ischaemic outcomes, whereas all but the ENTRUST-AF PCI study showed a reduction of bleeding complications in patients treated with DAT ${ }^{10-13}$.

Although no difference in ischaemic outcomes were observed in the individual trials, it must be noted that all studies were largely underpowered for thrombo-embolic endpoints and the trials included mostly low-risk patients with a small proportion of patients with acute coronary syndrome $(A C S)^{14,15}$. Some meta-analyses suggested a significant but small increase of stent thrombosis in patients treated with DAT ${ }^{14,16}$. A sub analysis of the AUGUSTUS trial pointed to a trade-off in ischaemic vs. bleeding risks. A significant reduction in ischaemic events was observed when TAT was used in the first month after $\mathrm{PCl}$, but at the equal cost of bleeding ${ }^{17}$. After 30 days, TAT continued to increase bleeding without significantly reducing ischemic events. The authors propose a patient-centric decision making on the use of TAT. The recent meta-analysis by Gargiulo et al. ${ }^{14}$ supports this concept of a personalised strategy. The authors found evidence for a subgroup of patients who had net benefit of TAT 
vs. DAT in favour of reducing ischaemic events; however, they could not provide tools for the identification of this subgroup of patients, nor do international guidelines provide specific guidance for patient selection.

In this study, we sought to find subgroups of patients at high thrombotic risk and to develop a prediction rule to identify high-risk patients who might benefit from TAT.

\section{Methods}

\section{Patient cohorts}

This study was a post hoc sub analysis of the RE-DUAL trial. The study protocol for this trial has been previously published ${ }^{18}$. In short, in the RE-DUAL PCI trial, the DAT group was treated with dabigatran $110 \mathrm{mg}$ or $150 \mathrm{mg}$ in combination with a P2Y12 inhibitor (clopidogrel in $87 \%$ or ticagrelor in $12 \%$ of patients). The TAT group consisted of VKA, aspirin and a $\mathrm{P}_{2} \mathrm{Y}_{12}$ inhibitor (clopidogrel in $90 \%$ or ticagrelor in $8 \%$ of patients). TAT was given for three months in patients undergoing $\mathrm{PCl}$ with $\mathrm{DES}$ and for one month in patients receiving a BMS. The study received the proper ethical oversight. The study protocol and any amendments were approved by the ethics committee at each participating center.

\section{Ischemic and Bleeding Endpoints}

The combined composite endpoint was defined as cardiovascular death, myocardial infarction (MI), stent thrombosis (definite or probable according to Academic Research Consortium criteria) or ischaemic stroke. The bleeding endpoint was defined as the first Bleeding Academic Research Consortium (BARC) 2, 3 or 5 bleeding within 365 days. For the purpose of a sensitivity analysis, follow-up was truncated after the first event (either thrombotic or bleeding event).

\section{Follow-up}

The mean follow-up after $\mathrm{PCl}$ was 14 months. For this analysis follow-up was truncated at 365 days to obtain risk estimates for the first year of DAT vs TAT. Groups were compared according to intention-to-treat protocol.

\section{Statistical analysis}

Baseline characteristics were compared between patients with and without ischaemic events during the 1-year follow-up by t-test or Chi-square or its nonparametric equivalents as appropriate.

\section{Predictors}

Based on clinical plausibility and availability in both trial datasets, variables were considered as candidate predictors. The variables included age, sex, body mass index, hypertension, 
hypercholesterolemia, diabetes mellitus including subgroups of insulin dependent diabetes, smoking, alcohol use, medical history (bleeding, $\mathrm{MI}, \mathrm{PCl}$, coronary bypass artery grafting, stroke, venous thrombo-embolisms or systemic embolism, renal failure, malignancy, peripheral artery disease, heart failure), MI at presentation, left ventricular ejection fraction, laboratory tests at presentation (haemoglobin, haematocrit, platelet count, leukocyte count, creatinine, estimated glomerular filtration rate by CKD-EPI), and angiographic and procedural characteristics (number of diseased vessels, left main disease, thrombus containing lesion, number of stented vessels, stented vessel/graft, bifurcation $\mathrm{PCl}$, lesion length $>30 \mathrm{~mm}$ and in-stent restenosis stenting). We did not include modifiable factors like medication use, periprocedural heparin use, factors of which reporting might be unreliable like New York Heart Association class classification, and factors with uncertain causal relation like index ECG rhythm and type of atrial fibrillation.

\section{Model development}

Since we wanted to characterize the patients' thrombotic risk based on their single clinical features irrespective of receiving DAT or TAT, individual candidate variables for the model were selected from a univariate Cox regression stratified for randomization arm and bare metal stent placement (the latter directly influenced treatment duration). Variables showing P-value $<0.30$ for the ischemic events model were considered as candidate variables. A Cox model for the combined ischemic endpoint was constructed with forced entry of the stratification variables. Stepwise selection from the candidate variables using a 0.05 significance level was performed. Missing values in the dataset for stepwise model selection were imputed by simple means (overview of missing in table S4). Based on beta-coefficients of the Cox model a point score was constructed using the methods as proposed in the Framingham Study risk scores. ${ }^{19}$

\section{Validation}

With the Cox model the expected hazard of the thrombotic end point given the covariates was predicted at 365 days. Also, the point score was calculated for each patient. Predictive accuracy of the model and point score was evaluated by area under the receiver operating curve (c-statistic). The cohort was divided in quintiles, deciles and demi-deciles based on the expected hazards, or grouped by point score to assess calibration. Also, goodness-of-fit was assessed by Hosmer-Lemeshow test.

Observed risks within the different risk categories and risk scores of ischaemic events, bleeding, and mortality were compared between the patients that received TAT or DAT to evaluate if a benefit of TAT over DAT could be found in patients at higher thrombotic risk. To compare the performance of the new risk score in relation to existing risk scores, c-statistic of the the $\mathrm{CHA}_{2} \mathrm{DS}_{2}$-VASc for the thrombotic end point in the RE-DUAL cohort was assessed. 
External validation was performed in the WOEST2 registry. The WOEST2 registry is a (as yet unpublished) cohort of 885 patients treated with $\mathrm{OAC}$ undergoing $\mathrm{PCl}$ (mean age 74 years, $31 \% \mathrm{PCl}$ for ACS, 38\% treated with TAT, 94\% clopidogrel). Differences in outcomes between TAT and DAT cohorts were not evaluated, as an inherent indication bias exists between the groups due to the observational design of this cohort.

\section{Results}

A total of 2725 patients was included in this analysis. In 209 patients (7.7 \%) the combined ischaemic endpoint occurred during the first year. Baseline characteristics of patients with and without ischaemic events are depicted in Table 1. Approximately half of the cohort (50.5\%) underwent $\mathrm{PCl}$ for the indication ACS. Patients with an ischaemic event during follow-up were more likely to have a medical history of $\mathrm{MI}$, heart failure, diabetes, renal failure, peripheral artery disease or prior stroke and were more likely to have presented with ACS. Left ventricular ejection fraction was lower in patients with an ischaemic event during follow-up and multivessel disease was more prevalent. Furthermore, there were significant differences in haemoglobin level, white blood cell count, platelet count and creatinin clearance. BARC 2, 3 or 5 bleedings were documented in 520 patients (19.1\%).

Table 1: Baseline characteristics of patients with and without ischaemic events during follow-up.

\begin{tabular}{|c|c|c|c|c|}
\hline & \multicolumn{2}{|l|}{ Ischaemic end point } & \multirow[b]{2}{*}{ p } & \multirow[b]{2}{*}{ test } \\
\hline & no & yes & & \\
\hline $\mathrm{n}$ & 2516 & 209 & & \\
\hline Triple therapy & $907(36.0)$ & $74(35.4)$ & 0.912 & \\
\hline Age (median [IQR]) & $71.00[65.00,77.00]$ & $71.50[65.00,78.00]$ & 0.458 & nonnorm \\
\hline Female sex (\%) & $611(24.3)$ & $44(21.1)$ & 0.334 & \\
\hline Body-mass index (median [IQR]) & $28.10[25.30,31.70]$ & $28.10[25.10,31.40]$ & 0.485 & nonnorm \\
\hline Hypertension (\%) & $2114(84.1)$ & $180(86.1)$ & 0.491 & \\
\hline Hypercholesterolemia (\%) & $1640(65.2)$ & $130(62.2)$ & 0.423 & \\
\hline Smoker (\%) & $310(12.3)$ & 27 ( 12.9$)$ & 0.888 & \\
\hline Diabetes Mellitus (\%) & 902 (35.9) & $91(43.5)$ & 0.032 & \\
\hline Insuline dependent DM (\%) & 248 ( 9.9) & $29(13.9)$ & 0.089 & \\
\hline Alcohol abuse (\%) & $1276(50.7)$ & $99(47.4)$ & 0.388 & \\
\hline Prior MI (\%) & $623(24.8)$ & $76(36.4)$ & $<0.001$ & \\
\hline Congestive heart failure (\%) & $849(33.8)$ & $88(42.1)$ & 0.018 & \\
\hline Prior bleeding (\%) & $32(1.3)$ & $0(0.0)$ & 0.189 & \\
\hline Prior GI bleeding (\%) & $167(6.6)$ & $16(7.7)$ & 0.675 & \\
\hline Stroke (\%) & $200(8.0)$ & $26(12.4)$ & 0.033 & \\
\hline Prior coronary revascularization (\%) & $951(37.8)$ & $92(44.0)$ & 0.089 & \\
\hline History of malignancy (\%) & 225 ( 9.1) & $16(7.8)$ & 0.595 & \\
\hline Peripheral artery disease (\%) & 161 ( 6.9) & $27(13.8)$ & 0.001 & \\
\hline ACS at baseline (\%) & $1253(49.8)$ & $122(58.4)$ & 0.021 & \\
\hline bl.acstype (\%) & & & $<0.001$ & \\
\hline STEMI & $280(22.8)$ & $25(20.8)$ & & \\
\hline NSTEMI & $509(41.4)$ & $73(60.8)$ & & \\
\hline UAP & $440(35.8)$ & $22(18.3)$ & & \\
\hline NYHA $3 / 4$ (\%) & $237(28.1)$ & $33(37.5)$ & 0.084 & \\
\hline LVEF at baseline (median [IQR]) & $54.00[45.00,60.00]$ & $47.00[35.00,55.00]$ & $<0.001$ & \\
\hline Atrial fibrillation or flutter at presentation (\%) & $1162(46.2)$ & $103(49.3)$ & 0.429 & \\
\hline
\end{tabular}


Table 1: Continued

\begin{tabular}{|c|c|c|c|c|}
\hline & \multicolumn{2}{|l|}{ Ischaemic end point } & \multirow[b]{2}{*}{$\mathbf{p}$} & \multirow[b]{2}{*}{ test } \\
\hline & no & yes & & \\
\hline Haemoglobin (mmol/L) (median [IQR]) & $8.50[7.76,9.18]$ & $8.32[7.51,8.94]$ & 0.050 & \\
\hline Haematocrit (\%) (median [IQR]) & $41.00[38.00,44.00]$ & $40.00[37.00,44.00]$ & 0.125 & \\
\hline Platelet count $\left({ }^{*} 10^{\wedge} 9 . \mathrm{L}\right)$ (median [IQR]) & $201.00[169.00,243.00]$ & $212.00[182.00,252.00]$ & 0.006 & \\
\hline Creatinin (mg/dL) (median [IQR]) & $1.00[0.85,1.19]$ & $1.08[0.91,1.22]$ & 0.001 & \\
\hline Creatinin $(\mu \mathrm{mol} / \mathrm{L})$ (median [IQR]) & $88.00[75.00,106.00]$ & $96.00[80.00,108.00]$ & 0.001 & \\
\hline eGFR (CKD-EPI) (median [IQR]) & $76.00[61.00,89.00]$ & $68.00[59.00,83.00]$ & $<0.001$ & \\
\hline White blood cell count (median [IQR]) & $7.33[6.09,8.92]$ & $7.70[6.45,9.30]$ & 0.021 & \\
\hline Femoral access (\%) & $889(35.6)$ & $83(40.3)$ & 0.203 & \\
\hline 3 vessel disease (\%) & $418(17.0)$ & $63(30.9)$ & $<0.001$ & nonnorm \\
\hline Complex procedure (\%) & $506(20.1)$ & $43(20.6)$ & 0.946 & \\
\hline *>2 vessels stenting $(\%)$ & $77(3.1)$ & $9(4.3)$ & 0.434 & nonnorm \\
\hline$*_{\text {in-stent restenosis stenting (\%) }}$ & $42(1.7)$ & 4 ( 1.9$)$ & 1.000 & nonnorm \\
\hline *prior brachytherapy lesion stenting (\%) & $2(0.1)$ & $0(0.0)$ & 1.000 & nonnorm \\
\hline *unprotected left main stenting (\%) & $44(1.7)$ & 4 ( 1.9$)$ & 1.000 & nonnorm \\
\hline *>2 lesions per vessel stenting (\%) & $144(5.7)$ & $12(5.7)$ & 1.000 & nonnorm \\
\hline *>30mm stenting $(\%)$ & $220(8.7)$ & $20(9.6)$ & 0.783 & nonnorm \\
\hline *bifurcation stenting (\%) & $88(3.5)$ & $4(1.9)$ & 0.308 & \\
\hline *venous graft stenting (\%) & $53(2.1)$ & $5(2.4)$ & 0.980 & \\
\hline *thrombus containing lesion stenting (\%) & $37(1.5)$ & $6(2.9)$ & 0.204 & \\
\hline BMS placement (\%) & $410(16.3)$ & $40(19.1)$ & 0.335 & \\
\hline Number of stented vessels (\%) & & & 0.123 & \\
\hline 1 & $2016(81.7)$ & $162(78.6)$ & & \\
\hline 2 & $382(15.5)$ & $33(16.0)$ & & \\
\hline 3 & $70(2.8)$ & $11(5.3)$ & & \\
\hline LAD (\%) & $1191(47.3)$ & $94(45.0)$ & 0.559 & \\
\hline LCX (\%) & $648(25.8)$ & $69(33.0)$ & 0.027 & \\
\hline RCA (\%) & $869(34.5)$ & $67(32.1)$ & 0.516 & \\
\hline Graft (\%) & $68(2.7)$ & $9(4.3)$ & 0.260 & \\
\hline Arterial graft (\%) & $9(0.4)$ & $2(1.0)$ & 0.456 & \\
\hline Venous graft (\%) & $53(2.1)$ & $5(2.4)$ & 0.980 & \\
\hline All-cause death (\%) & $36(1.4)$ & $77(36.8)$ & $<0.001$ & \\
\hline Composite outcome (\%) & $0(0.0)$ & $209(100.0)$ & $<0.001$ & \\
\hline MI or ST (\%) & $0(0.0)$ & $158(75.6)$ & $<0.001$ & \\
\hline BARC 2,3 , or 5 bleeding (\%) & $465(18.5)$ & $55(26.3)$ & 0.007 & \\
\hline BARC 3 or 5 bleeding (\%) & $100(4.0)$ & $27(12.9)$ & $<0.001$ & \\
\hline Cardiovascular death (\%) & $0(0.0)$ & $51(24.4)$ & $<0.001$ & \\
\hline Myocardial infarction (\%) & $0(0.0)$ & $110(52.6)$ & $<0.001$ & \\
\hline Stent thrombosis (\%) & $0(0.0)$ & $86(41.1)$ & $<0.001$ & \\
\hline Stroke (\%) & $3(0.1)$ & $36(17.2)$ & $<0.001$ & \\
\hline Ischemic stroke (\%) & $0(0.0)$ & $30(14.4)$ & $<0.001$ & \\
\hline Hemorrhagic stroke (\%) & $0(0.0)$ & $6(2.9)$ & $<0.001$ & \\
\hline
\end{tabular}

Table 2 shows results of stratified univariate Cox regression. Strong predictors for ischaemic events were decreased left ventricular ejection fraction, multivessel disease or multivessel stenting, myocardial infarction, diabetes mellitus, peripheral artery disease or stroke and a history of heart failure or renal failure. 
Table 2: Univariate analysis for composite ischaemic end point (* all corrected for treatment arm, study and baremetal stent)

\begin{tabular}{|c|c|c|c|c|}
\hline & beta & HR ( $95 \% \mathrm{Cl}$ for HR) & wald test & $p$ value \\
\hline LVEF (per \% increase) & -0.035 & $0.97(0.96-0.98)$ & 41 & $1.9 \mathrm{e}-10$ \\
\hline 3 vessel disease & 0.73 & $2.1(1.5-2.8)$ & 23 & $1.3 e-06$ \\
\hline Number of diseased vessels (per 1 vessel increase) & 0.41 & $1.5(1.3-1.8)$ & 23 & $1.7 \mathrm{e}-06$ \\
\hline Myocardial infarction at baseline & 0.65 & $1.9(1.5-2.5)$ & 22 & $3.2 \mathrm{e}-06$ \\
\hline History of myocardial infarction & 0.52 & $1.7(1.3-2.2)$ & 13 & 0.00028 \\
\hline 1 vessel disease & -0.51 & $0.6(0.45-0.79)$ & 13 & 0.00032 \\
\hline Peripheral artery disease & 0.74 & $2.1(1.4-3.1)$ & 13 & 0.00037 \\
\hline eGFR (by CKD-EPI, per point increase) & -0.013 & $0.99(0.98-0.99)$ & 12 & $5 e-04$ \\
\hline Heart failure or $\operatorname{LVEF}<30 \%$ & 0.48 & $1.6(1.2-2.1)$ & 11 & 0.00095 \\
\hline Creatinin (per $\mu \mathrm{mol} / \mathrm{L}$ increase) & 0.0088 & $1(1-1)$ & 11 & 0.00098 \\
\hline Platelet count (per 109/L increase) & 0.0032 & $1(1-1)$ & 10 & 0.0016 \\
\hline NYHA classification (per class increase) & 0.4 & $1.5(1.1-2)$ & 7.5 & 0.0063 \\
\hline History of renal failure & 0.43 & $1.5(1.1-2.1)$ & 6.7 & 0.0095 \\
\hline Heart failure & 0.36 & $1.4(1.1-1.9)$ & 6.7 & 0.0099 \\
\hline ACS at baseline & 0.36 & $1.4(1.1-1.9)$ & 6.6 & 0.01 \\
\hline History of stroke & 0.51 & $1.7(1.1-2.5)$ & 5.9 & 0.015 \\
\hline Graft stenting & 0.47 & $1.6(0.82-3.1)$ & 1.9 & 0.17 \\
\hline LCX stenting & 0.34 & $1.4(1.1-1.9)$ & 5.3 & 0.021 \\
\hline NYHA class 4 & 0.89 & $2.4(1.1-5.3)$ & 5.1 & 0.025 \\
\hline Haematocrit (per \% increase) & -0.034 & $0.97(0.94-1)$ & 4.6 & 0.032 \\
\hline Diabetes Mellitus & 0.29 & $1.3(1-1.8)$ & 4.5 & 0.035 \\
\hline White blood cell count (per 109/L increase) & 0.062 & $1.1(1-1.1)$ & 4.4 & 0.035 \\
\hline Haemoglobin (per mmol/L increase) & -0.15 & $0.86(0.75-0.99)$ & 4.3 & 0.038 \\
\hline 3 vessels stented & 0.62 & $1.9(1-3.4)$ & 4 & 0.046 \\
\hline NYHA class $3 / 4$ & 0.44 & $1.5(1-2.4)$ & 3.9 & 0.048 \\
\hline Prior coronary revascularization & 0.27 & $1.3(0.99-1.7)$ & 3.6 & 0.057 \\
\hline Number of vessels stented (per vessel increase) & 0.22 & $1.3(0.97-1.6)$ & 2.9 & 0.088 \\
\hline Insuline dependent diabetes mellitus & 0.33 & $1.4(0.94-2.1)$ & 2.8 & 0.095 \\
\hline Body-mass index (per kg/m2 increase) & -0.022 & $0.98(0.95-1)$ & 2.5 & 0.12 \\
\hline Thrombus containing lesion & 0.64 & $1.9(0.84-4.3)$ & 2.4 & 0.12 \\
\hline Prior $\mathrm{PCl}$ & 0.19 & $1.2(0.91-1.6)$ & 1.7 & 0.19 \\
\hline Prior CABG & 0.26 & $1.3(0.86-1.9)$ & 1.6 & 0.21 \\
\hline 1 vessel stented & -0.21 & $0.81(0.58-1.1)$ & 1.5 & 0.22 \\
\hline Alcohol abuse & -0.17 & $0.85(0.64-1.1)$ & 1.4 & 0.23 \\
\hline Bifurcation stenting & -0.6 & $0.55(0.2-1.5)$ & 1.4 & 0.24 \\
\hline Arterial graft stenting & 0.83 & $2.3(0.57-9.2)$ & 1.4 & 0.25 \\
\hline NYHA class 3 & 0.26 & $1.3(0.82-2)$ & 1.2 & 0.28 \\
\hline Hypercholesterolemia & -0.15 & $0.86(0.65-1.1)$ & 1.1 & 0.3 \\
\hline Female sex & -0.13 & $0.88(0.63-1.2)$ & 0.59 & 0.44 \\
\hline Hypertension & 0.14 & $1.2(0.78-1.7)$ & 0.5 & 0.48 \\
\hline Atrial fibrillation or flutter at baseline ECG & 0.092 & $1.1(0.83-1.4)$ & 0.44 & 0.51 \\
\hline LAD stented & -0.09 & $0.91(0.7-1.2)$ & 0.42 & 0.52 \\
\hline
\end{tabular}


Table 2: Continued

\begin{tabular}{|c|c|c|c|c|}
\hline & beta & HR ( $95 \% \mathrm{Cl}$ for HR) & wald test & $p$ value \\
\hline Past or active smoker & 0.085 & $1.1(0.83-1.4)$ & 0.37 & 0.54 \\
\hline Hyper coagulable condition & -0.57 & $0.57(0.079-4)$ & 0.32 & 0.57 \\
\hline Prior systemic embolism & -0.54 & $0.58(0.081-4.2)$ & 0.29 & 0.59 \\
\hline History of malignancy & -0.13 & $0.88(0.53-1.5)$ & 0.26 & 0.61 \\
\hline Total stent length $>30 \mathrm{~mm}$ & 0.12 & $1.1(0.71-1.8)$ & 0.25 & 0.62 \\
\hline Venous graft stenting & 0.14 & $1.2(0.47-2.8)$ & 0.10 & 0.76 \\
\hline In-stent restenosis stenting & 0.12 & $1.1(0.42-3)$ & 0.06 & 0.81 \\
\hline STEMI at baseline & 0.05 & $1.1(0.69-1.6)$ & 0.05 & 0.82 \\
\hline Prior VTE/SE & -0.083 & $0.92(0.43-2)$ & 0.05 & 0.83 \\
\hline Complex lesion stented & 0.038 & $1(0.74-1.5)$ & 0.05 & 0.83 \\
\hline Active smoker & 0.028 & $1(0.69-1.5)$ & 0.02 & 0.89 \\
\hline History of venous thromboembolism & -0.047 & $0.95(0.42-2.1)$ & 0.01 & 0.91 \\
\hline$>2$ lesions per vessel stenting & 0.015 & $1(0.57-1.8)$ & 0 & 0.96 \\
\hline Unprotected left main stenting & 0.02 & $1(0.38-2.7)$ & 0 & 0.97 \\
\hline Prior major bleeding or predisposition to bleeding & -15 & $3 e-07$ (0-Inf) & 0 & 0.99 \\
\hline Prior brachytherapy lesion stenting & -12 & $6.1 e-06(0-\operatorname{lnf})$ & 0 & 0.99 \\
\hline
\end{tabular}

After stepwise selection, the multivariable Cox regression model predicting ischaemic events contained left ventricular ejection fraction, number of diseased vessels, $\mathrm{Ml}$ as indication for index- $\mathrm{PCl}$, thrombocyte count, peripheral artery disease and creatinine clearance. (Table 3). The discriminatory capacity of the ischaemic model was fair (AUC 0.68, Cl 0.64-0.72, Figure S1).

Table 3: Cox proportional hazards model.

Analysis stratified for access site, and stent type

\begin{tabular}{lll}
\hline Predictor of events & HR $(95 \% \mathrm{Cl})$ & P value \\
\hline LVEF at baseline (per \% increase) & $0.973(0.963-0.984)$ & $<0.001$ \\
Number of diseased vessels & $1.376(1.162-1.631)$ & $<0.001$ \\
MI as indication for index-PCI & $1.693(1.284-2.233)$ & $<0.001$ \\
Platelet count (per $10^{9} / \mathrm{l}$ increase) & $1.003(1.001-1.005)$ & 0.002 \\
Peripheral artery disease & $1.739(1.152-2.627)$ & 0.008 \\
Creatinin clearance $\left(\right.$ per $\left.\mathrm{ml} / \mathrm{min} / \mathrm{m}^{2}\right)$ & $0.990(0.983-0.998)$ & 0.011 \\
\hline
\end{tabular}

Concordance $=$

Rsquare $=$

Likelihood ratio test $=$

Wald test $=$

Score (logrank) test $=$ $0.688(\mathrm{se}=0.032)$

$0.033($ max possible $=0.634$ )

91.36 on $6 \mathrm{df}, \mathrm{p}=<2 \mathrm{e}-16$

98.5 on $6 \mathrm{df}, \mathrm{p}=<2 \mathrm{e}-16$

100.6 on $6 \mathrm{df}, \mathrm{p}=<2 \mathrm{e}-16$ 
Observed ischemic and bleeding outcomes and mortality rates by quintiles for predicted hazards are depicted in Figure 1 and Table S1. Goodness of fit as assessed by HosmerLemeshow test was found to be good $(p=1.000)$. Incidence of ischaemic events ranged from $3.9 \%$ for the lowest quintile of thrombotic risk to $15.8 \%$ for the highest risk quintile. Comparing high-risk patients to low-intermediate risk patients, significantly more thromboembolic events were found in the high-risk patients ( $15.8 \%$ vs. $5.6 \%, p<0.001$, Table S1)

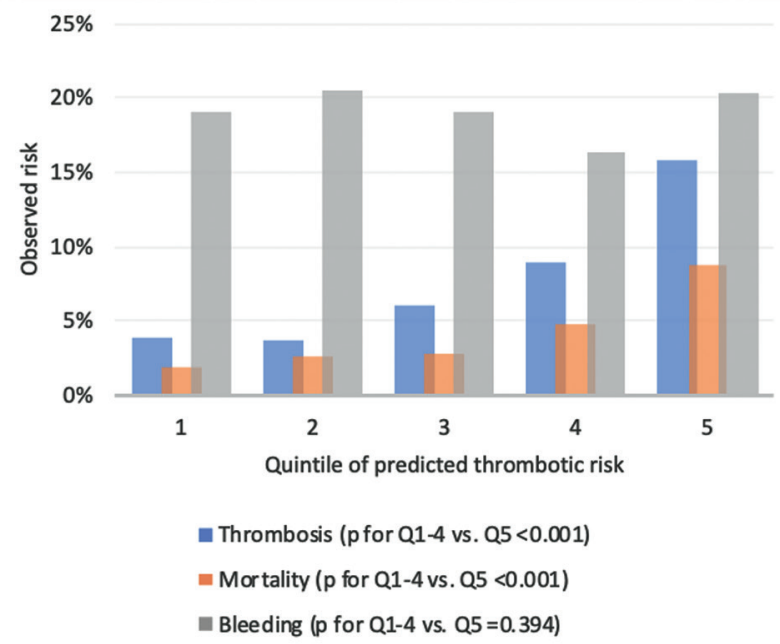

Figure 1:

Observed outcomes with the multivariable model for combined thrombotic end point, BARC 2,3 or 5 bleeding and mortality.

A numerical reduction of the thrombotic end point was observed in patients at the highest thrombotic risk treated with TAT as compared to DAT (Figure 2A). This effect was most pronounced in patients $>95^{\text {th }}$ percentile of thrombotic risk (Fig. 2B).

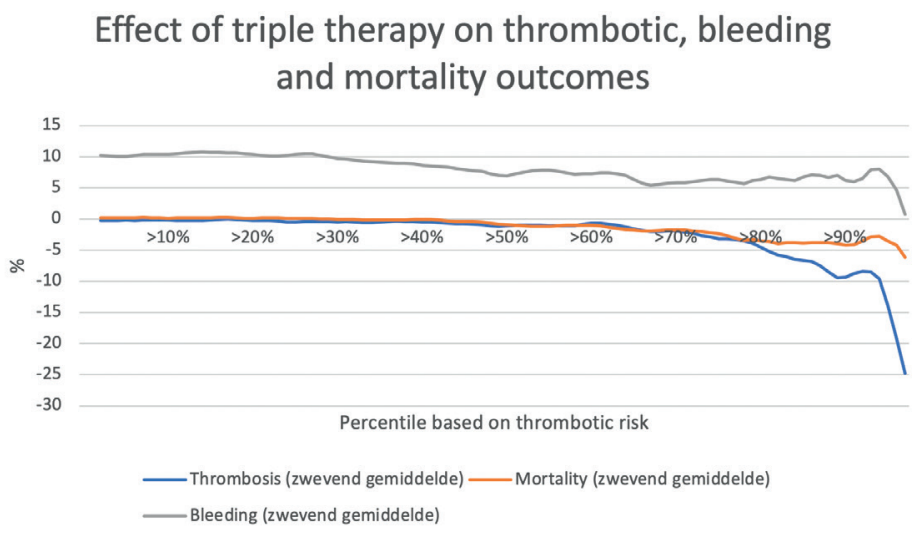

Figure 2:

Absolute risk difference of TAT vs. DAT for thrombotic end point, mortality and BARC 2, 3, 5 bleeding. 
B Effect of triple therapy on thrombotic, bleeding and mortality outcomes

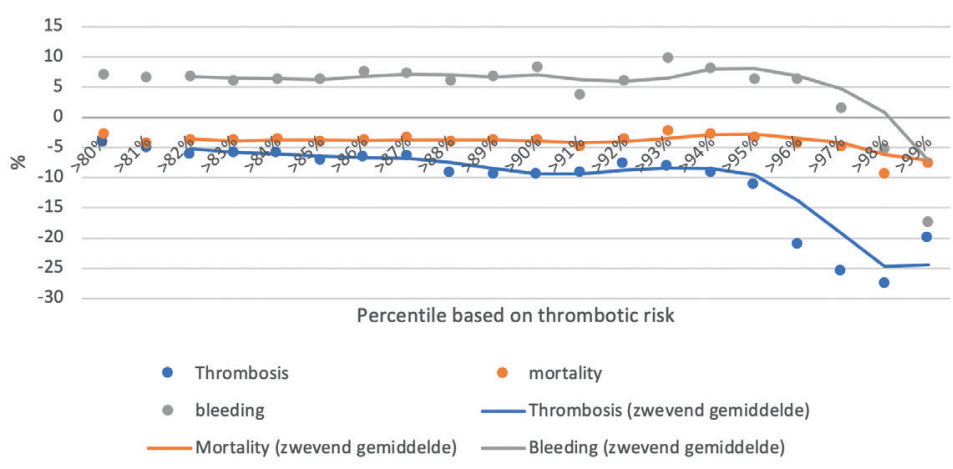

Figure 2: Continued

The simplified prediction rule based on the Cox regression model contained 7 variables (Table 4) and retained fair accuracy comparable to the original Cox regression model (AUC $0.66(0.62-0.69$, Fig. S2). The total risk score ranged from -1 points to 8 points. Higher scores were associated with a higher risk of thrombotic events $\left(p_{\text {trend }}<0.001\right)$. The calibration curve demonstrated excellent calibration for the combined thrombotic end point (Fig S3).

Table 4: Simplified prediction model.

\begin{tabular}{ll}
\hline LVEF $<30 \%$ & 3 \\
LVEF $30-50 \%$ & 1 \\
3-vessel disease & $\mathbf{2}$ \\
MI as indication for index-PCl & 2 \\
Platelet count $>400 * 109 / I$ & 3 \\
eGFR $>90 \mathrm{ml} / \mathrm{min} / \mathrm{m} 2$ & -1 \\
History of peripheral artery disease & $\mathbf{2}$ \\
\hline
\end{tabular}

When using a $>5$ points cut-off, a trend towards a reduction of the composite thrombotic end point in patients treated with TAT as compared to DAT was observed ( $p=0.09$, figure $3 A$ ). A significant reduction of myocardial infarction or stent thrombosis was also observed $(6.3 \%$ vs. $21.0 \%$, $p=0.04$; Fig. $3 B$ ). 


\section{A: Observed ischaemic outcomes}

Observed ischaemic outcomes

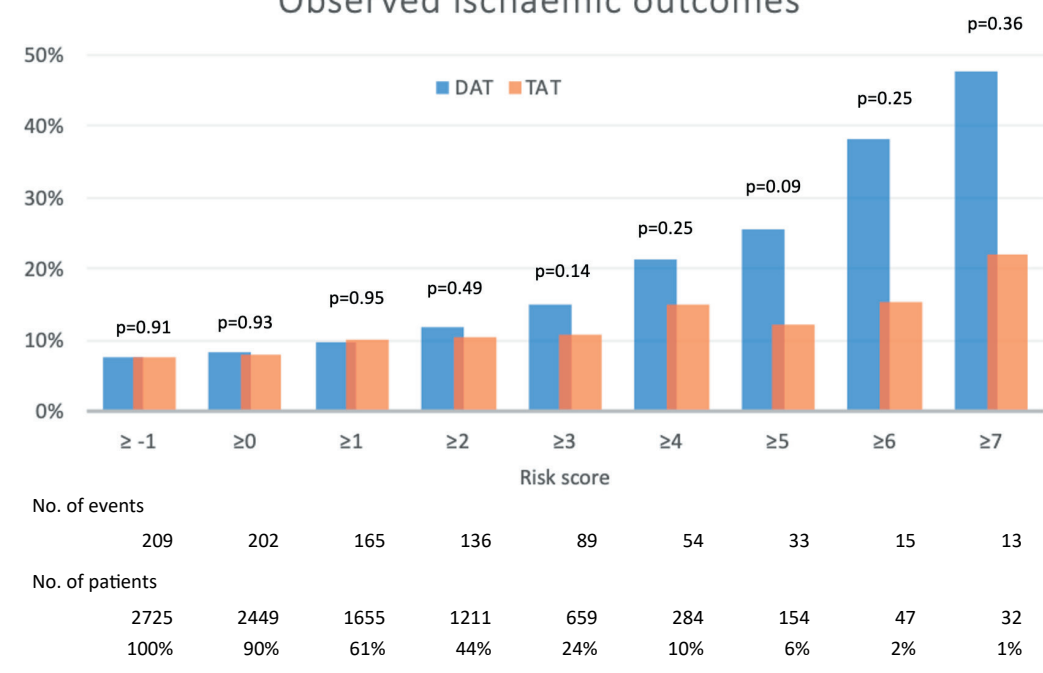

\section{B: Observed MI/ST outcomes}

Observed MI/ST outcomes

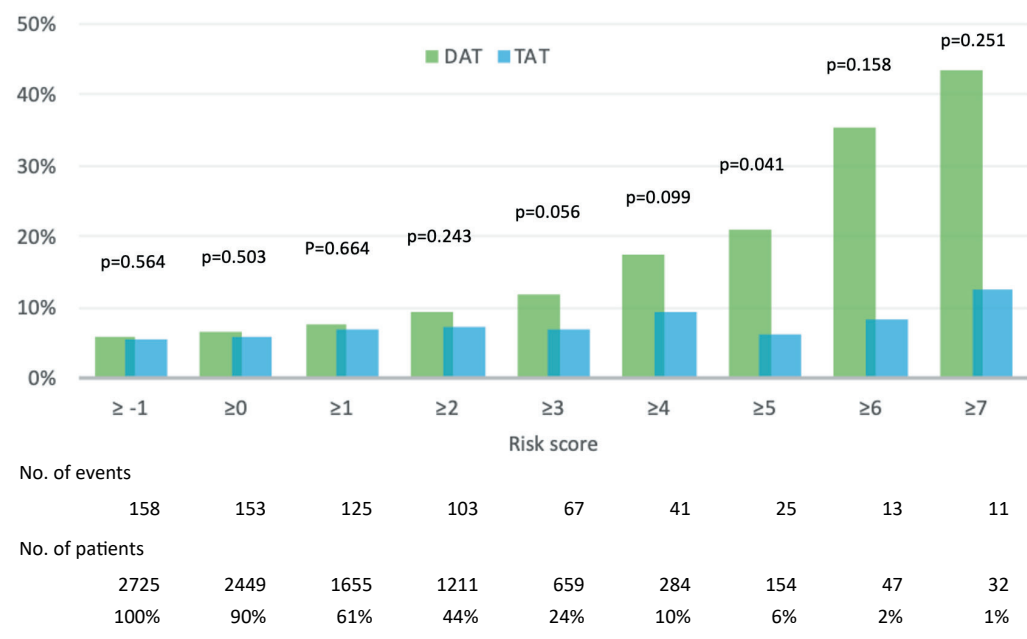

\section{Figure 3:}

Observed Outcomes for DAT vs TAT for different cut-offs of risk score. 


\section{C: Observed bleeding outcomes BARC $2+3+5$}

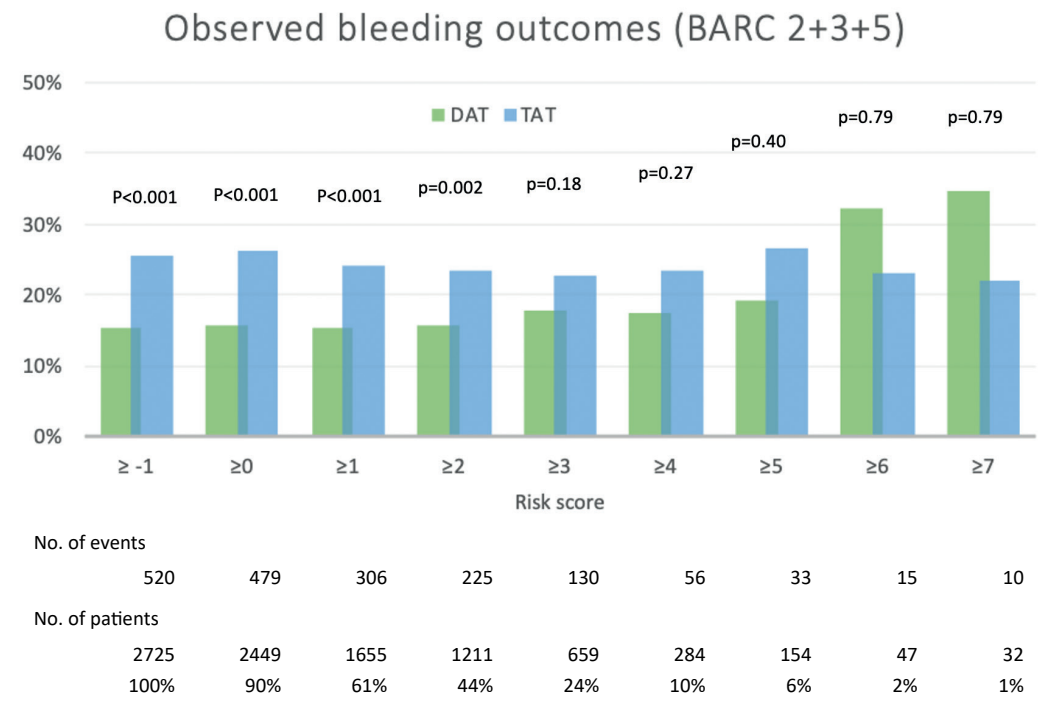

Figure 3: Continued

When considering other outcomes, bleeding events outnumbered ischemic events across all risk categories (Fig. 1) with a significant increase in patients using TAT as compared with DAT (Fig. 3C and S3B) in patients with low thrombotic risk. In patients $>95^{\text {th }}$ percentile of thrombotic risk or with a risk score $\geq 6$ the incremental bleeding risk of triple therapy was not found (Fig. 2 and Fig. 3C). A numerical benefit from TAT as compared to DAT with regard to net clinical benefit was found for patients with a risk score cut-off $\geq 5$, whereas in low risk patients treated with TAT a significantly poorer net clinical benefit was observed as compared to patients treated with DAT (Fig. S3).

\section{External validation}

The risk score was externally validated in the WOEST 2 registry. Discriminative capacity was similar to the internal validation (C-statistic $0.63, \mathrm{Cl} 0.56-0.70$, Fig. S5).

The score had an excellent overall ability to identify high risk patients with higher scores corresponding to higher risk of thrombotic outcomes ( $p$ for trend $<0.001$, Fig. 4). A score $\geq 5$ identified $11.8 \%$ of all patients at high thrombotic risk. Thrombotic risk in these highrisk patients was significantly higher as compared to the remainder of the cohort $(16.3 \% \mathrm{vs}$ $6.7 \%, p=0.001$ ). 


\section{Duration of triple therapy}

To study the timing of thrombotic events, a Kaplan Meier curve was constructed (Fig. 5) with separate outcomes for high-risk patients (risk score $\geq 5$ ) and patients not at high risk (risk score $<5$ ). Interestingly, the curves of high-risk patients continued to diverge beyond the first month up to 90 days after $\mathrm{PCl}$. Although this study cannot provide a definitive answer to the question of optimal treatment duration when TAT is given, this observation suggests that a substantial proportion of events continues to take place after the first month in patients treated with DAT but not in those treated with TAT. Therefore, when TAT is prescribed in patients at high thrombotic risk and TAT is well tolerated by the patient in the first month, continuing TAT up to three months might be considered.

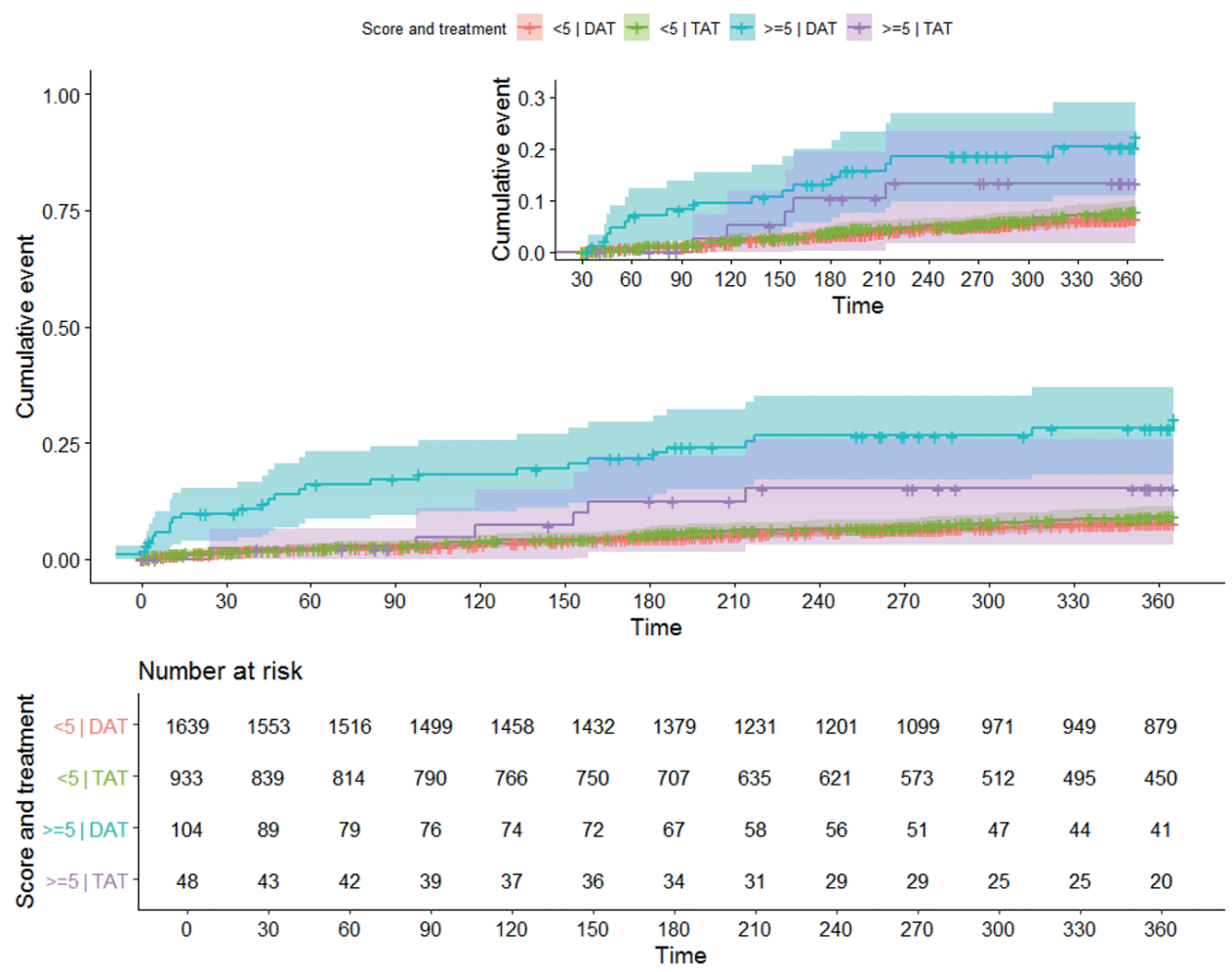

Figure 5:

Kaplan Meier curves for the timing of the combined thrombotic end point (with landmark analysis for events $>30$ days).

\section{Performance of the $\mathrm{CHA}_{2} \mathrm{DS}_{2}$-VASc score}

When applying the $\mathrm{CHA}_{2} \mathrm{DS}_{2}$-VASc in the RE-DUAL cohort, it showed only modest accuracy for the combined thrombotic end point (AUC 0.58 (CI 0.54-0.62, Fig. S6). 


\section{Discussion}

This study sought to identify AF patients undergoing $\mathrm{PCl}$ at high risk for recurrent ischemic events who might benefit from TAT. The model was able to identify patients with high thrombotic risk. Triple therapy in these patients at high thrombotic risk was associated with a numerical reduction in thrombo-embolic events as compared to DAT. A simplified prediction rule found a significant reduction in MI/ST with TAT in patients with a risk score $>5$. Importantly, the lower incidence of ischaemic events with TAT as compared to DAT was outnumbered by an increase in bleeding events in the overall population but not in patients at the highest thrombotic risk.

The observation of a reduction in ischaemic events in high-risk patients is in line with some meta-analysis and subgroup analyses which pointed to a possible benefit of TAT, especially in high risk patients. Two meta-analysis of randomised controlled trials signalled a reduction in terms of stent thrombosis (and a trend for myocardial infarction) associated with TAT ${ }^{14,16}$. Stent thrombosis was significantly reduced, although incidence rates were bvery low, although other meta-analyses did not support this findings ${ }^{5,20,21}$.

Our study is the first study to investigate the effect of TAT in patients at high thrombotic risk represented by a combination of high-risk characteristics. Several subgroup analyses of the randomised controlled trials based on single clinical variables (e.g. diabetes, age $\geq 80$ years, ACS patients) could not demonstrated a reduction in ischemic events associated with TAT ${ }^{22-24}$, which illustrates the complex and multifactorial aspect of high thrombotic risk which was adequately addressed in the current study by combining multiple patients characteristics.

Further randomised controlled studies will be needed to adequately address the question of TAT vs. DAT, particularly in high-risk patients. Of note, the results of the MASTER DAPT trial are expected this year. This randomised controlled trial (NCT03023020) specifically focuses on the sub group of patients at high bleeding risk ${ }^{25}$ in both patients with and without OAC. After a mandatory 30-day DAPT run-in phase, patients with clinically indicated OAC are randomized to up to a total of three months of DAPT vs. single antiplatelet therapy after the first month. The results of the trial, which aims to recruit approximately 4,300 HBR patients from $\geq 100$ interventional cardiology centers globally are to be awaited in 2021 .

\section{Clinical implications}

Using this prediction rule containing seven clinical, angiographical and procedural parameters, a significant reduction in MI/ST associated with TAT was found in patients at high thrombotic risk undergoing $\mathrm{PCl}$, without a penalty in terms of bleeding. Our findings are an important "proof of concept", which is in line with general beliefs of many cardiologists with regard to high-risk patients. 
On the other hand, for the majority of the population no benefit of TAT was found - and even harm in patients at low thrombotic risk, in whom an increase in BARC3 and 5 bleeding and a poorer net clinical benefit was observed. Therefore, our findings support the utilisation of DAT rather than TAT in the majority of AF patients undergoing $\mathrm{PCl}$, while reserving TAT for a small proportion of patients - as was adapted in the most recent ESC guideline on nonSTEMI ${ }^{7}$.

\section{Limitations}

The TAT arm in this study comprised vitamin $\mathrm{K}$ antagonists whereas in contemporary clinical practice NOACs are standard care for its favourable safety profile. In the RE-DUAL trial, DAT including a NOAC was compared to TAT using a VKA, which might have exaggerated bleeding risk in the latter group.

Although an overall increase of bleeding associated with TAT was observed, numerically fewer bleeding events were observed in patients with a risk score of $\geq 5$, which is an interesting observation and could be due to greater degrees of thrombin activation. A similar assymetrical treatment effect was observed in the PRECISE-DAPT bleeding score, in whom patients at high bleeding risk did no longer have a benefit in terms of a reduction in ischaemic events. Alternatively, this observation might be a play of chance or due to low patients numbers.

The performance of the score was good in the WOEST 2 registry which served as an external validation cohort. Although the AUC of 0.63 was modest (and typical of risk scores based on clinical factors), this applies to the overall fit of the risk score and does not necessarily correspond to the ability of the score to identify the patients at the highest risk. Finally, differences between DAT and TAT could not be tested, due to the indication bias inherent to the design of an observational registry. Before adapting this novel risk score into daily clinical practice, further external validation in randomised controlled trials is needed.

\section{Conclusion}

A clinical prediction rule was developed to estimate thrombotic risk in AF patients undergoing $\mathrm{PCl}$. The model was able to identify a subgroup of high-risk patients comprising $5 \%$ of the patients, in whom a significant reduction in MI/ST was observed with TAT, without a penalty in terms of bleeding. For patients not at high thrombotic risk, no benefit and even harm was found. Our findings support the use of TAT in this small subgroup of high-risk patients, while using DAT in the majority of AF patients undergoing $\mathrm{PCl}$. 


\section{References}

1. Hindricks G., Potpara T., Dagres N., et al. 2020 ESC Guidelines for the diagnosis and management of atrial fibrillation developed in collaboration with the European Association of Cardio-Thoracic Surgery (EACTS). Eur Heart J 2020. Doi: 10.1093/eurheartj/ehaa612.

2. Neumann F-J., Sousa-Uva M., Ahlsson A., et al. 2018 ESC/EACTS Guidelines on myocardial revascularization. European Heart Journal 2019;40(2):87-165. Doi: 10.1093/eurheartj/ehy394.

3. Valgimigli M., Bueno H., Byrne RA., et al. 2017 ESC focused update on dual antiplatelet therapy in coronary artery disease developed in collaboration with EACTS: The Task Force for dual antiplatelet therapy in coronary artery disease of the European Society of Cardiology (ESC) and of the European Association for Cardio-Thoracic Surgery (EACTS). European Heart Journal 2017. Doi: 10.1093/eurheartj/ehx419.

4. Mehta SR. Refining Antithrombotic Therapy for Atrial Fibrillation and Acute Coronary Syndromes or PCI. The New England Journal of Medicine 2019;380(16):1580-1. Doi: 10.1056/ NEJMe1902214.

5. Golwala HB., Cannon CP., Steg PG., et al. Safety and efficacy of dual vs. triple antithrombotic therapy in patients with atrial fibrillation following percutaneous coronary intervention: a systematic review and meta-analysis of randomized clinical trials. Eur Heart J 2018;39(19):1726-1735a. Doi: 10.1093/eurheartj/ehy162.

6. Lamberts M., Gislason GH., Olesen JB., et al. Oral anticoagulation and antiplatelets in atrial fibrillation patients after myocardial infarction and coronary intervention. J Am Coll Cardiol 2013;62(11):981-9. Doi: 10.1016/j.jacc.2013.05.029.

7. Collet J-P., Thiele H., Barbato E., et al. 2020 ESC Guidelines for the management of acute coronary syndromes in patients presenting without persistent ST-segment elevation. Eur Heart J 2020. Doi: 10.1093/eurheartj/ehaa575.

8. Angiolillo DJ., Goodman SG., Bhatt DL., et al. Antithrombotic Therapy in Patients With Atrial Fibrillation Treated With Oral Anticoagulation Undergoing Percutaneous Coronary Intervention. Circulation 2018;138(5):527-36. Doi: 10.1161/CIRCULATIONAHA.118.034722.

9. Dewilde WJM., Oirbans T., Verheugt FWA., et al. Use of clopidogrel with or without aspirin in patients taking oral anticoagulant therapy and undergoing percutaneous coronary intervention: an open-label, randomised, controlled trial. Lancet (London, England) 2013;381(9872):1107-15. Doi: 10.1016/S0140-6736(12)62177-1.

10. Cannon CP., Bhatt DL., Oldgren J., et al. Dual Antithrombotic Therapy with Dabigatran after PCI in Atrial Fibrillation. N Engl J Med 2017;377(16):1513-24. Doi: 10.1056/NEJMoa1708454.

11. Gibson CM., Mehran R., Bode C., et al. Prevention of Bleeding in Patients with Atrial Fibrillation Undergoing PCl. N Engl J Med 2016;375(25):2423-34. Doi: 10.1056/NEJMoa1611594.

12. Lopes RD., Heizer G., Aronson R., et al. Antithrombotic Therapy after Acute Coronary Syndrome or PCl in Atrial Fibrillation. N Engl J Med 2019;380(16):1509-24. Doi: 10.1056/ NEJMoa1817083. 
13. Vranckx P., Valgimigli M., Eckardt L., et al. Edoxaban-based versus vitamin $\mathrm{K}$ antagonist-based antithrombotic regimen after successful coronary stenting in patients with atrial fibrillation (ENTRUST-AF PCI): a randomised, open-label, phase 3b trial. Lancet 2019;394(10206):1335-43. Doi: 10.1016/S0140-6736(19)31872-0.

14. Gargiulo G., Goette A., Tijssen J., et al. Safety and efficacy outcomes of double vs. triple antithrombotic therapy in patients with atrial fibrillation following percutaneous coronary intervention: a systematic review and meta-analysis of non-vitamin $\mathrm{K}$ antagonist oral anticoagulant-based randomized clinical trials. Eur Heart J 2019;40(46):3757-67. Doi: 10.1093/ eurheartj/ehz732.

15. Godino C., Pivato CA., Rubino C., Russi A., Cera M., Margonato A. Antithrombotic Therapy After Percutaneous Coronary Intervention in Atrial Fibrillation. Am J Cardiol 2020;129:122-4. Doi: 10.1016/j.amjcard.2020.05.012.

16. Potpara TS., Mujovic N., Proietti M., et al. Revisiting the effects of omitting aspirin in combined antithrombotic therapies for atrial fibrillation and acute coronary syndromes or percutaneous coronary interventions: meta-analysis of pooled data from the PIONEER AF-PCI, RE-DUAL PCI, and AUGUSTUS trials. Europace 2020;22(1):33-46. Doi: 10.1093/europace/euz259.

17. Alexander JH., Wojdyla D., Vora AN., et al. The Risk / Benefit Tradeoff of Antithrombotic Therapy in Patients with Atrial Fibrillation Early and Late After an Acute Coronary Syndrome or Percutaneous Coronary Intervention: Insights from AUGUSTUS. Circulation 2020. Doi: 10.1161/ CIRCULATIONAHA.120.046534.

18. Cannon CP., Gropper S., Bhatt DL., et al. Design and Rationale of the RE-DUAL PCI Trial: A Prospective, Randomized, Phase 3b Study Comparing the Safety and Efficacy of Dual Antithrombotic Therapy With Dabigatran Etexilate Versus Warfarin Triple Therapy in Patients With Nonvalvular Atrial Fibrillation Who Have Undergone Percutaneous Coronary Intervention With Stenting. Clin Cardiol 2016;39(10):555-64. Doi: 10.1002/clc.22572.

19. Sullivan LM., Massaro JM., D'Agostino RB. Presentation of multivariate data for clinical use: The Framingham Study risk score functions. Stat Med 2004;23(10):1631-60. Doi: 10.1002/ sim.1742.

20. Lopes RD., Hong H., Harskamp RE., et al. Safety and Efficacy of Antithrombotic Strategies in Patients With Atrial Fibrillation Undergoing Percutaneous Coronary Intervention: A Network Meta-analysis of Randomized Controlled Trials. JAMA Cardiol 2019. Doi: 10.1001/ jamacardio.2019.1880.

21. Cavallari I., Patti G. Meta-Analysis Comparing the Safety and Efficacy of Dual Versus Triple Antithrombotic Therapy in Patients With Atrial Fibrillation Undergoing Percutaneous Coronary Intervention. Am J Cardiol 2018;121(6):718-24. Doi: 10.1016/j.amjcard.2017.12.014.

22. Oldgren J., Steg PG., Hohnloser SH., et al. Dabigatran dual therapy with ticagrelor or clopidogrel after percutaneous coronary intervention in atrial fibrillation patients with or without acute coronary syndrome: a subgroup analysis from the RE-DUAL PCI trial. Eur Heart J 2019;40(19):1553-62. Doi: 10.1093/eurheartj/ehz059. 
23. Windecker S., Lopes RD., Massaro T., et al. Antithrombotic Therapy in Patients with Atrial Fibrillation and Acute Coronary Syndrome Treated Medically or with Percutaneous Coronary Intervention or Undergoing Elective Percutaneous Coronary Intervention: Insights from the AUGUSTUS Trial. Circulation 2019. Doi: 10.1161/CIRCULATIONAHA.119.043308.

24. Maeng M., Steg PG., Bhatt DL., et al. Dabigatran Dual Therapy Versus Warfarin Triple Therapy Post-PCl in Patients With Atrial Fibrillation and Diabetes. JACC Cardiovasc Interv 2019;12(23):2346-55. Doi: 10.1016/j.jcin.2019.07.059.

25. Frigoli E., Smits P., Vranckx P., et al. Design and rationale of the Management of High Bleeding Risk Patients Post Bioresorbable Polymer Coated Stent Implantation With an Abbreviated Versus Standard DAPT Regimen (MASTER DAPT) Study. Am Heart J 2019;209:97-105. Doi: 10.1016/j.ahj.2018.10.009. 


\section{Supplementary material}

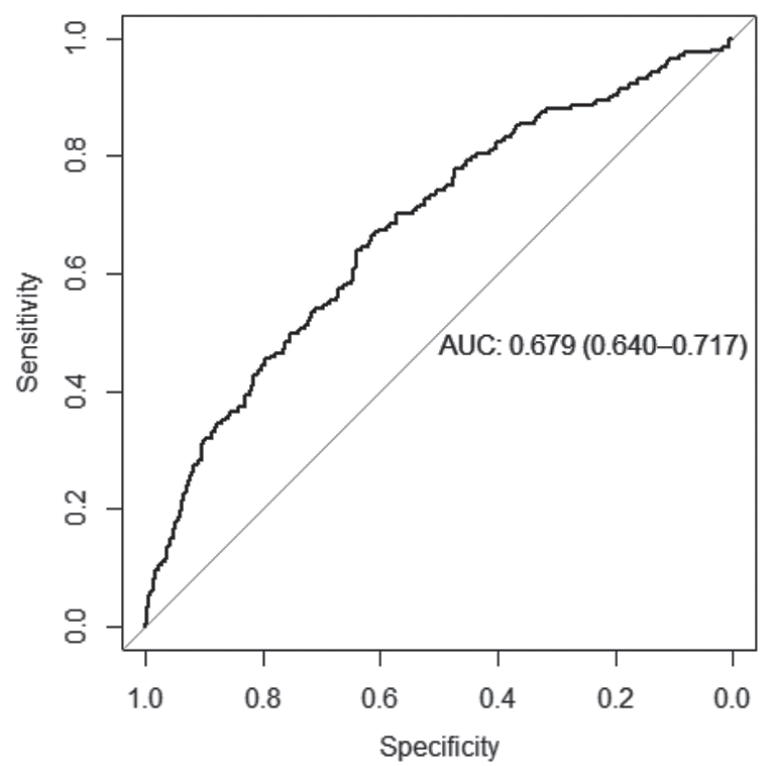

Figure S1:

Predictive accuracy for the combined thrombotic end point.

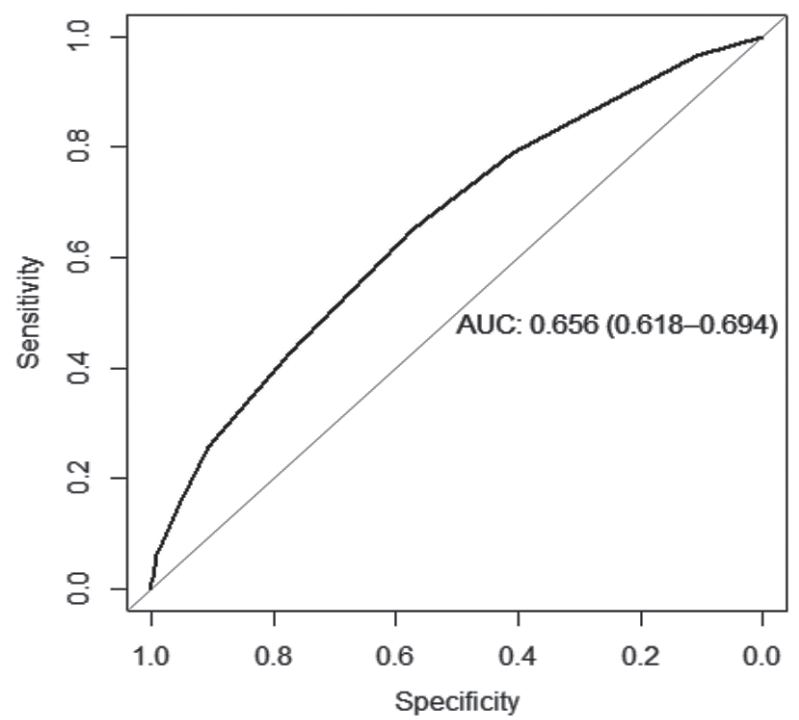

Figure S2:

Predictive accuracy for the combined thrombotic end point for the simplified prediction rule. 


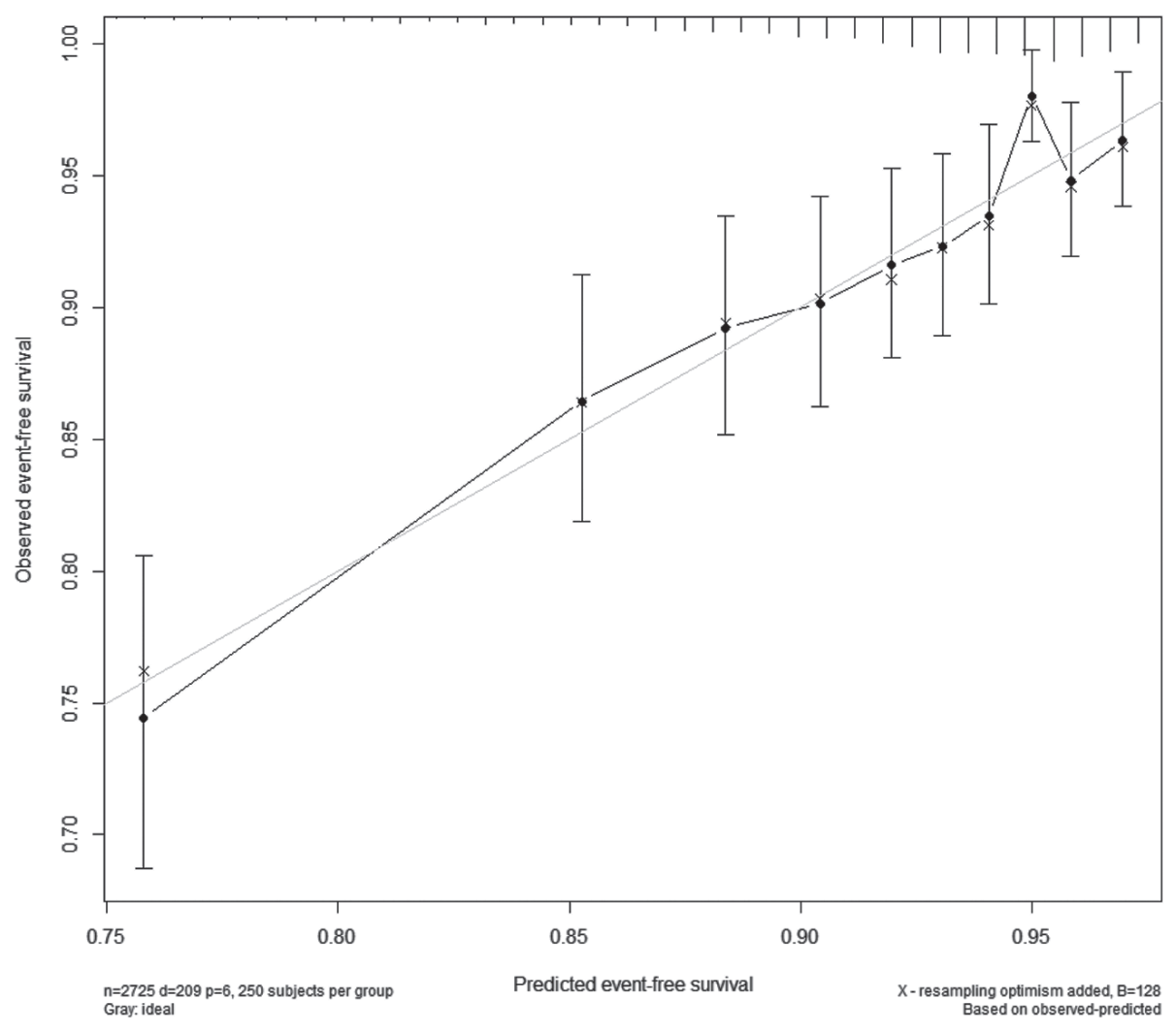

\section{Figure S3:}

Calibration curve. 


\section{A: Observed mortality outcomes}

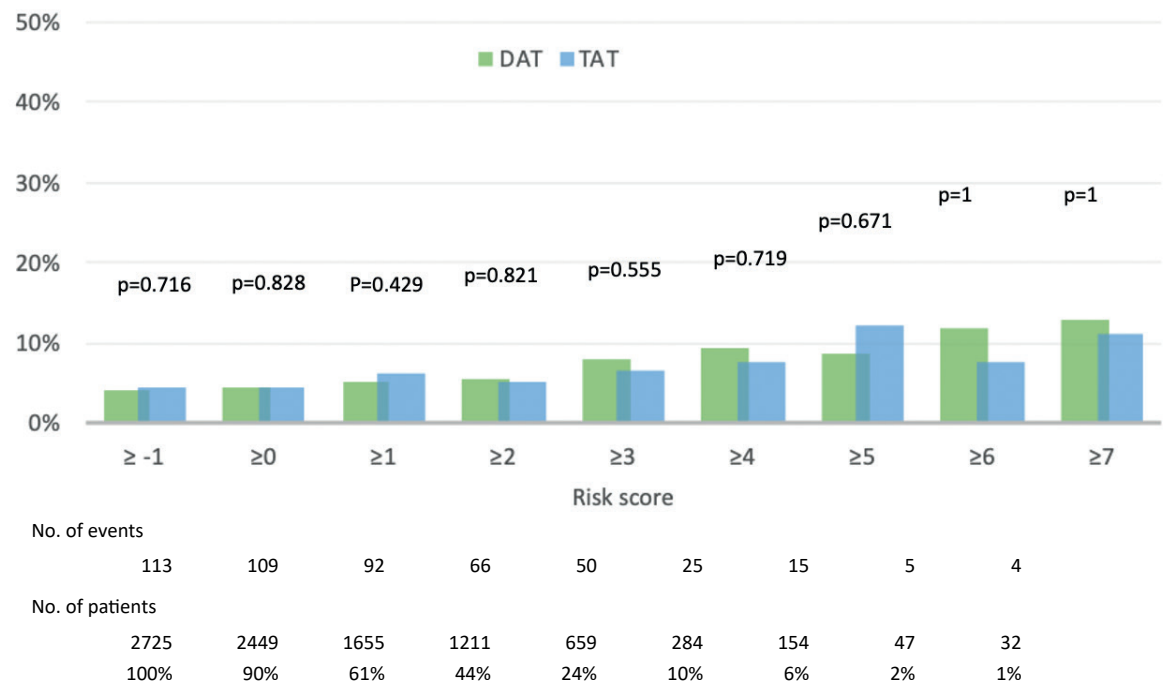

\section{B: Observed BARC $3+5$ outcomes}

$50 \%$

$$
\because \mathrm{DAT}=\mathrm{TAT}
$$

$40 \%$

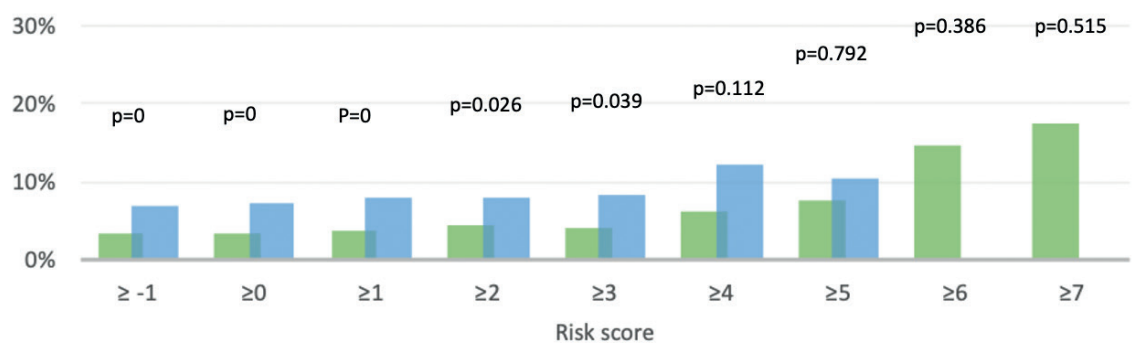

No. of events

$\begin{array}{rrrrrrrrr}127 & 122 & 89 & 70 & 37 & 24 & 13 & 5 & 4 \\ \text { No. of patients } & & & & & & & & \\ 2725 & 2449 & 1655 & 1211 & 659 & 284 & 154 & 47 & 32 \\ 100 \% & 90 \% & 61 \% & 44 \% & 24 \% & 10 \% & 6 \% & 2 \% & 1 \%\end{array}$

\section{Figure S4:}

Observed Outcomes for DAT vs TAT for different cut-offs of risk score. 


\section{C: Observed net clinical benefit (MI/ST/death/istroke/BARC2+3+5 bleeding) outcomes}

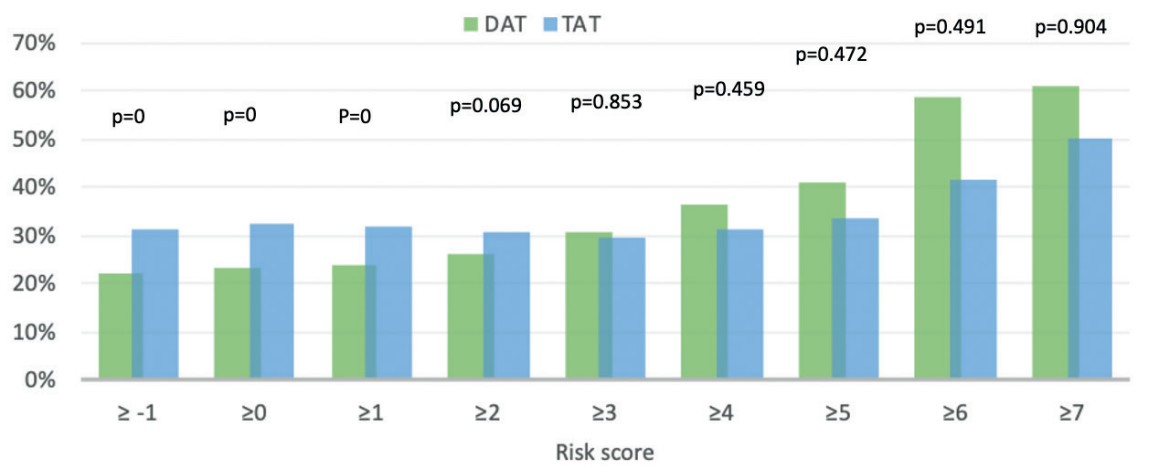

No. of events

$\begin{array}{rrrrrrrrr}696 & 647 & 445 & 336 & 200 & 98 & 59 & 26 & 19 \\ \text { No. of patients } & & & & & & & & \\ 2725 & 2449 & 1655 & 1211 & 659 & 284 & 154 & 47 & 32 \\ 100 \% & 90 \% & 61 \% & 44 \% & 24 \% & 10 \% & 6 \% & 2 \% & 1 \%\end{array}$

\section{D: Observed net clinical benefit (MI/ST/death/istroke/BARC3+5 bleeding) outcomes}

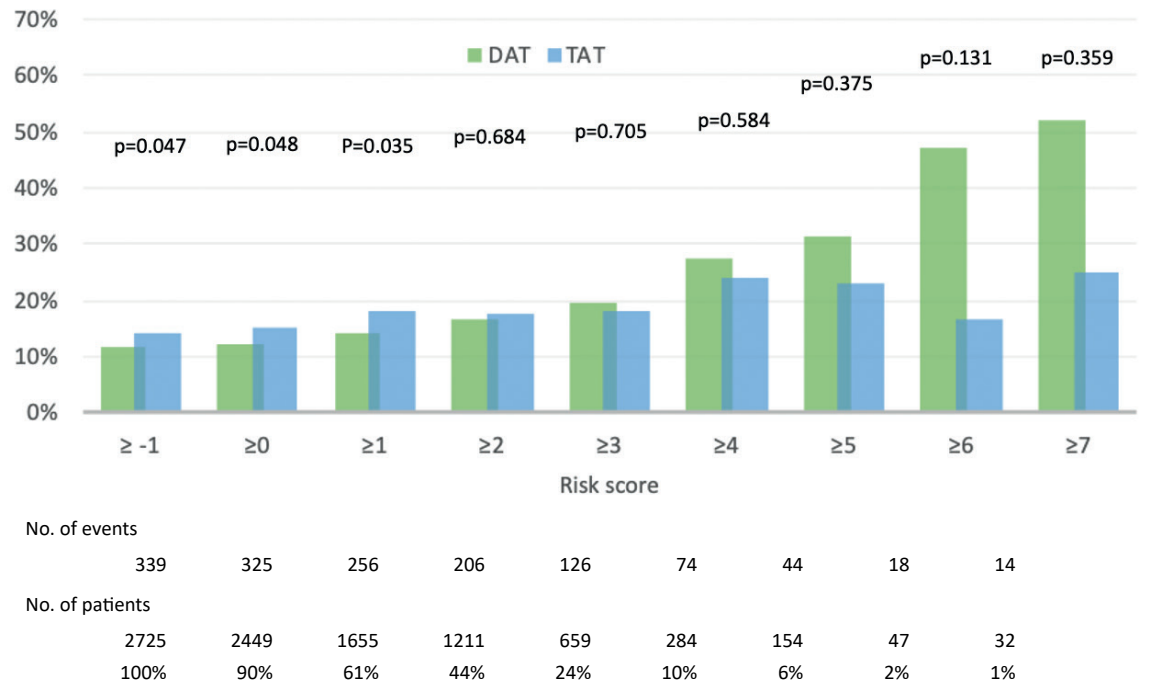

Figure S4: Continued 


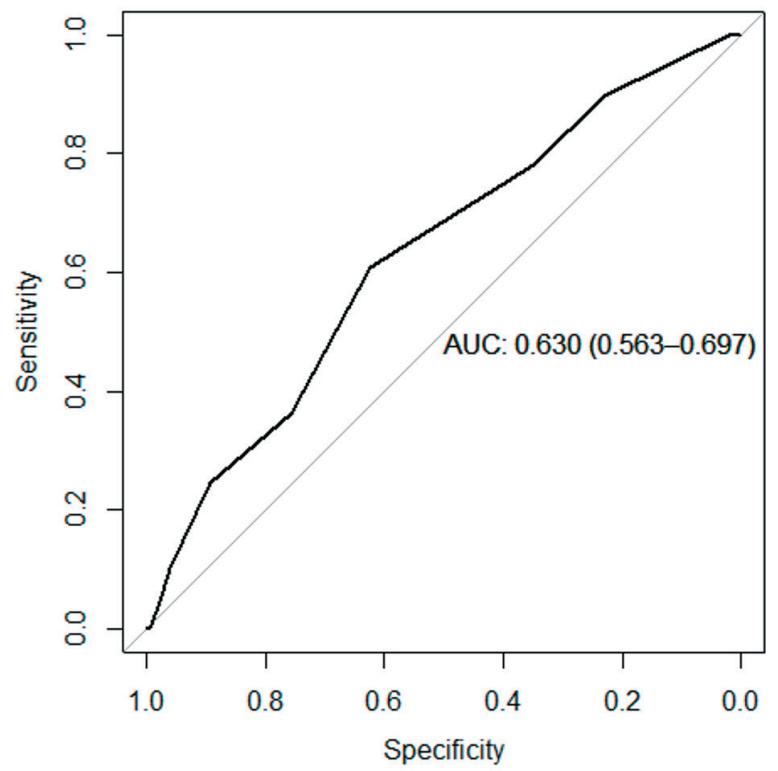

Figure S5:

C-statistic for external validation risk score in WOEST 2.

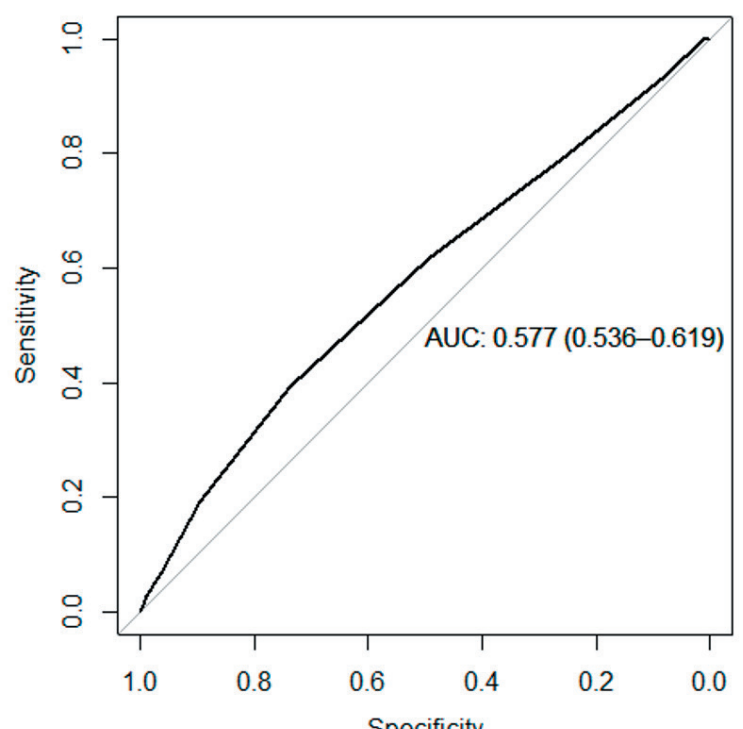

Figure S6:

C-statistic for the CHA2DS2-VASc score in the RE-DUAL cohort for the combined thrombotic end point. 


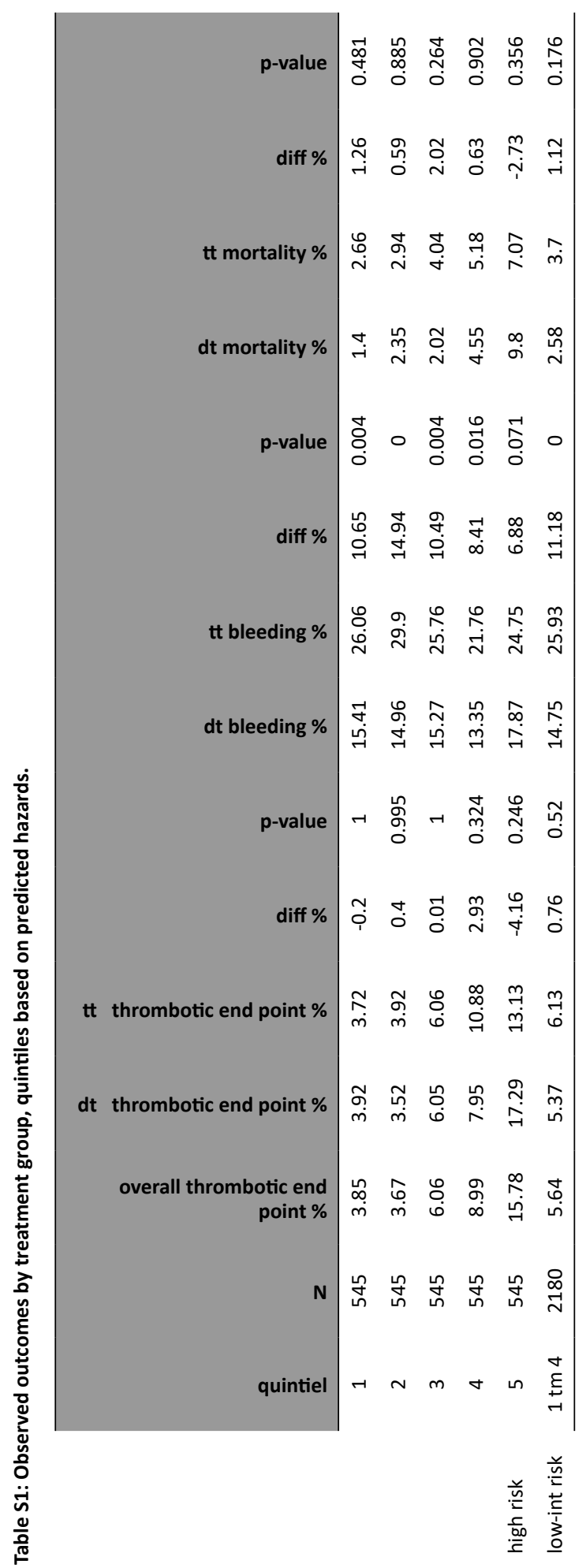




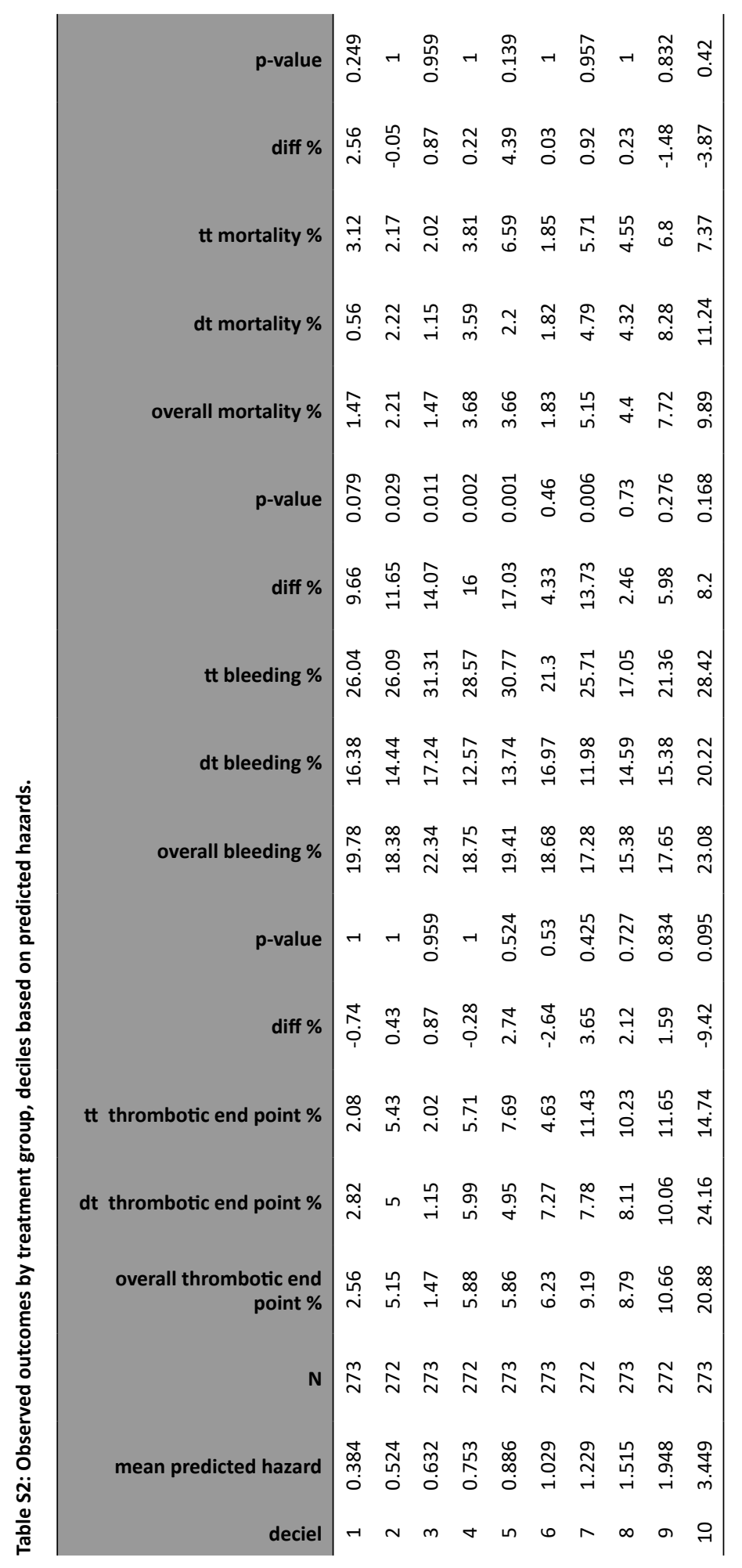




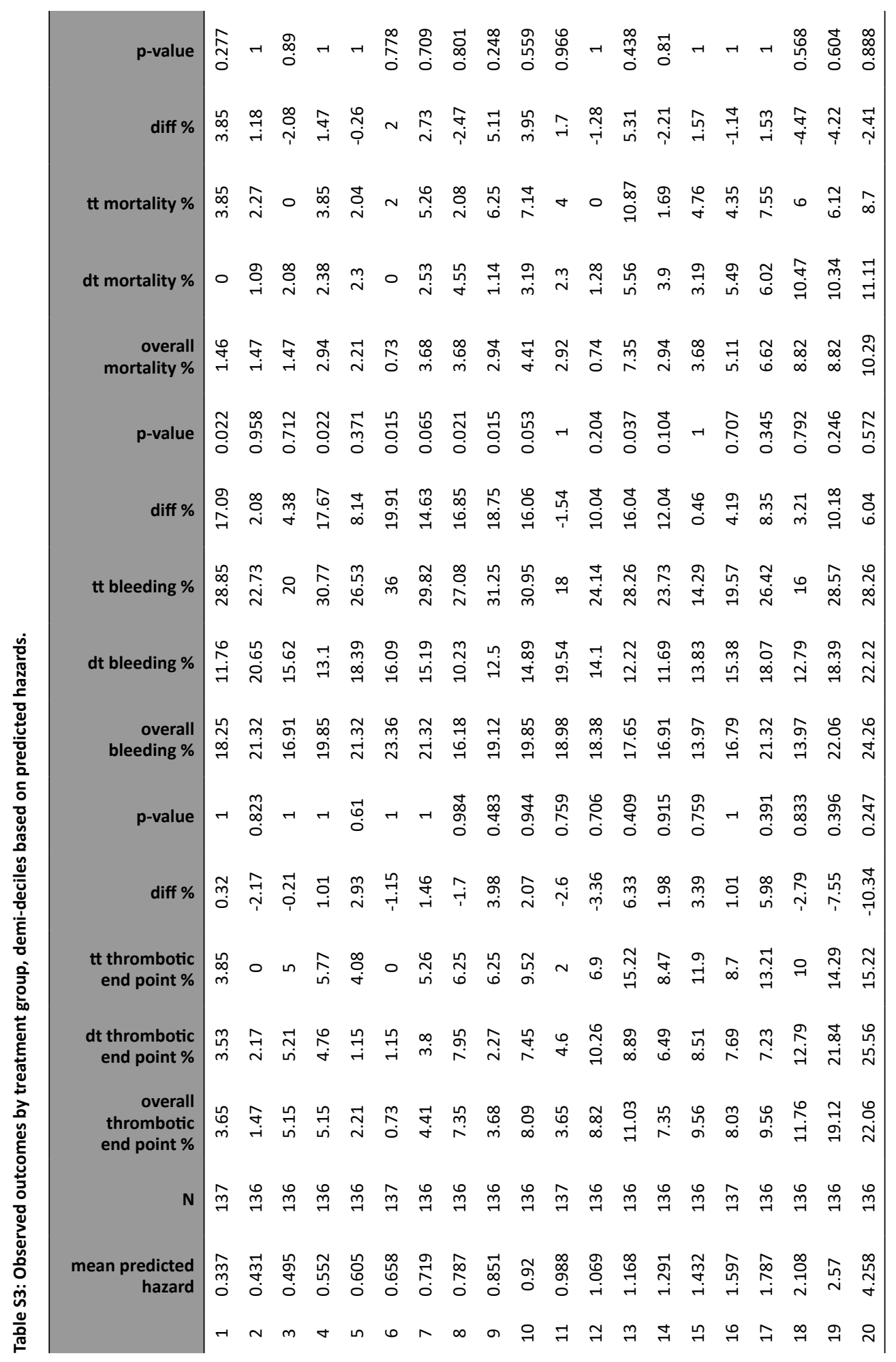


Table S4: Missing in dataset for the selected variables in the model.

\begin{tabular}{lll}
\hline & Missings & $\%$ \\
\hline LVEF & 188 & $6.90 \%$ \\
Number of diseased vessels & 63 & $2.31 \%$ \\
Myocardial infarction at baseline & 26 & $0.95 \%$ \\
Platelet count & 3 & $0.11 \%$ \\
Creatinin clearance & 12 & $0.44 \%$ \\
Peripheral artery disease & 179 & $6.57 \%$ \\
\hline
\end{tabular}

Table S5: Observed Clinical outcomes by subtypes of ischemic events.

\begin{tabular}{llllll}
\hline quintile & $\begin{array}{l}\mathbf{N} \text { in } \\
\text { quintile }\end{array}$ & $\begin{array}{l}\text { Myocardial } \\
\text { infarction N (\%) }\end{array}$ & $\begin{array}{l}\text { Stent } \\
\text { thrombosis N (\%) }\end{array}$ & $\begin{array}{l}\text { Ischemic } \\
\text { stroke N (\%) }\end{array}$ & $\begin{array}{l}\text { CV death } \\
\mathbf{N}(\%)\end{array}$ \\
\hline 1 & 545 & 2.39 & 1.83 & 0.18 & 0.92 \\
2 & 545 & 2.39 & 1.28 & 0.37 & 0.73 \\
3 & 545 & 3.12 & 2.39 & 0.92 & 1.28 \\
4 & 545 & 3.85 & 3.67 & 1.47 & 2.02 \\
5 & 545 & 8.44 & 6.61 & 2.57 & 4.40 \\
\hline
\end{tabular}




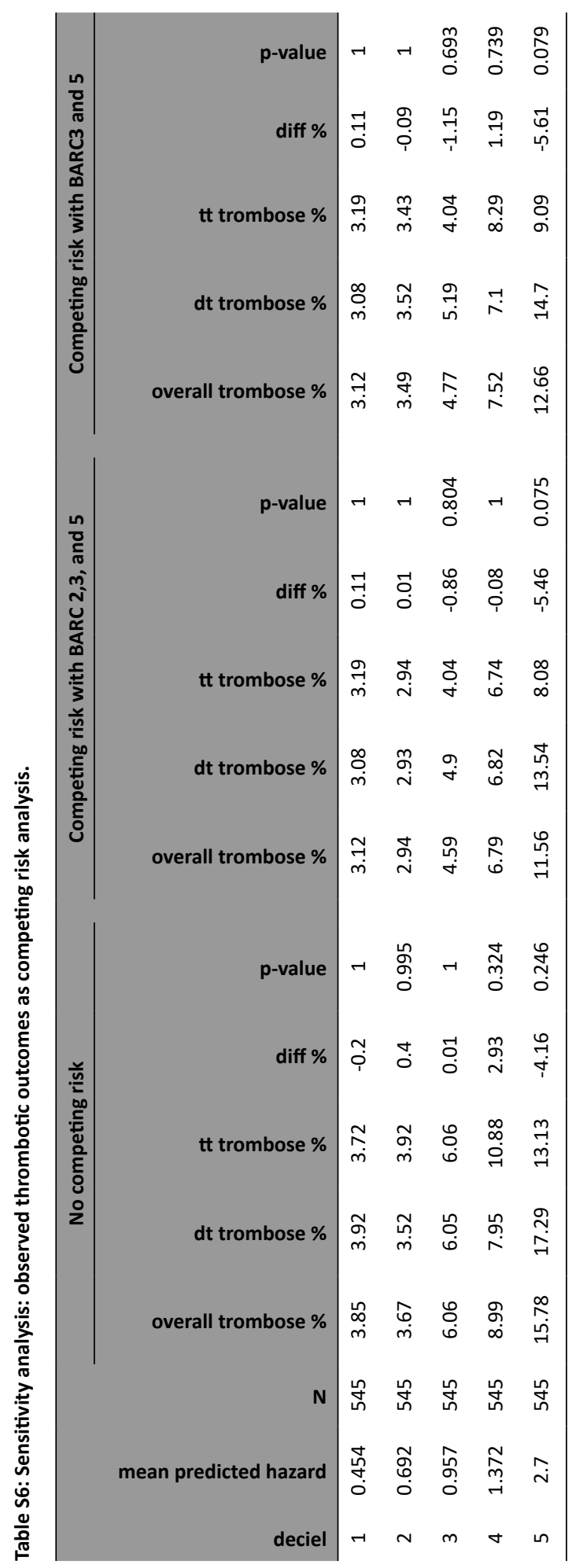


CHAPTER

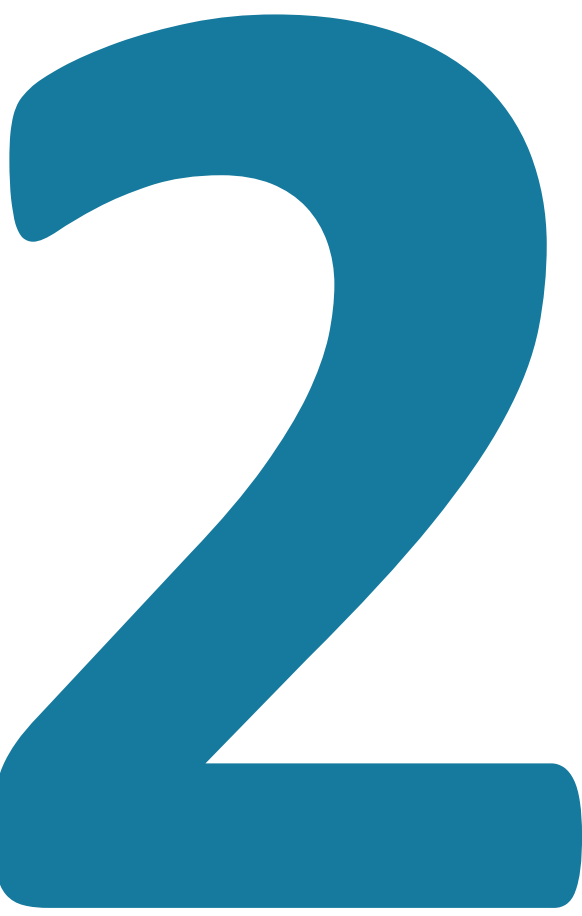




\section{Estimating bleeding risk in AF patients undergoing $\mathrm{PCl}$}

\section{Dual or Triple Therapy in AF patients undergoing $\mathrm{PCl}$ : the DATA-PCI risk score}

B. Zwart, W.L. Bor, B.K. Mahmoodi, A. de Veer, J.C. Kelder, C.P. Cannon, J.M. ten Berg

* B. Zwart and W.L. Bor contributed equally to this manuscript 


\begin{abstract}
Introduction:

The treatment of patients with atrial fibrillation $(\mathrm{AF})$ undergoing percutaneous coronary intervention ( $\mathrm{PCI}$ ) poses a challenge for cardiologists. Patients have an indication for both oral anti-coagulation (OAC) as well as antiplatelet therapy and are therefore at an increased risk of bleeding.
\end{abstract}

\title{
Methods:
}

We developed a prediction model in the RE-DUAL PCI trial. A Cox model predictive for BARC 2,3 and 5 bleeding was constructed by stepwise selection from the candidate variables. The expected hazard of bleeding events at 365 days was predicted and compared to observed risk. Based on beta-coefficients of the Cox model a risk score was constructed. External validation was performed in the WOEST trial.

\section{Results:}

In $19.1 \%$ (520/2725) of patients, a BARC 2, 3 or 5 bleeding was documented. The multivariable Cox prediction model contained age, haematocrit, $\mathrm{BMI}$, a history of malignancy and triple therapy. The discriminatory capacity in the derivation cohort was fair (AUC 0.70). In the simplified risk score, integer points were assigned to the variables. The total risk score ranged from -5 to +10 . Three risk categories could be distinguished: low bleeding risk (score $<1$ points, $10.7 \%$ bleeding risk), intermediate (1-2 points, $17.1 \%$ ) and high bleeding risk (>2 points, $26.9 \%$ ). Good discrimination and calibration were found in the WOEST trial.

\section{Conclusion:}

We developed a risk score which is able to estimate 1-year bleeding risk specifically for patients on $\mathrm{OAC}$ for $\mathrm{AF}$ undergoing $\mathrm{PCl}$. As bleeding risk is high in this population, it is essential to identify patients at increased bleeding risk. Moreover, this score can help to estimate bleeding risk with or without triple therapy and thus might aid in (shared) decision making. 


\section{Introduction}

The treatment of patients with atrial fibrillation (AF) undergoing percutaneous coronary intervention ( $\mathrm{PCl}$ ) poses a challenge for cardiologists and other clinicians in daily practice. As these patients have an indication for both oral anti-coagulation (OAC) as well as antiplatelet therapy with a $\mathrm{P}_{2} \mathrm{Y}_{12}$ inhibitor and/or aspirin, they are therefore at an increased risk of bleeding ${ }^{1-3}$. The combination of dual antiplatelet therapy and OAC (referred to as triple therapy') carries at least a two- to three-time risk of bleeding as compared to 'double therapy', a combination of OAC and a P2 $\mathrm{Y}_{12}$ inhibitor (DAT) ${ }^{4,5}$. However, DAT still carries at least a twofold risk of major bleeding when compared to single antiplatelet therapy $(6,7)$. Several recent trials and meta-analyses have investigated a regimen of double antithrombotic therapy (DAT) against triple therapy (TAT). Most studies suggested an substantially lower rate of bleeding complications associated with DAT, with overall no consistent differences in ischaemic outcomes ${ }^{8-12}$. Current international guidelines and consensus documents recommend TAT for one week and up to one month in patients at high thrombotic risk ${ }^{1,13,14}$. Recently, we developed a risk score to identify this subset of patients at high thrombotic risk (submitted). A proportion of $\sim 5 \%$ high-risk patients was identified who benefited from TAT.

Bleeding complication associated with antithrombotic therapy outnumber ischaemic event. One review estimated up to a 10 -fold difference in contemporary practice ${ }^{15}$. Arguably, net clinical risk of these patients seems to be determined more by bleeding risk than by ischaemic risk. As several studies have shown that bleeding after $\mathrm{PCl}$ is strongly associated with adverse outcomes and mortality, it is key to be able to estimate patients' individual risk.

For AF patients in the general population the HAS-BLED score can be used, whereas for patients undergoing $\mathrm{PCI}$ the CRUSADE score was developed. To date, no risk tool exists to estimate the bleeding risk in this specific group of patients. In this study, we developed a bleeding risk calculator specifically for $\mathrm{AF}$ patients who undergo $\mathrm{PCl}$.

\section{Methods}

\section{Patients cohorts}

The study was performed in the cohorts from two randomised controlled trials (WOEST trial, RE-DUAL PCI trial) comparing TAT versus DAT in PCI patients. The RE-DUAL cohort served as a derivation cohort and the WOEST cohort served as an external validation cohort.

In the RE-DUAL PCI trial, the DAT group was treated with dabigatran 110 or $150 \mathrm{mg}$ in combination with a $\mathrm{P}_{2} \mathrm{Y}_{12}$ inhibitor (clopidogrel in $87 \%$, or ticagrelor in $12 \%$ of patients). In the WOEST trial DAT consisted of VKA and clopidogrel. In both trials the TAT group consisted 
of VKA, aspirin and a $\mathrm{P}_{2} \mathrm{Y}_{12}$ inhibitor (100\% clopidogrel in WOEST, and clopidogrel in $90 \%$ or ticagrelor in $8 \%$ of patients in RE-DUAL).

\section{Endpoint definitions}

The bleeding endpoint was defined as the first Bleeding Academic Research Consortium (BARC) 2, 3 or 5 bleeding within 365 days. Follow-up was truncated after the first event. For instance, a bleeding after a recurrent thrombotic event would not be analysed since antithrombotic management might have been adjusted after the earlier thrombotic event. The composite ischaemic endpoint was defined as cardiovascular death, myocardial infarction (MI), stent thrombosis (definite or probable according to Academic Research Consortium [ARC] criteria) or ischaemic stroke.

\section{Follow-up}

The mean follow-up after PCl was 14 months in the RE-DUAL trial and 12 months in the WOEST trial. Groups were compared according to intention-to-treat protocol. For this analysis follow-up was truncated at 365 days to obtain risk estimates for the first year of double versus triple antithrombotic therapy.

\section{Statistical analysis}

Baseline characteristics were compared between patients with and without bleeding events during the 1-year follow-up by t-test, or its nonparametric equivalents as appropriate, or Chi-square for categorical variables.

\section{Predictors}

Based on clinical plausibility and availability in both trial datasets, variables were considered as candidate predictors. The variables included age, sex, BMI, hypertension, hypercholesterolemia, DM, smoking, alcohol use, medical history (bleeding, $\mathrm{MI}, \mathrm{PCl}, \mathrm{CABG}$, stroke, VTE or systemic embolism, renal failure, malignancy, PAD, heart failure), $\mathrm{MI}$ at presentation, LVEF, and laboratory tests at presentation (haemoglobin, haematocrit, platelet count, leukocyte count, creatinine, eGFR by CKD-EPI). We did not include modifiable factors like medication use.

\section{Model development}

Candidate variables for the Cox model were selected by univariate Cox regression stratified for access site and bare metal stent (BMS) placement (as this latter directly influenced treatment duration in RE-DUAL). Variables showing a P-value $<0.30$ were considered as candidate variables for inclusion in the model. A Cox model (stratified for access site and BMS placement) for the bleeding endpoint was constructed by stepwise selection from the candidate variables using a 0.05 significance level. Missing values in the dataset for stepwise model selection were imputed by simple means (for percentage of missing values 
per variable see table S1). Based on beta-coefficients of the Cox model a point score was constructed using the methods as proposed in the Framingham Study risk scores. ${ }^{16}$

\section{Internal validation}

With the Cox model the expected hazard of bleeding events given the covariates was predicted at 365 days. Also, the point score was calculated for each patient. Predictive accuracy of the model and point score was evaluated by area under the receiver operating curve. The cohort was divided in quintiles and deciles based on the expected hazards, or grouped by point score to assess calibration. Observed risks of ischaemic events, bleeding, and mortality were compared between the patients that received triple or DAT.

\section{External validation}

For every patient in the WOEST trial cohort the point score was calculated. Since malignancy was not recorded in the WOEST database no points were given for malignancy to any patient. Discrimination was evaluated by area under the receiver operating curve. Calibration was evaluated by plotting the observed bleeding risk in decile of the predicted point score. Observed risks of ischaemic events, bleeding, and mortality were compared between the patients that received triple or DAT.

\section{Results}

A total of 2725 patients were included in this analysis. In 520 patients, a BARC 2, 3 or 5 bleeding was documented (19.1\%). Baseline characteristics of patients with and without bleeding events are depicted in Table 1. Patients with a bleeding event during follow-up in the derivation cohort were more likely to have a history of malignancy or a history of previous $\mathrm{PCl}$, were older and were more often female. In addition, lower $\mathrm{BMI}$ and lower haemoglobin and haematocrit were more frequently observed, whereas fewer patients had undergone $\mathrm{PCl}$ to a coronary bypass graft or had received a long stent.

Table 1: Baseline characteristics of patients with and without bleeding events during follow-up (REDUAL, derivation cohort).

\begin{tabular}{|c|c|c|c|}
\hline & \multicolumn{2}{|c|}{ BARC 2,3 or 5 bleeding } & \multirow[b]{2}{*}{$\mathbf{p}$} \\
\hline & No $(N=2205)$ & Yes $(N=520)$ & \\
\hline \multicolumn{4}{|l|}{ Treatment arm } \\
\hline Triple therapy (\%) & $729(33.1)$ & $252(48.5)$ & $<0.001$ \\
\hline \multicolumn{4}{|l|}{ Demographics } \\
\hline $\begin{array}{l}\text { Age (mean (SD)) } \\
\text { Female sex (\%) } \\
\text { BMI (median [IQR]) }\end{array}$ & $\begin{array}{l}70.32(8.63) \\
521(23.6) \\
28.40[25.50,32.00]\end{array}$ & $\begin{array}{l}72.36(8.18) \\
134(25.8) \\
27.00[24.40,30.40]\end{array}$ & $\begin{array}{l}<0.001 \\
0.332 \\
<0.001\end{array}$ \\
\hline \multicolumn{4}{|l|}{ Comorbidities } \\
\hline $\begin{array}{l}\text { Hypertension (\%) } \\
\text { Hypercholesterolaemia (\%) }\end{array}$ & $\begin{array}{l}1844(83.7) \\
1433(65.0)\end{array}$ & $\begin{array}{l}450(86.5) \\
337(64.8)\end{array}$ & $\begin{array}{l}0.121 \\
0.969\end{array}$ \\
\hline
\end{tabular}


Table 1: Continued

\begin{tabular}{|c|c|c|c|}
\hline & \multicolumn{2}{|l|}{ BARC 2,3 or 5 bleeding } & \multirow[b]{2}{*}{$\mathbf{p}$} \\
\hline & No $(\mathrm{N}=2205)$ & Yes $(\mathrm{N}=520)$ & \\
\hline Current smoker (\%) & $278(12.6)$ & $59(11.3)$ & 0.474 \\
\hline Diabetes Mellitus (\%) & $793(36.0)$ & $200(38.5)$ & 0.314 \\
\hline Alcohol use (\%) & $1128(51.2)$ & $247(47.5)$ & 0.144 \\
\hline History of myocardial infarction (\%) & $553(25.1)$ & $146(28.1)$ & 0.176 \\
\hline History of heart failure (\%) & $766(34.8)$ & $171(32.9)$ & 0.449 \\
\hline History of GI bleed (\%) & $140(6.4)$ & $43(8.3)$ & 0.141 \\
\hline History of stroke (\%) & $183(8.3)$ & 43 ( 8.3$)$ & 1.000 \\
\hline History of renal failure (\%) & 365 (17.0) & 96 (18.9) & 0.320 \\
\hline History of $\mathrm{PCl}(\%)$ & $717(32.5)$ & $195(37.5)$ & 0.035 \\
\hline History of CABG (\%) & $227(10.3)$ & $60(11.5)$ & 0.454 \\
\hline History of malignancy (\%) & $175(8.1)$ & $66(13.1)$ & 0.001 \\
\hline History of peripheral artery disease (\%) & $149(7.2)$ & $39(8.1)$ & 0.594 \\
\hline History of venous thromboembolism (\%) & $75(3.4)$ & $13(2.5)$ & 0.363 \\
\hline \multicolumn{4}{|l|}{ Characteristics at presentation } \\
\hline Acute coronary syndrome (\%) & $1117(50.7)$ & $258(49.6)$ & 0.698 \\
\hline STEMI (\%) & $256(23.4)$ & $49(19.2)$ & \\
\hline NSTEMI (\%) & $476(43.5)$ & $106(41.6)$ & \\
\hline Unstable angina (\%) & $362(33.1)$ & $100(39.2)$ & \\
\hline LVEF (mean (SD)) & $51.06(12.31)$ & $50.92(13.23)$ & 0.822 \\
\hline ECG of AFib of AFlu (\%) & 1039 (47.1) & $226(43.5)$ & 0.145 \\
\hline Haemoglobin (mmol/l) (median [IQR]) & $8.50[7.82,9.18]$ & $8.32[7.57,9.06]$ & $<0.001$ \\
\hline Haematocrit (\%)(median [IQR]) & $41.00[38.00-44.00]$ & $40.00[37.00-44.00]$ & $<0.001$ \\
\hline White blood cell count (median [IQR]) & $7.36[6.12,8.96]$ & $7.42[6.12,8.89]$ & 0.986 \\
\hline Platelet count (median [IQR]) & $202.00[171.00,245.00]$ & $198.00[168.00,241.75]$ & 0.296 \\
\hline Creatinin (umol/I) (median [IQR]) & $88.00[74.00,106.00]$ & $88.00[77.00,105.00]$ & 0.700 \\
\hline eGFR (CKD-EPI) (median [IQR]) & $75.00[61.00,89.00]$ & $75.00[60.75,87.00]$ & 0.159 \\
\hline \multicolumn{4}{|l|}{ Procedural characteristics } \\
\hline Femoral access (\%) & $775(35.4)$ & $197(38.3)$ & 0.249 \\
\hline Heparin use (\%) & $1855(84.2)$ & $433(83.3)$ & 0.664 \\
\hline LMWH use (\%) & $332(15.1)$ & $66(12.7)$ & 0.191 \\
\hline Number of diseased vessels (\%) & & & 0.962 \\
\hline 1 & $1130(52.4)$ & $261(51.8)$ & \\
\hline 2 & $640(29.7)$ & $150(29.8)$ & \\
\hline 3 & $388(18.0)$ & $93(18.5)$ & \\
\hline Left main disease (\%) & 41 ( 1.9$)$ & $7(1.3)$ & 0.539 \\
\hline Intracoronary thrombus (\%) & $37(1.7)$ & $6(1.2)$ & 0.505 \\
\hline Number of diseased vessels (\%) & & & 0.220 \\
\hline 1 & $1758(81.2)$ & $420(82.4)$ & \\
\hline 2 & 345 (15.9) & $70(13.7)$ & \\
\hline 3 & $61(2.8)$ & $20(3.9)$ & \\
\hline Stent length >30mm (\%) & 195 ( 8.8) & 45 ( 8.7$)$ & 0.959 \\
\hline LAD stented $(\%)$ & $1061(48.1)$ & $224(43.1)$ & 0.043 \\
\hline LCx stented (\%) & $580(26.3)$ & $137(26.3)$ & 1.000 \\
\hline RCA stented (\%) & 747 (33.9) & $189(36.3)$ & 0.310 \\
\hline Bypass graft stented (\%) & $60(2.7)$ & $17(3.3)$ & 0.596 \\
\hline Bare metal stent placement (\%) & $381(17.3)$ & 69 (13.3) & 0.031 \\
\hline \multicolumn{4}{|l|}{ Outcomes at 365 days } \\
\hline Death (\%) & $74(3.4)$ & $39(7.5)$ & $<0.001$ \\
\hline Cardiovascular death (\%) & $32(1.5)$ & $19(3.7)$ & 0.002 \\
\hline Myocardial infarction (\%) & $80(3.6)$ & $30(5.8)$ & 0.035 \\
\hline Stent thrombosis (\%) & $67(3.0)$ & $19(3.7)$ & 0.560 \\
\hline Stroke (\%) & $24(1.1)$ & $15(2.9)$ & 0.004 \\
\hline Ischemic stroke (\%) & $23(1.0)$ & $7(1.3)$ & 0.717 \\
\hline Hemorrhagic stroke (\%) & $0(0.0)$ & $6(1.2)$ & $<0.001$ \\
\hline BARC 2,3 or 5 bleeding (\%) & $0(0.0)$ & $520(100.0)$ & $<0.001$ \\
\hline BARC 3 or 5 bleeding (\%) & $0(0.0)$ & $127(24.4)$ & $<0.001$ \\
\hline
\end{tabular}


Table 2 shows results of stratified univariate Cox regression. Multiple predictors for bleeding events were identified. Strong predictors were triple therapy, history of malignancy, alcohol use, higher age, and lower BMI, haematocrit or haemoglobin.

Table 2: Univariate cox regression for BARC 2,3 and 5 bleeding events.

\begin{tabular}{|c|c|c|c|c|}
\hline & Beta & HR (95\% Cl for HR) & Wald test & p-value \\
\hline Triple therapy (vs dual therapy) & 0.64 & $1.9(1.6-2.3)$ & 53 & $3.9 e-13$ \\
\hline Age & 0.03 & $1(1-1)$ & 28 & $9.5 e-08$ \\
\hline Haematocrit & -0.046 & $0.95(0.94-0.97)$ & 21 & $4 e-06$ \\
\hline Body-mass index & -0.039 & $0.96(0.94-0.98)$ & 18 & $2.8 \mathrm{e}-05$ \\
\hline Hx/ Malignancy & 0.49 & $1.6(1.3-2.1)$ & 14 & 0.00024 \\
\hline Haemoglobin & -0.16 & $0.85(0.78-0.93)$ & 13 & 0.0013 \\
\hline Alcohol use & -0.19 & $0.82(0.69-0.98)$ & 4.7 & 0.03 \\
\hline Hypertension & 0.24 & $1.3(0.99-1.6)$ & 3.5 & 0.062 \\
\hline Female sex & 0.16 & $1.2(0.97-1.4)$ & 2.6 & 0.11 \\
\hline $\mathrm{Hx} /$ coronary revascularization & 0.14 & $1.2(0.97-1.4)$ & 2.5 & 0.11 \\
\hline Hx/ Vascular disease & 0.14 & $1.2(0.96-1.4)$ & 2.4 & 0.13 \\
\hline eGFR & -0.003 & $1(0.99-1)$ & 2 & 0.16 \\
\hline Myocardial infarction as indication for procedure & -0.13 & $0.88(0.73-1.1)$ & 1.8 & 0.18 \\
\hline Hx/ Renal insufficiency & 0.14 & $1.1(0.92-1.4)$ & 1.5 & 0.23 \\
\hline Hx/ Myocardial infarction & 0.12 & $1.1(0.93-1.4)$ & 1.4 & 0.24 \\
\hline Active smoking & -0.14 & $0.87(0.66-1.1)$ & 1 & 0.31 \\
\hline Hx/ Venous thromboembolism/systemic embolism & -0.2 & $0.82(0.5-1.3)$ & 0.61 & 0.44 \\
\hline $\mathrm{Hx} /$ Peripheral arterial disease & 0.13 & $1.1(0.82-1.6)$ & 0.57 & 0.45 \\
\hline Hx/ Diabetes Mellitus & 0.067 & $1.1(0.9-1.3)$ & 0.55 & 0.46 \\
\hline Hx/ Hypercholesterolemia & -0.052 & $0.95(0.79-1.1)$ & 0.31 & 0.58 \\
\hline Hx/ Bleeding & 0.21 & $1.2(0.58-2.6)$ & 0.3 & 0.58 \\
\hline Left ventricular ejection fraction & -0.0016 & $1(0.99-1)$ & 0.2 & 0.65 \\
\hline Congestive heart failure/ LVEF $>\mathbf{3 0} \%$ & -0.024 & $0.98(0.81-1.2)$ & 0.06 & 0.8 \\
\hline Platelet count & $-5.8 e-05$ & $1(1-1)$ & 0.01 & 0.93 \\
\hline Creatinin & 0.00012 & $1(1-1)$ & 0.01 & 0.94 \\
\hline Current or past smoker & -0.006 & $0.99(0.83-1.2)$ & 0 & 0.95 \\
\hline Leukocyte count & 0.00068 & $1(0.96-1)$ & 0 & 0.97 \\
\hline Acute coronary syndrome as indication for procedure & 0.0023 & $1(0.84-1.2)$ & 0 & 0.98 \\
\hline Hx/ Stroke & 0.00041 & $1(0.73-1.4)$ & 0 & 1 \\
\hline
\end{tabular}

Corrected for access site and stent type. 
The multivariable Cox regression model predicting bleeding events contained triple therapy, age, haematocrit, BMI and a history of malignancy (Table 3). The discriminatory capacity of the bleeding model was fair (AUC 0.704 (Cl 0.678-0.730, Figure 1).

Table 3: Cox proportional hazards model predictive of BARC 2, 3 and 5 bleeding.

\begin{tabular}{lll} 
Predictor of events & HR $(95 \% \mathrm{Cl})$ & P value \\
\hline Triple therapy & $1.808(1.521-2.149)$ & $<0.001$ \\
Age & $1.018(1.001-1.030)$ & 0.001 \\
Haematocrit & $0.967(0.948-0.986)$ & 0.001 \\
Body-mass index & $0.973(0.955-0.991)$ & 0.003 \\
History of malignancy & $1.442(1.111-1.871)$ & 0.006 \\
\hline
\end{tabular}

Analysis stratified for access site, and stent type.

Concordance $=\quad 0.638(\mathrm{se}=0.02)$

Rsquare $=\quad 0.038(\max$ possible $=0.918)$

Likelihood ratio test $=104.3$ on $5 \mathrm{df}, \mathrm{p}=<2 \mathrm{e}-16$

Wald test $=\quad 105.1$ on $5 \mathrm{df}, \mathrm{p}=<2 \mathrm{e}-16$

Score (logrank) test $=107.3$ on $5 \mathrm{df}, \mathrm{p}=<2 \mathrm{e}-16$

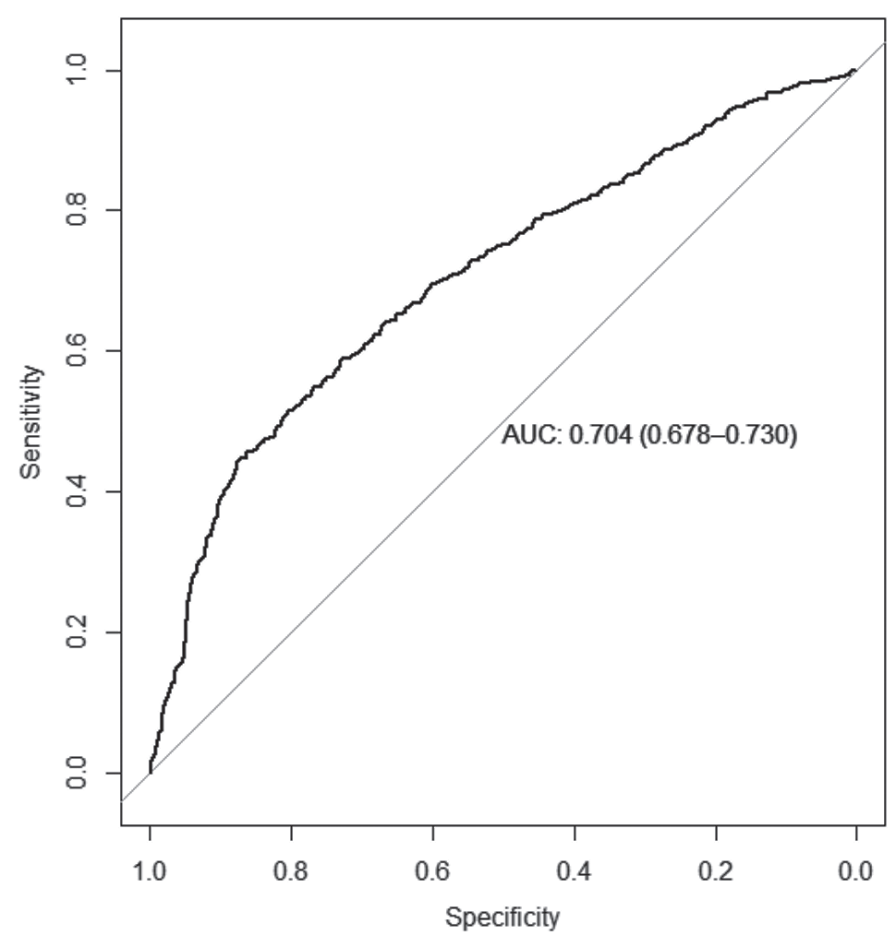

Figure 1: Predictive accuracy for the bleeding end point (RE-DUAL derivation cohort). 
In the simplified prediction model, integer points were assigned to the predictors. The following points were assigned: triple therapy +3 points; a history of malignancy +2 points; age +0 for age $<60$ years ranging to +4 points for age $>90$; haematocrit -2 to +3 points; $\mathrm{BMI}$ -3 to +1 points (Table 4). The total risk score ranged from -5 to +10 . Discrimination of the simplified prediction rule was moderate (AUC 0.64 (0.61-0.66) in the RE-DUAL derivation cohort (Fig. S1).

Table 4: Simplified prediction model.

\begin{tabular}{|c|c|c|c|c|c|}
\hline \multirow[t]{6}{*}{ Age } & $<60$ & +0 & Body-mass index & $<20$ & +1 \\
\hline & $60-70$ & +1 & & $20-25$ & +0 \\
\hline & $70-80$ & +2 & & $25-30$ & -1 \\
\hline & $80-90$ & +3 & & $30-35$ & -2 \\
\hline & $>90$ & +4 & & $35-40$ & -2 \\
\hline & & & & $>40$ & -3 \\
\hline \multirow[t]{6}{*}{ Haematocrit (\%) } & $<30$ & +3 & Malignancy & & +2 \\
\hline & $30-35$ & +2 & & & \\
\hline & $35-40$ & +1 & Triple therapy & & +3 \\
\hline & $40-45$ & +0 & & & \\
\hline & $45-50$ & -1 & & & \\
\hline & $>50$ & -2 & & & \\
\hline
\end{tabular}

Higher scores were associated with higher bleeding rates (Fig. 2 and Table S2). When clustered, a score of $<1$ points was associated with low bleeding risk ( $10.7 \%$ overall bleeding risk), a score of 1-2 points was associated with intermediate bleeding risk (17.1\%), whereas a score of $>2$ points was associated with high (26.9\%) bleeding risk (Table 5). 
A $40 \%$

$30 \%$

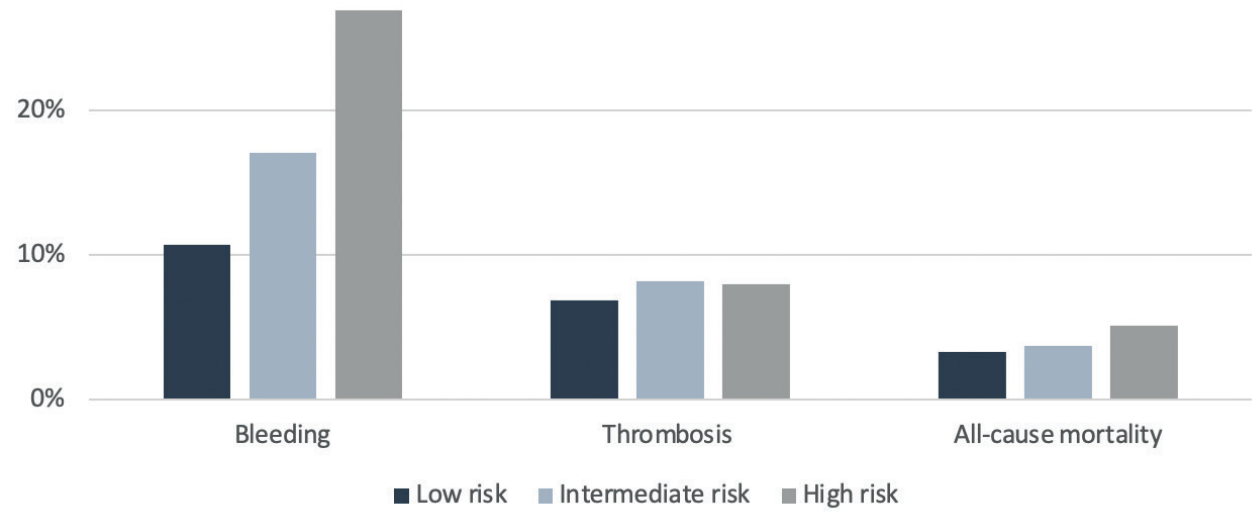

B $40 \%$

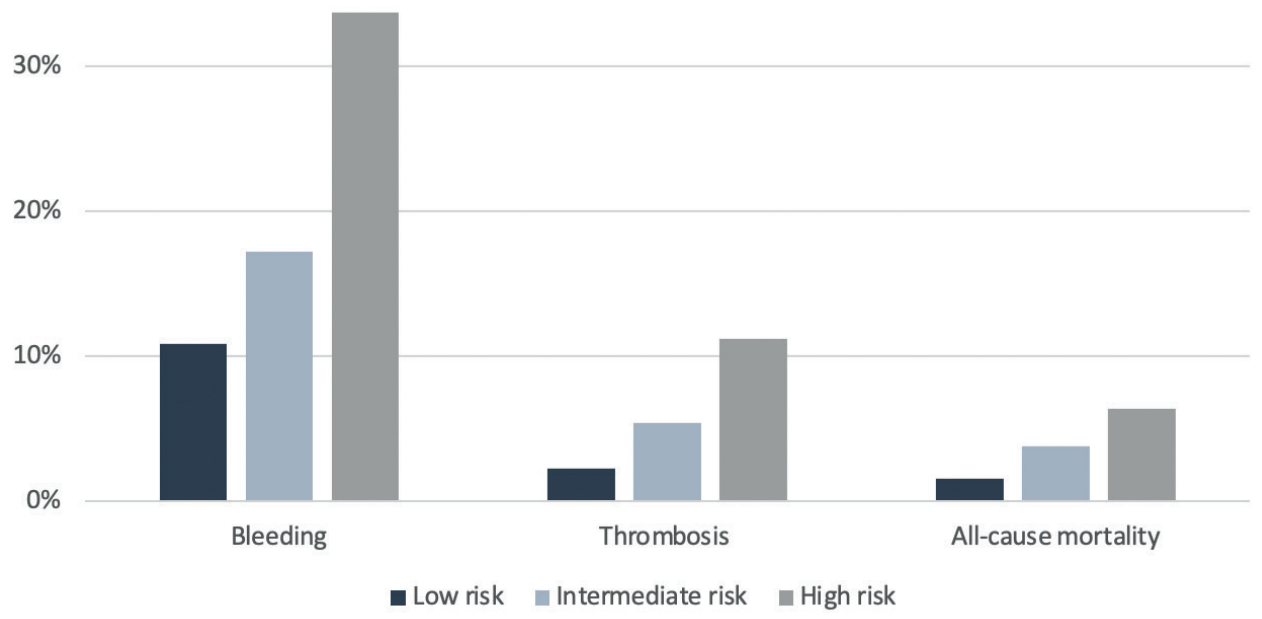

Figure 2: Observed Outcomes in the derivation cohort (A) and in the validation cohort (B).

Low risk: $<1$ points

Intermediate risk: 1-2 points

High risk: $>2$ points 


\section{Validation cohort}

The simplified prediction score was validated in the WOEST study cohort. Discrimination was moderate to fair (AUC $0.66(0.60-0.71$ ) (Fig. S2). Calibration was similar to the derivation cohort, with bleeding rates varying from $10.9 \%$ in low risk, $17.2 \%$ in intermediate risk to $33.7 \%$ in high-risk patients (Fig 4 and Table S3).

\section{Discussion}

This is the first available risk score which was specifically developed to estimate bleeding risk in $\mathrm{AF}$ patients undergoing $\mathrm{PCl}$. The prediction model, derived in the RE-DUAL trial and validated in the WOEST trial was able to estimate bleeding risk based on treatment strategy, age, haematocrit, BMI and history of malignancy. Patients were classified to have low bleeding risk ( 10\%), moderate bleeding risk (15-20\%) or high bleeding risk (> 25\%).

Previous studies have shown that post procedural bleeding confers a major risk of adverse outcomes including mortality ${ }^{17-19}$. Bleeding risk is very high in this particular population treated with a combination of anticoagulation and antiplatelet drugs. To date, no bleeding model existed for this specific patient population of AF patients undergoing $\mathrm{PCl}$. For ACS patients the CRUSADE risk score is being used, whereas the HAS-BLED score is currently being used to estimate bleeding risk in patients with atrial fibrillation. However, these risk scores were developed for different populations. The CRUSADE score was developed for (hospitalised) post-MI patients and is therefore not applicable to patients who undergo $\mathrm{PCI}$ for another indication than ACS. The HAS-BLED score was developed in AF patients who were treated with VKA-based OAC.

\section{Implications for clinical practice}

AF patients undergoing $\mathrm{PCl}$ have a substantially increased bleeding risk due to the combination of both OAC and antiplatelet agents. However, bleeding risk varies considerable between patients. It is essential to identify patients with increased bleeding risk, in order to be able to modifiable factors and to consider modifying the duration of antithrombotic therapy.

Moreover, this score can help to estimate bleeding risk with or without triple therapy in selected patients and thus might aid in (shared) decision making.

\section{Limitations}

One limitation of this study is that the triple therapy arm comprised vitamin $\mathrm{K}$ antagonists in a substantial proportion of patients. In the RE-DUAL trial, dual therapy including a NOAC was compared to triple therapy using a VKA, which might have exaggerated bleeding risk in the latter group. In WOEST, patients in both the dual and triple therapy received VKA. Indeed, when comparing bleeding rates in the AUGUSTUS trial (its design allowed a comparison for 
VKA-based TAT vs. NOAC based TAT), ISTH major or clinically relevant non-major bleeding were higher in VKA based TAT (18.7\%) as compared to NOAC-based TAT (13.8\%, p-value not provided) (9; supplementary files).

The performance of the bleeding score was modest with a c statistic of 0.70 for the derivation cohort. However, when compared to other risk scores such as HAS-BLED and CRUSADE, discriminatory properties were comparable with AUC's of 0.72 and 0.71 , respectively ${ }^{20,21}$. Another more recent bleeding score in AF patients, the biomarker based ABC-score, had a c-index 0.68 which is also similar to our model ${ }^{22}$. The PRECISE-DAPT, a bleeding score used to estimate bleeding risk in PCl patients treated with DAPT, a c-statistic of 0.65-0.70 was observed in the validation cohorts. ${ }^{23}$ Of note, the simplified prediction rule in WOEST had a similar performance as compared to the RE-DUAL derivation cohort. This slightly better AUC (although overlapping confidence intervals) in the WOEST is probably a shrinkage effect.

The performance of the HAS-BLED and CRUSADE score could not be tested, due to the fact that not all variables used in these scores were available in the RE-DUAL and WOEST datasets (e.g. heart rate and blood pressure for the CRUSADE and "labile INR's" and bleeding history for the HAS-BLED score).

\section{Conclusion and recommendation}

We developed a risk score which is able to estimate 1-year bleeding risk specifically for patients AF patients treated with oral anticoagulation undergoing $\mathrm{PCl}$. Bleeding risk in this population is high, but varies considerable between patients. Therefore it is essential to identify patients with increased bleeding risk. This score can help to estimate bleeding risk with or without triple therapy and thus might aid in (shared) decision making. 


\section{References}

1. Neumann F-J., Sousa-Uva M., Ahlsson A., et al. 2018 ESC/EACTS Guidelines on myocardial revascularization. European Heart Journal 2019;40(2):87-165. Doi: 10.1093/eurheartj/ehy394.

2. Valgimigli M., Bueno H., Byrne RA., et al. 2017 ESC focused update on dual antiplatelet therapy in coronary artery disease developed in collaboration with EACTS: The Task Force for dual antiplatelet therapy in coronary artery disease of the European Society of Cardiology (ESC) and of the European Association for Cardio-Thoracic Surgery (EACTS). European Heart Journal 2017. Doi: 10.1093/eurheartj/ehx419.

3. Hindricks G., Potpara T., Dagres N., et al. 2020 ESC Guidelines for the diagnosis and management of atrial fibrillation developed in collaboration with the European Association of Cardio-Thoracic Surgery (EACTS). Eur Heart J 2020. Doi: 10.1093/eurheartj/ehaa612.

4. Golwala HB., Cannon CP., Steg PG., et al. Safety and efficacy of dual vs. triple antithrombotic therapy in patients with atrial fibrillation following percutaneous coronary intervention: a systematic review and meta-analysis of randomized clinical trials. Eur Heart J 2018;39(19):1726-1735a. Doi: 10.1093/eurheartj/ehy162.

5. Lamberts M., Gislason GH., Olesen JB., et al. Oral anticoagulation and antiplatelets in atrial fibrillation patients after myocardial infarction and coronary intervention. J Am Coll Cardiol 2013;62(11):981-9. Doi: 10.1016/j.jacc.2013.05.029.

6. Rothberg MB., Celestin C., Fiore LD., Lawler E., Cook JR. Warfarin plus aspirin after myocardial infarction or the acute coronary syndrome: meta-analysis with estimates of risk and benefit. Ann Intern Med 2005;143(4):241-50. Doi: 10.7326/0003-4819-143-4-200508160-00005.

7. Chan NC., Weitz JI. Antithrombotic Agents. Circ Res 2019;124(3):426-36. Doi: 10.1161/ CIRCRESAHA.118.313155.

8. Dewilde WJM., Oirbans T., Verheugt FWA., et al. Use of clopidogrel with or without aspirin in patients taking oral anticoagulant therapy and undergoing percutaneous coronary intervention: an open-label, randomised, controlled trial. Lancet (London, England) 2013;381(9872):1107-15. Doi: 10.1016/S0140-6736(12)62177-1.

9. Cannon CP., Bhatt DL., Oldgren J., et al. Dual Antithrombotic Therapy with Dabigatran after PCl in Atrial Fibrillation. N Engl J Med 2017;377(16):1513-24. Doi: 10.1056/NEJMoa1708454.

10. Gibson CM., Mehran R., Bode C., et al. Prevention of Bleeding in Patients with Atrial Fibrillation Undergoing PCI. N Engl J Med 2016;375(25):2423-34. Doi: 10.1056/NEJMoa1611594.

11. Lopes RD., Heizer G., Aronson R., et al. Antithrombotic Therapy after Acute Coronary Syndrome or PCl in Atrial Fibrillation. N Engl J Med 2019;380(16):1509-24. Doi: 10.1056/ NEJMoa1817083.

12. Vranckx P., Valgimigli M., Eckardt L., et al. Edoxaban-based versus vitamin $\mathrm{K}$ antagonist-based antithrombotic regimen after successful coronary stenting in patients with atrial fibrillation (ENTRUST-AF PCI): a randomised, open-label, phase 3b trial. Lancet 2019;394(10206):1335-43. Doi: 10.1016/S0140-6736(19)31872-0. 
13. Collet J-P., Thiele H., Barbato E., et al. 2020 ESC Guidelines for the management of acute coronary syndromes in patients presenting without persistent ST-segment elevation. Eur Heart J 2020. Doi: 10.1093/eurheartj/ehaa575.

14. Angiolillo DJ., Goodman SG., Bhatt DL., et al. Antithrombotic Therapy in Patients With Atrial Fibrillation Treated With Oral Anticoagulation Undergoing Percutaneous Coronary Intervention. Circulation 2018;138(5):527-36. Doi: 10.1161/CIRCULATIONAHA.118.034722.

15. Gargiulo G., Goette A., Tijssen J., et al. Safety and efficacy outcomes of double vs. triple antithrombotic therapy in patients with atrial fibrillation following percutaneous coronary intervention: a systematic review and meta-analysis of non-vitamin $\mathrm{K}$ antagonist oral anticoagulant-based randomized clinical trials. Eur Heart J 2019;40(46):3757-67. Doi: 10.1093/ eurheartj/ehz732.

16. Sullivan LM., Massaro JM., D'Agostino RB. Presentation of multivariate data for clinical use: The Framingham Study risk score functions. Stat Med 2004;23(10):1631-60. Doi: 10.1002/ sim.1742.

17. Verheugt FWA., Steinhubl SR., Hamon M., et al. Incidence, prognostic impact, and influence of antithrombotic therapy on access and nonaccess site bleeding in percutaneous coronary intervention. JACC Cardiovasc Interv 2011;4(2):191-7. Doi: 10.1016/j.jcin.2010.10.011.

18. Brener SJ., Kirtane AJ., Stuckey TD., et al. The Impact of Timing of Ischemic and Hemorrhagic Events on Mortality After Percutaneous Coronary Intervention: The ADAPT-DES Study. JACC Cardiovascular Interventions 2016;9(14):1450-7. Doi: 10.1016/j.jcin.2016.04.037.

19. Généreux P., Giustino G., Witzenbichler B., et al. Incidence, Predictors, and Impact of Post-Discharge Bleeding After Percutaneous Coronary Intervention. J Am Coll Cardiol 2015;66(9):1036-45. Doi: 10.1016/j.jacc.2015.06.1323.

20. Subherwal S., Bach RG., Chen AY., et al. Baseline risk of major bleeding in non-STsegment-elevation myocardial infarction: the CRUSADE (Can Rapid risk stratification of Unstable angina patients Suppress ADverse outcomes with Early implementation of the ACC/AHA Guidelines) Bleeding Score. Circulation 2009;119(14):1873-82. Doi: 10.1161/ CIRCULATIONAHA.108.828541 [doi].

21. Pisters R., Lane DA., Nieuwlaat R., Vos CB de., Crijns HJGM., Lip GYH. A novel user-friendly score (HAS-BLED) to assess 1-year risk of major bleeding in patients with atrial fibrillation: the Euro Heart Survey. Chest 2010;138(5):1093-100. Doi: 10.1378/chest.10-0134.

22. Hijazi Z., Oldgren J., Lindbäck J., et al. The novel biomarker-based ABC (age, biomarkers, clinical history)-bleeding risk score for patients with atrial fibrillation: a derivation and validation study. Lancet 2016;387(10035):2302-11. Doi: 10.1016/S0140-6736(16)00741-8.

23. Costa F., Klaveren D van., James S., et al. Derivation and validation of the predicting bleeding complications in patients undergoing stent implantation and subsequent dual antiplatelet therapy (PRECISE-DAPT) score: a pooled analysis of individual-patient datasets from clinical trials. Lancet (London, England) 2017;389(10073):1025-34. Doi: 10.1016/S01406736(17)30397-5. 


\section{Supplement material}

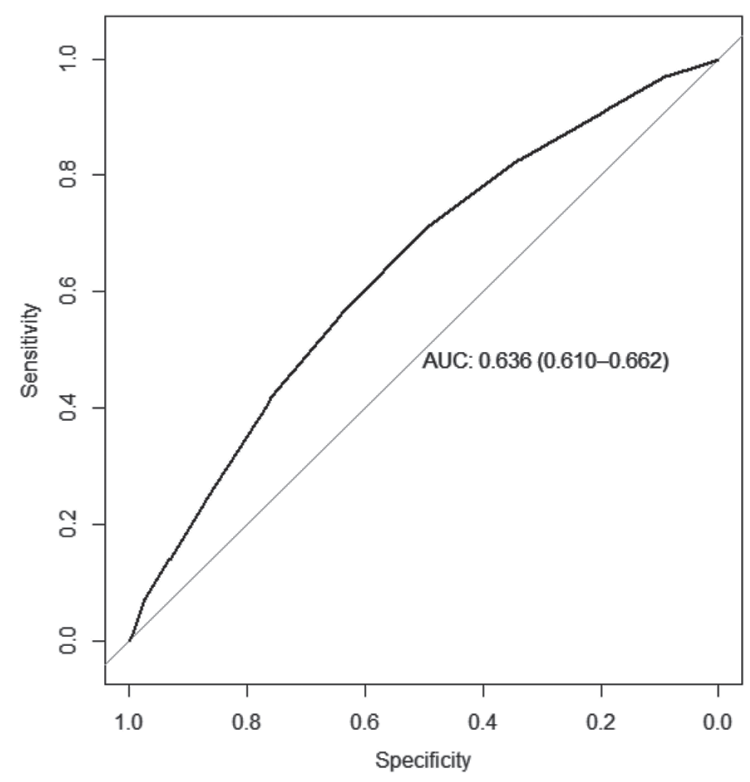

Figure S1: Predictive accuracy for the bleeding end point for the simplified prediction rule (RE-DUAL derivation cohort).

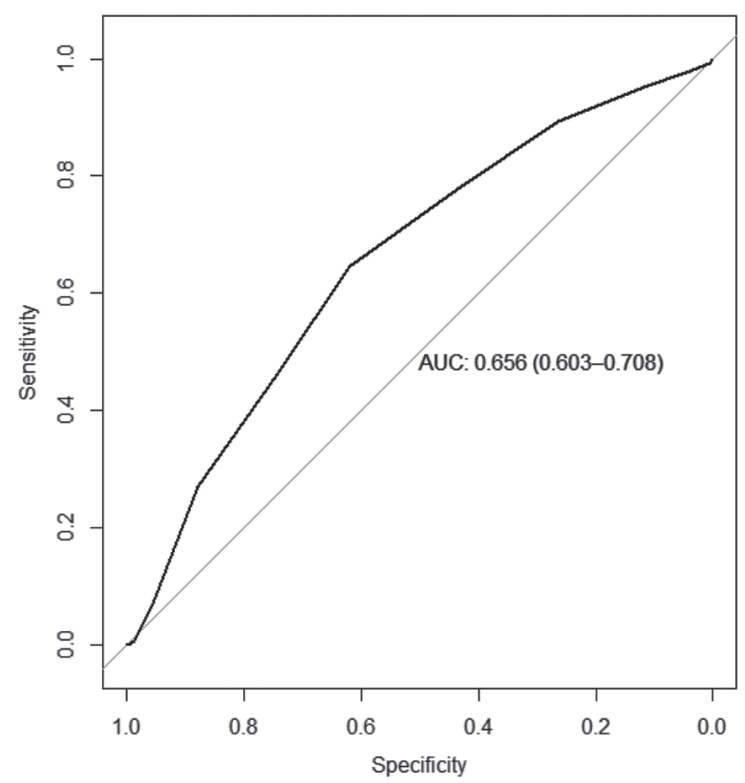

Figure S2: Predictive accuracy for the bleeding end point for the simplified prediction rule (WOEST validation cohort). 
Table S1: LBaseline characteristics of patients with and without bleeding events during follow-up (WOEST, validation cohort).

\begin{tabular}{llll}
\hline & \multicolumn{2}{l}{ BARC 2,3 or 5 bleeding } & \\
\cline { 2 - 3 } & No $(\mathrm{N}=433)$ & Yes $(\mathrm{N}=130)$ & $p$ \\
\hline
\end{tabular}

\section{Treatment arm}

Triple therapy (\%)

\section{Demographics}

Age (mean (SD))

Female sex (\%)

BMI (median [IQR])

\section{Comorbidities}

Hypertension (\%)

Hypercholesterolaemia (\%)

Current smoker (\%)

Diabetes Mellitus (\%)

History of myocardial infarction (\%)

History of heart failure (\%)

History of GI bleed (\%)

History of stroke (\%)

History of renal failure (\%)

History of $\mathrm{PCl}(\%)$

History of CABG (\%)

\section{Characteristics at presentation}

Acute coronary syndrome (\%)

STEMI (\%)

NSTE-ACS (\%)

LVEF (mean (SD))

ECG of AFib of AFlu (\%)

Haemoglobin (mmol/l) (median [IQR])

Haematocrit (\%) (mean (SD))

White blood cell count (median [IQR])

Platelet count (median [IQR])

Creatinin (umol/I) (median [IQR])

eGFR (CKD-EPI) (median [IQR])

\section{Procedural characteristics}

Femoral access (\%)

Heparin use (\%)

LMWH use (\%)

Number of diseased vessels (\%)$$
1
$$$$
2
$$

3

Left main disease (\%)

Number of diseased vessels (\%)

$$
\begin{aligned}
& 1 \\
& 2 \\
& 3
\end{aligned}
$$

Stent length $>30 \mathrm{~mm}(\%)$

LAD stented $(\%)$

LCx stented (\%)

RCA stented (\%)

Bypass graft stented (\%)

Bare metal stent placement (\%)
194 ( 44.8)

90 (69.2)

$<0.001$

$68.47(10.61)$

83 ( 19.2)

$27.46[24.78,30.42]$

$68.33(11.66)$

0.901

32 ( 24.6$)$

0.220

26.53 [24.57, 28.96]

0.055

$295(68.1)$
$302(69.7)$
$48(11.2)$
$115(26.6)$
$161(37.2)$
$103(23.9)$
$21(4.9)$
$73(16.9)$
$73(16.9)$
$154(35.6)$
$96(22.2)$

$91(70.0)$

94 ( 72.3)

14 ( 10.9)

25 ( 19.2)

35 ( 26.9)

38 ( 29.2)

7 ( 5.4$)$

26 (20.0)

26 ( 20.2)

33 ( 25.4)

34 ( 26.2)

0.768

0.652

1.000

0.114

0.041

0.266

0.992

0.495

0.465

0.038

0.409

$124(28.9)$
$12(9.7)$
$112(90.3)$
$46.30(14.23)$
$155(35.8)$
$8.53[7.90,9.20]$
$40.49(5.21)$
$208.00[177.00,244.00]$
$90.00[75.00,107.00]$
$75.00[59.00,91.00]$
$8.53[7.90,9.20]$

31 ( 24.2)

0.355

0 (0)

0.153

31 (100.0)

0.153

45.85 (15.08)

0.795

44 ( 33.8$)$

0.762

$8.13[7.50,8.90] \quad 0.004$

39.26 (5.49)

0.033

$210.00[174.00,247.00] \quad 0.903$

$91.00[75.00,110.00] \quad 0.775$

$75.00[58.00,90.00] \quad 0.862$

$8.13[7.50,8.90] \quad 0.004$

$322(74.9)$
$394(92.5)$
$99(22.9)$
$223(51.7)$
$130(30.2)$
$78(18.1)$
$31(7.4)$
$304(71.2)$
$102(23.9)$
$21(4.9)$
$104(24.3)$
$177(40.9)$
$101(23.3)$
$126(29.1)$
$26(6.0)$
$142(33.2)$

90 ( 70.9)

0.429

0.778

0.386

0.551

$65(50.0)$

36 ( 27.7)

29 (22.3)

16 ( 12.6)

0.096

$97(75.2)$

0.141

23 (17.8)

$8(6.2)$

29 ( 23.0)

0.859

$52(40.0)$

0.939

34 ( 26.6)

0.586

38 ( 29.2)

1.000

$6(4.6)$

0.701

47 (37.6)

0.418 
Table S1: Continued

\begin{tabular}{llll}
\hline & \multicolumn{2}{c}{ BARC 2, 3 or 5 bleeding } & \\
\cline { 2 - 3 } & No (N=433) & Yes (N=130) & \\
\hline Outcomes at 365 days & & \\
Death (\%) & $16(3.7)$ & $9(6.9)$ & 0.185 \\
Cardiovascular death (\%) & $8(1.8)$ & $2(1.5)$ & 1.000 \\
Myocardial infarction (\%) & $17(3.9)$ & $5(3.8)$ & 1.000 \\
Stent thrombosis (\%) & $12(2.8)$ & $1(0.8)$ & 0.317 \\
Stroke (\%) & $5(1.2)$ & $6(4.6)$ & 0.032 \\
Ischemic stroke (\%) & $5(1.2)$ & $5(3.8)$ & 0.097 \\
Hemorrhagic stroke (\%) & $0(0.0)$ & $1(0.8)$ & 0.523 \\
BARC 2, 3 or 5 bleeding (\%) & $0(0.0)$ & $130(100.0)$ & $<0.001$ \\
BARC 3 or 5 bleeding (\%) & $42(9.7)$ & $12(9.2)$ & 1.000 \\
\hline
\end{tabular}

Table S2: Observed bleeding outcomes, stratified by bleeding score in RE-DUAL cohort.

\begin{tabular}{clll}
\hline & Bleeding & Thrombosis & All- cause mortality \\
\hline score & Overall incidence & Overall incidence & Overall incidence \\
$<1$ & $10.71 \%$ & $6.9 \%$ & $3.33 \%$ \\
$\mathrm{~N}=840$ & $\mathrm{~N}=90$ & $\mathrm{~N}=58$ & $\mathrm{~N}=28$ \\
$\mathbf{1 - 2}$ & $17.09 \%$ & $8.16 \%$ & $3.7 \%$ \\
$\mathrm{~N}=784$ & $\mathrm{~N}=134$ & $\mathrm{~N}=64$ & $\mathrm{~N}=29$ \\
$>\mathbf{2}$ & $26.92 \%$ & $7.97 \%$ & $5.13 \%$ \\
$\mathrm{~N}=1092$ & $\mathrm{~N}=294$ & $\mathrm{~N}=87$ & $\mathrm{~N}=56$ \\
\hline
\end{tabular}

Low risk: $<1$ points

Intermediate risk: $1-2$ points

High risk: $>2$ points

Table S3: Observed bleeding outcomes, stratified by bleeding score in the WOEST cohort.

\begin{tabular}{clll}
\hline & Bleeding & Thrombosis & All- cause mortality \\
\hline score & Overall incidence & Overall incidence & Overall incidence \\
$<1$ & $10.94 \%$ & $2.34 \%$ & $1.56 \%$ \\
$\mathrm{~N}=128$ & $\mathrm{~N}=14$ & $\mathrm{~N}=3$ & $\mathrm{~N}=2$ \\
$\mathbf{1 - 2}$ & $17.2 \%$ & $5.38 \%$ & $3.76 \%$ \\
$\mathrm{~N}=186$ & $\mathrm{~N}=32$ & $\mathrm{~N}=10$ & $\mathrm{~N}=7$ \\
$>\mathbf{2}$ & $33.73 \%$ & $11.24 \%$ & $6.43 \%$ \\
$\mathrm{~N}=249$ & $\mathrm{~N}=84$ & $\mathrm{~N}=28$ & $\mathrm{~N}=16$ \\
\hline
\end{tabular}

Low risk: $<1$ points

Intermediate risk: $1-2$ points

High risk: $>2$ points 
Table S4: Sensitivity analyses for different bleeding definitions with the model developed for BARC 2, 3 and 5 bleeding.

\begin{tabular}{|c|c|c|c|c|c|c|}
\hline & \multicolumn{3}{|l|}{ REDUAL } & \multicolumn{3}{|l|}{ WOEST } \\
\hline & $\begin{array}{l}\text { BARC 2, 3, } \\
\text { and } 5\end{array}$ & BARC 3 and 5 & $\begin{array}{l}\text { TIMI major } \\
\text { and minor }\end{array}$ & $\begin{array}{l}\text { BARC 2, 3, } \\
\text { and } 5\end{array}$ & BARC 3 and 5 & $\begin{array}{l}\text { TIMI major } \\
\text { and minor }\end{array}$ \\
\hline AUC & $\begin{array}{l}0.636 \\
(0.610-0.662)\end{array}$ & $\begin{array}{l}0.527 \\
(0.481-573)\end{array}$ & $\begin{array}{l}0.483 \\
(0.443-0.523)\end{array}$ & $\begin{array}{l}0.656 \\
(0.603-0.708)\end{array}$ & $\begin{array}{l}0.488 \\
(0.381-0.596)\end{array}$ & $\begin{array}{l}0.556 \\
(0.441-0.672)\end{array}$ \\
\hline \multicolumn{7}{|c|}{ Incidence of bleeding per score } \\
\hline \multirow[t]{2}{*}{$<1$} & $10.71 \%$ & $6.55 \%$ & $8.21 \%$ & $10.94 \%$ & $7.81 \%$ & $7.81 \%$ \\
\hline & $\mathrm{N}=90$ & $N=55$ & $N=69$ & $\mathrm{~N}=14$ & $\mathrm{~N}=10$ & $N=10$ \\
\hline \multirow[t]{2}{*}{$1-2$} & $17.09 \%$ & $5.01 \%$ & $7.63 \%$ & $17.2 \%$ & $5.38 \%$ & $4.48 \%$ \\
\hline & $\mathrm{N}=134$ & $\mathrm{~N}=40$ & $\mathrm{~N}=61$ & $\mathrm{~N}=32$ & $\mathrm{~N}=10$ & $\mathrm{~N}=9$ \\
\hline \multirow[t]{2}{*}{$>2$} & $26.92 \%$ & $4.88 \%$ & $7.00 \%$ & $33.73 \%$ & $5.22 \%$ & $4.48 \%$ \\
\hline & $\mathrm{N}=294$ & $\mathrm{~N}=53$ & $\mathrm{~N}=76$ & $\mathrm{~N}=84$ & $\mathrm{~N}=13$ & $N=9$ \\
\hline
\end{tabular}


Estimating bleeding risk in AF patients undergoing PCI | 207 


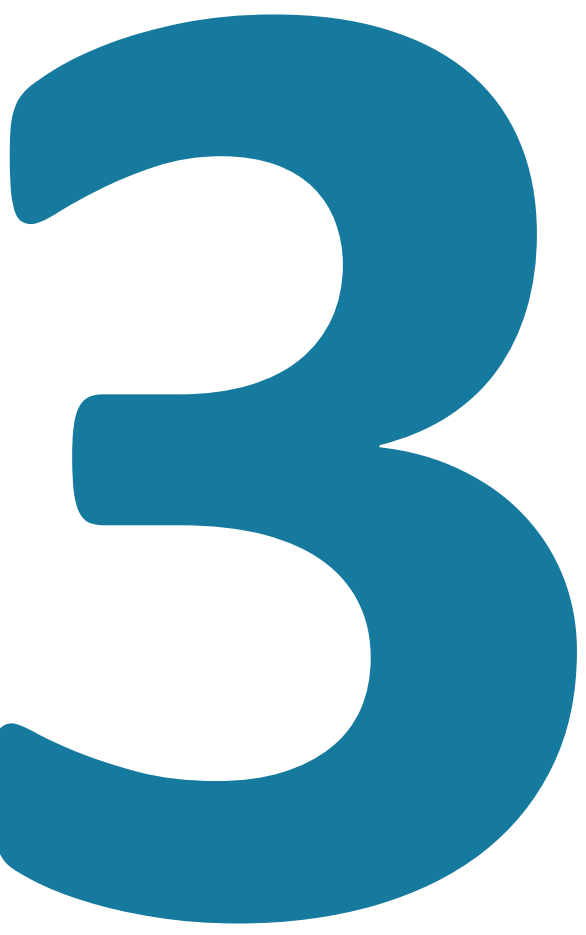




\section{Summary and General Discussion}





\section{Summary and General Discussion}

\section{Stent thrombosis}

In part I, the role of triggering mechanisms in provoking stent thrombosis is described. Furthermore, the relation between premature discontinuation of dual antiplatelet therapy (DAPT) and the incidence of stent thrombosis are discussed. Finally, the feasibility of using glycoprotein Ilb/IIla inhibitors in STEMI patients who have been pretreated with morphine is described.

Over the years, many predictors of stent thrombosis have been identified. This includes clinical (e.g. diabetes, LVEF<30\%), procedural (e.g. undersizing, edge dissection), angiographic (e.g. TIMI flow grade <3) and genetic risk factors (e.g. carriers of the CYP2C19*2 allele). Furthermore, premature cessation of clopidogrel and high on-treatment platelet reactivity (HPR) are strong predictors of ST. Nonetheless, it is surprising why only a small proportion of patients with risk factors for ST eventually develop ST.

Chapter $\mathbf{5}$ explored possible triggering mechanisms of ST. In a substantial number of patients (23\%), a triggering mechanisms preceding the stent thrombosis was identified. This included vigorous exercise, emotional stress or an active infection at the time of stent thrombosis. In addition, analysis of circadian variation showed a steep peak incidence from 7am-12pm.

These findings are in line with known triggering mechanisms in spontaneous myocardial infarction (i.e. not stent-related). Both physical exercise, timing of onset and emotional stress have all previously been identified as triggering mechanisms for myocardial infarction ${ }^{1-4}$. Stent thrombosis and spontaneous myocardial infarction share many pathophysiological pathways. These processes include increased sympathetic activity and vagal withdrawal, elevation in plasma catecholamines and renin levels, increased thrombin generation, increased heart rate and blood pressure, exercise induced coronary-artery spasm, increased systemic inflammation, increased vascular resistance, increased vessel-wall stress, a heightened platelet reactivity status and a hypercoagulability state. The identification of potential triggering mechanisms of ST might have important clinical implications related to both prognosis and prevention.

First, it should be acknowledged that some patients might be more vulnerable to stressinduced biological responses than others. Second, in relation to prevention, the ideal approach should involve a range of various strategies for the different types of triggering. Patients undergoing coronary stent implantation should be encouraged to perform moderate physical activity on a regular basis, because the beneficial effects of exercise training in the secondary prevention of coronary artery disease have been well 
established ${ }^{5}$. Importantly, there is ample evidence that regular moderate exercise lowers both the baseline risk as well as the relative risk that an episode of heavy physical exertion will trigger myocardial infarction ${ }^{6,7}$. However, caution remains warranted when patients plan to perform vigorous exercise, especially when untrained. This supports the current practice of performing an exercise test under supervised conditions in patients who engage in cardiac rehabilitation after a myocardial infarction.

All patients undergoing $\mathrm{PCl}$ with stent implantation receive dual antiplatelet therapy (DAPT). Several previous studies have established the relationship between premature discontinuation of clopidogrel and the occurrence of stent thrombosis ${ }^{8-10}$. On the other hand, more recent trials explored a shorter DAPT duration and suggested that a shorter DAPT duration up to 3 months might be as safe as the standard regimen ${ }^{11,12}$. Therefore, the absolute risk of stent thrombosis after early clopidogrel discontinuation was studied in a matched cohort of ST patients (Chapter 6). The incidence of stent thrombosis was found to be as high as $35.4 \%$ when clopidogrel was discontinued in the first month after $\mathrm{PCl}$ and was still $11.7 \%$ in case of clopidogrel cessation in the first 180 days. Hence, the risk of stent thrombosis was very high in this cohort of mainly ACS patients, and therefore early clopidogrel cessation should be avoided based on these data.

The absolute incidence of stent thrombosis found in this study seem quite high when compared to contemporary stent thrombosis rates, but is line with other (scarce) data from this era. Schulz et al. ${ }^{13}$ found a stent thrombosis rate of $\sim 12 \%$ when clopidogrel was discontinued in the first 6 months.

On the other hand, these findings seem to contrast to more recent studies suggesting that a short (3-6 month) regimen could be safe. However, these studies included mostly low-risk patients or were not powered to detected differences in ischaemic outcomes.

The SMART-DATE study was a large randomised trial which assigned a total of 2712 ACS patients to either 6 or 12 months of DAPT ${ }^{14}$. The authors found that myocardial infarction occurred more frequently in the 6-month DAPT group than in the 12-month or longer DAPT group (HR 2.41 (1.15-5.05), $p=0.02$ ). A meta-analysis of six randomized controlled trials published in 2017 concluded that in ACS patients, 3 but not 6 months of DAPT was associated with higher ST and $\mathrm{MI}$ rates ${ }^{15}$. However, another meta-analysis suggested no increase in ischaemic events with short term DAPT in ACS patients ${ }^{16}$.

In conclusion, based on these data, cardiologists should be reluctant in reducing DAPT duration after ACS. However, the characteristics of our patient cohort imply that the conclusions of this study cannot fully be translated to contemporary $\mathrm{PCl}$ practice. Most patients received a first generation drug-eluting stents (DES) and patients were treated with 
clopidogrel because the more potent P2Y12-inhibitors prasugrel and ticagrelor had not yet been introduced at the time of this registry. Both prasugrel and ticagrelor are associated with a reduction in the rate of ischaemic events, including stent thrombosis ${ }^{17-20}$. While the prodrug clopidogrel (i.e. an inactive metabolite) needs to be metabolized into its active form, prasugrel and ticagrelor have a faster onset of action and achieve high levels of platelet inhibition within 1-2 hours ${ }^{21,22}$. Furthermore, ticagrelor and prasugrel have shown more consistent platelet inhibition during maintenance therapy, whereas high-on-treatment platelet reactivity remains a drawback of clopidogrel with inadequate platelet inhibition exposing patients to an increased risk of stent thrombosis ${ }^{22-24}$ Ticagrelor and prasugrel have now become the P2Y12-inhibitor of choice in ACS, recommended by international guidelines ${ }^{26,27}$.

Chapter 7 discusses the use of an additional anti-thrombotic agent in patients presenting with STEMI who receive morphine before undergoing primary $\mathrm{PCI}$. Morphine is often used in STEMI patients for analgesia, sedation, anxiolysis, and to reduce adrenergic drive, heart rate and myocardial oxygen consumption. However, morphine is also known to delay the absorption of P2Y12-inhibitors, which exposes them to increased risk of ST after primary $\mathrm{PCl}$.

Therefore, in this chapter the effect of concomitant glycoprotein IIb/IIla inhibitors (GPI) in morphine treated STEMI patients was tested, following the introduction of a new local guideline. 33 cases of stent thrombosis were identified. Overall, a reduction in stent thrombosis associated with GPI was observed ( $0.4 \%(5 / 1217)$ vs. $2.6 \%(28 / 1080), p<0.0001)$. When looking into detail, $27 / 30$ of stent thrombosis patients in whom morphine use was known had received morphine prior to $\mathrm{PCl}$. The vast majority (85\%) of these patients had received morphine but not GPI.

A numerical but statistically not-significant increase in GUSTO moderate-to-severe bleeding was observed, although limited by small patients numbers. The risk of bleeding associated with GPI use is well documented though. Therefore, a strategy of default GPI use in all morphine treated patients might exposes these patients to a high risk of haemorrhagic complications.

However, GPI seems highly effective in preventing stent thrombosis and can be used in selected patients (e.g. complex $\mathrm{PCl}$, edge dissection, low flow state in cardiogenic shock, etc.). Moreover, alternative strategies are needed in order mitigate ST risk in morphine treated STEMI patients, without the downside of high bleeding risk. A recent addition to the portfolio of antithrombotic drugs is the introduction of cangrelor to the market. Cangrelor is an intravenous, reversibly-binding P2Y12-inhibitor. It has an ultra-quick onset and offset of action and is therefore very suitable for use in patients at high thrombotic risk. 
Cangrelor is highly potent with a near complete inhibition of platelet aggregation within two minutes after bolus injection. ${ }^{28}$ Effectivity of cangrelor in clinical practice was assessed in the Cangrelor versus standard therapy to achieve optimal management of platelet inhibition (CHAMPION) trials. In an individual patient meta-analysis of these three trials, cangrelor was found to be effective in reducing myocardial infarction and stent thrombosis. ${ }^{29}$ It might be reasonable to administer cangrelor to morphine treated STEMI patients. In addition, use of cangrelor is appealing in other patients at high thrombotic risk undergoing $\mathrm{PCl}$ who have not been properly preloaded with a P2Y12-inhibitor (e.g. patients undergoing high risk adhoc $\mathrm{PCl}$ or STEMI patents presenting with resuscitated cardiac arrest).

In Chapter 8, three case descriptions of patients with a particularly interesting case of stent thrombosis are described for illustrative purposes.

\section{Incidence of stent thrombosis anno 2020 and novel insights into pathophysiology}

It is estimated that newer generation DES are associated with approximately $50 \%$ reduction of stent thrombosis. ${ }^{30,31}$ Current rates of ST are estimated to be approximately $0,5-0.8 \%$ in the first year. ${ }^{32,33}$ Very late ST beyond one year has become a rarity with incidence rates of ST in newer generation DES be estimated at 0.1-0.2 per 100 persons-years ${ }^{34}$. The total ST risk amounts to $<1 \%$ even at a follow-up duration of more than five years ${ }^{32,35}$.

Systematic intracoronary imaging together with autopsy studies have provided further detailed insights into the pathophysiology of ST. A Report of the PREvention of Late Stent Thrombosis by an Interdisciplinary Global European Effort (PRESTIGE) Consortium showed that the main findings with optical coherence tomography (OCT) in in acute and subacute ST patients were uncovered struts and underexpansion. ${ }^{36}$ In patients presenting with (very) late ST, a more heterogenous etiology was observed, with neoatherosclerosis and uncovered struts as most frequent findings, although underexpansion and severe restenosis were found as well. Neoatherosclerosis is an accelerated form of de-novo atherosclerosis arising within the stent, which typically can develop within months after implantation. ${ }^{37}$ Like atherosclerosis in native coronary arteries, plaque disruption or erosion might subsequently cause thrombosis. Another underlying cause of stent thrombosis is positive vessel remodelling, in which a space between the previously placed stent and vessel wall develops over time (i.e. late acquired malaposition). This can also be appreciated with OCT or intravascular ultrasound (IVUS)..$^{38}$ Moreover, other concepts related to the stent have evolved, such as late luminal loss (which may contribute to late re-stenosis) and vasomotor dysfunction proximal and distal to the stented segment. ${ }^{31}$

Autopsy studies confirmed that the underlying mechanism in many cases was chronic inflammation in combination with a hypersensitivity reactions against the stents polymer. ${ }^{31,39}$ This chronic state of inflammation appeared to be the principal cause of the aforementioned 
neoatherosclerosis and vessel modelling, as well as impaired endothelialisation and slower strut healing. ${ }^{39}$ The stents polymer is an important component of the stent at least partially triggering this state of chronic inflammation. ${ }^{40}$

\section{Introduction of newer generation DES}

Improvements in the design of the newest generation DES have been made with regard to the scaffold (i.e. the metal platform, including strut geometry and thickness) and the polymer which carries the antiproliferative drug (e.g. dosing and pharmacokinetic release) ${ }^{35}$. Accordingly, newer generation stents have thinner struts, more biocompatible or even biodegradable coatings and lower doses of antiproliferative drugs. ${ }^{31}$

Newer generation stents such as Resolute, Xience and Synergy are composed of alternative metal alloys such as cobalt-chromium $(\mathrm{CoCr})$ and platinum-chromium $(\mathrm{PtCr})^{41}$. These newer alloys combine reduction in strut thickness with increased radial strength. Stent thickness is of major importance, because thinner struts are associated with faster rates of endothelialisation and lower thrombogenicity. ${ }^{42}$ Whereas first generation DES used rather thick struts (120 - 140 um), newer generation DES have a strut diameter of 70-90 um or a strut thickness of even <70um in "ultrathin strut" DES. In addition to strut thickness, it was acknowledged that strut width is an important determinant of blood flow dynamics and manufacturers managed to produce stents with a smaller "footprint" which improved its hemodynamic profile and lowered shear stress. ${ }^{42}$

Another improvement of newer generation DES is the use of polymers with improved biocompatibility and the introduction of biodegradable polymers or even fully polymer-free DES. Some newer-generation DES still use durable (permanent) polymers but managed to improve the biocompatibility (e.g. Xience everolimus-eluting stent (EES), PROMUS Element EES and Resolute zotarolimus-eluting stent (ZES) ${ }^{42}$. These improved polymers reduce platelet adhesion / activation and, importantly, cause less inflammation and improved healing. Other stents such as Synergy EES and Orsiro Sirolimus-eluting stents (SES) use biodegradable polymers. Because the polymer dissolves over time, the exposure of the vessel wall to the polymer-induced vessel wall inflammation is only limited in time and one is essentially left with a BMS after full release of the polymer and drug. ${ }^{40}$ Biodegradable DES might have increased long-term safety including stent thrombosis as compared to early generation permanent-polymer DES and comparable results with second-generation ( $\mathrm{CoCr}$ or $\mathrm{PtCr}$ ) permanent-polymer DES ${ }^{39,40}$.

Although the concept of biodegradable polymers or polymer-free devices is appealing and performance appears to be at par with other newer generation DES, conflicting evidence exists regarding long term superiority ${ }^{39,43-45}$. However, more recent studies did show promising results for the ultrathin-strut stent when combined with biodegradable polymers. In the SORT 
OUT VII ${ }^{46}$, an ultrathin-strut biodegradable polymer stent demonstrated to be superior to a thicker (but also biodegradable polymer) stent with regard to definite stent thrombosis rates. Another very recent and interesting study ${ }^{47}$ compared an ultrathin-strut ( $\left.60 \mu \mathrm{m}\right)$ bioresorbable polymer stent with a thin-strut $(80 \mu \mathrm{m})$ durable-polymer everolimus-eluting stent and showed superiority with regard to target vessel $\mathrm{MI}$ and late or very late stent thrombosis. Another study in STEMI patients ${ }^{48}$ compared ultrathin-strut biodegradable polymer SES vs. thin strut durable polymer EES and suggested a significant lower rate of target lesion failure at 1 year with the ultra-thin strut biodegradable stent but not stent thrombosis or myocardial infarction. Finally, the BIO-RESORT trial ${ }^{49}$ compared two biodegradable very-thin and ultrathin-strut biodegradable polymer stents with a thin-strut durable polymer stent. Although the overall study was negative, sub analyses suggested that the thinner strut-stents may be beneficial in patients with small target vessels and in patients with severely calcified coronary artery disease ${ }^{50,51}$.

In conclusion, the combination of (ultra)thin stent struts with a biodegradable polymer coating might be a successful recipe in further improving long-term efficacy and safety in the contemporary generation DES. However, these promising results have yet to be confirmed by more large scale randomized controlled trials.

\section{Tailored therapy based on platelet function testing}

Part II addresses platelet function testing. Chapter 9 is a review paper discussing the prevalence of high (and low) on-treatment platelet reactivity in patients treated with aspirin and P2Y12-inhibitors. An overview of the relationship between high and low on-treatment reactivity with clinical outcomes is given. Furthermore, a summary is provided of studies which sought to establish a benefit of alternative antiplatelet regimens based on platelet function tests. Finally, currently available platelet functions and its indications for clinical use are discussed.

In Chapter 10, four platelet function tests are compared in a cohort of stent thrombosis patients. Correlation and agreement between the individual platelet function tests are discussed. Moreover, the feasibility of a composite conclusion based on more than one test is described. HPR rates in this patients cohort ranged from 14.6 for the Verifynow with the commonly used cut-off $>235$ platelet reactivity units (PRU) to $49.7 \%$ for the VasodilatorStimulated Phosphoprotein Assay (VASP). HPR according to the composite based on ${ }^{3} 2$ out of 3 tests was present in $29.8 \%$ of patients. Correlation between the different tests was found to be weak to moderate. When comparing the individual tests to the composite based on three other tests, the VerifyNow test (cut-off PRU >235) had a low sensitivity and did not identify $50 \%$ of patients who were found to have HPR according to the composite advice (of note, the VerifyNow performed better when the lower cut-off was used). On the other hand, 
the VASP assay seemed to "over-identify" HPR: in 43,3\% HPR was present according to the VASP assay whereas the panel of tests considered these patients as non-HPR. In conclusion, a considerable variability in HPR rates was found. Agreement between the individual tests and between the individual tests and a panel of three tests was weak to moderate at best. Given the large degree of variability within the individual tests, a conclusion based on a panel of three tests seems a feasible and promising alternative.

So what could be the future of tailoring treatment in patients exhibiting HPR? As discussed in Chapter 8, smaller studies suggested that tailoring treatment based on platelet function testing could improve outcomes ${ }^{52,53}$, but larger randomized controlled trials failed to demonstrate a benefit of this individualized treatment ${ }^{54-57}$.

Two more recent study rather focused on a strategy of "de-escalating" from the more potent P2Y12-inhibitors back to clopidogrel ${ }^{58}$.

The TROPICAL-ACS study randomized 2610 ACS patients to either standard treatment with prasugrel or a strategy of platelet function testing-guided maintenance therapy with clopidogrel or prasugrel from day 14 after hospital discharge (i.e. de-escalation to clopidogrel in patients without HPR) ${ }^{58}$. In the guided de-escalation group, HPR status was established in 511 patients (39\%). Platelet function guided de-escalation was found to be non-inferior to standard treatment. No benefit in terms of reducing bleeding complication was found.

The TOPIC trial ${ }^{59}$ randomized more than 1200 ACS patients who underwent $\mathrm{PCl}$ to a strategy of standard DAPT with prasugrel versus a regimen of de-escalation to clopidogrel in the other study arm (i.e. without platelet function monitoring or selection otherwise). De-escalation was applicable only if the first month post $\mathrm{PCl}$ had been uneventful. A de-escalation strategy was superior to an unchanged DAPT strategy in terms of reducing bleeding, whereas no increase in bleeding events was observed.

Other studies individualized treatment based on CYP2C19 polymorphisms rather than on the presence of HPR per se. CYP2C19 is a hepatic enzyme which is involved in the activation of the prodrug clopidogrel. Several genetic polymorphisms have been described, among which the loss-of-function alleles CYP2C19*2 and CYP2C19*3 are most relevant in clinical practice. Both alleles have independently been associated with ischaemic events in clopidogrel treated patients. ${ }^{60}$

The recently published POPular Genetics trial randomized patients undergoing primary PCI to a standard regimen of ticagrelor (or prasugrel) versus a so-called genotype-guided group, in which carriers of CYP2C19*2 or CYP2C19*3 alleles received ticagrelor or prasugrel and 
noncarriers received clopidogrel ${ }^{61}$ Genotype-guided therapy was non-inferior to standard treatment with respect to thrombotic events, but resulted in a lower incidence of bleeding.

The TAILOR-PCI study (NCT01742117, presented ACC 2020 meeting) enrolling more than 5,000 patients undergoing $\mathrm{PCI}$ for ACS or stable coronary artery disease randomized patients to either conventional therapy with clopidogrel versus genotype-guided therapy, existing of ticagrelor for carriers of the CYP2C19 loss-of-function allele or clopidogrel for non-carriers. The primary end point occurred in $4 \%$ of the genotype-guided group versus $5.9 \%$ in the conventional group, although the point of significance was just missed (HR 0.66, $p=0.056$ ).

Trials investigating tailored treatment based on genetic testing are promising as well, be it either intensifying treatment in clopidogrel treated patients undergoing $\mathrm{PCl}$ or de-escalating treatment in STEMI patients. Obviously, the presence of HPR depends on more than genetic factors alone. Therefore, it is curious why genotype-guided trials seems to be more effective as compared to a platelet function testing based strategy. One can only speculate whether this is either an effect of the large variability in determining HPR with platelet function testing, or a result of trial size or just a matter of chance. However, genotype based testing is an elegant and feasible strategy and might be considered as an alternative to platelet function testing, especially when platelet function testing is not available.

In conclusion, the early randomized controlled trials did not show a benefit of individualizing P2Y12-inhibitor treatment based on platelet function testing with regard to ischaemic end points. More recent studies show that a strategy of de-escalation guided by platelet function testing or genetic testing might be safe and reduce bleeding. Current ESC guidelines recommend to consider de-escalation guided by either platelet function testing or CYP2C19directed genotyping, especially in patients deemed unsuitable for 12-month potent platelet inhibition ${ }^{26,27}$.

\section{Antithrombotic therapy in AF patients undergoing PCI}

Part III addresses the subgroup of AF patients who undergo PCI. Currently, these patients are more and more treated with oral anticoagulation and a P2Y12-inhibitor but with the omittance of aspirin. However, most trials comparing so-called double antithrombotic treatment (DAT) with triple antithrombotic therapy (TAT) were underpowered for thrombotic events.

Chapter 11 investigated whether patients at high thrombotic risk might still benefit from a strategy of TAT. In a secondary analysis of the RE-DUAL PCI trial, a Cox proportional hazards model was built to compare effect of TAT versus DAT was calculated in the highest proportion of predicted thrombotic risk. In 209 patients (7.7\%) the combined ischaemic endpoint occurred during the first year. A simplified prediction rule was constructed 
containing 7 variables. In patients with a risk score ${ }^{3} 5$ (N 154, 5.7\%), a significant reduction in the composite of myocardial infarction and stent thrombosis was observed with TAT vs. DAT $(6.3 \%$ vs. $21.0 \%, p=0.04)$, without a penalty in terms of bleeding. In patients at low thrombotic risk, a significant increase in bleeding was observed without a reduction of thrombotic events. These findings support the use of TAT in a small subgroup ( $5 \%$ of patients), while using DAT in the majority of AF patients undergoing $\mathrm{PCl}$.

The observation of fewer ischaemic events in high-risk patients with TAT is in line with some meta-analysis and subgroup analyses which pointed to a possible benefit of TAT, especially in high risk patients. Two meta-analysis of randomised controlled trials signalled a difference in terms of stent thrombosis, although incidence rates were low ${ }^{62,63}$. Interestingly, the meta-analysis by Gargiulo proposed a trade-off on individual patient basis of the number needed to treat for harm (NNTH, i.e. bleeding) and benefit (NNTB, i.e. ischaemic events). They constructed a model calculating the risk between NNTH and NNTB for different risk strata. This highlights the concept that individual risks of bleeding and MI influence the overall risk/benefit ratio of each therapeutic strategy. The model suggested that bleeding risk prevails in most patients, although there might be a smaller sub group of patients who have predominant ischaemic risk with low bleeding risk. The authors do not provide a tool to use in clinical practice but this is rather a theoretical frame work.

The current study is the first study to investigate the effect of TAT in patients at high thrombotic risk represented by a combination of high-risk characteristics. Several subgroup analyses of the randomised controlled trials based on single clinical variables (e.g. diabetes, age ${ }^{3} 80$ years, ACS patients) could not demonstrated a reduction in ischemic events associated with TAT ${ }^{64-66}$, which illustrates the complex and multifactorial aspect of high thrombotic risk which was adequately addressed in the current study by combining multiple patients characteristics.

Our findings are an important "proof of concept", which is in line with general beliefs of many cardiologists with regard to high-risk patients. Using this prediction rule containing seven clinical, angiographical and procedural parameters, a significant reduction in MI/ST associated with TAT was found in patients at high thrombotic risk undergoing $\mathrm{PCl}$, without a penalty in terms of bleeding. On the other hand, these data suggest to use DAT as default therapy in the majority of patients.

The performance of the score was fair in the WOEST 2 registry which served as an external validation cohort. Differences between DAT and TAT could not be tested in this registry. Before adapting this novel risk score into daily clinical practice, further external validation in an independent randomised controlled trials is needed. 
Risk stratification for estimating bleeding risk was investigated in chapter 12 . The development and validation of a prediction tool to estimate individual patients bleeding risk is described. Based on the RE-DUAL study, a Cox model for Bleeding Academic Research Consortium (BARC) 2, 3 and 5 bleeding was constructed by stepwise selection from candidate variables. Expected hazard of bleeding events at 365 days was predicted. Based on beta-coefficients of the Cox model, a point score was developed. The simplified prediction model contained the following variables: triple therapy, age, haematocrit, BMI and a history of malignancy. Three risk categories could be distinguished: low bleeding risk ( 10\%), moderate bleeding risk (15-20\%) and high bleeding risk (>25\%).

This is the first available risk score that has been specifically developed to estimate bleeding risk in $\mathrm{AF}$ patients undergoing $\mathrm{PCl}$. The prediction model, which was validated in the WOEST study, was able to estimate bleeding risk with fair c-statistics. To date, no other risk scores exists for this patient category. Traditionally used risk scores such as CRUSADE and HASBLED scores are not applicable to this specific patient group and cannot be used because different variables are used.

Even when baseline bleeding risk is high in these patients treated with a combination of anticoagulation and (dual) antiplatelet therapy, bleeding risk varies considerably between patients. It is essential to identify patients with increased bleeding risk. This score estimates bleeding risk and helps to balance the antithrombotic benefits and drawbacks of bleeding complications, especially when triple therapy is considered. 


\section{Future perspectives}

Although the incidence of stent thrombosis has declined by half in the last decade, it is estimated that over three million $\mathrm{PCl}$ procedures are performed worldwide, illustrating that the total burden of stent thrombosis still remains significant. Even though overall stent thrombosis risk is low now, specific subgroups of patients deserve attention. Future research should investigate whether morphine pretreated STEMI should receive additional antithrombotic therapy (such as GPI or Cangrelor) by default. Furthermore, studies investigating optimal duration of DAPT after ACS should not only focus on reducing ischaemic events, but also on reducing hemorrhagic complications, given the strong link with adverse outcomes. In an ideal world, a net clinical risk score should be developed that yields a patient-tailored advice on DAPT regimen and duration.

With regard to $\mathrm{AF}$ patients undergoing $\mathrm{PCl}$, even more unchartered territory lies ahead. All evidence taken together suggests that DAT should be the default strategy in most AF patients undergoing $\mathrm{PCl}$. We found a small ( $\sim \%$ of patients) subset of patients who seem to benefit from triple antithrombotic therapy. Further external validation in an independent randomised controlled trials is needed. Future studies could shed light on the optimal duration when TAT is used in this specific high-risk subgroup (either a short course of one month, either three months or even longer).

Finally, additional risk models are needed that incorporate both bleeding and thrombotic risk. When all randomized trials evaluating TAT vs. DAT in AF patients undergoing PCI were to be pooled, it might be possible to construct a prediction model estimating a patients net clinical risk. 


\section{References}

1. Muller JE, Tofler GH, Stone PH. Circadian variation and triggers of onset of acute cardiovascular disease. Circulation. 1989 Apr;79(4):733-43.

2. Mittleman MA, Maclure M, Tofler GH, Sherwood JB, Goldberg RJ, Muller JE. Triggering of acute myocardial infarction by heavy physical exertion. Protection against triggering by regular exertion. Determinants of Myocardial Infarction Onset Study Investigators. N Engl J Med. 1993 Dec 2;329(23):1677-83.

3. Meier CR, Jick SS, Derby LE, Vasilakis C, Jick H. Acute respiratory-tract infections and risk of first-time acute myocardial infarction. Lancet. 1998 May 16;351(9114):1467-71.

4. Bhattacharyya MR, Steptoe A. Emotional triggers of acute coronary syndromes: strength of evidence, biological processes, and clinical implications. Prog Cardiovasc Dis. 2007 Apr;49(5):353-65.

5. Warburton DER, Nicol CW, Bredin SSD. Health benefits of physical activity: the evidence. CMAJ. 2006 Mar 14;174(6):801-9.

6. Willich SN, Lewis M, Löwel H, Arntz HR, Schubert F, Schröder R. Physical exertion as a trigger of acute myocardial infarction. Triggers and Mechanisms of Myocardial Infarction Study Group. N Engl J Med. 1993 Dec 2;329(23):1684-90.

7. Giri S, Thompson PD, Kiernan FJ, Clive J, Fram DB, Mitchel JF, et al. Clinical and angiographic characteristics of exertion-related acute myocardial infarction. JAMA. 1999 Nov 10;282(18):1731-6.

8. Werkum JW van, Heestermans AA, Zomer AC, Kelder JC, Suttorp MJ, Rensing BJ, et al. Predictors of coronary stent thrombosis: the Dutch Stent Thrombosis Registry. Journal of the American College of Cardiology. 2009 Apr 21;53(16):1399-409.

9. Airoldi F, Colombo A, Morici N, Latib A, Cosgrave J, Buellesfeld L, et al. Incidence and predictors of drug-eluting stent thrombosis during and after discontinuation of thienopyridine treatment. Circulation. 2007 Aug 14;116(7):745-54.

10. D’Ascenzo F, Bollati M, Clementi F, Castagno D, Lagerqvist B, de la Torre Hernandez JM, et al. Incidence and predictors of coronary stent thrombosis: evidence from an international collaborative meta-analysis including 30 studies, 221,066 patients, and 4276 thromboses. Int J Cardiol. 2013 Jul 31;167(2):575-84.

11. Feres F, Costa RA, Abizaid A, Leon MB, Marin-Neto J, Botelho RV, et al. Three vs twelve months of dual antiplatelet therapy after zotarolimus-eluting stents: the OPTIMIZE randomized trial. Jama. 2013 Dec 18;310(23):2510-22.

12. Kim BK, Hong MK, Shin DH, Nam CM, Kim JS, Ko YG, et al. A new strategy for discontinuation of dual antiplatelet therapy: the RESET Trial (REal Safety and Efficacy of 3-month dual antiplatelet Therapy following Endeavor zotarolimus-eluting stent implantation). Journal of the American College of Cardiology. 2012 Oct 9;60(15):1340-8. 
13. Schulz S, Schuster T, Mehilli J, Byrne RA, Ellert J, Massberg S, et al. Stent thrombosis after drugeluting stent implantation: incidence, timing, and relation to discontinuation of clopidogrel therapy over a 4-year period. European heart journal. 2009 Nov;30(22):2714-21.

14. Hahn J-Y, Song YB, Oh J-H, Cho D-K, Lee JB, Doh J-H, et al. 6-month versus 12-month or longer dual antiplatelet therapy after percutaneous coronary intervention in patients with acute coronary syndrome (SMART-DATE): a randomised, open-label, non-inferiority trial. Lancet. 2018 31;391(10127):1274-84.

15. Palmerini T, Riva DD, Benedetto U, Reggiani LB, Feres F, Abizaid A, et al. Three, six, or twelve months of dual antiplatelet therapy after DES implantation in patients with or without acute coronary syndromes: an individual patient data pairwise and network meta-analysis of six randomized trials and 11473 patients. European Heart Journal. 2017 Jan 21;

16. Yin S-H-L, Xu P, Wang B, Lu Y, Wu Q-Y, Zhou M-L, et al. Duration of dual antiplatelet therapy after percutaneous coronary intervention with drug-eluting stent: systematic review and network meta-analysis. BMJ. 2019 28;365:12222.

17. Wiviott SD, Braunwald E, McCabe CH, Montalescot G, Ruzyllo W, Gottlieb S, et al. Prasugrel versus clopidogrel in patients with acute coronary syndromes. N Engl J Med. 2007 Nov 15;357(20):2001-15.

18. Steg PG, James S, Harrington RA, Ardissino D, Becker RC, Cannon CP, et al. Ticagrelor versus clopidogrel in patients with ST-elevation acute coronary syndromes intended for reperfusion with primary percutaneous coronary intervention: A Platelet Inhibition and Patient Outcomes (PLATO) trial subgroup analysis. Circulation. 2010 Nov 23;122(21):2131-41.

19. Wiviott SD, Braunwald E, McCabe CH, Horvath I, Keltai M, Herrman J-PR, et al. Intensive oral antiplatelet therapy for reduction of ischaemic events including stent thrombosis in patients with acute coronary syndromes treated with percutaneous coronary intervention and stenting in the TRITON-TIMI 38 trial: a subanalysis of a randomised trial. Lancet. $2008 \mathrm{Apr}$ 19;371(9621):1353-63.

20. Steg PG, Harrington RA, Emanuelsson H, Katus HA, Mahaffey KW, Meier B, et al. Stent thrombosis with ticagrelor versus clopidogrel in patients with acute coronary syndromes: an analysis from the prospective, randomized PLATO trial. Circulation. 2013 Sep 3;128(10):105565.

21. Gurbel PA, Bliden KP, Butler K, Tantry US, Gesheff T, Wei C, et al. Randomized double-blind assessment of the ONSET and OFFSET of the antiplatelet effects of ticagrelor versus clopidogrel in patients with stable coronary artery disease: the ONSET/OFFSET study. Circulation. 2009 Dec 22;120(25):2577-85.

22. Wallentin L, Varenhorst C, James S, Erlinge D, Braun OO, Jakubowski JA, et al. Prasugrel achieves greater and faster $\mathrm{P} 2 \mathrm{Y} 12$ receptor-mediated platelet inhibition than clopidogrel due to more efficient generation of its active metabolite in aspirin-treated patients with coronary artery disease. Eur Heart J. 2008 Jan;29(1):21-30.

23. Tantry US, Bonello L, Aradi D, Price MJ, Jeong Y-H, Angiolillo DJ, et al. Consensus and update on the definition of on-treatment platelet reactivity to adenosine diphosphate associated 
with ischemia and bleeding. Journal of the American College of Cardiology. 2013 Dec 17;62(24):2261-73.

24. Orme R, Judge HM, Storey RF. Monitoring Antiplatelet Therapy. Seminars in Thrombosis and Hemostasis. 2017 Apr;43(3):311-9.

25. Angiolillo DJ, Fernandez-Ortiz A, Bernardo E, Alfonso F, Macaya C, Bass TA, et al. Variability in individual responsiveness to clopidogrel: clinical implications, management, and future perspectives. J Am Coll Cardiol. 2007 Apr 10;49(14):1505-16.

26. Neumann F-J, Sousa-Uva M, Ahlsson A, Alfonso F, Banning AP, Benedetto U, et al. 2018 ESC/EACTS Guidelines on myocardial revascularization. European Heart Journal. 2019 Jan 7;40(2):87-165.

27. Collet J-P, Thiele H, Barbato E, Barthélémy O, Bauersachs J, Bhatt DL, et al. 2020 ESC Guidelines for the management of acute coronary syndromes in patients presenting without persistent ST-segment elevation. Eur Heart J. 2020 Aug 29;

28. Storey RF, Oldroyd KG, Wilcox RG. Open multicentre study of the P2T receptor antagonist AR-C69931MX assessing safety, tolerability and activity in patients with acute coronary syndromes. Thromb Haemost. 2001 Mar;85(3):401-7.

29. Steg PG, Bhatt DL, Hamm CW, Stone GW, Gibson CM, Mahaffey KW, et al. Effect of cangrelor on periprocedural outcomes in percutaneous coronary interventions: a pooled analysis of patientlevel data. Lancet. 2013 Dec 14;382(9909):1981-92.

30. Bittl JA, Baber U, Bradley SM, Wijeysundera DN. Duration of Dual Antiplatelet Therapy: A Systematic Review for the 2016 ACC/AHA Guideline Focused Update on Duration of Dual Antiplatelet Therapy in Patients With Coronary Artery Disease: A Report of the American College of Cardiology/American Heart Association Task Force on Clinical Practice Guidelines. Journal of the American College of Cardiology. 2016 Mar 22;

31. Byrne RA, Joner M, Kastrati A. Stent thrombosis and restenosis: what have we learned and where are we going? The Andreas Gruntzig Lecture ESC 2014. European heart journal. 2015 Dec 14;36(47):3320-31.

32. Tada T, Byrne RA, Simunovic I, King LA, Cassese S, Joner M, et al. Risk of stent thrombosis among bare-metal stents, first-generation drug-eluting stents, and second-generation drugeluting stents: results from a registry of 18,334 patients. JACC Cardiovascular interventions. 2013 Dec;6(12):1267-74.

33. Räber L, Magro M, Stefanini GG, Kalesan B, van Domburg RT, Onuma Y, et al. Very late coronary stent thrombosis of a newer-generation everolimus-eluting stent compared with early-generation drug-eluting stents: a prospective cohort study. Circulation. $2012 \mathrm{Mar}$ 6;125(9):1110-21.

34. Valgimigli M, Bueno H, Byrne RA, Collet J-P, Costa F, Jeppsson A, et al. 2017 ESC focused update on dual antiplatelet therapy in coronary artery disease developed in collaboration with EACTS: The Task Force for dual antiplatelet therapy in coronary artery disease of the European Society of Cardiology (ESC) and of the European Association for Cardio-Thoracic Surgery (EACTS). European Heart Journal. 2017 26; 
35. Torrado J, Buckley L, Durán A, Trujillo P, Toldo S, Valle Raleigh J, et al. Restenosis, Stent Thrombosis, and Bleeding Complications: Navigating Between Scylla and Charybdis. J Am Coll Cardiol. 2018 17;71(15):1676-95.

36. Adriaenssens T, Joner M, Godschalk TC, Malik N, Alfonso F, Xhepa E, et al. Optical Coherence Tomography Findings in Patients With Coronary Stent Thrombosis: A Report of the PRESTIGE Consortium (Prevention of Late Stent Thrombosis by an Interdisciplinary Global European Effort). Circulation. 2017 Sep 12;136(11):1007-21.

37. Otsuka F, Byrne RA, Yahagi K, Mori H, Ladich E, Fowler DR, et al. Neoatherosclerosis: overview of histopathologic findings and implications for intravascular imaging assessment. European heart journal. 2015 Aug 21;36(32):2147-59.

38. Gopalakrishnan M, Lotfi AS. Stent Thrombosis. Semin Thromb Hemost. 2018 Feb;44(1):46-51.

39. Gori T, Polimeni A, Indolfi C, Räber L, Adriaenssens T, Münzel T. Predictors of stent thrombosis and their implications for clinical practice. Nat Rev Cardiol. 2019;16(4):243-56.

40. Rizas KD, Mehilli J. Stent Polymers: Do They Make a Difference? Circ Cardiovasc Interv. 2016;9(6).

41. Sakamoto A, Jinnouchi H, Torii S, Virmani R, Finn AV. Understanding the Impact of Stent and Scaffold Material and Strut Design on Coronary Artery Thrombosis from the Basic and Clinical Points of View. Bioengineering (Basel). 2018 Sep 4;5(3).

42. Torii S, Jinnouchi H, Sakamoto A, Kutyna M, Cornelissen A, Kuntz S, et al. Drug-eluting coronary stents: insights from preclinical and pathology studies. Nat Rev Cardiol. 2020;17(1):37-51.

43. Zhu P, Zhou X, Zhang C, Li H, Zhang Z, Song Z. Safety and efficacy of ultrathin strut biodegradable polymer sirolimus-eluting stent versus durable polymer drug-eluting stents: a meta-analysis of randomized trials. BMC Cardiovasc Disord. 2018 15;18(1):170.

44. Mridha N, Subhaharan D, Niranjan S, Rashid MK, Psaltis P, Singh K. A meta-analysis of randomized controlled trials to compare long-term clinical outcomes of bioabsorbable polymer and durable polymer drug-eluting stents. Eur Heart J Qual Care Clin Outcomes. 2019 01;5(2):105-13.

45. El-Hayek G, Bangalore S, Casso Dominguez A, Devireddy C, Jaber W, Kumar G, et al. MetaAnalysis of Randomized Clinical Trials Comparing Biodegradable Polymer Drug-Eluting Stent to Second-Generation Durable Polymer Drug-Eluting Stents. JACC Cardiovasc Interv. 2017 13;10(5):462-73.

46. Jensen LO, Thayssen P, Maeng M, Ravkilde J, Krusell LR, Raungaard B, et al. Randomized Comparison of a Biodegradable Polymer Ultrathin Strut Sirolimus-Eluting Stent With a Biodegradable Polymer Biolimus-Eluting Stent in Patients Treated With Percutaneous Coronary Intervention: The SORT OUT VII Trial. Circ Cardiovasc Interv. 2016;9(7).

47. Kandzari DE, Koolen JJ, Doros G, Garcia-Garcia HM, Bennett J, Roguin A, et al. Ultrathin Bioresorbable-Polymer Sirolimus-Eluting Stents Versus Thin Durable-Polymer EverolimusEluting Stents for Coronary Revascularization: 3-Year Outcomes From the Randomized BIOFLOW V Trial. JACC Cardiovasc Interv. 2020 08;13(11):1343-53. 
48. Iglesias JF, Muller O, Heg D, Roffi M, Kurz DJ, Moarof I, et al. Biodegradable polymer sirolimuseluting stents versus durable polymer everolimus-eluting stents in patients with ST-segment elevation myocardial infarction (BIOSTEMI): a single-blind, prospective, randomised superiority trial. Lancet. 2019 05;394(10205):1243-53.

49. Buiten RA, Ploumen EH, Zocca P, Doggen CJM, Danse PW, Schotborgh CE, et al. Thin, Very Thin, or Ultrathin Strut Biodegradable or Durable Polymer-Coated Drug-Eluting Stents: 3-Year Outcomes of BIO-RESORT. JACC Cardiovasc Interv. 2019 09;12(17):1650-60.

50. Buiten RA, Ploumen EH, Zocca P, Doggen CJM, van Houwelingen KG, Danse PW, et al. Three contemporary thin-strut drug-eluting stents implanted in severely calcified coronary lesions of participants in a randomized all-comers trial. Catheter Cardiovasc Interv. 2020 Nov;96(5):E508-15.

51. Buiten RA, Ploumen EH, Zocca P, Doggen CJM, van der Heijden LC, Kok MM, et al. Outcomes in Patients Treated With Thin-Strut, Very Thin-Strut, or Ultrathin-Strut Drug-Eluting Stents in Small Coronary Vessels: A Prespecified Analysis of the Randomized BIO-RESORT Trial. JAMA Cardiol. 2019 01;4(7):659-69.

52. Hazarbasanov D, Velchev V, Finkov B, Postadjian A, Kostov E, Rifai N, et al. Tailoring clopidogrel dose according to multiple electrode aggregometry decreases the rate of ischemic complications after percutaneous coronary intervention. Journal of Thrombosis and Thrombolysis. 2012 Jul;34(1):85-90.

53. Siller-Matula JM, Francesconi M, Dechant C, Jilma B, Maurer G, Delle-Karth G, et al. Personalized antiplatelet treatment after percutaneous coronary intervention: the MADONNA study. International Journal of Cardiology. 2013 Sep 1;167(5):2018-23.

54. Price MJ, Berger PB, Teirstein PS, Tanguay J-F, Angiolillo DJ, Spriggs D, et al. Standard- vs highdose clopidogrel based on platelet function testing after percutaneous coronary intervention: the GRAVITAS randomized trial. JAMA. 2011 Mar 16;305(11):1097-105.

55. Collet J-P, Cuisset T, Rangé G, Cayla G, Elhadad S, Pouillot C, et al. Bedside monitoring to adjust antiplatelet therapy for coronary stenting. The New England Journal of Medicine. $2012 \mathrm{Nov}$ 29;367(22):2100-9.

56. Trenk D, Stone GW, Gawaz M, Kastrati A, Angiolillo DJ, Müller U, et al. A randomized trial of prasugrel versus clopidogrel in patients with high platelet reactivity on clopidogrel after elective percutaneous coronary intervention with implantation of drug-eluting stents: results of the TRIGGER-PCI (Testing Platelet Reactivity In Patients Undergoing Elective Stent Placement on Clopidogrel to Guide Alternative Therapy With Prasugrel) study. Journal of the American College of Cardiology. 2012 Jun 12;59(24):2159-64.

57. Cayla G, Cuisset T, Silvain J, Leclercq F, Manzo-Silberman S, Saint-Etienne C, et al. Platelet function monitoring to adjust antiplatelet therapy in elderly patients stented for an acute coronary syndrome (ANTARCTIC): an open-label, blinded-endpoint, randomised controlled superiority trial. Lancet (London, England). 2016 Oct 22;388(10055):2015-22.

58. Sibbing D, Aradi D, Jacobshagen C, Gross L, Trenk D, Geisler T, et al. Guided de-escalation of antiplatelet treatment in patients with acute coronary syndrome undergoing percutaneous 
coronary intervention (TROPICAL-ACS): a randomised, open-label, multicentre trial. Lancet. 2017 Oct 14;390(10104):1747-57.

59. Cuisset T, Deharo P, Quilici J, Johnson TW, Deffarges S, Bassez C, et al. Benefit of switching dual antiplatelet therapy after acute coronary syndrome: the TOPIC (timing of platelet inhibition after acute coronary syndrome) randomized study. Eur Heart J. 2017 Nov 1;38(41):3070-8.

60. Mega JL, Close SL, Wiviott SD, Shen L, Hockett RD, Brandt JT, et al. Cytochrome p-450 polymorphisms and response to clopidogrel. The New England Journal of Medicine. 2009 Jan 22;360(4):354-62.

61. Claassens DMF, Vos GJA, Bergmeijer TO, Hermanides RS, van 't Hof AWJ, van der Harst P, et al. A Genotype-Guided Strategy for Oral P2Y12 Inhibitors in Primary PCI. N Engl J Med. 2019 24;381(17):1621-31.

62. Gargiulo G, Goette A, Tijssen J, Eckardt L, Lewalter T, Vranckx P, et al. Safety and efficacy outcomes of double vs. triple antithrombotic therapy in patients with atrial fibrillation following percutaneous coronary intervention: a systematic review and meta-analysis of nonvitamin K antagonist oral anticoagulant-based randomized clinical trials. Eur Heart J. 2019 Dec 7;40(46):3757-67.

63. Potpara TS, Mujovic N, Proietti M, Dagres N, Hindricks G, Collet J-P, et al. Revisiting the effects of omitting aspirin in combined antithrombotic therapies for atrial fibrillation and acute coronary syndromes or percutaneous coronary interventions: meta-analysis of pooled data from the PIONEER AF-PCI, RE-DUAL PCI, and AUGUSTUS trials. Europace. 2020 Jan 1;22(1):3346.

64. Oldgren J, Steg PG, Hohnloser SH, Lip GYH, Kimura T, Nordaby M, et al. Dabigatran dual therapy with ticagrelor or clopidogrel after percutaneous coronary intervention in atrial fibrillation patients with or without acute coronary syndrome: a subgroup analysis from the RE-DUAL PCI trial. Eur Heart J. 2019 May 14;40(19):1553-62.

65. Windecker S, Lopes RD, Massaro T, Jones-Burton C, Granger CB, Aronson R, et al. Antithrombotic Therapy in Patients with Atrial Fibrillation and Acute Coronary Syndrome Treated Medically or with Percutaneous Coronary Intervention or Undergoing Elective Percutaneous Coronary Intervention: Insights from the AUGUSTUS Trial. Circulation. 2019 Sep 26;

66. Maeng M, Steg PG, Bhatt DL, Hohnloser SH, Nordaby M, Miede C, et al. Dabigatran Dual Therapy Versus Warfarin Triple Therapy Post-PCI in Patients With Atrial Fibrillation and Diabetes. JACC Cardiovasc Interv. 2019 Dec 9;12(23):2346-55. x 


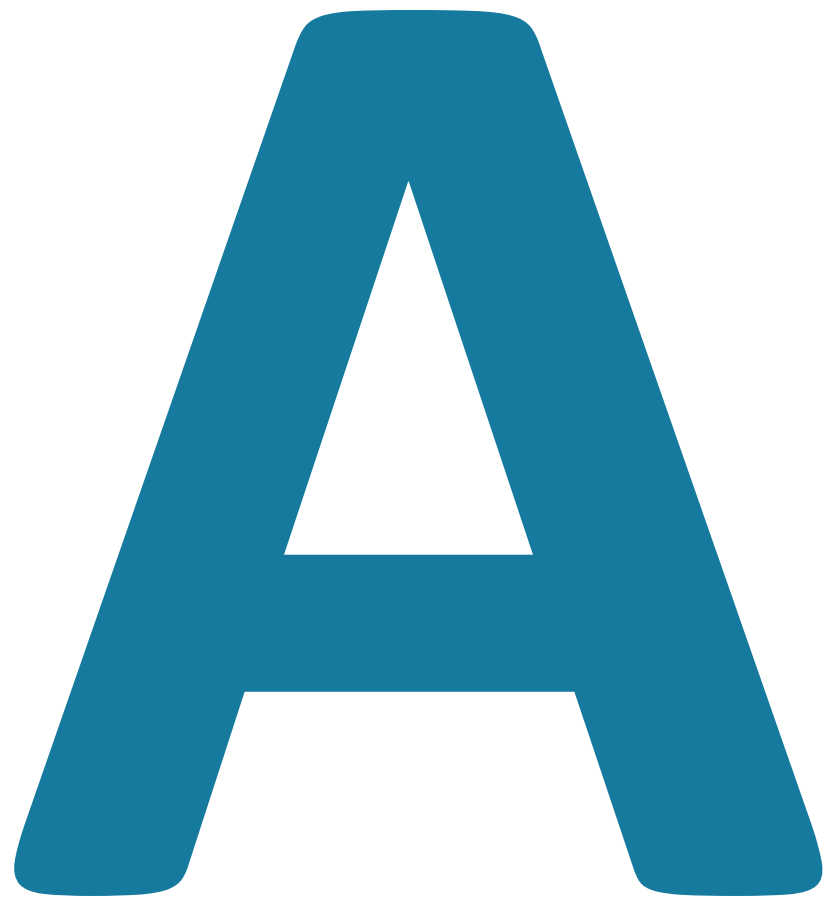




\section{Appendices}

Nederlandse Samenvatting Impact Paragraph

Dankwoord

List of publications

Curriculum Vitae 


\section{Nederlandse samenvatting}

In de inleiding van dit proefschrift wordt het fenomeen stenttrombose geïntroduceerd. Stenttrombose is het optreden van een abrupte afsluiting van een eerder geplaatste kransaderstent door een bloedstolsel. Een kransaderstent (coronaire stent) wordt geïmplanteerd tijdens een dotterbehandeling (percutane coronaire interventie; $\mathrm{PCl}$ ) om het bloedvat voor de lange termijn open te houden.

In eerdere onderzoeken zijn verschillende risicofactoren voor het optreden van stent trombose geïdentificeerd, zoals diabetes en hartfalen. Daarnaast spelen factoren gerelateerd aan de dotterprocedure een rol, zoals het plaatsen van een te kleine stent, of als tijdens het plaatsen va de stent een dissectie aan de rand van de stent is ontstaan. Ook het (te) vroeg staken van de bloedplaatjesremmende medicijnen is een belangrijke risicofactor en daarnaast zijn genetische factoren zijn van belang: dragers van een afwijkend CYP2C19 gen (dit gen is van belang bij het metabolisme en activeren van de plaatjesremmer clopidogrel) hebben een hoger risico op stenttrombose. Stent trombose presenteert zich meestal als een acuut hartinfarct en is een gevaarlijke complicatie van $\mathrm{PCl}$ met een hoge sterfte.

Door de jaren heen zijn stents veel beter geworden en werden bloedplaatjesremmende medicijnen (plaatjesremmers) steeds krachtiger. Daardoor nam het aantal stent tromboses af, terwijl er meer aandacht kwam voor bloedingen als bijwerkingen van plaatjesremmers. Daarnaast werd duidelijk dat niet iedere patiënt dezelfde behandeling hoeft te krijgen. Waar voorheen patiënten na een $\mathrm{PCl}$ standaard een jaar behandeld werden met twee plaatjesremmers (dubbele plaatjesremming; DAPT), kunnen sommige patiënten tegenwoordig korter ( 6 maanden of minder) behandeld, terwijl bepaalde andere patiëntengroepen juist langer behandeld zouden moeten worden. Risicoscores kunnen helpen bij het bepalen van de optimale duur van DAPT.

Het derde onderwerp in dit proefschrift is de behandeling van patiënten met boezemfibrilleren die een $\mathrm{PCl}$ ondergaan. Omdat deze patiëntengroep meestal ook al behandeld wordt met orale antistolling, hebben zij een extra verhoogd risico op bloedingen als gevolg van de combinatie van de verschillende bloedverdunners.

\section{Deel I Stenttrombose}

In hoofdstuk 4 van dit proefschrift wordt de rol van uitlokkende factoren bij het optreden van stenttrombose beschreven. Zoals hierboven beschreven, zijn al veel risicofactoren voor stenttrombose bekend. Toch is het opvallend dat slechts een klein deel van de patiënten met bekende risicofactoren uiteindelijk een stent trombose ontwikkeld - en andersom, waarom sommige mensen zonder risicofactoren toch een stent trombose krijgen. In een groot cohort 
patiënten met stenttrombose, werd in $23 \%$ van de patiënten een uitlokkende factor voor de stenttrombose geïdentificeerd, zoals zware lichamelijke inspanning, emotionele stress of de aanwezigheid van een infectie. Daarnaast werd een duidelijke variatie over de dag gezien, waarbij we hebben kunnen vaststellen dat een stenttromboses meestal in de ochtenduren plaatsvind (piek tussen 7 uur's ochtends en 12 uur's middags).

In hoofdstuk 5 werd het absolute risico op het krijgen van stenttrombose na het stoppen met clopidogrel onderzocht. Clopidogrel is een veelgebruikte P2Y12-remmer en meerdere studies hebben aangetoond dat het vroeg stoppen een belangrijke oorzaak van stent trombose is. Het absolute risico op het krijgen van stenttrombose in een cohort van voornamelijk patiënten met acuut coronair syndroom bedroeg in deze studie $4.6 \%$ in vergelijking met $1.7 \%$ voor patiënten die clopidogrel niet hadden gestopt. Bij mensen die clopidogrel stopten in de eerste 30 dagen was het risico zelfs $35 \%$ en dit percentage was respectievelijk $19 \%$ en $12 \%$ voor 90 en 180 dagen.

Patiënten met een ST-elevatie myocardinfarct (STEMI) krijgen vaak morfine toegediend, om pijn en angst te verminderen. Daarnaast heeft het een gunstig effect op de adrenaline respons en daardoor op hartfrequentie en zuurstofgebruik van het hart. Een bijwerking van morfine is echter dat het de maaglediging vertraagt en daardoor de opname en werking van P2Y12-remmers, waardoor deze patiënten een hoger risico op stenttrombose hebben. In hoofdstuk 6 wordt het effect van de plaatjesremmer Glycoproteine-IIb/IIla-remmers (GPI) bij deze STEMI patiënten die morfine hebben gekregen onderzocht. Als onderdeel van een lokale richtlijn werd deze patiëntengroep standaard behandeld met GPI. In de groep die behandeld werd met GPI werd een significant lager aantal stent tromboses gezien $(0.4 \%$ (5/1217) vs. $2.6 \%(28 / 1080), p<0.0001)$. Als keerzijde werd een (niet statistisch significant) verschil in bloedingen gezien.

Deel 1 van dit proefschrift wordt afgesloten met drie illustratieve casus van individuele patiënten met een stenttrombose (hoofdstuk 7).

\section{Deel II Behandeling op maat met behulp van plaatjesfunctietesten}

Hoofdstuk 8 is een overzichtsartikel waarin het voorkomen van zogenaamde hoge plaatjesreactiviteit (HPR; high on-treatment platelet reactivity) bij patiënten behandeld met P2Y12-remmers wordt beschreven. Als er sprake is van HPR betekent dat in de praktijk dat plaatjesremmers onvoldoende werkzaam zijn en dat mensen dus een hoger risico op een hartinfarct of stenttrombose hebben. De relatie tussen HPR en klinische uitkomsten wordt beschreven. Daarnaast worden de testen beschreven die beschikbaar zijn voor het meten van plaatjesfunctie. Tenslotte wordt een samenvatting gegeven van studies die op-maatbehandeling gebaseerd op plaatjesfunctietesten hebben onderzocht. 
In de praktijk worden vier verschillende plaatjesfunctietesten (assays) gebruikt, maar weinig is bekend over de correlatie tussen de verschillende testen. In hoofdstuk 9 wordt de correlatie tussen vier testen beschreven. Daarnaast wordt een combinatietest voorgesteld, die gebaseerd is op meer dan 1 afzonderlijke test. In dit onderzoek bleek er een belangrijke variatie te bestaan tussen het voorkomen van HPR volgens de verschillende testen. In een cohort van stenttrombose patiënten varieerde het voorkomen van HPR van $14.6 \%$ voor de Verifynow assay (met de veelgebruikte afkapwaarde van >235 PRU) tot $49.7 \%$ voor de VASP assay. Correlatie tussen de verschillende testen was zwak - hooguit matig. Wanneer de testen werden vergeleken met een composiet van drie verschillende testen en met lichttransmissie aggregometrie (de 'gouden standaard'), leidde de Verifynow assay met de hoge afkapwaarde tot het onderschatten van het aantal patiënten met HPR, terwijl de VASP assay juist een overschatting gaf.

\section{Deel III Antitrombotische behandeling in AF patiënten die $\mathrm{PCl}$ ondergaan}

Patiënten met boezemfibrilleren die een $\mathrm{PCl}$ ondergaan, worden meestal behandeld met zowel orale antistolling (OAC) als met twee plaatjesremmers (clopidogrel en aspirine). De combinatie van deze drie bloedverdunners (triple therapie; TAT) leidt tot een tweemaal hoger risico op bloedingen. Daarom wordt tegenwoordig meestal dubbele behandeling (DAT) met OAC en clopidogrel gegeven: dit lijkt bij de meeste patiënten veilig.

Aan de andere kant zijn er patiënten met een hoog 'trombotisch risico' die een grote kans hebben op een nieuwe hartinfarcten of andere acute problemen. Deze hoog-risico patiënten zouden wèl baat kunnen hebben bij de zogenaamde triple therapie. Tot op heden was dit niet goed onderzocht. In hoofdstuk 10 werd daarom onderzocht welke patiënten baat hebben bij de intensievere triple behandeling. Met behulp van een Cox proportioneel model werd een risico score ontwikkeld. In patiënten met een risicoscore van $\geq 5$ ( $N$ 154, $5.7 \%$ van het cohort) was een significant lager aantal stent tromboses en hartinfarcten te zien als zij met triple therapie werden behandeld, zonder dat het aantal bloedingen toenam. Patiënten met een lagere score hadden helemaal geen baat bij triple behandeling en hadden juist wel meer bloedingen. Deze studie ondersteunt dus het gebruik van triple behandeling bij de kleine groep 'hoog-risico' patiënten, die met behulp van deze score goed kunnen worden geïdentificeerd.

Bloedingen komen frequent voor bij deze patiëntengroep door de combinatie van verschillende bloedverdunners. Het optreden van bloedingen is overigens een gevaarlijke "bijwerking" en geeft een hoog risico op ziekenhuisopnames en overlijden (sommige studies suggereren dat bloedingen een even groot risico op overlijden geven als een hartinfarct). In het laatste hoofdstuk van dit proefschrift, hoofdstuk 11 wordt de ontwikkeling van een bloedingsscore beschreven. Op basis van een Cox model werd een puntenmodel 
ontwikkeld. Deze risicoscore bevatte de items leeftijd, hematocriet, BMI, maligniteit in de voorgeschiedenis en behandeling met triple therapie. Drie risico categorieën konden worden onderscheiden: laag bloedingsrisico ( $10 \%$, matig bloedingsrisico (17\%) en hoog bloedingsrisico (27\%). Dit is de eerste risicoscore die specifiek van toepassing is op patiënten met boezemfibrilleren die een $\mathrm{PCl}$ ondergaan. Bij deze groep is het risico op bloedingen dus duidelijk verhoogd, maar onderling blijkt het nog sterk te variëren. Het is daarom essentieel om bij de individuele patiënt het bloedingsrisico in te schatten en vervolgens af te wegen tegen de trombotische risico's.

\section{Verleden, heden en toekomst}

In de studies beschreven in dit proefschrift worden de globale ontwikkelingen die de interventiecardiologie de afgelopen tien jaar heeft doorgemaakt beschreven. Door de sterke afname van het probleem stent trombose, is de aandacht nu meer gericht op de afweging tussen voorkomen van trombose en het bloedingsrisico dat gepaard gaan met bloedplaatjesremmers. De uitdagingen aan de horizon zijn om risicoscores verder te verfijnen en om geïndividualiseerde behandeling daadwerkelijk meer in te zetten in de dagelijkse klinische cardiologiepraktijk. 


\section{Impact paragraph}

In this section, the impact of the research performed in this thesis will be discussed, including a summary of its main findings for non-medical readers, the implications for daily practice and the contribution of this thesis to the scientific field.

Cardiovascular disease is the worldwide leading cause of death. It is estimated that it contributes to $31 \%$ of all deaths worldwide, representing 17.9 million people each year. Among these, the vast majority (85\%) are due to either heart attacks or stroke. Heart attacks are causes by a blockage in the blood vessels supplying the heart muscle. A heart attack is treated with medication including blood thinners and usually with angioplasty (using a balloon threaded through an artery to unblock the blood vessel). Nowadays, it is standard practice to implant a coronary stent (a small metal tube), which secures long-term patency of the treated blood vessel.

The research described in this thesis comprises two fields of interest related to heart attacks. First, it elaborates on treatment with antiplatelet drugs (blood thinners) in patients with heart attacks or following coronary angioplasty. Second, the subject of stent thrombosis, a feared complication of angioplasty, is discussed. In stent thrombosis, the previously implanted stent is blocked by a thrombus (blood clot), causing a (new) heart attack.

\section{Scientific impact and impact for patients}

In the first chapter of this thesis, we showed that the risk of stent thrombosis is high when the blood thinner clopidogrel is discontinued prematurely. This is very relevant for patients, as stent thrombosis is a dangerous condition, which can be lethal. Patients should be careful not to discontinue their medication prematurely after coronary angioplasty. However, some conditions during follow-up, such as undergoing surgery, might necessitate early discontinuation of blood thinners. Patients should be aware of the importance of dual antiplatelet treatment after $\mathrm{PCl}$ and are advised to discuss this issue with their cardiologist when early discontinuation is warranted.

Another important finding in this manuscript is the possible beneficial effect of Glycoprotein Ilb/IIla inhibitors (GPI; a class of strong blood thinners) among heart attack patients who are treated with morphine. Morphine is often given to patients suffering heart attacks to alleviate pain and anxiety. However, morphine delays the absorption of blood thinners from the stomach and therefore can compromise its actions. Therefore, these patients have an increased risk of stent thrombosis. We showed that GPI can reduce this risk of stent thrombosis. However, further research is needed as GPI is associated with bleeding complications as well. Therefore, it should be used selectively in clinical practice. 
The last part of this thesis concerns the specific group of patients with atrial fibrillation (a heart rhythm condition) who undergo coronary angioplasty. As these patients are already treated with a specific type of blood thinners (anticoagulation), the combination of blood thinners is particularly difficult in this patient group. On the one hand, they tend to have an increased risk of bleeding because of this combination of drugs. On the other hand, it is unknown which combination of medication is optimal both from the perspective of the rhythm disorder and for the angioplasty. In the last part of this thesis, we developed a risk tool able to select high-risk patients who qualify for an intensified course of blood thinners. A second risk calculator was developed aimed at estimating bleeding risk in individual patients. Both risk calculators are very relevant for patients in daily practice, as they enable personalised medicine, in which a specific treatment balancing benefits and risks for an individual patient can be chosen. Moreover, it fosters shared decision making between patient and physician, based on the specific patient characteristics and conditions.

\section{Dissemination of knowledge}

In our efforts to share our knowledge with fellow researchers and clinicians, the majority of the research presented in this manuscript was published in peer-reviewed national and international scientific journals. In addition, the results of several studies were presented at international congresses, including the European Society of Cardiology congresses, the Euro Thrombosis conference and the American Heart Association scientific sessions. Finally, chapter two of this thesis is based on a position paper, which was written in order to inform other Dutch cardiologists about current developments in the field of shortening and prolonging treatment with antiplatelet medication. 


\section{List of publications}

van Werkum JW, Heestermans AACM, de Korte FI, Kelder JC, Suttorp M-J, Rensing BJWM, Zwart B, Brueren BRG, Koolen JJ, Dambrink J-HE, van't Hof AWJ, Verheugt FWA, ten Berg JM. Long-term clinical outcome after a first angiographically confirmed coronary stent thrombosis: an analysis of 431 cases. Circulation. 2009;119:828-34.

Zomer AC, Zwart B, van Werkum JW, Suttorp M-J. Time does not heal every wound: coronary stent thrombosis of a bare-metal stent more than one decade after its implantation. Platelets. 2009;20:594-7.

Zwart B, van Werkum JW, Heestermans AACM, Ten Berg JM. Coronary stent thrombosis in the current era: challenges and opportunities for treatment. Curr Treat Options Cardiovasc Med. 2010;12:46-57.

Zwart B, Van Kerkvoorde TC, van Werkum JW, Breet NJ, Ten Berg JM, Van't Hof AWJ. Vigorous exercise as a triggering mechanism for late stent thrombosis: A description of three cases. Platelets. 2010;21:72-6.

Heestermans A a. CM, van Werkum JW, Zwart B, van der Heyden JA, Kelder JC, Breet NJ, van't Hof AWJ, Dambrink J-HE, Koolen JJ, Brueren BRG, Zijlstra F, ten Berg JM. Acute and subacute stent thrombosis after primary percutaneous coronary intervention for STsegment elevation myocardial infarction: incidence, predictors and clinical outcome. J Thromb Haemost. 2010;8:2385-93.

Harmsze AM, van Werkum JW, Ten Berg JM, Zwart B, Bouman HJ, Breet NJ, van 't Hof AWJ, Ruven HJT, Hackeng CM, Klungel OH, de Boer A, Deneer VHM. CYP2C19*2 and CYP2C9*3 alleles are associated with stent thrombosis: a case-control study. Eur Heart J. 2010;31:304653.

Zwart B, van Werkum JW, Heestermans AACM, Kelder JC, Zomer AC, van 't Hof AWJ, Verheugt FWA, Ten Berg JM. Triggering mechanisms of stent thrombosis. Eurolntervention. 2011;6:722-8.

Teeuwen K, Zwart B, van Werkum JW, Joner M, ten Berg JM. 3-dimensional optical coherence tomography imaging in early coronary stent thrombosis. JACC Cardiovasc Interv. 2011;4:256-7.

Zwart B, Ten Berg JM. Kortere antistolling na PCl, ook bij vrouwen. Ned Tijdschr Geneeskd. 2016;160:D980 
Godschalk TC, Willemsen LM, Zwart B, Bergmeijer TO, Janssen PWA, Kelder JC, Hackeng CM, Berg JMT. Effect of Tailored Antiplatelet Therapy to Reduce Recurrent Stent Thrombosis and Cardiac Death After a First Episode of Stent Thrombosis. The American Journal of Cardiology. 2017;119:1500-1506

Vis JC, Borleffs CJ, Zwart B, Nuis RJ, Scherptong RWC. Short-term career perspectives of young cardiologists in the Netherlands. Neth Heart J. 2017;25:455-60.

Zwart B, Ten Berg JM. Antiplatelet therapy: New score for predicting bleeding risk after DAPT. Nat Rev Cardiol. 2017;14:321-2.

Zwart B, Godschalk TC, Kelder JC, Berg JMT. High risk of stent thrombosis in the first 6 months after coronary stenting: Do not discontinue clopidogrel early after ACS. Journal of Interventional Cardiology. 2017;30:421-6.

Zwart B, ten Berg JM. Monitoren van trombocytenaggregatieremmers in de praktijk. Nederlands Tijdschrift voor Hematologie 2017;14:367-372.

Zwart B, Ten Berg JM. Dual antiplatelet therapy duration in patients following percutaneous coronary intervention or after acute coronary syndrome: one size does not fit all. Future Cardiol. 2017;13:199-201.

Ten Berg JM, Zwart B, van 't Hof AWJ, Liem A, Waltenberger J, de Winter RJ, Jukema JW. Optimal duration of dual antiplatelet therapy after percutaneous coronary intervention or after acute coronary syndrome : Practical lessons from a review. Neth Heart J. 2017;25:655-63.

Gregg ED, Zwart B. A man with chest pain and a broad QRS complex. BMJ 2018;361;k1191. DOI: 10.1136

Zwart B, Ten Berg JM. Atrial fibrillation and coronary stenting: is the AUGUSTUS trial the end of triple therapy? Future Cardiol. 2019;15:319-21.

Zwart B, Godschalk TC, Zheng K, Denteneer J, Kelder JC, Ten Berg JM. Measuring high ontreatment platelet reactivity in clinical practice; should we use a panel of platelet function tests? Blood Coagul Fibrinolysis. 2019;30:263-9.

Zwart B, Ten Berg JM, van 't Hof AW, Tonino Pa. L, Appelman Y, Liem AH, Arslan F, Waltenberger J, Jukema JW, de Winter RJ, Damman P. Indications for an early invasive strategy in NSTE-ACS patients. Neth Heart J. 2020;28:131-5. 
Zwart B, Yazdani M, Ow KW, Richardson JD, Iqbal J, Gunn JP, Storey RF. Use of glycoprotein Ilb/IIla antagonists to prevent stent thrombosis in morphine-treated patients with STelevation myocardial infarction. Platelets. 2020;31:174-8.

Zwart B, Parker WAE, Storey RF. New Antithrombotic Drugs in Acute Coronary Syndrome. J Clin Med. 2020;9. 


\section{Curriculum Vitae}

Bastiaan Zwart was born in Drachten on the $27^{\text {th }}$ of January 1985. After completing his secondary school (Stedelijk Gymnasium, Leeuwarden), he started studying medicine at the University of Utrecht in 2003. During his study, he spent a research internship at the St. Antonius hospital Nieuwegein, which led to his first oral presentation at the American Heart Association scientific sessions in New Orleans, US. He obtained his medical degree in 2010. After graduating, he started working in the Emergency Department in the Zuwe Hofpoort hospital in Woerden, where he gained skills in acute surgical and medical care. Being particularly interested in design and reimbursement of healthcare systems, he broadened his horizon by working as a consultant with KPMG Advisory for a year. He then realised that working as a clinical doctor should be the foundation of his working practice. In 2013, he started cardiology specialist training at St. Antonius hospital in Nieuwegein under supervision of prof. dr. J.M. Ten Berg. During his cardiology training, he commenced his scientific career, which would result in this thesis. In 2016, he worked as a registrar in the Northern General Hospital in Sheffield, United Kingdom, where he spent much time in the cathlab and started performing PCl's. From 2018-2020 he specialised in interventional cardiology in the Catharina hospital, Eindhoven (under supervision of dr. P.A.L. Tonino). In 2021, he joined the cardiology staff at the Elisabeth-Tweesteden hospital in Tilburg as an interventional cardiologist. 
